\title{
ORSPHERE: PHYSICS MEASUREMENTS FOR BARE, HEU(93.2)-METAL SPHERE
}

Margaret A. Marshall John D. Bess J. Blair Briggs

Christine E. White James P. Dyrda Nigel P. Tancock John Mihalczo

March 2015

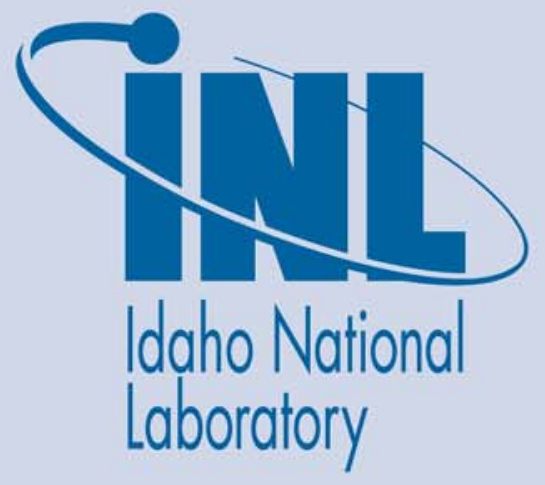

The INL is a U.S. Department of Energy National Laboratory operated by Battelle Energy Alliance 
INL/EXT-13-30309

Revison 1

\title{
ORSPHERE: PHYSICS MEASUREMENTS FOR BARE, HEU(93.2)-METAL SPHERE
}

\author{
Margaret A. Marshall \\ John D. Bess \\ J. Blair Briggs \\ Christine E. White \\ James P. Dyrda \\ Nigel P. Tancock \\ John Mihalczo
}

March 2015

Idaho National Laboratory

Idaho Falls, Idaho 83415

http://www.inl.gov

Prepared for the

U.S. Department of Energy

Office of Nuclear Science

Under DOE Idaho Operations Office

Contract DE-AC07-05ID14517 


\title{
ORSPHERE: PHYSICS MEASUREMENTS FOR BARE, HEU(93.2)-METAL SPHERE
}

\author{
Evaluator \\ Margaret A. Marshall \\ Idaho National Laboratory \\ Internal Reviewers \\ John D. Bess \\ J. Blair Briggs \\ Christine E. White
}

Independent Reviewers

James P. Dyrda

Nigel P. Tancock

Atomic Weapons Establishment

Udo Wehmann

Under Subcontract to OECD NEA

John T. Mihalczo

Oak Ridge National Laboratory 
NEA/NSC/DOC(2006)1

Fundamental-FUND

ORSPHERE-FUND-EXP-001

CRIT-REAC-COEF-KIN-RRATE

Status of Compilation/Evaluation/Peer Review

\begin{tabular}{|c|c|c|c|c|c|}
\hline \multicolumn{2}{|r|}{ Section 1} & \multirow[t]{2}{*}{ Compiled } & \multirow[t]{2}{*}{$\begin{array}{c}\text { Independent } \\
\text { Review }\end{array}$} & \multirow[t]{2}{*}{$\begin{array}{c}\text { Working } \\
\text { Group Review }\end{array}$} & \multirow[t]{2}{*}{ Approved } \\
\hline 1.0 & DETAILED DESCRIPTION & & & & \\
\hline 1.1 & $\begin{array}{l}\text { Description of the Critical and/or } \\
\text { Subcritical Configuration }\end{array}$ & YES & YES & YES & YES \\
\hline 1.2 & $\begin{array}{l}\text { Description of Buckling and } \\
\text { Extrapolation-Length Measurements }\end{array}$ & NA & NA & NA & NA \\
\hline 1.3 & $\begin{array}{l}\text { Description of Spectral- } \\
\text { Characteristics Measurements }\end{array}$ & NA & NA & NA & NA \\
\hline 1.4 & $\begin{array}{l}\text { Description of Reactivity-Effects } \\
\text { Measurements }\end{array}$ & YES & YES & YES & YES \\
\hline 1.5 & $\begin{array}{l}\text { Description of Reactivity-Coefficient } \\
\text { Measurements }\end{array}$ & YES & YES & YES & YES \\
\hline 1.6 & Description of Kinetics Measurements & YES & YES & YES & YES \\
\hline 1.7 & $\begin{array}{l}\text { Description of Reaction-Rate } \\
\text { Distribution Measurements }\end{array}$ & YES & YES & YES & YES \\
\hline 1.8 & $\begin{array}{l}\text { Description of Power-Distribution } \\
\text { Measurements }\end{array}$ & NA & NA & NA & NA \\
\hline 1.9 & Description of Isotopic Measurements & NA & NA & NA & NA \\
\hline 1.10 & $\begin{array}{l}\text { Description of Other Miscellaneous } \\
\text { Types of Measurements }\end{array}$ & NA & NA & NA & NA \\
\hline & Section 2 & Evaluated & $\begin{array}{c}\text { Independent } \\
\text { Review }\end{array}$ & $\begin{array}{c}\text { Working } \\
\text { Group Review }\end{array}$ & Approved \\
\hline 2.0 & $\begin{array}{l}\text { EVALUATION OF } \\
\text { EXPERIMENTAL DATA }\end{array}$ & & & & \\
\hline 2.1 & $\begin{array}{l}\text { Evaluation of Critical and/or } \\
\text { Subcritical Configuration Data }\end{array}$ & YES & YES & YES & YES \\
\hline 2.2 & $\begin{array}{l}\text { Evaluation of Buckling and } \\
\text { Extrapolation Length Data }\end{array}$ & NA & NA & NA & NA \\
\hline 2.3 & $\begin{array}{l}\text { Evaluation of Spectral-Characteristics } \\
\text { Data }\end{array}$ & NA & NA & NA & NA \\
\hline 2.4 & Evaluation of Reactivity-Effects Data & YES & YES & YES & YES \\
\hline 2.5 & $\begin{array}{l}\text { Evaluation of Reactivity-Coefficient } \\
\text { Data }\end{array}$ & YES & YES & YES & YES \\
\hline 2.6 & $\begin{array}{l}\text { Evaluation of Kinetics-Measurements } \\
\text { Data }\end{array}$ & YES & YES & YES & YES \\
\hline & $\begin{array}{l}\text { Evaluation of Reaction-Rate } \\
\text { Distributions }\end{array}$ & YES & YES & YES & YES \\
\hline & $\begin{array}{l}\text { Evaluation of Power-Distribution } \\
\text { Data }\end{array}$ & NA & NA & NA & NA \\
\hline 2.9 & Evaluation of Isotopic Measurements & NA & NA & NA & NA \\
\hline 2.10 & $\begin{array}{l}\text { Evaluation of Other Miscellaneous } \\
\text { Types of Measurements }\end{array}$ & NA & NA & NA & NA \\
\hline
\end{tabular}


NEA/NSC/DOC(2006)1

Fundamental-FUND

ORSPHERE-FUND-EXP-001

CRIT-REAC-COEF-KIN-RRATE

\begin{tabular}{|c|c|c|c|c|}
\hline Section 3 & Compiled & $\begin{array}{l}\text { Independent } \\
\text { Review }\end{array}$ & $\begin{array}{c}\text { Working } \\
\text { Group Review }\end{array}$ & Approved \\
\hline BENCHMARK SPECIFICATIONS & & & & \\
\hline $\begin{array}{l}\text { Benchmark-Model Specifications for Critical } \\
\text { and/or Subcritical Measurements }\end{array}$ & YES & YES & YES & YES \\
\hline $\begin{array}{l}\text { 3.2 } \\
\text { Benchmark-Model Specifications for } \\
\text { Buckling and Extrapolation-length } \\
\text { Measurements }\end{array}$ & NA & NA & NA & NA \\
\hline $\begin{array}{l}\text { 3.3 Benchmark-Model Specifications for Spectral- } \\
\text { Characteristics Measurements }\end{array}$ & NA & NA & NA & NA \\
\hline $\begin{array}{l}\text { 3.4 Benchmark-Model Specifications for } \\
\text { Reactivity-Effects Measurements }\end{array}$ & YES & YES & YES & YES \\
\hline $\begin{array}{ll}3.5 & \text { Benchmark-Model Specifications for } \\
& \text { Reactivity-Coefficient Measurements }\end{array}$ & YES & YES & YES & YES \\
\hline $\begin{array}{l}\text { 3.6 Benchmark-Model Specifications for } \\
\text { Kinetics Measurements }\end{array}$ & YES & YES & YES & YES \\
\hline $\begin{array}{ll}3.7 & \text { Benchmark-Model Specifications for Reaction- } \\
& \text { Rate Distribution Measurements }\end{array}$ & YES & YES & YES & YES \\
\hline $\begin{array}{ll}3.8 & \text { Benchmark-Model Specifications for Power- } \\
& \text { Distribution Measurements } \\
\end{array}$ & NA & NA & NA & NA \\
\hline $\begin{array}{ll}3.9 & \text { Benchmark-Model Specifications for Isotopic } \\
& \text { Measurements } \\
\end{array}$ & NA & NA & NA & NA \\
\hline $\begin{array}{l}\text { 3.10 Benchmark-Model Specifications of Other } \\
\text { Miscellaneous Types of Measurements }\end{array}$ & NA & NA & NA & NA \\
\hline Section 4 & Compiled & $\begin{array}{l}\text { Independent } \\
\text { Review }\end{array}$ & $\begin{array}{c}\text { Working } \\
\text { Group Review }\end{array}$ & Approved \\
\hline RESULTS OF SAMPLE CALCULATIONS & & & & \\
\hline $\begin{array}{l}\text { 4.1 Results of Calculations of the Critical or } \\
\text { Subcritical Configurations }\end{array}$ & YES & YES & YES & YES \\
\hline $\begin{array}{l}\text { 4.2 Results of Buckling and Extrapolation Length } \\
\text { Calculations }\end{array}$ & NA & NA & NA & NA \\
\hline Results of Spectral-Characteristics Calculations & NA & NA & NA & NA \\
\hline Results of Reactivity-Effect Calculations & YES & YES & YES & YES \\
\hline Results of Reactivity-Coefficient Calculations & YES & YES & YES & YES \\
\hline Results of Kinetics-Parameter Calculations & YES & YES & YES & YES \\
\hline Results of Reaction-Rate Distribution & YES & YES & YES & YES \\
\hline Results of Power-Distribution Calculations & NA & NA & NA & NA \\
\hline $4.9 \quad$ Results of Isotopic Calculations & NA & NA & NA & NA \\
\hline $\begin{array}{ll}4.10 & \text { Results of Calculations of Other } \\
& \text { Miscellaneous Types of Measurements }\end{array}$ & NA & NA & NA & NA \\
\hline Section 5 & Compiled & $\begin{array}{l}\text { Independent } \\
\text { Review }\end{array}$ & $\begin{array}{c}\text { Working } \\
\text { Group Review }\end{array}$ & Approved \\
\hline 5.0 REFERENCES & YES & YES & YES & YES \\
\hline $\begin{array}{l}\text { Appendix A: Computer Codes, Cross Sections, and } \\
\text { Typical Input Listings }\end{array}$ & YES & YES & YES & YES \\
\hline
\end{tabular}


NEA/NSC/DOC(2006)1

Fundamental-FUND

ORSPHERE-FUND-EXP-001

CRIT-REAC-COEF-KIN-RRATE

ORSPHERE: PHYSICS MEASUREMENTS FOR BARE, HEU(93.2)-METAL SPHERE

\author{
IDENTIFICATION NUMBER: ORSPHERE-FUND-EXP-001 \\ CRIT-REAC-COEF-KIN-RRATE
}

KEY WORDS: acceptable, bare, central void reactivity, critical experiment, delayed neutron fraction, fission density, highly enriched, metal, neutron importance, ORALLOY, ORCEF, prompt neutron decay constant, sphere, unmoderated, unreflected, uranium, uranium worth

\title{
SUMMARY INFORMATION
}

\subsection{DETAILED DESCRIPTION}

In the early 1970s Dr. John T. Mihalczo (team leader), J.J. Lynn, and J.R. Taylor performed experiments at the Oak Ridge Critical Experiments Facility (ORCEF) with highly enriched uranium (HEU) metal (called Oak Ridge Alloy or ORALLOY) in an attempt to recreate GODIVA I results with greater accuracy than those performed at Los Alamos National Laboratory in the 1950s (HEU-MET-FAST-001). The purpose of the Oak Ridge ORALLOY Sphere (ORSphere) experiments was to estimate the unreflected and unmoderated critical mass of an idealized sphere of uranium metal corrected to a density, purity, and isotopic composition such that it could be compared with the GODIVA I experiments. "The very accurate description of this sphere, as assembled, establishes it as an ideal benchmark for calculational methods and cross-section data files" (Reference 1). While performing the ORSphere experiments care was taken to accurately document component dimensions ( \pm 0.0001 inches), masses $( \pm 0.01 \mathrm{~g})$, and material data. The experiment was also set up to minimize the amount of structural material in the sphere proximity. Two, correlated spheres were evaluated and judged to be acceptable as criticality benchmark experiments. This evaluation is given in HEU-MET-FAST-100. The second, smaller sphere was used for additional reactor physics measurements. Worth measurements (Reference 1, 2, 3 and 4), the delayed neutron fraction (Reference 3, 4 and 5) and surface material worth coefficient (Reference 1 and 2) are all measured and judged to be acceptable as benchmark data. The prompt neutron decay constant (Reference 6 and 7), relative fission density (Reference 8) and relative neutron importance (Reference 8 ) measurements are also evaluated and judged to be acceptable benchmark data..

Information for the evaluation was compiled from References 1 through 8 , the experimental logbooks $8^{\mathrm{a}}$ and $9 ;$, additional drawings and notes provided by the experimenter; and communication with the lead experimenter, John T. Mihalczo.

\footnotetext{
${ }^{a}$ Radiation Safety Information Computation Center (RSICC), The ORNL Critical Experiments Logbooks, Book 108r, http://rsicc.ornl.gov/RelatedLinks.aspx? $\mathrm{t}=$ criticallist.

${ }^{\mathrm{b}}$ This logbook was scanned by the experimenter September 2012 and is not currently available on the RSICC website.
} 


\section{NEA/NSC/DOC(2006)1 \\ Fundamental-FUND \\ ORSPHERE-FUND-EXP-001 \\ CRIT-REAC-COEF-KIN-RRATE}

\subsection{Description of the Critical and/or Subcritical Configuration}

The criticality portion of this evaluation has been reviewed and approved by the International Criticality Safety Benchmark Evaluation Project (ICSBEP) and has been published under the following identifier: HEU-MET-FAST-100. ${ }^{\text {a }}$ A sketch and a photo of the assembly has been provided as Figure 1.1-1 and Figure 1.1-2 for reference.

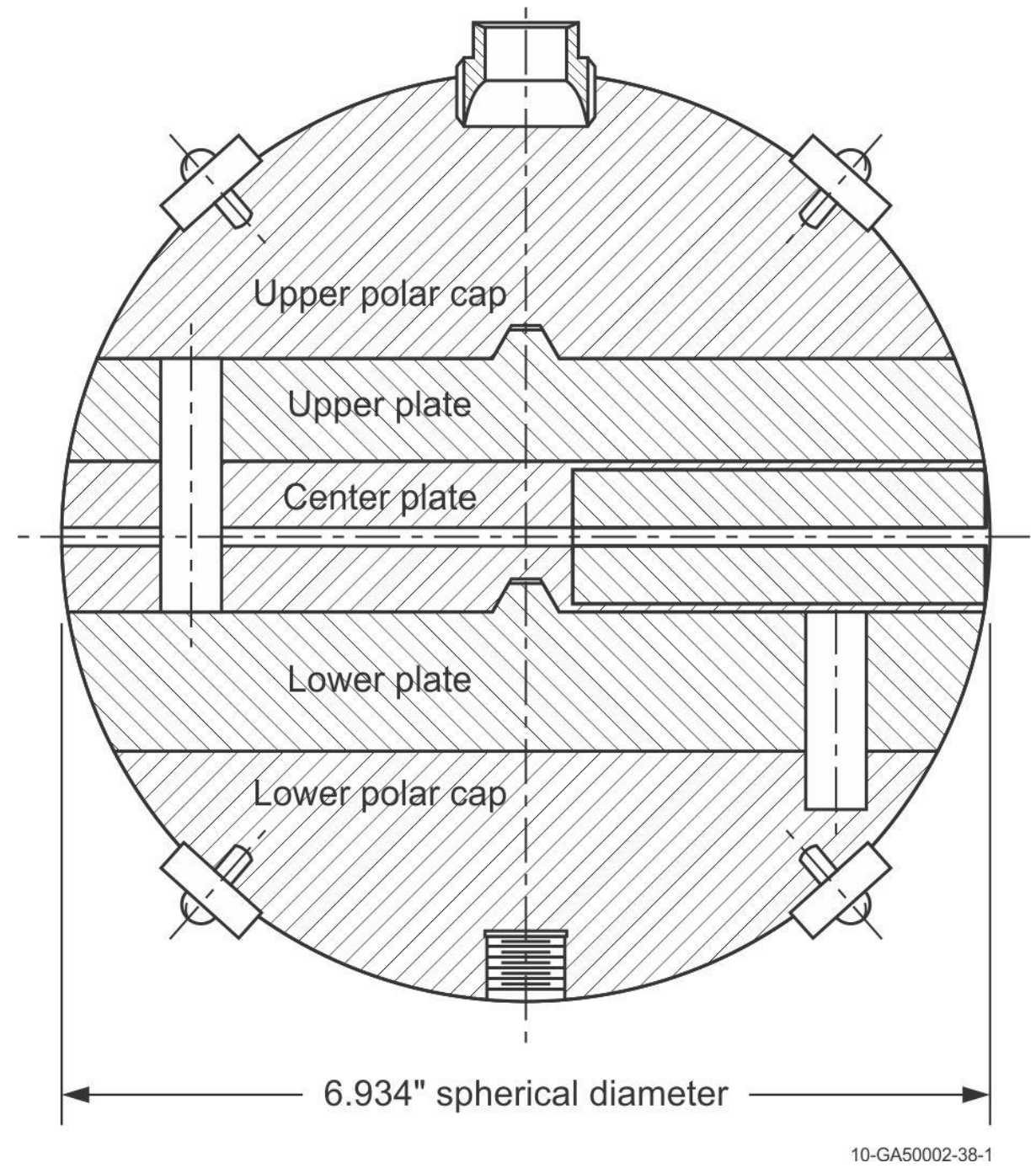

Figure 1.1-1. Sketch of the Assembled Five Sphere Parts.

\footnotetext{
${ }^{\text {a }}$ International Handbook of Evaluated Criticality Safety Benchmark Experiments, NEA/NSC/DOC(95)03, OECDNEA, Paris (2013).
} 
NEA/NSC/DOC(2006)1

Fundamental-FUND

ORSPHERE-FUND-EXP-001

CRIT-REAC-COEF-KIN-RRATE

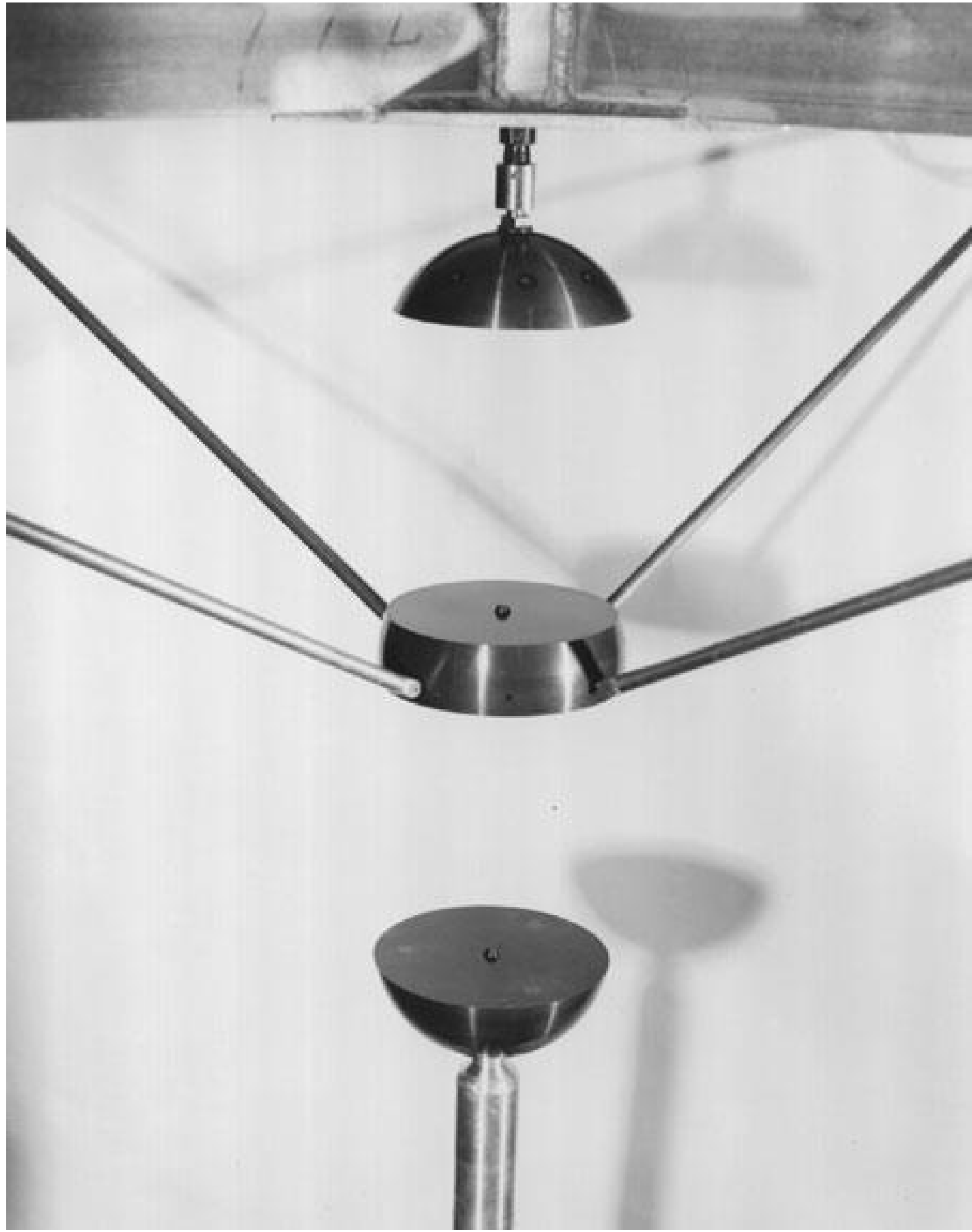

Figure 1.1-2. Photograph of the Disassembled Three Part Sphere.

\subsection{Description of Buckling and Extrapolation Length Measurements}

Buckling and extrapolation length measurements were not made. 
NEA/NSC/DOC(2006)1

Fundamental-FUND

ORSPHERE-FUND-EXP-001

CRIT-REAC-COEF-KIN-RRATE

\subsection{Description of Spectral Characteristics Measurements}

Spectral characteristics measurements were not made.

\subsection{Description of Reactivity Effects Measurements}

\subsubsection{Overview of Experiment}

Many reactivity measurements were performed on the critical spheres. These measurements were recorded in the logbooks. Because it is not always evident how logbook data should be interpreted, only worth measurements that are published or are summarized in tables provided by the experimenter are presented and evaluated in this benchmark report.

The worth of the mass adjustment buttons and diametral filler rod were measured using the critical sphere described as Case 2 in HEU-MET-FAST-100. ${ }^{\mathrm{a}}$ The mass adjustment buttons were made of ORALLOY, stainless steel, and aluminum and were of various thicknesses. The buttons were placed both on the surface of the sphere and the empty socket hole in the upper polar cap. Changes were made to the center plate of the 3.4420-inch-radius critical sphere for the central void worth measurement.

\subsubsection{Geometry of the Experiment Configuration and Measurement Procedure}

\subsubsection{Central Void Reactivity}

The central void reactivity ${ }^{\mathrm{a}}$ was measured and results were reported in Reference 3 and 4 . The reactivity of the central void was measured by determining system reactivity for the 3.4420 -inch-average-radius sphere with and without a 0.460 -inch diameter uranium metal sphere present at the center of the sphere. This measurement required that the geometry of the central plate be varied from the central plate geometry used in the critical configuration (Section 1.1). No other section of the sphere was altered. A variable number of uranium buttons, placed on the outer surface of the 3.4420-cm-average-radius sphere, were used. The modified central plate of the central section is shown in Figure 1.4-1. The modification of the diametral hole allowed for a uranium plug to be inserted and removed from the sphere to create a 0.230 -inch radius void at the center of the sphere. A 0.460-inch diameter uranium metal sphere (15.614 g) was used to fill the void region in order to simulate a solid sphere. The plug and sphere are shown in Figure 1.4-2 with manufacturing tolerances. By comparison of the sphere reactivity with and without the sphere present at the center of the ORSphere the worth of the central void was determined. All other holes in the center plate were filled with plugs when reactivity measurements were performed. The measurement process to obtain the stable reactor period is described in Reference 3 as follows:

The system was assembled with the small central sphere in place to slightly above delayed criticality by use of a small removable reflector. When the power or fission rate reached the appropriate level, the small reflector was removed in $\sim 0.2 \mathrm{~s}$. The positive stable reactor period was obtained from the reaction rate as a function of time in seven external detectors containing $\mathrm{BF}_{3}$ that were either neutron counters or neutron sensitive ionization chambers. For the four neutron counters, the count rate was measured as a function of time; for the three ionization chambers, the output current was recorded on strip-chart recorders as a function of time. All detectors were external to the sphere at distances from 6 to 15 feet and were surrounded by at least 2 inches of paraffin moderator (see Figure 1.4-3). The stable reactor periods were obtained graphically. The shorter reactor periods were measured over at least two decades of purely exponential change. The longer stable reactor periods were measured for at least a time period of 30 minutes of purely exponential change. The sphere was then disassembled by either raising the upper polar cap or lowering the lower section. The small, central uranium sphere was removed manually, and the system was reassembled with the small reflector in place to a power level from

\footnotetext{
${ }^{\text {a }}$ This worth is also called the central uranium reactivity. To be consistent with Reference 3 and 4, it is called central void worth or central void reactivity in this evaluation.
} 
which the reactor period could again be measured after the small additional reflector was removed.

Multiple runs, 43, with a variable number of mass adjustment buttons were performed on ten separate days between May 19 and August 10, 1972. Once the stable reactor periods were obtained, the Inhour equation was used to determine the system reactivity in dollars. This required the use of delayed neutron parameters. The relative yield and decay constants from Keepin et al. for ${ }^{235} \mathrm{U}$ and ${ }^{238} \mathrm{U}$ were used. ${ }^{\mathrm{a}}$ The fraction of fission for ${ }^{234} \mathrm{U}$ and ${ }^{236} \mathrm{U}$ were split $50 / 50$ between ${ }^{235} \mathrm{U}$ and ${ }^{238} \mathrm{U}$. The fraction of fissions, obtained from neutron transport calculations, and Keepin data was provided in Reference 3 and is shown in Table 1.4-1 at the end of Section 1.4.2. The system reactivity of the ORSphere with the small central sphere present, versus the reactivity with the small central sphere removed, yielded the worth of the small central sphere, or inversely, the worth of the central void region. The stable reactor periods are provided in Table 1.4-2 at the end of this section and a sample calculation of the central void region worth is given in Appendix B. A table is provided by the experimenter, Table 1.4-3, which gives the calculated reactivity for each detector of each run. The average central void region worth was $9.165 \pm 0.023 \phi$. This value is the variance weighted average of the daily averages and standard deviations. ${ }^{\mathrm{b}}$ The given error is the standard deviation of the mean of all measurements with all detectors. The distribution of the mean measurements is given in Figure 1.4-4.

\footnotetext{
${ }^{a}$ The Keepin et al. delayed neutron parameters were provided in Reference 3 and were obtained from: G.R. Keepin, T.F. Wimmett, and R.K. Zeigler, Phys. Rev., 107, 1044 (1975).

${ }^{\mathrm{b}}$ Personal communication with J.T. Mihalczo, November 25, 2013.
} 
NEA/NSC/DOC(2006)1

Fundamental-FUND

ORSPHERE-FUND-EXP-001

CRIT-REAC-COEF-KIN-RRATE

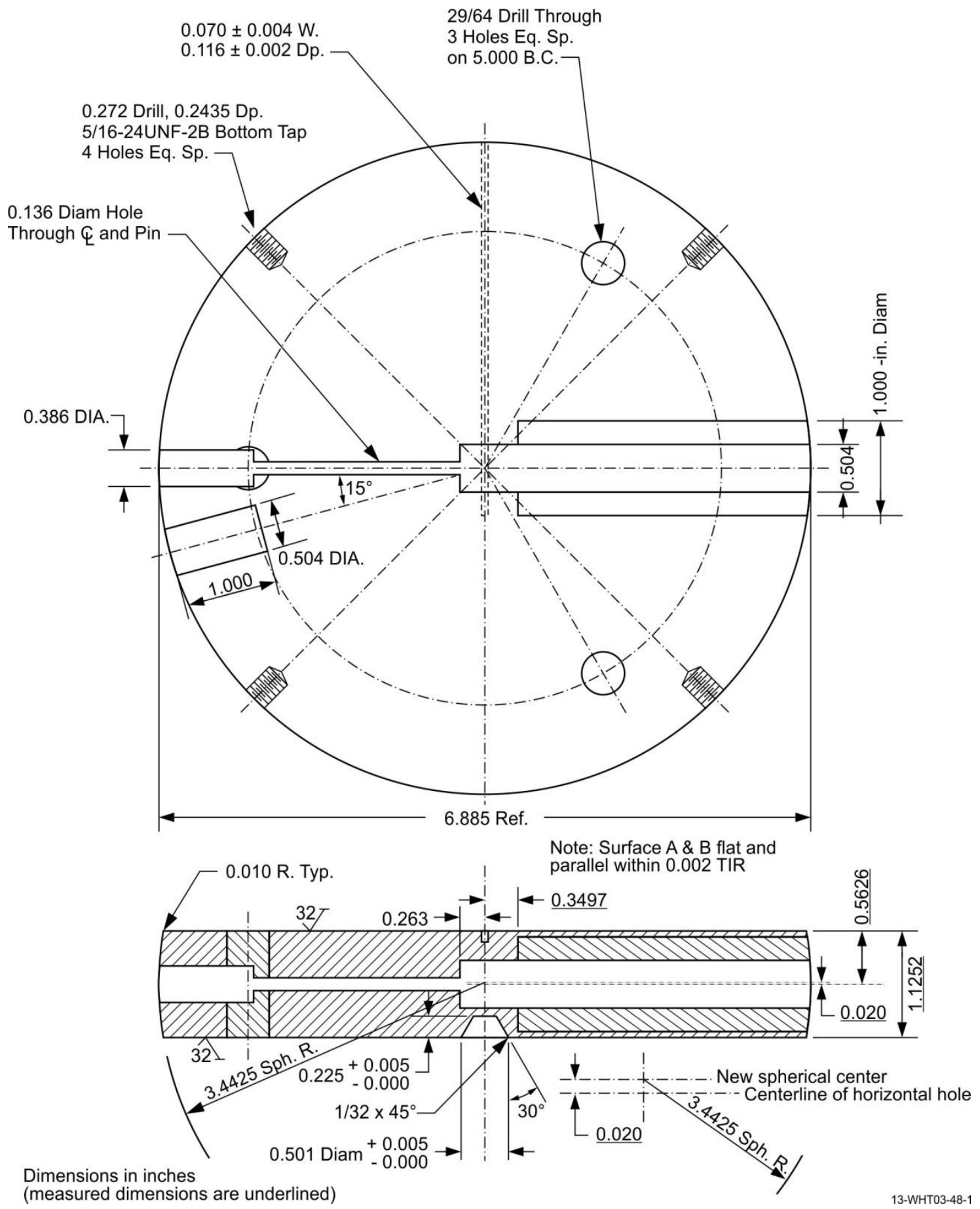

Figure 1.4-1. Modified Central Plate for Center Section of 3.4420-inch-average Radius Sphere. ${ }^{\mathrm{a}}$

\footnotetext{
${ }^{\text {a }}$ This figure is based on the original drawing in Reference 3; however, the figure has been redrawn with changes to the drawing for improved clarity but no changes to the dimensions.
} 
NEA/NSC/DOC(2006)1

Fundamental-FUND

ORSPHERE-FUND-EXP-001

CRIT-REAC-COEF-KIN-RRATE

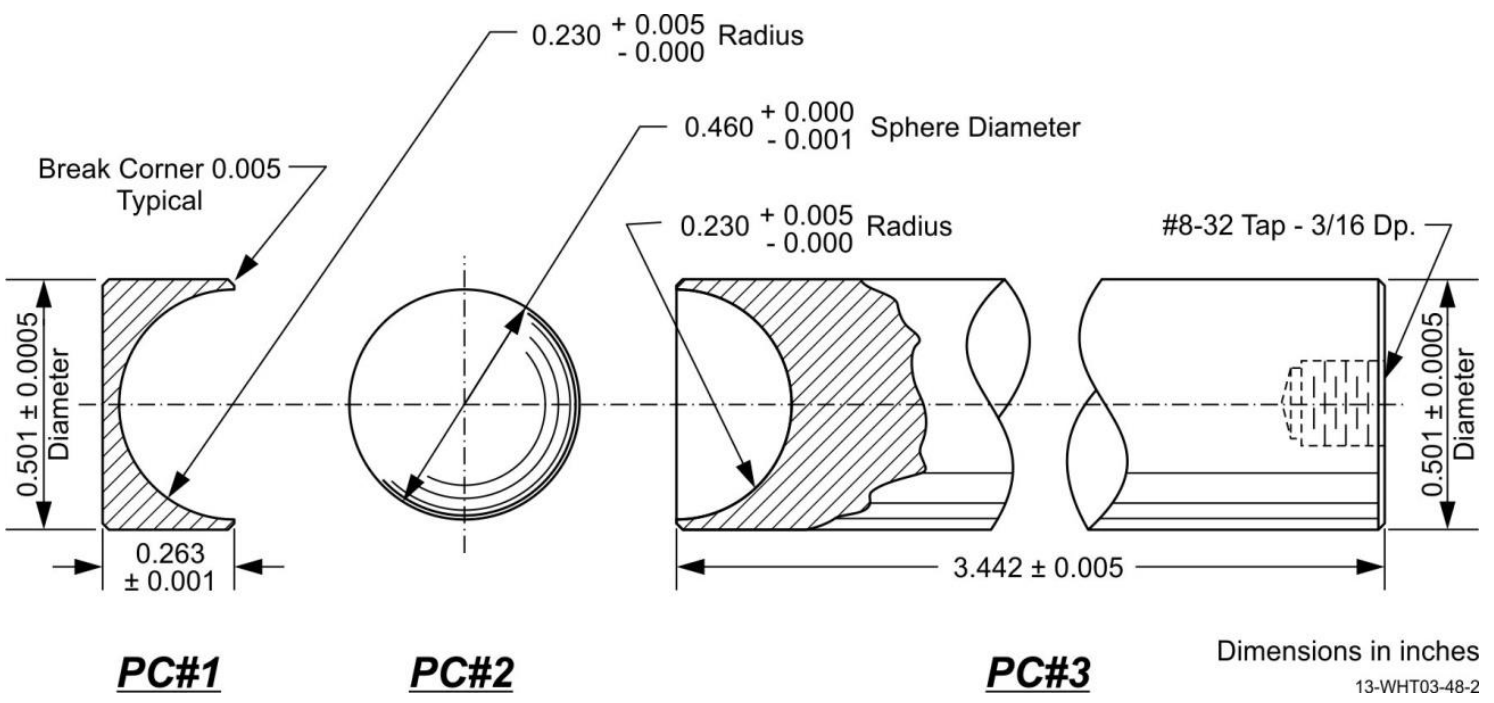

Figure 1.4-2. Dimensions and Manufacturing Tolerances of Plug and Sphere for Central Void Region Worth Measurement (Reference 3). 


\section{NEA/NSC/DOC(2006)1 \\ Fundamental-FUND \\ ORSPHERE-FUND-EXP-001 \\ CRIT-REAC-COEF-KIN-RRATE}

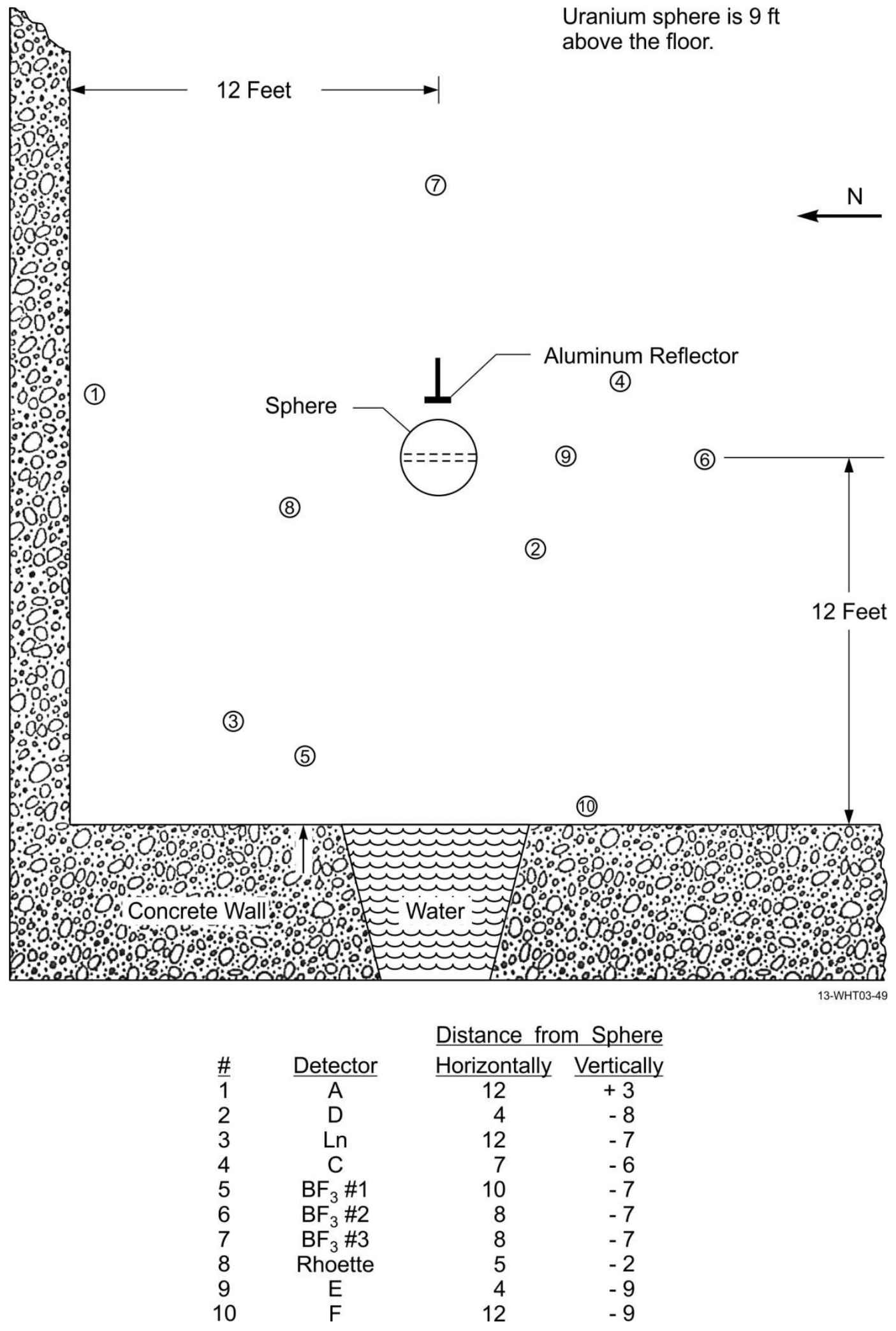

Figure 1.4-3. Plan View of Detector Location for ORSphere Experiments. ${ }^{\mathrm{a}}$

\footnotetext{
${ }^{a}$ This drawing was provided by the experimenter. Locations are given in units of feet. The west wall has six water windows in it and is described in the safety analysis report for the ORCEF. (Personal email communication with J.T. Mihalczo, February 20, 2013)
} 


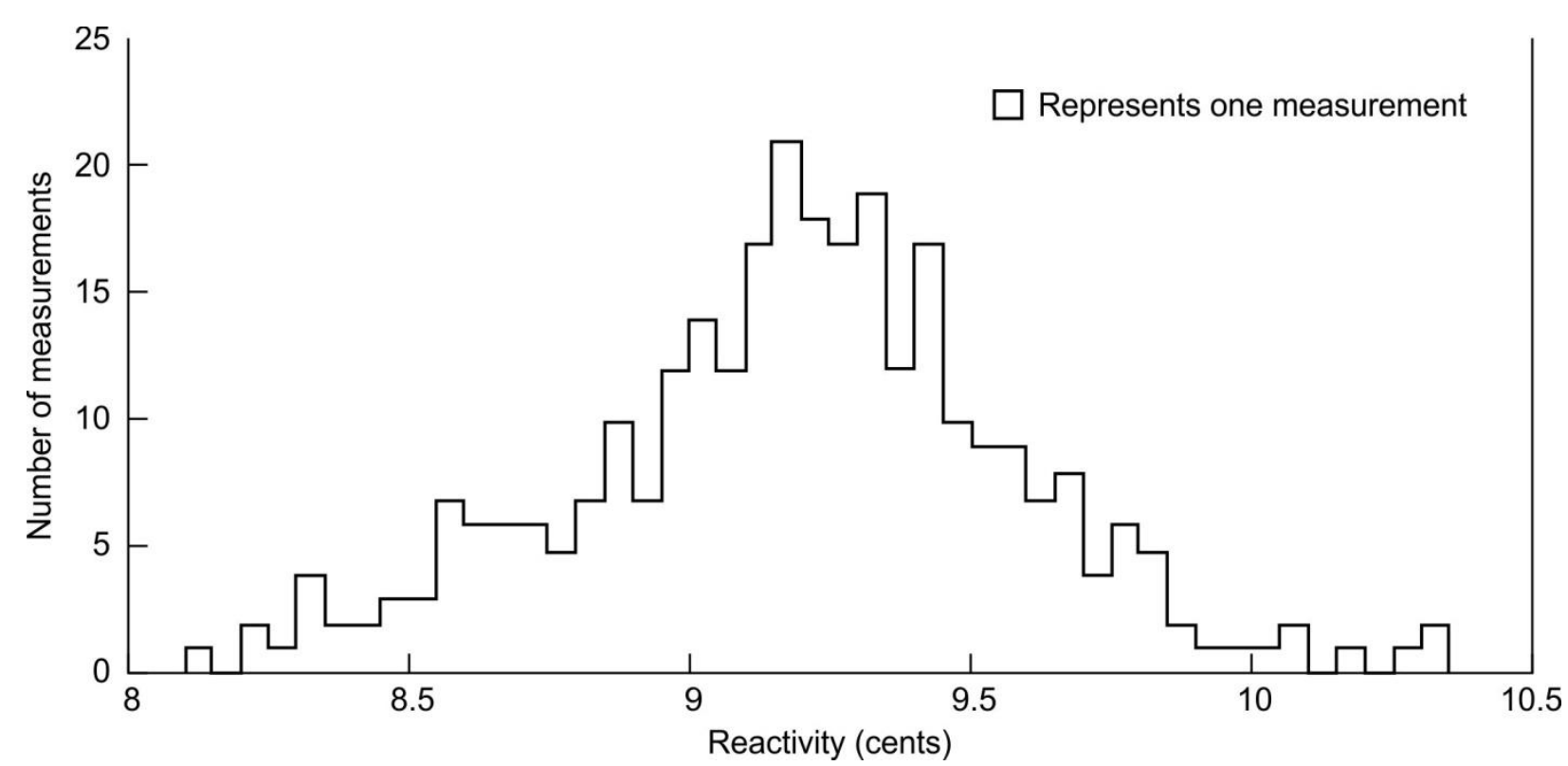

Figure 1.4-4. Distribution of Measured Central Void Region Worth Values.

\subsubsection{Worth of Buttons on the Sphere Surface}

Reactivity worths were measured for various types of surface mass adjustment buttons using system reactivity measurements. The system reactivity was determined by measuring the stable reactor period of the sphere both with and without the buttons. The Inhour equation was then used to convert the stable reactor period into system reactivity in dollars/cents. The delayed neutron parameters of uranium isotopes for fast fission of Keepin, Wimett, and Zeigler (1957) were used in the Inhour equation. The change in system reactivity when buttons are added or removed yields the worth of the buttons. A more thorough explanation of the measurements of the stable reactor period and the conversion to reactivity in dollars is given with the description of the central void reactivity and Appendix B.

The only published mass adjustment button worths are given in Reference 1. Adding 16, 0.250-inchthick surface uranium mass adjustment buttons (43.9 g each) increased the reactivity of the 3.4420-inchaverage-radius sphere, with diametral filler rod in place, from $-23 \phi$ to $+12.4 \phi$. The inner and outer diameter for all the buttons, regardless of material and thickness, was the same. ${ }^{\mathrm{a}}$ The button diameter was smaller than the diameter of the button recesses and had a diameter of 0.8720 inch and an inner diameter of 0.1770 inch. $^{\mathrm{b}}$ Reference 3 gives the button diameter as 0.8750 inch which is actually the diameter of the button recess. All mass adjustment buttons placed on the outside of the sphere were held in place using No.8-55 stainless steel screws. The screws were each tightened so that the underside of the head was flush with the outer surface of the button. ${ }^{\mathrm{c}}$. When the buttons were present they were held in place by screws and when removed the screws were also removed.

The logbook provides worth results for four, $1 / 8$-inch-thick uranium mass adjustment buttons on the surface of the sphere. These measurements were performed with the 3.4420-inch-average-radius sphere with 12, 1/8-inch-thick uranium mass adjustment buttons held in place with No.8-55 screws stainless steel (Type 304) screws. The worth was measured by determining the system reactivity for the sphere with and without four, 1/8-inch-thick uranium mass adjustment buttons placed in the four remaining mass adjustment button recesses. The exact location of the four added and removed mass adjustment buttons was not available; however, the measured buttons were probably split between the upper and lower polar caps. ${ }^{\mathrm{d}}$ The measured results were provided in the logbook ${ }^{\mathrm{a}}$ and in a typed table provided by

\footnotetext{
${ }^{\text {a }}$ Personal email communication with J.T. Mihalczo, August 13, 2013.

${ }^{\mathrm{b}}$ Personal email communication with J.T. Mihalczo, September 6, 2013 and Reference 1.

${ }^{\mathrm{c}}$ Personal email communication with J.T. Mihalczo, August 15 and October 8, 2013. The screw type is found in Reference 5 and 7, see Figure 1.6-2.

d Personal communication with J.T. Mihalczo, October 8, 2013. 
the experimenter and are in Table 1.4-4 at the end of Section 1.4.2. The table states that "holding screws were not involved." However, in the logbook it is clear that the base case had 12, 1/8-inch-thick buttons with screws for four other buttons. Four buttons were then added to the sphere, thus filling the 16 available spaces. This method allowed the worth of 4 buttons to be measured without including the worth of the screws. The average worth for four, 1/8-inch-thick uranium mass adjustment buttons on the surface of the sphere was $+6.1415 \pm 0.0834 \varnothing$.

The worth of one aluminum button on the surface of the sphere, including the holding screw, was measured. The aluminum buttons were aluminum Type 6061 and had the same dimensions as the uranium buttons. ${ }^{\mathrm{b}}$ For these measurements, the 3.4420-inch-average-radius sphere had 12 and 13, 1/8inch-thick uranium mass adjustment buttons on the surface of the sphere. Four or three $1 / 8$-inch-thick aluminum buttons were added to or removed from the sphere using the remaining mass adjustment button recesses and held in place using holding screws. The logbook gives the stable reactor period of these measurements. The reactor periods were converted into system reactivity and then the worth per aluminum button, including the holding screw was determined. The results are given in Table 1.4-5 at the end of Section 1.4.2. ${ }^{\mathrm{c}}$ The average worth per 1/8-inch-thick aluminum button with holding screw was $0.7058 \pm 0.0104 \not$.

\subsubsection{Worth of Buttons in Empty Socket Hole of Upper Polar Cap}

Three uranium mass adjustment buttons were placed in the empty socket hole in the upper polar cap of the sphere. The three uranium buttons had a total mass of $65.2 \mathrm{~g}$ and each had a thickness of 0.1250 inch, an inner diameter of $0.1770 \mathrm{inch}$ and an outer diameter of 0.8720 inches. The 3.4420 -inch-averageradius sphere was used with 13, 1/8-inch-thick and one 1/16-inch-thick uranium buttons on the surface of the sphere and a $3 / 8$ inch aluminum shim. According to the experimenter, the $3 / 8$ inch aluminum shim was referring to the distance position of the aluminum reflector used to achieve exactly delayed critical. ${ }^{\mathrm{d}}$ Stable reactor period values for five runs from five detectors, measured with and without the buttons for each run, is recorded in the logbook along with the associated system reactivities. ${ }^{\mathrm{e}}$ Additionally, a typed table of the logbook results was provided by the experimenter with the worth for each detector measurement for each run as well as the average worth given. This table is recreated as Table 1.4-6 at the end of Section 1.4.2. The average worth of the three uranium mass adjustment buttons in the empty socket hole was $7.86 \pm 0.04 \not$.

The logbook also gives a reactivity worth measurement for three $1 / 8$-inch-thick aluminum buttons placed in the empty socket hole. The aluminum buttons were aluminum Type 6061 and had the same dimensions as the uranium buttons. ${ }^{\mathrm{f}}$ The sphere used for the aluminum button worth measurement had 15 1/8-inch-thick uranium mass adjustment buttons on the surface of the sphere and a $5 / 8$ inch aluminum shim. According to the experimenter, the $5 / 8$ inch aluminum shim refers to the distance to the aluminum reflector used to achieve exactly delayed critical. ${ }^{\mathrm{g}}$ Similar to the uranium button in the empty socket hole measurements, results were provided in the logbook as well as in a typed table provided by the experimenter. The results from the table are given as Table 1.4-7 at the end of Section 1.4.2. ${ }^{\mathrm{h}}$ The mass of the aluminum buttons was not provided. The average worth for the three, $1 / 8$-inch-thick aluminum buttons in the empty socket hole of the upper polar cap was $3.1259 \pm 0.0358 \notin$.

The worth of three 1/8-inch-thick stainless steel buttons, with dimensions the same as the uranium mass adjustment buttons, in the empty socket hole was measured. The stainless steel buttons were stainless steel Type 304 and had the same dimensions as the uranium buttons. ${ }^{i}$ The sphere used had 16 1/8-inch

\footnotetext{
${ }^{\mathrm{a}}$ Logbook 8, page 129-130.

${ }^{\mathrm{b}}$ Personal email communication with J.T. Mihalczo, August 13, 2013.

${ }^{\mathrm{c}}$ Logbook 8, page 139-140.

${ }^{d}$ Personal email communication with J.T. Mihalczo, September 19, 2013.

e Logbook 8, page 143-144.

${ }^{f}$ Personal email communication with J.T. Mihalczo, August 13, 2013.

${ }^{g}$ Personal email communication with J.T. Mihalczo, September 19, 2013.

${ }^{\mathrm{h}}$ Logbook 8, page 145-146.

i Personal email communication with J.T. Mihalczo, August 13, 2013. 


\section{Fundamental-FUND \\ ORSPHERE-FUND-EXP-001 \\ CRIT-REAC-COEF-KIN-RRATE}

uranium buttons on the surface of the 3.4420-inch-average radius sphere and a 1/4-inch aluminum shim. According to the experimenter, the $1 / 4$ inch aluminum shim was referring to the distance position of the aluminum reflector used to achieve exactly delayed critical. ${ }^{\mathrm{a}}$ The measurement and reporting methods were the same as for the aluminum button worth. The table of results is given in Table 1.4-8 at the end of Section 1.4.2. ${ }^{\mathrm{b}}$ The mass of the stainless steel buttons was not given. The average worth for the three $1 / 8$-inch-thick stainless steel buttons was $4.7228 \pm 0.0420 \not$.

\subsubsection{Diametral Filler Rod Reactivity Worth}

The uranium diametral filler rod was actually two sections of rods that were placed in the diametral hole of the sphere. The two rods were of 0.1293-inch diameter and 4.265- and 2.745-inch long (17.117 and $11.046 \mathrm{~g}$, respectively). Dimensional certification reports give the rod lengths as 4.2650 inches and 2.7545 inches and the diameter as $0.1290 / 0.1295$ inches, which averaged to $0.1293 \mathrm{inch}$. The length of the shorter filler rod did not agree between Reference 1 and the certification report, this discrepancy is discussed in Section 2.4.4. The masses on the dimensional certification report are the same as those given in Reference 1. The total length of two filler rods was slightly greater than the length of the diametral hole. ${ }^{\mathrm{c}}$ The worth of the diametral rod was found by measuring the stable reactor period for the 3.4420-inch-average-radius sphere with 16, 1/8-inch-thick uranium mass adjustment buttons with and without the diametral filler rods in place. The results are given in the logbook and in a typed table provided by the experimenter and are shown in Table 1.4-9 at the end of Section 1.4.2. ${ }^{\mathrm{d}}$ The published worth of the filler rod was given as $+11.23 \pm 0.07 \notin$ (Reference 1 and 2); the experimenter's notes give the average worth as $11.2340 \pm 0.0717 \phi$.

Table 1.4-1. Fission Fractions and Delayed Neutron Parameters (Reference 3).

\begin{tabular}{|c|c|c|c|c|c|c|c|c|c|c|c|}
\hline \multicolumn{12}{|c|}{ "Keepin Delayed Neutron Parameters ${ }^{(\mathrm{a})}$} \\
\hline Group & \multicolumn{3}{|c|}{$\begin{array}{l}\text { Relative Yield } \\
{ }^{235} \mathrm{U}\end{array}$} & \multicolumn{3}{|c|}{$\begin{array}{l}\text { Decay Constant } \\
{ }^{235} \mathrm{U} \\
\end{array}$} & \multicolumn{3}{|c|}{$\begin{array}{l}\text { Relative Yield } \\
{ }^{238} \mathrm{U}\end{array}$} & \multicolumn{2}{|c|}{$\begin{array}{c}\text { Decay Constant } \\
{ }^{238} \mathrm{U}\end{array}$} \\
\hline 1 & 0.038 & \pm & 0.003 & 0.0127 & \pm & 0.0002 & 0.013 & \pm & 0.001 & 0.0132 & \pm 0.0003 \\
\hline 2 & 0.213 & \pm & 0.005 & 0.0317 & \pm & 0.0008 & 0.137 & \pm & 0.002 & 0.0321 & \pm 0.0006 \\
\hline 3 & 0.188 & \pm & 0.016 & 0.115 & \pm & 0.003 & 0.162 & \pm & 0.020 & 0.139 & $\pm \quad 0.005$ \\
\hline 4 & 0.407 & \pm & 0.007 & 0.311 & \pm & 0.008 & 0.388 & \pm & 0.012 & 0.358 & $\pm \quad 0.014$ \\
\hline 5 & 0.128 & \pm & 0.008 & 1.40 & \pm & 0.081 & 0.225 & \pm & 0.013 & 1.41 & $\pm \quad 0.067$ \\
\hline 6 & 0.026 & \pm & 0.003 & 3.87 & \pm & 0.369 & 0.075 & \pm & 0.005 & 4.02 & $\pm \quad 0.214$ \\
\hline \multicolumn{12}{|c|}{ Fission Fraction ${ }^{(b)}$} \\
\hline & & $241^{\circ}$ & & ${ }^{235} \mathrm{U}$ & .192 & & ${ }^{236} \mathrm{U}$ & 0.012 & & ${ }^{238} \mathrm{U}$ & $0.9714 \%$ \\
\hline
\end{tabular}

(a) The delayed neutron parameters were provided in Reference 3 but they were originally published by Keepin et al.

(b) The fission fractions were "obtained from one-dimensional $S_{n}$ neutron transport calculation with ENDF/B-VI cross sections for a delayed critical sphere" (Reference 3 ).

\footnotetext{
${ }^{a}$ Personal email communication with J.T. Mihalczo, September 19, 2013.

${ }^{\mathrm{b}}$ Logbook 8, page 147-148.

${ }^{\mathrm{c}}$ Personal communication with J.T. Mihalczo, April 15, 2013. The diametral filler rod was not machined to match the curve of the sphere.

${ }^{\mathrm{d}}$ Logbook 8, page 134-135.
} 


\section{NEA/NSC/DOC(2006)1 \\ Fundamental-FUND \\ ORSPHERE-FUND-EXP-001 \\ CRIT-REAC-COEF-KIN-RRATE}

Table 1.4-2. Stable Reactor Period Values for Central Void Reactivity Measurements (Reference 3).

\begin{tabular}{|c|c|c|c|c|c|c|c|c|c|c|}
\hline \multirow{3}{*}{\multicolumn{2}{|c|}{$\begin{array}{c}\text { Run } \\
\text { Number }\end{array}$}} & \multirow{4}{*}{$\begin{array}{c}\text { Shutdown } \\
\text { Method }^{(a)} \\
\text { UPC }\end{array}$} & \multirow{4}{*}{$\begin{array}{c}\begin{array}{c}\text { Number } \\
\text { Of Mass } \\
\text { Adjustment } \\
\text { Buttons }\end{array} \\
12^{\text {(c) }}\end{array}$} & \multicolumn{7}{|c|}{ Reactor Period (s) from } \\
\hline & & & & \multicolumn{3}{|c|}{ Ion Chambers } & \multicolumn{4}{|c|}{ Neutron Counters ${ }^{(b)}$} \\
\hline & & & & \multirow{2}{*}{$\begin{array}{c}\text { A } \\
94.9\end{array}$} & \multirow{2}{*}{$\frac{\mathrm{D}}{103.3}$} & \multirow{2}{*}{$\frac{\mathrm{Ln}}{299.3}$} & \multirow{2}{*}{$\begin{array}{c}1 \\
(B F \# 1) \\
97.7\end{array}$} & \multirow{2}{*}{$\begin{array}{c}2 \\
(B F \# 2) \\
-\end{array}$} & \multirow{2}{*}{$\begin{array}{c}\begin{array}{c}3 \\
(B F \# 3) \\
97.7\end{array} \\
\end{array}$} & \multirow{2}{*}{$\begin{array}{c}\begin{array}{c}4 \\
(T M C)\end{array} \\
99.3\end{array}$} \\
\hline 528 & $\overline{\mathrm{A}}$ & & & & & & & & & \\
\hline & B & & & 1750 & 2081 & 2314 & 2149 & - & 2149 & 2070 \\
\hline & A & UPC & $12^{(\mathrm{c})}$ & 86.7 & 99.1 & 97.7 & 96.4 & - & 91.9 & 98.5 \\
\hline & B & & & 1002 & 1110 & 964 & 1244 & - & 1231 & 1164 \\
\hline \multirow[t]{2}{*}{530} & A & UPC & $12^{(\mathrm{c})}$ & 249 & 250 & 239 & 286 & - & 278 & 244 \\
\hline & B & & & 60.4 & 63.1 & 61.4 & 61.9 & - & 63.2 & 62.7 \\
\hline & A & UPC & $9^{(c)}$ & 216 & 196 & 186 & 180 & - & 179 & 169 \\
\hline & B & & & -415 & -456 & -429 & -438 & - & -427 & -416 \\
\hline \multirow[t]{2}{*}{532} & A & UPC & $9^{(\mathrm{c})}$ & 172 & 167 & 193 & 184 & - & 181 & 184 \\
\hline & $\mathrm{B}^{(\mathrm{d})}$ & & & -507 & -555 & -523 & -518 & - & -533 & -560 \\
\hline \multirow[t]{2}{*}{533} & $\mathrm{~A}$ & UPC & $9^{(\mathrm{c})}$ & -282 & -278 & -258 & -261 & -261 & -261 & -260 \\
\hline & $\mathrm{B}^{(\mathrm{e})}$ & & & 250 & 261 & 266 & 245 & 242 & 245 & 262 \\
\hline \multirow[t]{2}{*}{534} & A & UPC & $9^{(c)}$ & -320 & -305 & -312 & -305 & -305 & -298 & -292 \\
\hline & B & & & 231 & 243 & 253 & 255 & 256 & 254 & 247 \\
\hline \multirow[t]{2}{*}{535} & $\mathrm{~A}^{(\mathrm{e})}$ & UPC & $9^{(\mathrm{c})}$ & 241 & 248 & 246 & 240 & 254 & 245 & 249 \\
\hline & B & & & -277 & -297 & -302 & -292 & -287 & -289 & -289 \\
\hline \multirow[t]{2}{*}{536} & A & UPC & $9^{(\mathrm{c})}$ & 281 & 307 & 287 & 261 & 261 & 267 & 281 \\
\hline & B & & & $-324^{(\mathrm{f})}$ & -319 & -289 & -302 & -293 & -297 & -317 \\
\hline \multirow[t]{2}{*}{537} & $\mathrm{~A}^{(\mathrm{c})}$ & UPC & $9^{(c)}$ & -305 & -300 & -290 & -289 & -289 & -287 & -287 \\
\hline & B & & & 320 & 350 & 332 & 322 & 317 & 324 & 331 \\
\hline \multirow[t]{2}{*}{538} & A & LS & $9^{(\mathrm{c})}$ & 293 & 294 & 295 & 304 & 300 & 298 & 311 \\
\hline & B & & & -327 & -288 & -302 & -305 & -313 & -308 & -326 \\
\hline
\end{tabular}


Fundamental-FUND

ORSPHERE-FUND-EXP-001

CRIT-REAC-COEF-KIN-RRATE

Table 1.4-2 (cont'd.) Stable Reactor Period Values for Central Void Reactivity Measurements (Reference 3).

\begin{tabular}{|c|c|c|c|c|c|c|c|c|c|c|}
\hline \multirow{3}{*}{\multicolumn{2}{|c|}{$\begin{array}{l}\text { Run } \\
\text { Number }\end{array}$}} & \multirow{3}{*}{$\begin{array}{l}\text { Shutdown } \\
\text { Method }^{\text {(a) }}\end{array}$} & \multirow{3}{*}{$\begin{array}{c}\text { Number } \\
\text { Of Mass } \\
\text { Adjustment } \\
\text { Buttons }\end{array}$} & \multicolumn{7}{|c|}{ Reactor Period (s) from } \\
\hline & & & & \multicolumn{3}{|c|}{ Ion Chambers } & \multicolumn{4}{|c|}{ Neutron Counters $^{(b)}$} \\
\hline & & & & A & $\mathrm{D}$ & Ln & $\begin{array}{c}1 \\
(B F \# 1)\end{array}$ & $\begin{array}{c}2 \\
(B F \# 2)\end{array}$ & $\begin{array}{c}3 \\
(B F \# 3) \\
(B F \quad\end{array}$ & $\begin{array}{c}4 \\
(T M C)\end{array}$ \\
\hline & A & LS & $9^{(\mathrm{c})}$ & 221 & 244 & 233 & 230 & 228 & 228 & 236 \\
\hline & $\mathrm{B}$ & & & -299 & -316 & -300 & -295 & -296 & -295 & -299 \\
\hline & A & LS & 10 & -282 & -303 & -293 & -300 & -300 & $-302^{(\mathrm{f})}$ & -284 \\
\hline & $\mathrm{B}$ & & & 242 & 255 & 251 & 248 & 246 & 250 & $227^{(\mathrm{f})}$ \\
\hline \multirow[t]{2}{*}{541} & A & LS & 10 & -299 & -314 & -304 & -302 & -316 & -304 & -301 \\
\hline & B & & & 278 & 233 & 237 & 240 & 234 & 238 & 240 \\
\hline \multirow[t]{2}{*}{542} & A & LS & 10 & 254 & 260 & 260 & 241 & 248 & 248 & 286 \\
\hline & B & & & -286 & -276 & -258 & -284 & -283 & -281 & -291 \\
\hline & A & LS & 10 & 278 & 296 & 304 & 292 & 300 & 285 & 293 \\
\hline & B & & & -305 & -270 & -274 & -283 & -292 & -287 & -287 \\
\hline \multirow[t]{2}{*}{544} & A & LS & 10 & -306 & -290 & -277 & -287 & -292 & -280 & -279 \\
\hline & B & & & 241 & 291 & 279 & 274 & 270 & 266 & 279 \\
\hline \multirow[t]{2}{*}{545} & A & LS & 10 & 303 & 305 & 300 & 289 & 292 & 302 & 298 \\
\hline & B & & & -276 & -290 & -286 & -280 & -281 & $-278^{(\mathrm{f})}$ & -286 \\
\hline & A & LS & 10 & -297 & -305 & -271 & -278 & -284 & -276 & -287 \\
\hline & B & & & 284 & 301 & 289 & 284 & 302 & 291 & 293 \\
\hline \multirow[t]{2}{*}{547} & A & LS & 10 & 300 & 288 & 310 & 302 & 302 & 302 & 302 \\
\hline & B & & & -265 & -299 & -297 & -279 & -292 & -284 & -287 \\
\hline \multirow[t]{2}{*}{548} & A & LS & 10 & -282 & -299 & -305 & -291 & -295 & -292 & -288 \\
\hline & B & & & 249 & 271 & 279 & 271 & 268 & 272 & 275 \\
\hline \multirow{2}{*}{549} & A & LS & 10 & 273 & 280 & 278 & 272 & 272 & 274 & 274 \\
\hline & B & & & -322 & -303 & -296 & -305 & -308 & -313 & -303 \\
\hline \multirow[t]{2}{*}{550} & A & LS & 10 & -291 & -306 & -274 & -287 & -281 & -287 & -287 \\
\hline & B & & & 273 & 302 & 302 & 292 & 302 & 302 & 291 \\
\hline \multirow[t]{2}{*}{551} & A & LS & 10 & 283 & 279 & 282 & 266 & 266 & 276 & 273 \\
\hline & B & & & -281 & -294 & -315 & -293 & -285 & -289 & -284 \\
\hline & A & LS & 10 & -286 & -298 & -310 & -289 & -285 & -289 & -286 \\
\hline & B & & & 254 & 285 & 287 & 284 & 276 & 271 & 271 \\
\hline \multirow[t]{2}{*}{553} & A & LS & 10 & 279 & 285 & 286 & 284 & 279 & 284 & 278 \\
\hline & B & & & -286 & -295 & -281 & -285 & -287 & -286 & -288 \\
\hline \multirow[t]{2}{*}{554} & A & LS & 10 & -310 & -299 & -304 & -292 & -289 & -289 & -286 \\
\hline & B & & & 286 & 289 & 291 & 268 & 271 & 268 & 282 \\
\hline \multirow[t]{2}{*}{555} & A & LS & 10 & 292 & 300 & 307 & 285 & 285 & 292 & 285 \\
\hline & B & & & -281 & -314 & -286 & -292 & -287 & -294 & -290 \\
\hline 556 & A & LS & 10 & -282 & -295 & -298 & -301 & -300 & -305 & -283 \\
\hline & B & & & 273 & 310 & 294 & 300 & 296 & 301 & $296^{(\mathrm{f})}$ \\
\hline 557 & A & LS & 10 & 268 & 276 & 278 & 266 & 266 & 294 & 270 \\
\hline & B & & & -297 & -299 & -281 & -294 & -291 & $-294^{(\mathrm{f})}$ & -287 \\
\hline
\end{tabular}


NEA/NSC/DOC(2006)1

Fundamental-FUND

ORSPHERE-FUND-EXP-001

CRIT-REAC-COEF-KIN-RRATE

Table 1.4-2 (cont'd.). Stable Reactor Period Values for Central Void Reactivity Measurements (Reference 3).

\begin{tabular}{|c|c|c|c|c|c|c|c|c|c|}
\hline \multirow{3}{*}{$\begin{array}{l}\text { Run } \\
\text { Number }\end{array}$} & \multirow{3}{*}{$\begin{array}{c}\text { Shutdow } \\
n \\
\text { Method }^{(\text {a) }}\end{array}$} & \multirow{3}{*}{$\begin{array}{c}\text { Number } \\
\text { Of Mass } \\
\text { Adjustment } \\
\text { Buttons }\end{array}$} & \multicolumn{7}{|c|}{ Reactor Period (s) from } \\
\hline & & & \multicolumn{3}{|c|}{ Ion Chambers } & \multicolumn{4}{|c|}{ Neutron Counters ${ }^{(b)}$} \\
\hline & & & A & D & $\mathrm{Ln}$ & $\begin{array}{c}1 \\
(B F \# l)\end{array}$ & $\begin{array}{c}2 \\
(B F \# 2)\end{array}$ & $\begin{array}{c}3 \\
(B F \# 3)\end{array}$ & $\begin{array}{c}4 \\
(T M C) \\
\end{array}$ \\
\hline $558 \quad \mathrm{~A}$ & LS & 10 & -296 & -299 & -280 & -296 & -301 & -296 & -297 \\
\hline B & & & 257 & 273 & 268 & 266 & 268 & 262 & 264 \\
\hline $559 \quad \mathrm{~A}$ & LS & 10 & 269 & 279 & 274 & 266 & 263 & 266 & 262 \\
\hline B & & & -287 & -306 & -272 & -292 & -292 & -305 & -294 \\
\hline $560 \quad$ A & LS & 10 & -313 & -300 & -301 & -296 & -292 & -294 & -291 \\
\hline $\mathrm{B}$ & & & 221 & 239 & 250 & 242 & 240 & 238 & 241 \\
\hline $561 \quad$ A & LS & 10 & 231 & 239 & 248 & 240 & 234 & 237 & 238 \\
\hline B & & & -289 & -291 & -291 & -288 & -292 & -287 & -309 \\
\hline $562 \quad$ A & UPC & 10 & -282 & -300 & -297 & -294 & -294 & -288 & -292 \\
\hline B & & & 268 & 271 & 279 & $263^{(\mathrm{f})}$ & $262^{(\mathrm{f})}$ & $267^{(\mathrm{f})}$ & 270 \\
\hline 563 & UPC & 10 & 316 & 332 & 339 & 328 & 326 & 320 & 335 \\
\hline $\mathrm{B}$ & & & -296 & -268 & -278 & -300 & -304 & -302 & -300 \\
\hline $564 \quad$ A & UPC & 10 & -282 & -296 & -305 & -294 & -297 & -297 & -295 \\
\hline B & & & 252 & 256 & 259 & 254 & 249 & 249 & 251 \\
\hline $565 \quad$ A & UPC & 10 & 247 & 255 & 250 & 248 & 249 & 249 & 248 \\
\hline B & & & -289 & -301 & -294 & -292 & -291 & -289 & -290 \\
\hline 566 & UPC & 10 & -282 & -296 & -291 & -284 & -291 & -292 & -293 \\
\hline B & & & 247 & 269 & 274 & 268 & 272 & 270 & 269 \\
\hline 569 & UPC & 10 & 302 & 284 & 304 & 272 & 274 & 266 & 282 \\
\hline B & & & -276 & -272 & -278 & -280 & $-279^{(\mathrm{f})}$ & $-282^{(\mathrm{f})}$ & -277 \\
\hline $570 \quad \mathrm{~A}$ & UPC & 10 & -270 & -275 & -268 & -280 & -279 & -280 & -277 \\
\hline B & & & 277 & 297 & 299 & 291 & 299 & 277 & 279 \\
\hline $571 \quad$ A & UPC & 10 & 286 & 301 & 284 & 270 & 272 & 274 & 275 \\
\hline B & & & -272 & -285 & -290 & -306 & -309 & $-310^{(\mathrm{f})}$ & -311 \\
\hline $572 \quad \mathrm{~A}$ & UPC & 10 & -263 & -271 & -265 & -280 & -277 & -274 & -276 \\
\hline B & & & 286 & 298 & 302 & 292 & 291 & 293 & 289 \\
\hline
\end{tabular}

(a) UPC designates that the upper polar cap was raised to disassemble the system. LS designates that the lower section consisting of the lower polar cap and lower plate was removed to disassemble the system.

(b) In Reference 3 the neutron counters are labeled as 1, 2,3, and 4. When comparing results with the logbook it can be determined which numbers correspond to which detector. The detector names have been included in this table. These numbers do not coincide with the detector numbers given in Figure 1.4-3.

(c) For these measurements a small aluminum reflector (worth a few cents) was present at various distances from the sphere. For all other measurements, this aluminum reflector was removed. Mass adjustment buttons were equally divided between upper and lower polar caps. For an odd number of buttons, the upper polar cap had one more button than the bottom.

(d) Central void region empty.

(e) Central void region filled with uranium metal

(f) This value varied between Reference 3 and the logbook. The logbook value was used and recorded in this table rather than the Reference 3 value. The incorrect values in Reference 3 are typographical errors mostly associated with the omission of a minus sign. This is supported by the results in Appendix B. 


\section{NEA/NSC/DOC(2006)1}

Fundamental-FUND

ORSPHERE-FUND-EXP-001

CRIT-REAC-COEF-KIN-RRATE

Table 1.4-3. Worth in Cents $(\phi)$ of a 0.460 -inch-diameter ${ }^{235} U$ Sphere in the Center of a 3.4420 -inch-average-radius ${ }^{235} U$ Sphere. ${ }^{(a)}$

\begin{tabular}{|c|c|c|c|c|c|c|c|c|c|}
\hline \multirow{2}{*}{$\begin{array}{l}\text { Run } \\
\text { Date }\end{array}$} & \multirow{2}{*}{ Run No. } & \multirow{2}{*}{ A } & \multirow{2}{*}{$\mathrm{D}$} & \multirow{2}{*}{ Ln } & \multirow{2}{*}{ TMC } & \multicolumn{3}{|c|}{$\mathrm{BF}_{3}$} & \multirow{2}{*}{$\begin{array}{c}\text { Average Each } \\
\text { Run }\end{array}$} \\
\hline & & & & & & No. 1 & No. 2 & No. 3 & \\
\hline \multirow{6}{*}{$\begin{array}{c}\text { May } \\
19, \\
1972\end{array}$} & 528 & 9.28 & 8.77 & 9.11 & 9.05 & 9.19 & -- & 9.19 & 9.0983 \\
\hline & 529 & 9.50 & 8.55 & 8.50 & 8.65 & 8.89 & -- & 9.25 & 8.8900 \\
\hline & 530 & 9.51 & 9.06 & 9.16 & 9.04 & 9.76 & -- & 9.45 & 9.3300 \\
\hline & 531 & 8.45 & 8.58 & 9.03 & 9.64 & 9.10 & -- & 9.25 & 9.0083 \\
\hline & 532 & 8.89 & 8.78 & 8.21 & 8.27 & 8.47 & -- & 8.49 & 8.5183 \\
\hline & & & & & & & & & 8.9690 \\
\hline \multirow{6}{*}{$\begin{array}{c}\text { May } \\
30, \\
1972\end{array}$} & 533 & 9.71 & 9.64 & 10.06 & 10.06 & 10.30 & 10.35 & 10.30 & 10.0600 \\
\hline & 534 & 9.32 & 9.37 & 9.08 & 9.55 & 9.18 & 9.16 & 9.32 & 9.2829 \\
\hline & 535 & 9.97 & 9.44 & 9.37 & 9.58 & 9.67 & 9.54 & 9.64 & 9.6014 \\
\hline & 536 & 8.49 & 8.27 & 9.05 & 8.60 & 9.14 & 9.32 & 9.15 & 8.8600 \\
\hline & 537 & 8.37 & 8.18 & 8.54 & 8.61 & 8.66 & 8.71 & 8.68 & 8.5357 \\
\hline & & & & & & & & & 9.2680 \\
\hline \multirow{5}{*}{$\begin{array}{c}\text { June } \\
1, \\
1972\end{array}$} & 538 & 8.29 & 8.98 & 8.69 & 8.10 & 8.54 & 8.44 & 8.55 & 8.5129 \\
\hline & 539 & 9.87 & 9.14 & 9.63 & 9.60 & 9.78 & 9.80 & 9.82 & 9.6629 \\
\hline & 540 & 9.84 & 9.22 & 9.47 & 10.07 & 9.38 & 9.41 & 9.32 & 9.5300 \\
\hline & 541 & 8.96 & 9.38 & 9.49 & 9.43 & 9.47 & 9.31 & 9.47 & 9.3586 \\
\hline & & & & & & & & & 9.2661 \\
\hline \multirow{6}{*}{$\begin{array}{c}\text { June } \\
26, \\
1972\end{array}$} & 542 & 9.56 & 9.69 & 10.15 & 9.02 & 9.82 & 9.73 & 9.77 & 9.6771 \\
\hline & 543 & 8.85 & 9.37 & 9.19 & 9.01 & 9.12 & 8.83 & 9.11 & 9.0671 \\
\hline & 544 & 9.38 & 8.98 & 9.41 & 9.37 & 9.25 & 9.21 & 9.51 & 9.3014 \\
\hline & 545 & 9.14 & 8.82 & 8.95 & 8.98 & 9.21 & 9.16 & 9.11 & 9.0529 \\
\hline & 546 & 8.92 & 8.57 & 9.42 & 9.01 & 9.32 & 8.98 & 9.29 & 9.0729 \\
\hline & & & & & & & & & 9.2343 \\
\hline \multirow{5}{*}{$\begin{array}{c}\text { June } \\
28, \\
1972\end{array}$} & 547 & 9.44 & 8.84 & 8.62 & 8.91 & 9.09 & 8.81 & 8.98 & 8.9557 \\
\hline & 548 & 9.75 & 9.06 & 8.84 & 9.22 & 9.12 & 9.18 & 9.18 & 9.1929 \\
\hline & 549 & 8.63 & 8.87 & 9.02 & 8.94 & 8.93 & 8.87 & 8.76 & 8.8600 \\
\hline & 550 & 9.19 & 8.54 & 9.20 & 9.04 & 9.03 & 9.04 & 8.91 & 8.9929 \\
\hline & & & & & & & & & 9.0004 \\
\hline
\end{tabular}




\section{NEA/NSC/DOC(2006)1}

Fundamental-FUND

ORSPHERE-FUND-EXP-001

CRIT-REAC-COEF-KIN-RRATE

Table 1.4-3 (cont'd.). Worth in Cents $(\varnothing)$ of a 0.460-inch-diameter ${ }^{235} \mathrm{U}$ Sphere in the Center of a 3.4420-inch-average-radius ${ }^{235} \mathrm{U}$ Sphere. ${ }^{(\mathrm{a})}$

\begin{tabular}{|c|c|c|c|c|c|c|c|c|c|}
\hline \multirow{2}{*}{$\begin{array}{l}\text { Run } \\
\text { Date } \\
\end{array}$} & \multirow{2}{*}{ Run No. } & \multirow{2}{*}{ A } & \multirow{2}{*}{$\mathrm{D}$} & \multirow{2}{*}{$\mathrm{Ln}$} & \multirow{2}{*}{ TMC } & \multicolumn{3}{|c|}{$\mathrm{BF}_{3}$} & \multirow{2}{*}{$\begin{array}{c}\text { Average Each } \\
\text { Run } \\
\end{array}$} \\
\hline & & & & & & No. 1 & No. 2 & No. 3 & \\
\hline & 551 & 9.27 & 9.05 & 8.62 & 9.34 & 9.24 & 9.40 & 9.19 & 9.1586 \\
\hline July & 552 & 9.56 & 8.89 & 8.65 & 9.32 & 9.08 & 9.27 & 9.26 & 9.1471 \\
\hline 26 & 553 & 9.21 & 8.95 & 9.23 & 9.18 & 9.16 & 9.19 & 9.14 & 9.1514 \\
\hline \multirow[t]{2}{*}{1972} & 554 & 8.90 & 8.82 & 8.71 & 9.17 & 9.24 & 9.26 & 9.30 & 9.0571 \\
\hline & & & & & & & & & 9.1286 \\
\hline & 555 & 9.16 & 8.42 & 8.88 & 9.05 & 9.01 & 9.11 & 8.89 & 8.9314 \\
\hline July & 556 & 9.38 & 8.66 & 8.78 & 9.07 & 8.65 & 8.72 & 8.57 & 8.8329 \\
\hline 28 & 557 & 9.14 & 8.99 & 9.33 & 9.31 & 9.22 & 9.28 & 8.87 & 9.1629 \\
\hline \multirow[t]{2}{*}{1972} & 558 & 9.32 & 9.03 & 9.49 & 9.19 & 9.18 & 9.06 & 9.24 & 9.2157 \\
\hline & & & & & & & & & 9.0357 \\
\hline & 559 & 9.32 & 8.82 & 9.59 & 9.28 & 9.26 & 9.31 & 9.01 & 9.2271 \\
\hline July & 560 & 9.62 & 9.52 & 9.34 & 9.67 & 9.55 & 9.67 & 9.66 & 9.5757 \\
\hline 31 , & 561 & 9.79 & 9.70 & 9.56 & 9.38 & 9.75 & 9.79 & 9.82 & 9.6843 \\
\hline \multirow[t]{2}{*}{1972} & 562 & 9.45 & 9.04 & 8.99 & 9.21 & 9.25 & 9.28 & 9.33 & 9.2214 \\
\hline & & & & & & & & & 9.4272 \\
\hline & 563 & 8.58 & 9.04 & 8.74 & 8.31 & 8.38 & 8.33 & 8.42 & 8.5429 \\
\hline August & 564 & 9.68 & 9.33 & 9.12 & 9.43 & 9.40 & 9.44 & 9.44 & 9.4057 \\
\hline 1 & 565 & 9.61 & 9.25 & 9.48 & 9.58 & 9.54 & 9.56 & 9.60 & 9.5171 \\
\hline \multirow[t]{2}{*}{1972} & 566 & 9.76 & 9.14 & 9.17 & 9.20 & 9.41 & 9.18 & 9.21 & 9.2957 \\
\hline & & & & & & & & & 9.1904 \\
\hline & 569 & 9.15 & 9.46 & 9.09 & 9.37 & 9.43 & 9.43 & 9.47 & 9.3429 \\
\hline August & 570 & 9.60 & 9.24 & 9.38 & 9.41 & 9.19 & 9.12 & 9.36 & 9.3286 \\
\hline 10 & 571 & 9.44 & 8.96 & 9.06 & 8.78 & 8.94 & 8.86 & 8.81 & 8.9786 \\
\hline \multirow[t]{2}{*}{1972} & 572 & 9.66 & 9.32 & 9.42 & 9.30 & 9.18 & 9.26 & 9.30 & 9.3486 \\
\hline & & & & & & & & & 9.2497 \\
\hline
\end{tabular}

(a) This table is recreated from a printed table provided by the experimenter. All averages and notes were provided by the experimenter. 


\section{NEA/NSC/DOC(2006)1}

Fundamental-FUND

ORSPHERE-FUND-EXP-001

CRIT-REAC-COEF-KIN-RRATE

Table 1.4-4. Stable Reactor Period and Worth in Cents $(\phi)$ for Four 1/8-inch Uranium Buttons on Surface of the Sphere. ${ }^{(a)}$

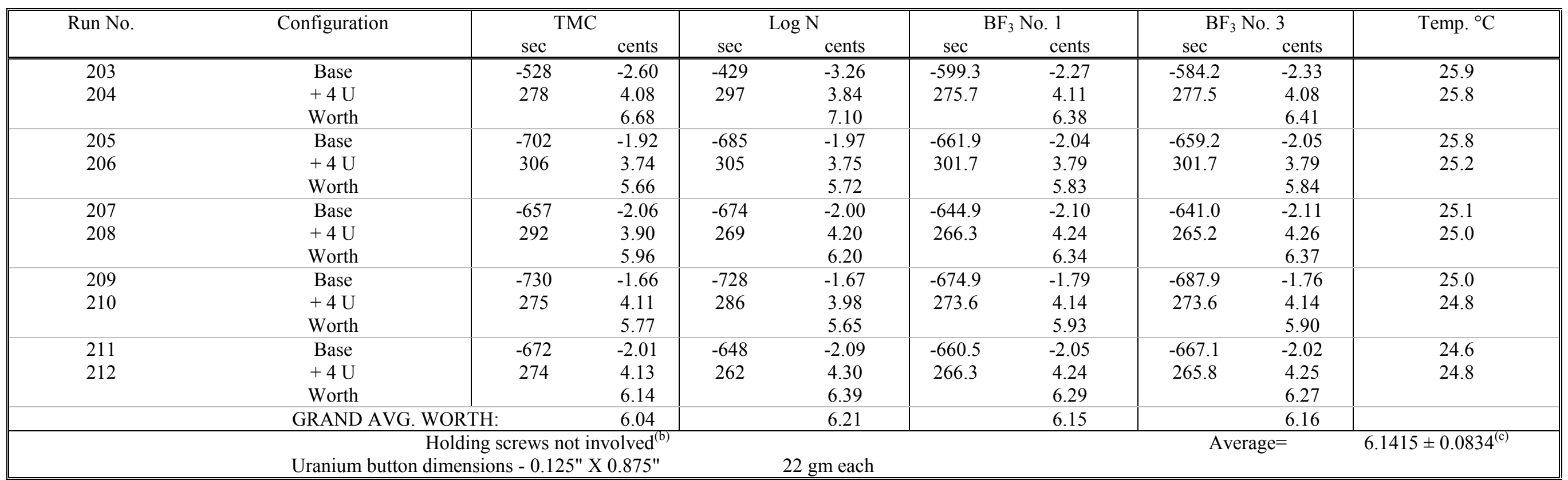

(a) This table is recreated from a printed table provided by the experimenter. All averages and notes were provided by the experimenter.

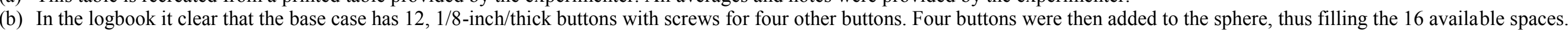
This method allowed the worth of 4 buttons to be measured without including the worth of the screws.

(c) Standard deviation of the mean. 


\section{NEA/NSC/DOC(2006)1}

Fundamental-FUND

ORSPHERE-FUND-EXP-001

CRIT-REAC-COEF-KIN-RRATE

Table 1.4-5. Stable Reactor Period and Worth in Cents $(\phi)$ for one 1/8-inch-thick Aluminum Buttons on the Surface of the Sphere. ${ }^{(a)}$

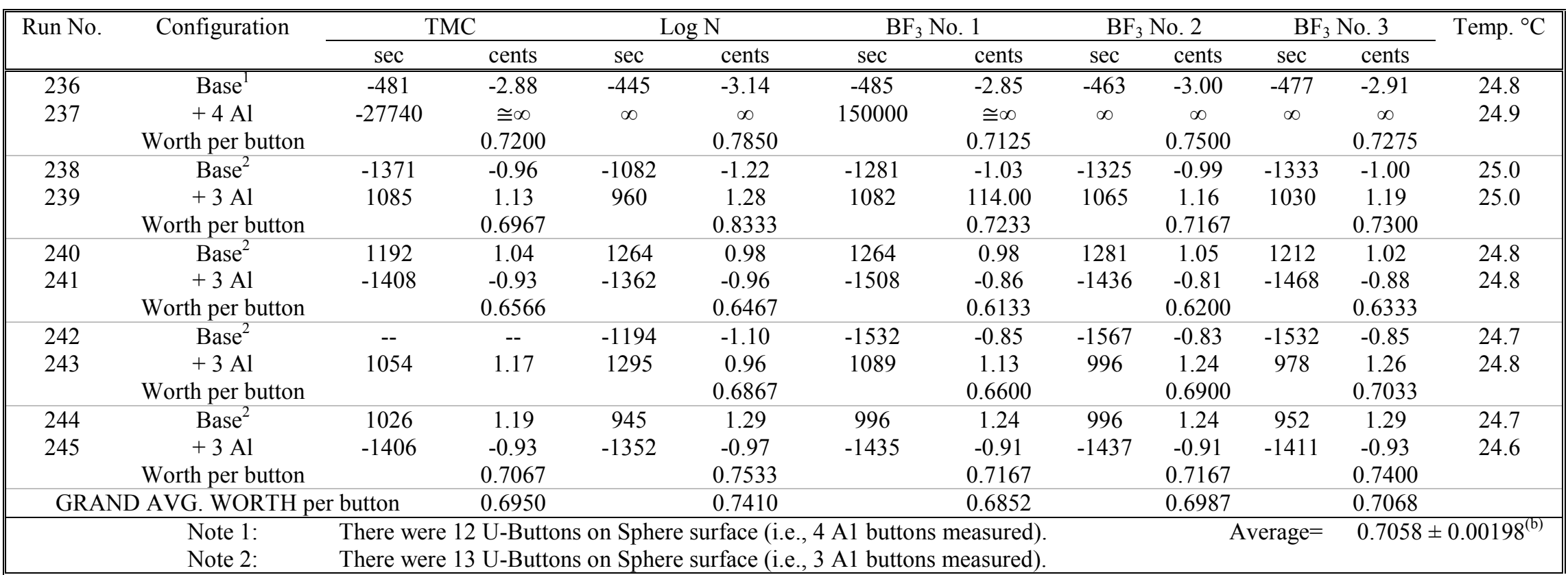

(a) This table is recreated from a printed table provided by the experimenter. All averages and notes were provided by the experimenter.

(b) Standard deviation of the mean. 


\section{NEA/NSC/DOC(2006)1}

Fundamental-FUND

ORSPHERE-FUND-EXP-001

CRIT-REAC-COEF-KIN-RRATE

Table 1.4-6. Stable Reactor Period and Worth in Cents $(\not)$ for Three 1/8-inch-thick Uranium Buttons in Empty Socket Hole. ${ }^{(a)}$

\begin{tabular}{|c|c|c|c|c|c|c|c|c|c|c|c|c|}
\hline \multirow[t]{2}{*}{ Run No. } & \multirow[t]{2}{*}{ Configuration } & \multicolumn{2}{|c|}{ TMC } & \multicolumn{2}{|c|}{$\log N$} & \multicolumn{2}{|c|}{$\mathrm{BF}_{3}$ No. 1} & \multicolumn{2}{|c|}{$\mathrm{BF}_{3}$ No. 2} & \multicolumn{2}{|c|}{$\mathrm{BF}_{3}$ No. 3} & \multirow[t]{2}{*}{ Temp. ${ }^{\circ} \mathrm{C}$} \\
\hline & & $\mathrm{sec}$ & cents & $\mathrm{sec}$ & cents & $\mathrm{sec}$ & cents & $\mathrm{sec}$ & cents & $\mathrm{sec}$ & cents & \\
\hline $247 \mathrm{~A}$ & Base & 571 & 2.10 & 541 & 2.21 & -- & -- & -- & -- & -- & -- & 25.6 \\
\hline 247B & $\begin{array}{c}-3 \mathrm{U} \\
\text { Worth }\end{array}$ & -261 & $\begin{array}{c}-5.77 \\
7.87\end{array}$ & -257 & $\begin{array}{c}-5.87 \\
8.08\end{array}$ & -- & $\begin{array}{l}-- \\
--\end{array}$ & -- & $\begin{array}{l}-- \\
--\end{array}$ & -- & $\begin{array}{l}-- \\
--\end{array}$ & 25.5 \\
\hline $248 \mathrm{~A}$ & Base & 601 & 2.03 & 613 & 1.97 & 558 & 2.15 & 581 & 2.07 & 588 & -2.05 & 25.5 \\
\hline 248B & $\begin{array}{c}-3 \mathrm{U} \\
\text { Worth }\end{array}$ & -259 & $\begin{array}{c}-5.82 \\
7.85\end{array}$ & -275 & $\begin{array}{c}-5.42 \\
7.39\end{array}$ & -265 & $\begin{array}{c}-5.66 \\
7.81\end{array}$ & -260 & $\begin{array}{c}-5.79 \\
7.86\end{array}$ & -259 & $\begin{array}{c}-5.82 \\
7.87\end{array}$ & 25.5 \\
\hline $249 \mathrm{~A}$ & Base & 580 & -2.07 & 613 & 1.97 & 607 & 1.99 & 581 & 2.07 & 618 & 1.95 & 25.4 \\
\hline 249B & $\begin{array}{c}-3 \mathrm{U} \\
\text { Worth }\end{array}$ & -260 & $\begin{array}{c}-5.79 \\
7.86\end{array}$ & -260 & $\begin{array}{c}-5.79 \\
7.76\end{array}$ & -252 & $\begin{array}{c}-6.01 \\
8.00\end{array}$ & -250 & $\begin{array}{c}-6.06 \\
8.13\end{array}$ & -251 & $\begin{array}{r}-6.05 \\
8.00\end{array}$ & 25.0 \\
\hline $250 \mathrm{~A}$ & Base & 621 & 1.94 & 623 & 1.94 & 582 & 2.07 & 584 & 2.06 & 580 & 2.07 & 25.3 \\
\hline $250 \mathrm{~B}$ & $\begin{array}{c}-3 \mathrm{U} \\
\text { Worth }\end{array}$ & -261 & $\begin{array}{c}-5.77 \\
7.71\end{array}$ & -260 & $\begin{array}{c}-5.79 \\
7.73\end{array}$ & & $\begin{array}{l}-- \\
--\end{array}$ & & $\begin{array}{l}-- \\
--\end{array}$ & & $\begin{array}{l}-- \\
--\end{array}$ & 25.1 \\
\hline $251 \mathrm{~A}$ & Base & 605 & 1.99 & 580 & 2.07 & 589 & 2.04 & 567 & 2.12 & 592 & 2.03 & 25.1 \\
\hline $251 \mathrm{~B}$ & $\begin{array}{c}-3 U \\
\text { Worth }\end{array}$ & -259 & $\begin{array}{c}-5.82 \\
7.81\end{array}$ & -266 & $\begin{array}{c}-5.64 \\
7.71\end{array}$ & -258 & $\begin{array}{c}-5.85 \\
7.89\end{array}$ & -254 & $\begin{array}{c}-5.96 \\
8.08\end{array}$ & -256 & $\begin{array}{c}-5.90 \\
7.93\end{array}$ & 24.9 \\
\hline & \multicolumn{2}{|c|}{ GRAND AVG. WORTH: } & 7.82 & & 7.73 & & 7.90 & & 8.02 & & 7.93 & \\
\hline Note: & \multicolumn{5}{|c|}{$\begin{array}{l}\text { Base Conf. = Top Socket out, E Pin in. } \\
13 \text { (1/8 in.) and } 1 \text { (1/16 in.) Uranium Buttons on surface } \\
\text { Al shim @ } 3 / 8 \text { in. from the sphere } \\
3(1 / 8 \text { in.) Uranium Buttons in Socket Hole } \\
\end{array}$} & & & & & \multicolumn{3}{|c|}{ Average $=7.860 \pm 0.0091^{(b)}$} \\
\hline
\end{tabular}

(a) This table is recreated from a printed table provided by the experimenter. All averages and notes were provided by the experimenter.

(b) Standard deviation of the mean. 


\section{NEA/NSC/DOC(2006)1}

Fundamental-FUND

ORSPHERE-FUND-EXP-001

CRIT-REAC-COEF-KIN-RRATE

Table 1.4-7. Stable Reactor Period and Worth in Cents $(\not)$ for Three 1/8-inch-thick Aluminum Buttons in Empty Socket Hole. ${ }^{(a)}$

\begin{tabular}{|c|c|c|c|c|c|c|c|c|c|c|c|c|}
\hline \multirow[t]{2}{*}{ Run No. } & \multirow[t]{2}{*}{ Configuration } & \multicolumn{2}{|c|}{ TMC } & \multicolumn{2}{|c|}{$\overline{\log N}$} & \multicolumn{2}{|c|}{ 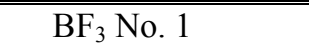 } & \multicolumn{2}{|c|}{$\overline{\mathrm{BF}_{3} \text { No. } 2}$} & \multicolumn{2}{|c|}{ 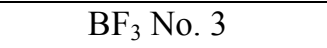 } & \multirow[t]{2}{*}{ Temp. ${ }^{\circ} \mathrm{C}$} \\
\hline & & $\mathrm{sec}$ & cents & $\mathrm{sec}$ & cents & $\mathrm{sec}$ & cents & $\mathrm{sec}$ & cents & $\mathrm{sec}$ & cents & \\
\hline $252 \mathrm{~A}$ & Base & -600 & -2.27 & -564 & -2.42 & -614 & -2.21 & -605 & -2.25 & -615 & -2.21 & 25.4 \\
\hline $252 \mathrm{~B}$ & $-3 \mathrm{Al}$ & -269 & -5.56 & -274 & -5.44 & -276 & -5.40 & -278 & -5.35 & -271 & -5.51 & 25.5 \\
\hline \multicolumn{2}{|r|}{ Worth } & & 3.29 & & 3.02 & & 3.19 & & 3.10 & & 3.30 & \\
\hline $253 \mathrm{~A}$ & Base & -588 & -2.32 & -501 & -2.75 & -589 & -2.31 & -591 & -2.31 & -602 & -2.61 & 25.3 \\
\hline 253B & $-3 \mathrm{Al}$ & -272 & -5.49 & -270 & -5.38 & -276 & -5.40 & -264 & -5.69 & -264 & -5.69 & 25.2 \\
\hline \multicolumn{2}{|r|}{ Worth } & & 3.17 & & 2.63 & & 3.09 & & 3.38 & & 3.08 & \\
\hline $254 \mathrm{~A}$ & Base & -569 & -2.40 & -575 & -2.38 & -555 & -2.47 & -555 & -2.47 & -584 & -2.34 & 25.0 \\
\hline 254B & $-3 \mathrm{Al}$ & -272 & -5.49 & -268 & -5.59 & -- & -- & -270 & -5.53 & -270 & -5.53 & 25.0 \\
\hline \multicolumn{2}{|r|}{ Worth } & & 3.09 & & 3.21 & & -- & & 3.06 & & 3.19 & \\
\hline $255 \mathrm{~A}$ & Base & -576 & -2.37 & -550 & -2.49 & -- & -- & -542 & -2.53 & -540 & -2.54 & 25.3 \\
\hline $255 \mathrm{~B}$ & $-3 \mathrm{Al}$ & -260 & -5.79 & -265 & -5.66 & -- & -- & -270 & -5.53 & -264 & -5.68 & 25.3 \\
\hline \multicolumn{2}{|r|}{ Worth } & & 3.42 & & 3.17 & & -- & & 3.00 & & 3.14 & \\
\hline $256 \mathrm{~A}$ & Base & -573 & -2.38 & -573 & -2.38 & -- & -- & -547 & -2.51 & -573 & -2.38 & 25.2 \\
\hline $256 \mathrm{~B}$ & $-3 \mathrm{Al}$ & -274 & -5.44 & -275 & -5.42 & -- & -- & -276 & -5.40 & -266 & -5.63 & 25.0 \\
\hline & Worth & & 3.06 & & 3.04 & & -- & & 2.89 & & 3.25 & \\
\hline & \multicolumn{2}{|c|}{ GRAND AVG. WORTH } & 3.21 & & 3.01 & & 3.14 & & 3.09 & & 3.19 & \\
\hline Note: & \multicolumn{2}{|c|}{ Base Configuration: } & $\begin{array}{l}\text { Top Socket } \\
\text { Al Shim @ } \\
3 \text { (1/8 in.) A }\end{array}$ & $\begin{array}{l}\text { Pin in, } 1 \\
{ }^{\circ} \mathrm{C} \text { Meas } \\
\text { um Butto }\end{array}$ & $\begin{array}{l}8{ }^{235} \mathrm{U}-\mathrm{B} \\
\text { d between } \\
\text { Socket Hc }\end{array}$ & $\begin{array}{l}\text { on Surfa } \\
\text { tton and }\end{array}$ & ere Surfac & & & Average $=$ & 3.1259 & $.0078^{(b)}$ \\
\hline
\end{tabular}

(a) This table is recreated from a printed table provided by the experimenter. All averages and notes were provided by the experimenter.

(b) Standard deviation of the mean. 


\section{NEA/NSC/DOC(2006)1}

Fundamental-FUND

ORSPHERE-FUND-EXP-001

CRIT-REAC-COEF-KIN-RRATE

Table 1.4-8. Stable Reactor Period and Worth in Cents $(\not)$ for Three 1/8-inch-thick Stainless Steel Buttons in the Empty Socket Hole. ${ }^{(a)}$

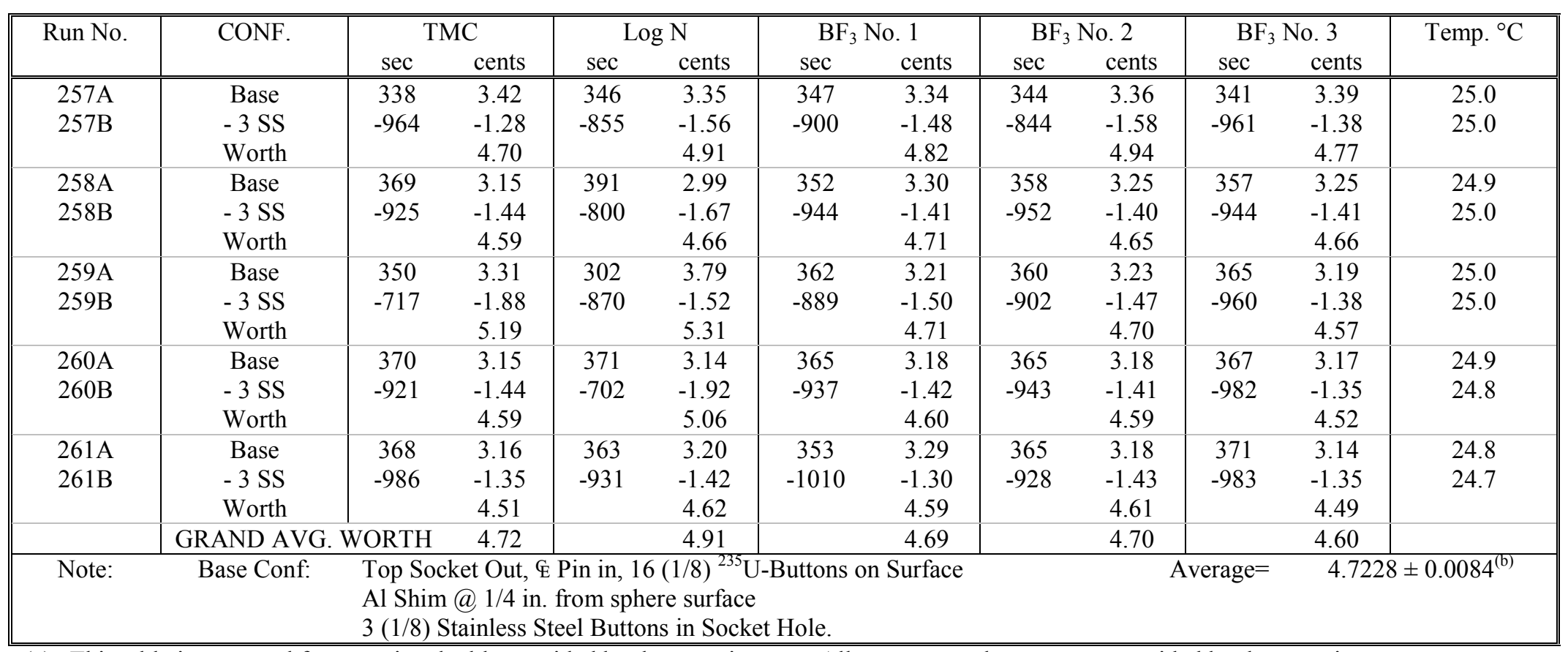

(a) This table is recreated from a printed table provided by the experimenter. All averages and notes were provided by the experimenter.

(b) Standard deviation of the mean. 


\section{NEA/NSC/DOC(2006)1}

Fundamental-FUND

ORSPHERE-FUND-EXP-001

CRIT-REAC-COEF-KIN-RRATE

Table 1.4-9. Stable Reactor Period and Reactivity Worth in Cents $(\dot{\infty})$ for The Diametral Filler Rod. ${ }^{(a)}$

\begin{tabular}{|c|c|c|c|c|c|c|c|c|c|c|c|c|}
\hline \multirow[t]{2}{*}{ Run No. } & \multirow[t]{2}{*}{ CONF. } & \multicolumn{2}{|c|}{ TMC } & \multicolumn{2}{|c|}{$\overline{\log N}$} & \multicolumn{2}{|c|}{ 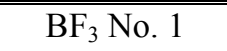 } & \multicolumn{2}{|c|}{ 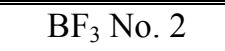 } & \multicolumn{2}{|c|}{$\overline{\mathrm{BF}_{3} \text { No. } 3}$} & \multirow[t]{2}{*}{$\overline{\text { Temp. }}{ }^{\circ} \mathrm{C}$} \\
\hline & & $\mathrm{sec}$ & cents & $\mathrm{sec}$ & cents & $\mathrm{sec}$ & cents & $\mathrm{sec}$ & cents & sec & cents & \\
\hline 216 & Base & -214 & -7.36 & -229 & -6.76 & -216 & -7.28 & -215.0 & -7.32 & -214 & -7.36 & 25.9 \\
\hline 217 & $\begin{array}{c}\text { + Diametral Rod } \\
\text { Worth }\end{array}$ & 291 & $\begin{array}{c}3.92 \\
11.28\end{array}$ & 286 & $\begin{array}{c}3.98 \\
10.74\end{array}$ & 282.7 & $\begin{array}{c}4.02 \\
11.30\end{array}$ & 280.1 & $\begin{array}{l}4.05 \\
11.37\end{array}$ & 278.7 & $\begin{array}{c}4.07 \\
11.43\end{array}$ & 25.5 \\
\hline 218 & Base & -220 & -7.11 & -231 & -6.69 & -224.1 & -6.91 & -221.5 & -7.05 & -221.8 & -7.03 & 25.4 \\
\hline 219 & $\begin{array}{c}\text { + Diametral Rod } \\
\text { Worth }\end{array}$ & 290 & $\begin{array}{c}3.93 \\
11.04\end{array}$ & 284 & $\begin{array}{l}4.01 \\
10.70\end{array}$ & 272.3 & $\begin{array}{c}4.01 \\
10.92\end{array}$ & 267.1 & $\begin{array}{c}4.23 \\
11.28\end{array}$ & 281.4 & $\begin{array}{l}4.03 \\
11.06\end{array}$ & 25.3 \\
\hline 220 & Base & -229 & -6.76 & -223 & -6.99 & -209.8 & -7.55 & -212.4 & -7.43 & -229.3 & -6.75 & 25.1 \\
\hline 221 & $\begin{array}{c}\text { + Diametral Rod } \\
\text { Worth }\end{array}$ & 280 & $\begin{array}{c}4.05 \\
10.81\end{array}$ & 287 & $\begin{array}{c}3.96 \\
10.95\end{array}$ & 286.6 & $\begin{array}{c}3.97 \\
11.53\end{array}$ & 289.2 & $\begin{array}{c}3.94 \\
11.37\end{array}$ & 278.8 & $\begin{array}{c}4.07 \\
10.82\end{array}$ & 24.9 \\
\hline 222 & Base & -215 & -7.32 & -214 & -7.36 & -207.2 & -7.68 & -206.5 & -7.70 & -209.1 & -7.58 & 25.0 \\
\hline 223 & $\begin{array}{c}\text { + Diametral Rod } \\
\text { Worth }\end{array}$ & 261 & $\begin{array}{c}4.32 \\
11.64\end{array}$ & 272 & $\begin{array}{c}4.16 \\
11.52\end{array}$ & 267.9 & $\begin{array}{c}4.22 \\
11.90\end{array}$ & 274.1 & $\begin{array}{c}4.13 \\
11.83\end{array}$ & L271.2 & $\begin{array}{l}4.17 \\
11.75\end{array}$ & 25.0 \\
\hline 224 & Base & -224 & -6.95 & -235 & -6.55 & -222.8 & -7.00 & -218.6 & -7.17 & -217.6 & -7.20 & 25.0 \\
\hline 225 & $\begin{array}{c}\text { + Diametral Rod } \\
\text { Worth }\end{array}$ & 263 & $\begin{array}{l}4.29 \\
11.24\end{array}$ & 284 & $\begin{array}{l}4.01 \\
10.56\end{array}$ & 271.5 & $\begin{array}{l}4.16 \\
11.16\end{array}$ & 273.4 & $\begin{array}{c}4.14 \\
11.31\end{array}$ & 273.1 & $\begin{array}{l}4.15 \\
11.35\end{array}$ & 25.0 \\
\hline & \multicolumn{2}{|c|}{ GRAND AVG. WORTH } & 11.20 & & 10.89 & & 11.36 & & 11.43 & & 11.28 & \\
\hline & & & & & & & & & & verage $=$ & 11.23 & $\pm .0717^{(\mathrm{b})}$ \\
\hline
\end{tabular}

(a) This table is recreated from a printed table provided by the experimenter. All averages and notes were provided by the experimenter.

(b) Standard deviation of the mean. 


\section{NEA/NSC/DOC(2006)1}

Fundamental-FUND

ORSPHERE-FUND-EXP-001

CRIT-REAC-COEF-KIN-RRATE

All measured reactivity worths are summarized in Table 1.4-10.

Table 1.4-10. Summary of Measured Reactivity Worths.

\begin{tabular}{|c|c|}
\hline & $\begin{array}{l}\text { Measured Worth with } \\
\text { Standard Deviation }(\phi)\end{array}$ \\
\hline Central Void & $9.165 \pm 0.023$ \\
\hline $\begin{array}{l}\text { Sixteen, } 0.635-\mathrm{cm} \text {-thick Uranium } \\
\text { Buttons on Sphere Surface }\end{array}$ & From $-23 \notin$ to $+12.4 \varnothing$ \\
\hline $\begin{array}{l}\text { Four, 0.3175-cm-thick Uranium } \\
\text { Buttons on Sphere Surface }\end{array}$ & $6.1415 \pm 0.0834$ \\
\hline $\begin{array}{l}\text { One, } 0.3175 \text {-cm-thick Aluminum } \\
\text { Button on Sphere Surface }\end{array}$ & $0.7058 \pm 0.0104$ \\
\hline $\begin{array}{l}\text { Three, } 0.3175 \text {-cm-thick Uranium } \\
\text { Buttons in Socket Hole }\end{array}$ & $7.86 \pm 0.04$ \\
\hline $\begin{array}{l}\text { Three, } 0.3175 \text {-cm-thick Stainless } \\
\text { Steel Buttons in Socket Hole }\end{array}$ & $4.7228 \pm 0.0420$ \\
\hline $\begin{array}{l}\text { Three, } 0.3175 \text {-cm-thick Aluminum } \\
\text { Buttons in Socket Hole }\end{array}$ & $3.1259 \pm 0.0358$ \\
\hline Diametral Filler Rod & $11.2340 \pm 0.0717$ \\
\hline
\end{tabular}




\section{NEA/NSC/DOC(2006)1 \\ Fundamental-FUND \\ ORSPHERE-FUND-EXP-001 \\ CRIT-REAC-COEF-KIN-RRATE}

\subsubsection{Material Data}

The materials for the sphere are given in Section 1.3 of HEU-MET-FAST-100.

The small sphere and plug for the central void reactivity measurement was made such that the material was identical to the surrounding sphere. Impurity, isotopic composition or density data was not provided for the small sphere and plug. An isotopic composition for the "plugs for 0.500 -in-diam holes" was given in Reference 2 and is presented in Table 1.4-11. It is not known if this isotopic composition applies to the plug in the 0.504-inch-diameter surface hole. However, the experimenter has access to month isotopic composition averages for the Y-12 plant. "The material used for the central worth measurements was fabricated in April 1972." The corresponding isotopic composition would be: ${ }^{\mathrm{a}}$

$\begin{array}{lr}{ }^{234} \mathrm{U} & 0.985 \text { wt.\% } \\ { }^{235} \mathrm{U} & 93.161 \text { wt.\% } \\ { }^{236} \mathrm{U} & 0.442 \text { wt.\% } \\ { }^{238} \mathrm{U} & 5.412 \text { wt.\% }\end{array}$

The isotopic composition and impurity data for the uranium mass adjustment buttons is given in Reference 1 and presented in Table 1.4-11 and Table 1.4-12. The isotopic composition but not impurity data were given in Reference 1 for the diametral filler rods, see Table 1.4-11.

According to the experimenter, the aluminum buttons were aluminum Type 6061 and the steel buttons were stainless steel Type 304 . $^{\text {b }}$ The screws used to hold the buttons in place were stainless steel Type $304 .^{\mathrm{c}}$

\footnotetext{
${ }^{\text {a }}$ Personal email communication with J.T. Mihalczo, September 6 and 10, 2013.

${ }^{\mathrm{b}}$ Personal email communication with J.T. Mihalczo, August 13, 2013.

${ }^{\mathrm{c}}$ Personal communication with J.T. Mihalczo, October 8, 2013. 
NEA/NSC/DOC(2006)1

Fundamental-FUND

ORSPHERE-FUND-EXP-001

CRIT-REAC-COEF-KIN-RRATE

Table 1.4-11. Isotopic Content of Uranium Metal Parts

(Reference 1 and 2, additions by the evaluator are italic).

\begin{tabular}{|lcccc||}
\hline \multirow{2}{*}{ Part Description } & \multicolumn{4}{c}{${\text { Isotopic Content (wt.\%) }{ }^{(\mathrm{a})}}$} \\
\cline { 2 - 5 } & ${ }^{234} \mathrm{U}$ & ${ }^{235} \mathrm{U}$ & ${ }^{236} \mathrm{U}$ & ${ }^{238} \mathrm{U}$ \\
\hline \hline Upper Polar Cap & 0.9844 & $93.21^{(\mathrm{b})}$ & 0.03593 & 5.76967 \\
\hline Upper Plate & 0.9844 & $93.21^{(\mathrm{b})}$ & 0.03593 & 5.76967 \\
\hline Central Plate & 0.9843 & $93.20^{(\mathrm{b})}$ & 0.03592 & 5.77978 \\
\hline Lower Plate & 0.9845 & $93.22^{(\mathrm{b})}$ & 0.03593 & 5.75957 \\
\hline Lower Polar Cap & 0.9841 & $93.18^{(\mathrm{b})}$ & 0.03592 & 5.79998 \\
Mass adjustment buttons and upper socket & 0.9846 & $93.23^{(\mathrm{b})}$ & 0.03594 & 5.74946 \\
\hline Plug for target hole & 0.9954 & 93.156 & 0.451 & 5.3976 \\
\hline Pins for central part & 0.9860 & 93.171 & 0.424 & 5.4190 \\
\hline Pins for lower part & 0.9954 & 93.156 & 0.451 & 5.3976 \\
\hline Plugs for 0.500-in.-diam. holes (Ref. 2) ${ }^{(\mathrm{b}, \mathrm{c})}$ & 0.988 & 93.164 & 0.4460 & 5.4020 \\
\hline Split Plugs (Ref. 2) ${ }^{(\mathrm{c})}$ & 0.985 & 93.154 & 0.460 & 5.3880 \\
Filler rods for 0.136-in-dia diametral hole & 0.9954 & 93.156 & 0.451 & 5.3976 \\
\hline Mass adjustment buttons (0.063 in. thick) & 0.9954 & 93.156 & 0.451 & 5.3976 \\
\hline \hline
\end{tabular}

(a) These isotopic compositions were from the average monthly isotopic compositions of $\sim 93.2 \mathrm{wt} . \%{ }^{235} \mathrm{U}$ ORALLOY parts at the Y-12 for the month in which the parts were fabricated except where noted. The ${ }^{234} \mathrm{U}$ and ${ }^{236} \mathrm{U}$ are known to $\pm 1 \%$ of the values stated, and the ${ }^{235} \mathrm{U}$ to four significant figures (i.e. $\pm 0.005)$. The ${ }^{238} \mathrm{U}$ percentage is by difference and is not accurate beyond the third digit. The weighted average isotopic compositions for these parts comprising the major parts, target hole filler and pins are 0.9844 wt. $\%{ }^{234} \mathrm{U}, 93.20$ wt. $\%{ }^{235} \mathrm{U}, 0.04626$ wt. $\%{ }^{236} \mathrm{U}$, and 5.7693 wt. $\%{ }^{238} \mathrm{U}$. (The weighted averaged isotopic composition calculation could not be reproduced because the weight of the target hole filler and pins was not given.)

(b) Measured and documented values. Written as "Measured and reported out," in Reference 2.

(c) The following is footnote (c) in Reference 2 although a reference to footnote (c) does not appear anywhere in the table. It is believed that it applies to the lines for the plugs for the 0.500-inchdiameter holes and the split plugs.

Solid plugs were provided to fill all holes. Split filler plugs with inside diameters of 0.082 and 0.136 were provided to fit around the shafts of the various detectors and sources inserted into the 0.500 radial and 0.375 -in.-diam surface holes. 
NEA/NSC/DOC(2006)1

Fundamental-FUND

ORSPHERE-FUND-EXP-001

CRIT-REAC-COEF-KIN-RRATE

Table 1.4-12. Impurity Content of Enriched Uranium Sphere Parts

(Reference 1 additions by the evaluator are italic).

\begin{tabular}{|c|c|c|c|c|c|c|c|c|c|c|c|c|c|c|}
\hline \multirow[b]{2}{*}{$\begin{array}{l}\text { ORNL } \\
\text { Part \# }\end{array}$} & \multirow[b]{2}{*}{$\begin{array}{c}\text { Part } \\
\text { Description }\end{array}$} & \multirow[b]{2}{*}{$\begin{array}{l}\text { Gram U } \\
\text { per } \\
\text { gram of } \\
\text { uranium }^{(\text {a) }} \\
\text { metal }^{\text {(a) }} \\
\text { x100 }\end{array}$} & \multicolumn{12}{|c|}{ Impurity Content $(\mathrm{ppm})^{(\mathrm{c}, \mathrm{d})}$} \\
\hline & & & $\begin{array}{l}\text { Boron } \\
\text { Equiv- } \\
\text { alent }^{(b)}\end{array}$ & $\mathrm{Be}$ & $\mathrm{Li}$ & $\mathrm{Al}$ & $\mathrm{Si}$ & $\begin{array}{c}\text { Total } \\
\mathrm{Fe}, \\
\mathrm{Mn}, \\
\mathrm{Ni}, \mathrm{Cr}, \\
\mathrm{V} \mathrm{Cu}\end{array}$ & B & Co & $\mathrm{Ca}$ & $\mathrm{C}$ & $\mathrm{O}$ & $\mathrm{N}$ \\
\hline $1-6$ & $\begin{array}{l}\text { Upper Polar } \\
\text { Cap }\end{array}$ & 99.961 & 0.647 & $<0.01$ & $<0.2$ & 6 & 80 & 85 & 0.5 & $<1$ & $<10$ & 202 & 20 & 30 \\
\hline $1-8$ & Upper Plate & 99.966 & 0.408 & $<0.01$ & $<0.2$ & 4 & 100 & 34 & 0.3 & $<1$ & $<10$ & 159 & 20 & 30 \\
\hline $1-10$ & Central Plate & 99.966 & 0.328 & $<0.01$ & $<0.2$ & 4 & 200 & 50 & 0.2 & $<1$ & $<10$ & 159 & 20 & 30 \\
\hline $1-11$ & Lower Plate & 99.949 & 0.629 & $<0.01$ & $<0.2$ & 8 & 125 & 57 & 0.5 & $<1$ & $<10$ & 142 & 20 & 30 \\
\hline $1-12$ & $\begin{array}{l}\text { Lower Polar } \\
\text { Cap }\end{array}$ & 99.912 & 0.242 & $<0.01$ & $<0.2$ & 5 & 100 & 83 & 0.1 & $<1$ & $<10$ & 179 & 20 & 30 \\
\hline $1-4$ & $\begin{array}{l}16 \text { Mass } \\
\text { Adjustment } \\
\text { Buttons, } \\
0.250 \text {-in. } \\
\text { Thick }\end{array}$ & 99.955 & 0.348 & $<0.01$ & $<0.2$ & 2 & 200 & 68 & 0.2 & $<1$ & $<10$ & 306 & 20 & 30 \\
\hline $1-5$ & $\begin{array}{l}16 \text { Mass } \\
\text { Adjustment } \\
\text { Buttons, } \\
0.125 \text {-in. } \\
\text { Thick }\end{array}$ & 99.955 & 0.348 & $<0.01$ & $<0.2$ & 2 & 200 & 68 & 0.2 & $<1$ & $<10$ & 306 & 20 & 30 \\
\hline $1-1$ & $\begin{array}{l}\text { Socket for } \\
\text { upper polar } \\
\text { cap }\end{array}$ & 99.955 & 0.348 & $<0.01$ & $<0.2$ & 2 & 200 & 68 & 0.2 & $<1$ & $<10$ & 306 & 20 & 30 \\
\hline
\end{tabular}

(a) Reported to 5 digits; accurate to 4 digits. This is the uranium weight fraction in the ORALLOY.

(b) Boron equivalent is the parts per million boron that has the same thermal neutron absorption cross section as all impurities. Boron equivalent is only for elements in the table excluding oxygen and nitrogen. Boron equivalent is an approximation for the effect of impurities for assemblies with thermal neutron spectra where the predominant effect is boron absorption but is irrelevant for fission spectrum assemblies.

(c) In addition to these impurities, there were $20 \mathrm{ppm}$ oxygen and $30 \mathrm{ppm}$ nitrogen.

(d) Reference 1 gives an average impurity content of $99.95 \mathrm{~g}$ of uranium per $100 \mathrm{~g}$ of material, $5 \mathrm{ppm}, \mathrm{Al}, 120 \mathrm{ppm} \mathrm{Si}, 62$ ppm metals, $0.3 \mathrm{ppm} \mathrm{B,} 168 \mathrm{ppm} \mathrm{C,} 20 \mathrm{ppm} O$, and $30 \mathrm{ppm} \mathrm{N}$.

\subsubsection{Temperature Data}

Dimensional measurements of all parts were performed at the $\mathrm{Y}-12$ plant at $70^{\circ} \mathrm{F}\left(21.1^{\circ} \mathrm{C}\right)$. Reference 1 gives the experimental temperature as $24.5^{\circ} \mathrm{C}\left(76^{\circ} \mathrm{F}\right)$. However in Table 1.4-4 through Table 1.4-9 various variable experimental temperatures are given.

The temperature coefficient for the ORSphere should be the same as the measured coefficient of about $1 / 3 \notin$ per degree centigrade for GODIVA I,${ }^{\mathrm{a}}$ as is typically used for other ORCEF bare HEU (ORALLOY) experiments. ${ }^{\mathrm{b}}$

${ }^{a}$ R.E. Peterson and G.A. Newby, “An unreflected U-235 Critical Assembly,” Nucl. Sci. and Eng., 1, 112-125 (1956).

${ }^{\mathrm{b}}$ Personal email communication with J.T. Mihalczo, March 11, 2013

Revision: 1

Date: March 31, 2015

Page 26 of 169 
NEA/NSC/DOC(2006)1

Fundamental-FUND

ORSPHERE-FUND-EXP-001

CRIT-REAC-COEF-KIN-RRATE

\subsubsection{Additional Information Relevant to Reactivity Effects Measurements}

Additional information was not identified.

\subsection{Description of Reactivity Coefficient Measurements}

\subsubsection{Overview of Experiment}

The reactivity per gram of surface material was evaluated using the change in reactivity between the 3.4665-inch-average-radius sphere and the 3.4420-inch-average-radius sphere.

\subsubsection{Geometry of the Experiment Configuration and Measurement Procedure}

The geometry of the 3.4665-inch- and 3.4420-inch-average radius spheres are described in Section 1.2 of HEU-MET-FAST-100. ${ }^{a}$ The system reactivity for the larger sphere was $68.1 \pm 2.0 \varnothing$ and the smaller sphere had a worth of $-23.4 \notin$. $^{\mathrm{b}}$ This $91.5 \notin$ change in reactivity divided by the $1125 \mathrm{~g}$ of surface material which was removed yields a reactivity coefficient for surface material of $0.081 \pm 0.001 \varnothing$ per gram ORALLOY surface material. ${ }^{\mathrm{c}}$ However, this value has not been corrected to account for the tilt between the lower and center plate of the larger diameter sphere that is not present for the smaller diameter sphere. ${ }^{\mathrm{d}}$ The gap between the plates was 0.0045 inches on one side and zero on the other yielding an average gap of $2.25 \times 10^{-3}$ inches. "Using a measured reactivity worth of the gap of $2.2 \pm 0.1$ cents per thousandths of an inch, this correction is $5.0 \pm 0.2$ cents and the resulting excess reactivity of the system corrected to no gap between the lower and central section is $73.1 \pm 2.0$ cents" (Reference 1 ).

\subsubsection{Material Data}

The material data for the sphere are given in Section 1.3 of HEU-MET-FAST-100.

\subsubsection{Temperature Data}

The temperature data for the sphere are given in Section 1.4 of HEU-MET-FAST-100.

\subsubsection{Additional Information Relevant to Reactivity Coefficient Measurements}

Additional information was not identified.

\subsection{Description of Kinetics Measurements}

\subsubsection{Overview of Experiment}

The effective delayed neutron fraction, $\beta_{\text {eff, }}$ for the ORSphere was measured using time correlation measurements with californium-252 (Reference 5). It was also determined as the ratio of measured and calculated central void reactivities (Reference 3 and 4).

The prompt neutron decay constant for the ORSphere was determined using hundreds of Rossi- $\alpha$ and randomly pulsed neutron measurements with californium-252 (Reference 6 and 7).

\footnotetext{
a International Handbook of Evaluated Criticality Safety Benchmark Experiments, NEA/NSC/DOC(95)03, OECDNEA, Paris (2013).

${ }^{\mathrm{b}}$ Reference 1 gives a reactivity of $-23 \phi$. The logbook, gives an average reactivity of $-23.4 \phi$.

${ }^{c}$ These values are rounded in Reference 1 . In HEU-MET-FAST-100 the exact values are $91.1 \phi$ reactivity change and $1125.04 \mathrm{~g}$ mass difference. The reactivity coefficient still rounds to $0.081 \not / \mathrm{g}$ ORALLOY surface material.

${ }^{\mathrm{d}}$ Personal communication with J.T Mihalczo, September 3, 2013.
} 
NEA/NSC/DOC(2006)1

Fundamental-FUND

ORSPHERE-FUND-EXP-001

CRIT-REAC-COEF-KIN-RRATE

\subsubsection{Geometry of the Experiment Configuration and Measurement Procedure}

The kinetic parameter measurements were performed using the 3.4425-inch-nominal-radius/3.4420-inchaverage-radius sphere. The central plate was machined as shown in Figure 1.6-2 to allow for necessary fission sources and detectors.

\subsubsection{Delayed Neutron Fraction}

The effective delayed neutron fraction was measured using a time correlation randomly pulsed neutron measurement and a Rossi- $\alpha$ measurement; this method has been shown to be incorrect and is briefly described here to preserve all experimental measurements. ${ }^{a}$ The experimental setup is shown in Figure 1.6-1 and the geometry of the sphere is shown in Figure 1.6-2. More detailed descriptions of the geometry and the methods are given in Reference 5.The resulting $\beta_{\text {eff }}$ value was $0.00602 \pm 0.00008$ which is much lower than the $\beta_{\text {eff }}$ value from the central void reactivity measurements $(0.00657 \pm 0.00002$, see end of Section 1.6.2.1) and the $\beta_{\text {eff }}$ value measured for GODIVA I (0.0066). Reference 5 attributes the low value to possible "improper theoretical formulation for correcting point kinetics for spatial effects." The experimenter has stated that this value is clearly wrong and should not be used. ${ }^{\mathrm{b}}$

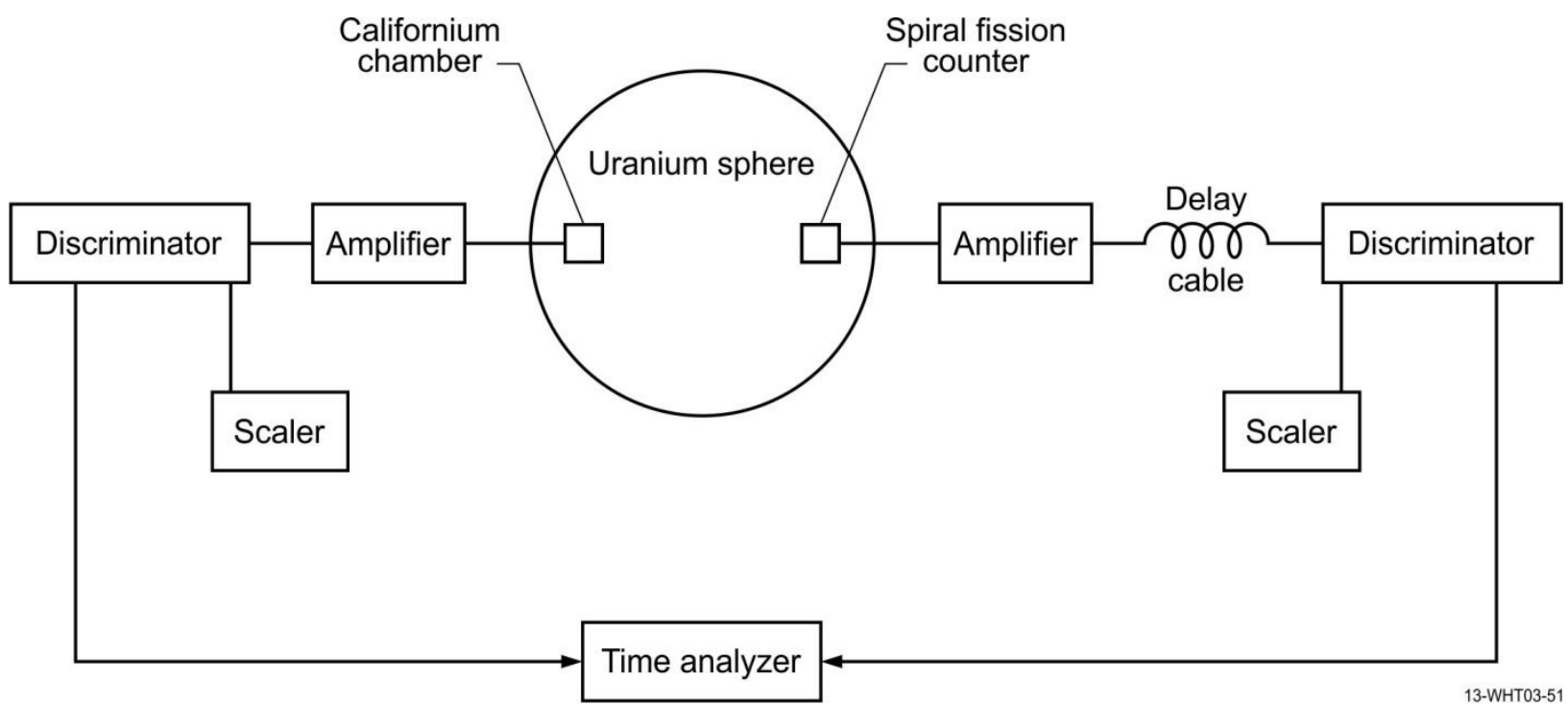

Figure 1.6-1. Block Diagram of Instrumentation for Time Correlation Measurements (Reference 5).

\footnotetext{
a "The theory for the analysis is not correct and gave an impossible value of the delayed neutron fraction which should not be used for even a reference. It was published to see if some bright theorist could come up with a better interpretation. Beta effective was $10 \%$ lower than beta which is impossible. Similar unpublished measurements for JEZEBEL and FLATOP with a Pu core and FLATTOP with a uranium core were also $10 \%$ too low which is impossible!" Personal communication with J.T. Mihalczo, September 3, 2013.

${ }^{b}$ Personal email communication with J.T. Mihalczo, July 15, 2013.
} 

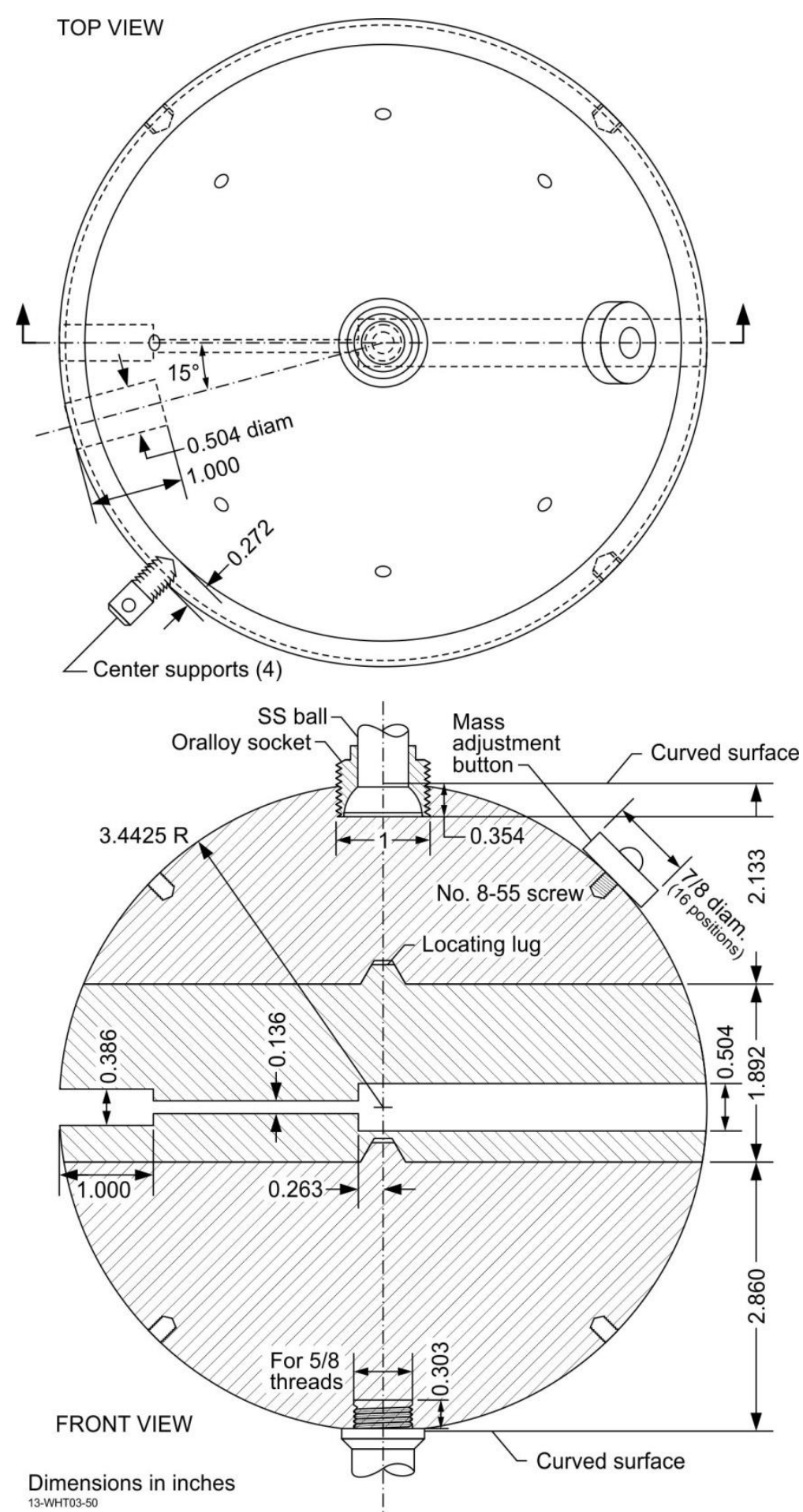

Figure 1.6-2. Sphere Geometry Time Correlation Measurements (Reference 5 and 7).

The effective delayed neutron fraction for the ORSphere was also determined using the central void reactivity. As described in Section 1.4, the reactivity was measured using the stable reactor period in units of dollars. The void worth was calculated in units of $\Delta \mathrm{k}$ using $\mathrm{S}_{n}$ transport theory, extrapolated to infinite order $\mathrm{S}_{n}$, with a precision of at least $10^{-7} \Delta \mathrm{k}$. ONEDANT and XSDRNPM codes with HansenRoach and ENDF/B-VI cross section libraries were used. The average reactivity of the central void was $6.02 \pm 0.01 \times 10^{-4} \Delta \mathrm{k}$. According to Reference 3 this uncertainty "essentially includes all the variation in these calculated values (this choice is somewhat arbitrary but conservative)". This calculation is discussed in more depth in Reference 3 and 4 . The ratio of the measured worth in dollars and the calculated worth in $\Delta \mathrm{k}$ yields the effective delayed neutron fraction, $\beta_{\text {eff }}=\rho(\Delta k) / \rho(\$)$. The resulting 
$\beta_{\text {eff }}$ value was $0.00657 \pm 0.00002$. This derived value agrees well with the delayed neutron fraction measured with GODIVA I (0.0066).

\subsubsection{Prompt Neutron Decay Constant}

Measurements of the prompt neutron decay constant, $\alpha$, were performed in 1971, 1972, and 1975, but final results were not published until 2011 by the experimenter, J.T. Mihaclzo in Reference 6 . The results were not originally published because the "neutron decay constant obtained by fitting the time decay for a single measurement had a larger uncertainty than previous measurements." The experimenter published the results many years later when it was realized that because of the large number of measurements the prompt neutron decay constant could be accurately obtained from measurements if the average for all measurements were used. Reference 6 and 7 both discuss this measurement. Reference 6 is a more recent re-analyzing of the experiment data using more data points. It also provides more detail and is thus considered the main reference. ${ }^{a}$ All information and quotes regarding the prompt neutron decay constant measurements are taken from Reference 6 unless noted otherwise.

Rossi- $\alpha$ and randomly pulsed neutron measurements were performed to measure the prompt neutron decay constant. $\mathrm{A}^{252} \mathrm{Cf}$ source was used for the measurements. Less than $0.15 \mu \mathrm{g}$ of ${ }^{252} \mathrm{Cf}$ "was electroplated on one electrode of a parallel plate or annular ionization chamber, and thus served as a time-tagged source of fission neutrons. There were three californium ionization chambers with spontaneous fission rates of $\sim 25,000$ to 86,000 fissions per second. One was a $0.5 \times 0.5$-inch-diameter right circular cylinder; one was a 0.375 -inch-diameter, 0.5 -inch-high cylindrical chamber; and the other has a diameter of 1.00 inch and a height of 1.00 inch". See Table 1.6-1 for more details for the chambers and for assigned chamber numbers. The 0.5 -inch-diameter source ionization chambers had a 0.125 -inchdiameter shaft to contain the voltage/signal cables. "The 0.375 -inch-diameter source ionization chamber had a large-diameter shaft $(0.25$ inch)" for the same purpose.

The ORSphere had "two 1-inch-deep reentrant holes at the surface, one machined for a 0.5 -inch-outside diameter, 0.5 -inch-long chamber and one for the 0.375 -inch-outside diameter, 1.0-inch-long chamber." These reentrant holes are shown in Figure 1.4-1 and Figure 1.6-2. The 1.000-inch-deep, 0.504-inchdiameter reentrant hole was called a surface hole $(\mathrm{SH})$ and the other 1.000-inch deep reentrant hole was called the 0.386-inch-diameter portion of the diametric hole (DH). Split fissile plugs, which were uranium metal annuli split down the center-line of the sphere, of various lengths were used around the shafts of the detectors when they were interior to the sphere to reduce the amount of void introduced into the sphere.

A spiral fission counter (SFC) built by J. C. Hogterp of Los Alamos National Laboratory was used for neutron detection. The fission counter had $63.8 \mathrm{mg}$ of $\sim 93 \mathrm{wt} . \%{ }^{235} \mathrm{U}$ metal and was a 0.5 -inch-diameter, 0.5 -inch-high right circular cylindrical counter with a 0.125 -inch-diameter shaft. Split plugs were also used around the shaft of the SFC when they were inside the sphere.

The SFC, for single input, or a ${ }^{252} \mathrm{Cf}$ ionization chamber and the $\mathrm{SFC}$, for double input, could be connected to the two-channel, shift-register time analyzer, made available by John Orndoff of Los Alamos National Laboratory. The analyzer "had 19 time bins with selectable width as short as $0.25 \mu$ s." The time analyzer is described in more detail in Section 2 of Reference 6.

When the prompt neutron decay constant measurements were performed the center plate geometry was the same as the geometry shown in Figure 1.4-1 and Figure 1.6-2. The geometries of all other sphere plates were the same as those given for the critical assembly sphere in HEU-MET-FAST-100. To achieve the desired reactivity, up to 16 mass adjustment buttons and a 70-g aluminum reflector worth approximately $2 \not$, which was remotely positioned, were used. The system was kept as close to exactly delayed critical as possible using a variable number of uranium buttons. For each measurement there were "at least two (usually more) verifications of delayed criticality each day" (Reference 7). In the logbook the system reactivity checks ranged from approximately $-0.5 \phi$ to $+0.5 \phi$.

${ }^{a}$ Personal email communication with J.T. Mihalczo, April 1, 2014. 


\section{Fundamental-FUND}

ORSPHERE-FUND-EXP-001

A number of Rossi- $\alpha$ and randomly pulsed neutron experiments were performed at delayed critical. The placement of the ${ }^{252} \mathrm{Cf}$ source and the SFC varied between measurements. "[The] two different $\mathrm{Cf}$ sources could be located either at the surface of the sphere in holes especially sized to hold the two different diameter sources or at various radial locations in the diametral hole (DH) of the sphere, including the center. The spiral fission chamber detector was also located at different radii, including the center. The SFC also fit in the surface hole (SH) for the 0.5 -inch-diameter Cf sources." The SFC and the ionization chambers were usually placed at opposite ends of the sphere so as much uranium was between the two as possible. Plugs were used so that as little void was introduced to the volume of the sphere as possible; this was done by filling unused holes with tight fitting plugs and using the split plugs around the shafts of the detectors and source ionization chambers.

Additionally, a "limited [number of] measurements were performed with $\mathrm{NaI}$ and ${ }^{6} \mathrm{Li}$ glass scintillation detectors adjacent to the surface of the sphere." These measurements are discussed further in Reference 6 but only limited details regarding the scintillators were given.

For the Rossi- $\alpha$ measurements the sphere was assembled continuously and for the randomly pulsed neutron measurements the sphere was typically cycled 25 times per prompt neutron decay measurements between assembled and disassembled "to reduce the background from fission chains initiated by delayed neutrons from previous fission that produced counts not correlated with the latest californium source fission." Runs were performed such that the random pulsed neutron measurements and Rossi- $\alpha$ measurements were back-to-back. An example of the plotted data is shown in Figure 1.6-3.

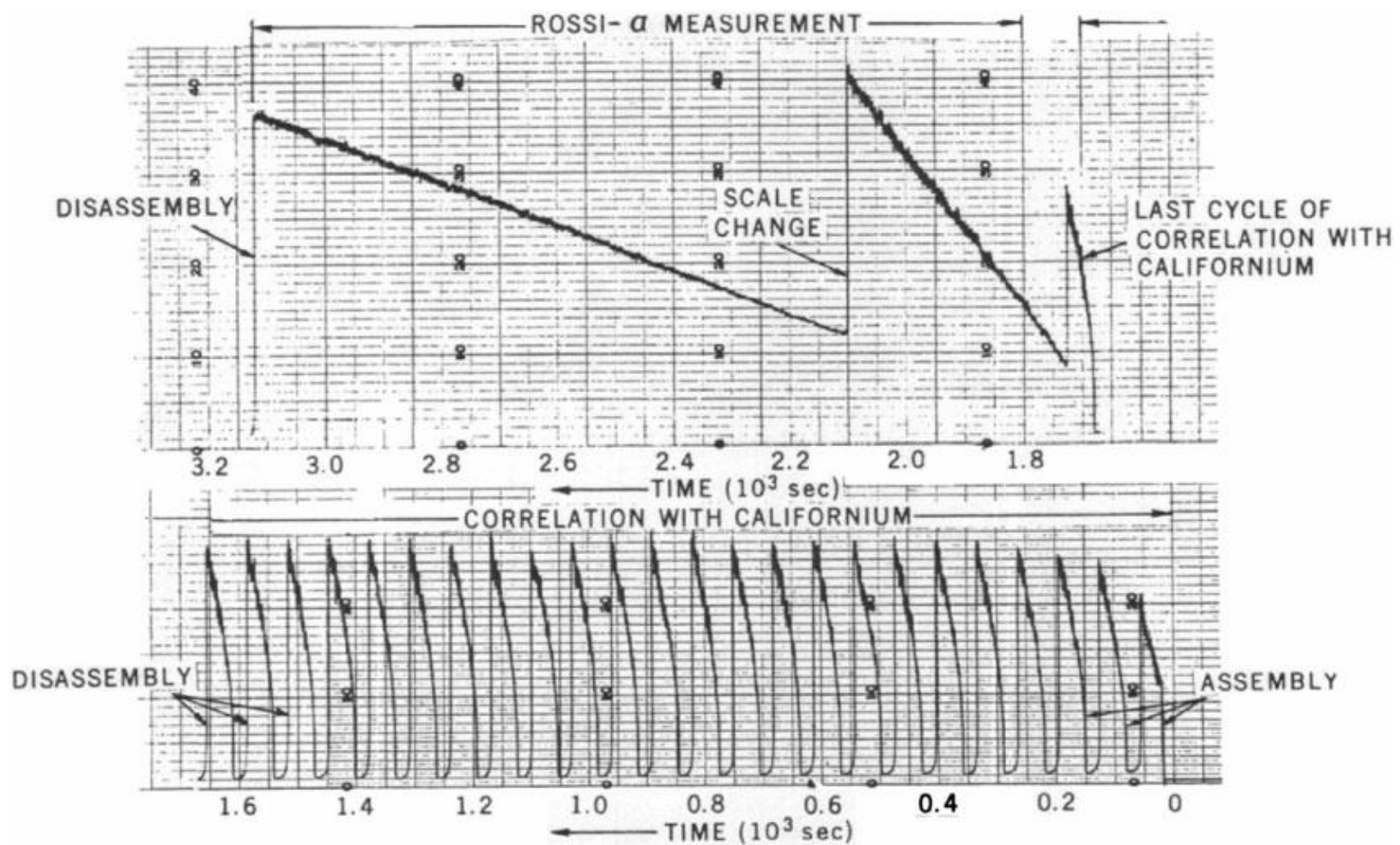

Figure 1.6-3. Fission Rate during Randomly Pulsed Neutron and Rossi- $\alpha$ Measurements.

(Note the time starts at zero at the bottom right of the randomly pulsed neutron measurements and increases until $\sim 3125 \mathrm{~s}$ at the top left of the Rossi- $\alpha$ measurement.)

"The data from both types of measurements were fitted by nonlinear least-squares method to the function $D+E \exp (-\alpha t)$ to determine the prompt neutron decay constant $(\alpha)$ with the value of $D$ fixed and obtained appropriately from the average count rate, the detected $\mathrm{Cf}$ fission rate, and the width of the time bins." Measured values were averaged using a variance weighted average. "All measurements were included in the average even though some were more than $3 \sigma$ away from the average. Since these usually had larger statistical uncertainty, they did not significantly affect the average value." For more 
information regarding the derivation of the prompt neutron decay constant see Reference 6 . An example of typical count results is shown in Figure 1.6-4 and average results are summarized in Table 1.6-1.

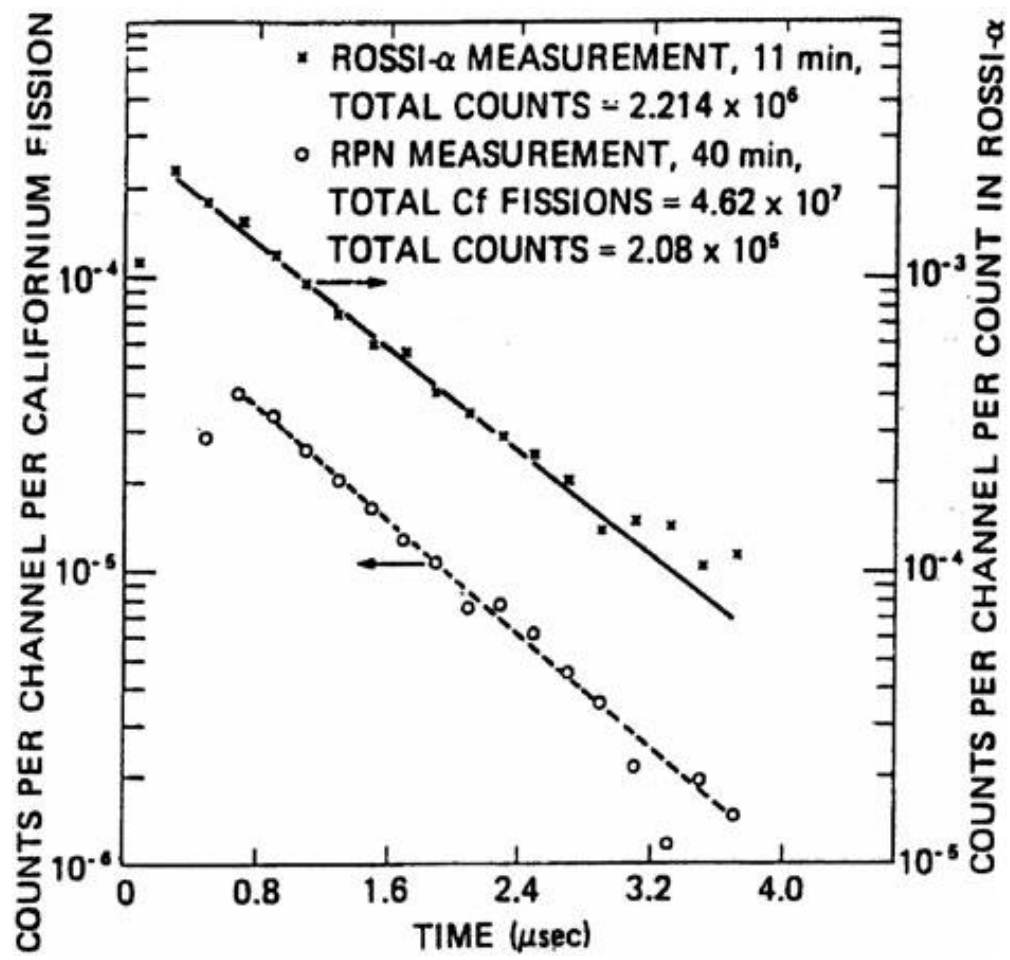

Figure 1.6-4. Typical Results of Rossi- $\alpha$ and Randomly Pulsed Neutron Measurements.

Table 1.6-1. Average of Prompt Neutron Decay Constant Measurements (Reference 6).

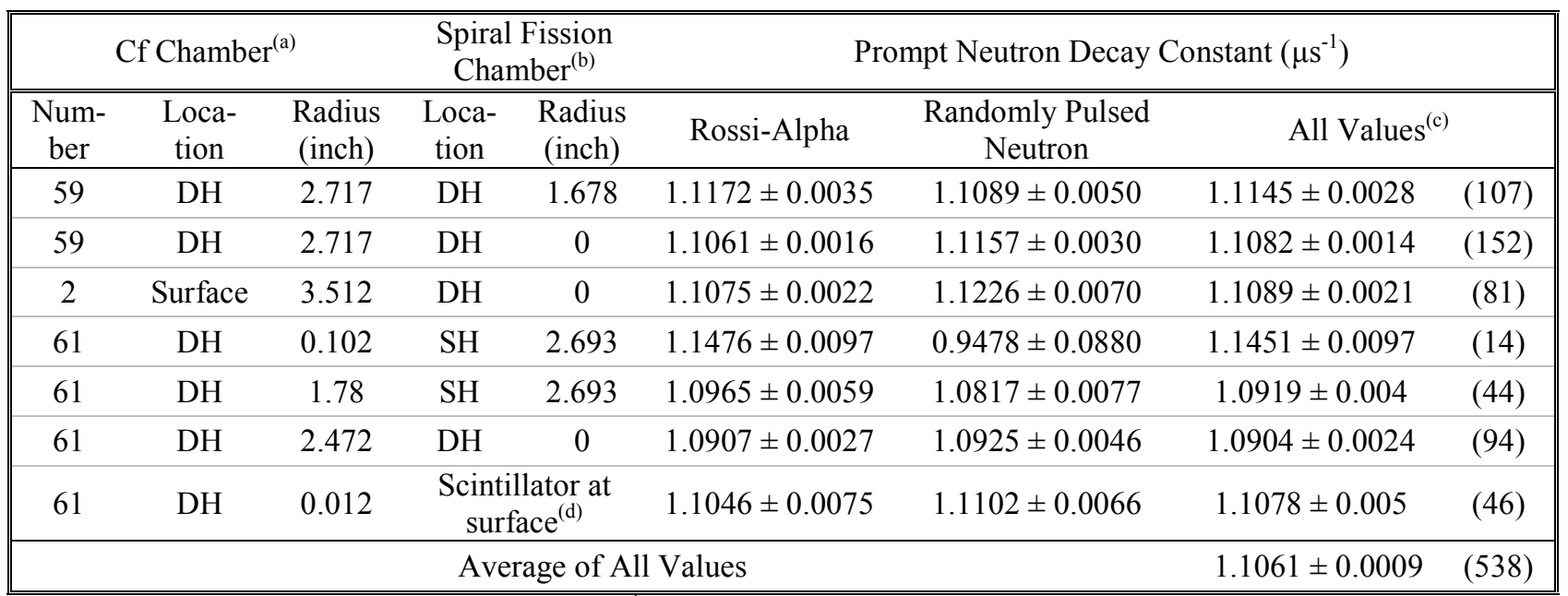

(a) Chamber 61 (0.500-inch-diameter; $8.6 \times 10^{4}$ fissions/second) could be at any radius in the $\mathrm{DH}$ and in the 0.504 inch-diameter SH. Chamber 59 (0.375-inch-diameter; $2.6 \times 10^{4}$ fissions/second) could be located only at one end of the $\mathrm{DH}$, and chamber 2 (1.000-inch-diameter; $5.6 \times 10^{4}$ fissions/second) only adjacent to the outer surface. The radial location given in the location of the $\mathrm{Cf}$ deposit in the ionization chamber.

(b) The 0.50-inch-diameter, 0.500-inch-long SFC could be placed at any radius in the diametral hole or in the 0.5in.-diameter SH. The radial location given is for the center of the SFC.

(c) The values in parentheses are the numbers of both types of measurements that were performed.

(d) The scintillator was adjacent to the outer surface of the sphere. The scintillators were shielded with 0.25 -inchthick lead, and this lead shielding actually was in contact with the sphere surface. 


\section{NEA/NSC/DOC(2006)1 \\ Fundamental-FUND \\ ORSPHERE-FUND-EXP-001 \\ CRIT-REAC-COEF-KIN-RRATE}

The average of all measurements of the prompt neutron decay constant is $1.1061 \pm 0.0009 \mu \mathrm{s}^{-1}$.

\subsubsection{Mean Neutron Generation Time}

The mean neutron generation time, $\Lambda$, was not reported by the experimenter, but it can be derived from the independently measured delayed neutron fraction, $\beta_{\text {eff, }}$ and the prompt neutron decay constant, $\alpha$, see Section 2.6.3.

\subsubsection{Material Data}

The uranium metal of the sphere is described for the Case 2 sphere in Section 1.3 of HEU-MET-FAST-100.

The material for the plugs was uranium metal but it is not explicitly stated that the material is the same composition and isotopic composition as the surrounding sphere. The isotopic composition for the split plugs is given in Table 1.4-11.

The sources used were ${ }^{252} \mathrm{Cf}$ sources with less than $0.15 \mu \mathrm{g}$ of ${ }^{252} \mathrm{Cf}$. No additional material data were given for the ionization chambers.

The spiral fission chamber contained $63.8 \mathrm{mg}$ of $\sim 93 \mathrm{wt} . \%{ }^{235} \mathrm{U}$ metal. No additional material data were given for the spiral fission chamber.

\subsubsection{Temperature Data}

The temperature data for the sphere are given in Section 1.4 of HEU-MET-FAST-100.

\subsubsection{Additional Information Relevant to Kinetics Measurements}

Additional information was not identified.

\subsection{Description of Reaction-Rate Distribution Measurements}

\subsubsection{Overview of Experiment}

The relative neutron importance and relative fission density along the center line of the sphere were measured. The critical sphere described as Case 2 in HEU-MET-FAST-100 was used but with a modified center plate, as described in Section 1.4.2. The purpose of the measurements was to "properly account for spatial effects in the point reactor kinetics description of Rossi- $\alpha$ measurements" (Reference 8).

\subsubsection{Geometry of the Experiment Configuration and Measurement Procedure}

\subsubsection{Relative Neutron Importance}

The idea of the relative neutron importance measurements was to determine the radial dependence of the effect, or importance, of neutrons born inside the sphere at different radial positions on the neutron population within and external to the sphere. To measure this, a ${ }^{252} \mathrm{Cf}$ neutron source was passed through a 0.345 -cm-diametral hole in the ORSphere. "The count rates of $\mathrm{BF}_{3}$ proportional counters external to the sphere were observed and the relative count rate was assumed to be proportional to the relative importance of fission neutrons from ${ }^{252} \mathrm{Cf}$ (Maxwellian neutron spectrum with a temperature of 1.4 $\mathrm{MeV})$ " (Reference 8). The source "was a solid Cf source made especially for the purpose of these measurements." The diametral hole of varying diameter in the center plate, as shown in Figure 1.4-1 and Figure 1.6-2, was plugged with filler plugs of 1.270 - and $0.965-\mathrm{cm}$ outer diameter and $0.345-\mathrm{cm}$ inner

\footnotetext{
${ }^{a}$ Personal email communication with J.T. Mihalczo, January 26, 2015.
} 
NEA/NSC/DOC(2006)1

Fundamental-FUND

ORSPHERE-FUND-EXP-001

CRIT-REAC-COEF-KIN-RRATE

diameter. This created a diametral hole of constant diameter for the source to pass through. The source was a ${ }^{252} \mathrm{Cf}$ neutron source "contained in a 0.315 -cm-diameter $\times 0.961-\mathrm{cm}$-long welded stainless-steel cylinder positioned remotely with a $0.330-\mathrm{cm}$-diameter solid uranium metal push rod by a small electricmotor-powered screw drive. The hole [in front of the source] was filled with 0.330 -cm-diameter uranium metal cylinders, either 1.270 - or 0.635 -cm long. The total reactivity effect associated with the source motion was $<0.3$ cents" (Reference 8 ).

The small 70-gram aluminum reflector was used to compensate for the change in reactivity as the source moved through the diametral hole. The required position of the aluminum reflector was determined by moving an empty source container through the sphere and adjusting the reflector to maintain the system at delayed critical. The aluminum reflector was oriented such that it did not have an effect on the relative neutron importance measurement. " "The surface mass-adjustment buttons (44 and $22 \mathrm{~g}$ of uranium each) that were required to achieve criticality were removed for the importance function measurement for which the sphere reactivity was -20 cents" (Reference 8 ).

The effect of sphere position and room return on the neutron importance function was experimentally investigated. The position of the sphere and the three $\mathrm{BF}_{3}$ detectors in the experimental room is shown in Figure 1.7-1. It was found that the orientation of the sphere and the detector location had no measureable effect on neutron importance. The effect of the walls was determined by placing a $279 \times 173 \times 15.9-\mathrm{cm}$ polyethylene slab $170 \mathrm{~cm}$ from the sphere; the short dimension was parallel to the floor. The neutron importance was found to be independent of the slab. The effect of the source centering in its container was evaluated and found to have the largest effect near the outer surface of the sphere but the effect was still much less than $1 \%$.

The relative neutron importance measurements were normalized to one at the center of the sphere and results are given in Table 1.7-1 and shown in Figure 1.7-2.

${ }^{\text {a }}$ Personal email communication with J.T. Mihalczo, January 19, 2015. 
NEA/NSC/DOC(2006)1

Fundamental-FUND

ORSPHERE-FUND-EXP-001

CRIT-REAC-COEF-KIN-RRATE

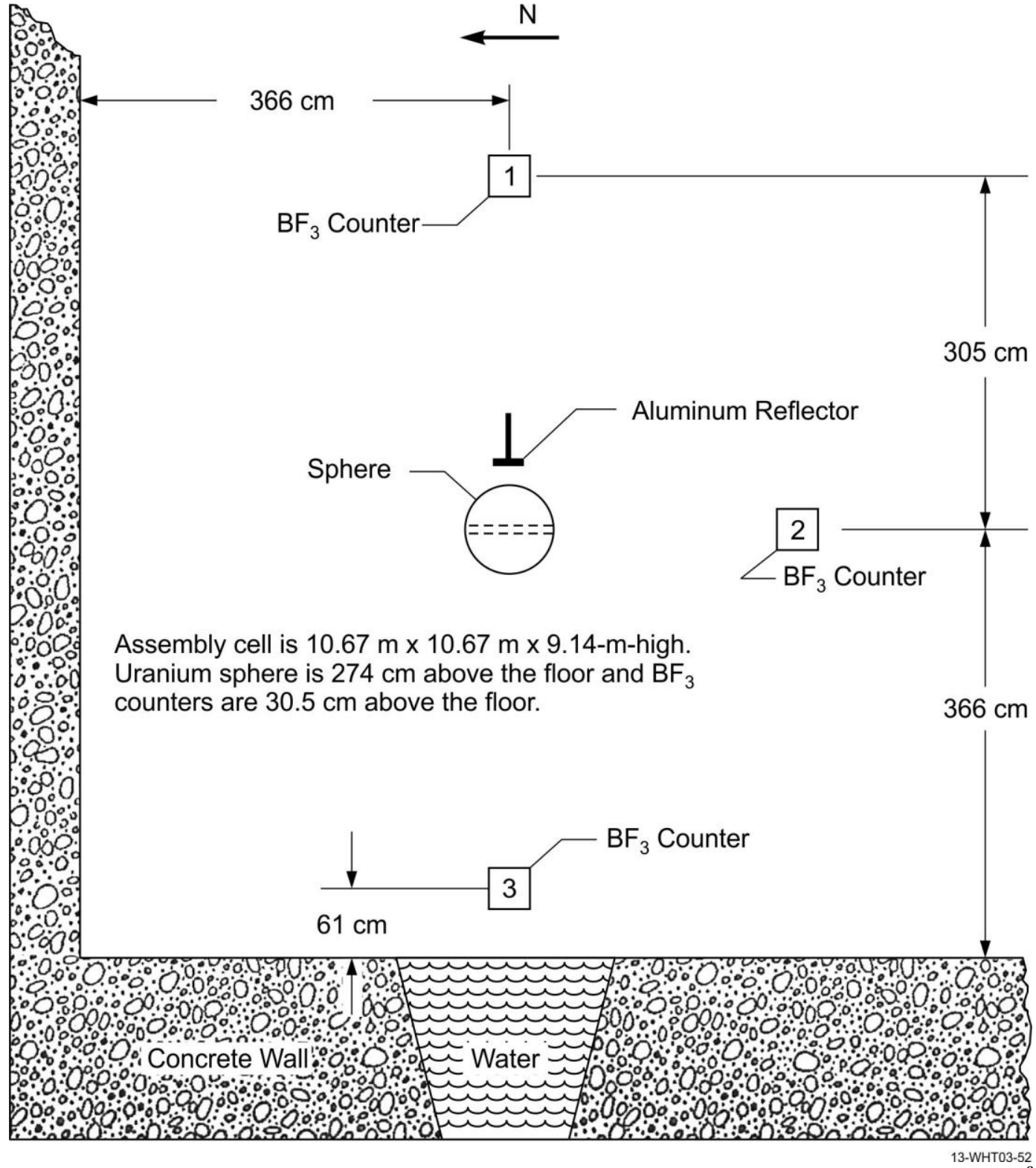

Figure 1.7-1. Plan View of $\mathrm{BF}_{3}$ Detector Location for Neutron Importance Measurements.

\footnotetext{
${ }^{\text {a }}$ This drawing was provided in Reference 8 . The west wall has six water windows in it and is described in the safety analysis report for the ORCEF. (Personal email communication with J.T. Mihalczo, February 20, 2013.)
} 
Table 1.7-1. Relative Importance of Neutrons as a Function of Radius.

\begin{tabular}{|c|c|c|c|}
\hline $\begin{array}{c}\text { Radius }^{(a)} \\
(\mathrm{cm})\end{array}$ & $\begin{array}{c}\text { Average Relative } \\
\text { Neutron Importance }\end{array}$ & $\begin{array}{l}\operatorname{Radius}^{(\mathrm{a}, \mathrm{d})} \\
(\mathrm{cm})\end{array}$ & $\begin{array}{c}\text { Average Relative } \\
\text { Neutron Importance }\end{array}$ \\
\hline-8.138 & $0.278 \pm 0.003^{(b)}$ & -0.470 & $0.992 \pm 0.002^{(b)}$ \\
\hline$-8.105^{(\mathrm{c})}$ & $0.267 \pm 0.002$ & $0.660^{(\mathrm{c})}$ & $0.986 \pm 0.001$ \\
\hline-8.100 & $0.289 \pm 0.001$ & $0.805^{(\mathrm{e})}$ & $0.985 \pm 0.002$ \\
\hline-8.004 & $0.299 \pm 0.001$ & 0.904 & $0.992 \pm 0.001$ \\
\hline$-7.480^{(\mathrm{e})}$ & $0.379 \pm 0.002$ & $1.905^{(\mathrm{c})}$ & $0.951 \pm 0.002$ \\
\hline$-6.833^{(\mathrm{e})}$ & $0.464 \pm 0.002$ & 2.024 & $0.956 \pm 0.001$ \\
\hline-6.825 & $0.458 \pm 0.003$ & $2.078^{(\mathrm{e})}$ & $0.932 \pm 0.002$ \\
\hline$-6.759^{(c)}$ & $0.425 \pm 0.002$ & $3.175^{(\mathrm{c})}$ & $0.864 \pm 0.001$ \\
\hline-6.731 & $0.468 \pm 0.003$ & 3.449 & $0.848 \pm 0.090$ \\
\hline$-5.730^{(\mathrm{c})}$ & $0.578 \pm 0.002$ & $4.445^{(\mathrm{c})}$ & $0.750 \pm 0.001$ \\
\hline-5.583 & $0.620 \pm 0.002$ & $4.646^{(\mathrm{e})}$ & $0.716 \pm 0.001$ \\
\hline-5.484 & $0.624 \pm 0.002$ & 4.722 & $0.737 \pm 0.001$ \\
\hline-5.428 & $0.633 \pm 0.003$ & $5.712^{(\mathrm{c})}$ & $0.608 \pm 0.001$ \\
\hline$-4.392^{(\mathrm{c})}$ & $0.729 \pm 0.003$ & $5.895^{(\mathrm{e})}$ & $0.576 \pm 0.001$ \\
\hline$-4.288^{(\mathrm{e})}$ & $0.759 \pm 0.001$ & 5.994 & $0.589 \pm 0.001$ \\
\hline-4.221 & $0.770 \pm 0.002$ & 7.216 & $0.418 \pm 0.001$ \\
\hline-4.166 & $0.761 \pm 0.002$ & $7.419^{(\mathrm{e})}$ & $0.414 \pm 0.002$ \\
\hline-3.208 & $0.860 \pm 0.001$ & $7.650^{(\mathrm{c})}$ & $0.364 \pm 0.001$ \\
\hline$-3.170^{(\mathrm{c})}$ & $0.849 \pm 0.001$ & $8.273^{(c)}$ & $0.277 \pm 0.001$ \\
\hline$-3.012^{(\mathrm{e})}$ & $0.875 \pm 0.001$ & 8.400 & $0.264 \pm 0.001$ \\
\hline-2.891 & $0.886 \pm 0.002$ & $8.443^{(\mathrm{e})}$ & $0.243 \pm 0.001$ \\
\hline$-1.900^{(\mathrm{c})}$ & $0.936 \pm 0.001$ & $8.590^{(\mathrm{e})}$ & $0.230 \pm 0.001$ \\
\hline$-1.740^{(\mathrm{e})}$ & $0.956 \pm 0.003$ & 8.618 & $0.224 \pm 0.001$ \\
\hline-1.618 & $0.958 \pm 0.002$ & $8.745^{(\mathrm{c})}$ & $0.204 \pm 0.002$ \\
\hline$-0.632^{(\mathrm{c})}$ & $0.987 \pm 0.001$ & $9.091^{(\mathrm{f})}$ & $0.165 \pm 0.001$ \\
\hline
\end{tabular}

(a) Minus sign refers to values measured on the east or south half of the sphere.

(b) Errors in measure values given in this and subsequent tables are precision based on repeated measurement.

(c) Importance given for these radii is the average of measurements performed (i) with the sphere oriented so that the diametral hole was in the east-west direction, (ii) with the sphere oriented so that the diametral hole was in the north-south direction, (iii) with the sphere oriented so that the diametral hole was in the north-south direction and with a $279-\times 173-\times 15.9-\mathrm{cm}$ polyethylene slab placed $170 \mathrm{~cm}$ north of the sphere center. For each orientation three counters were used and 2 to 4 measurements were made which $10^{6}$ counts were obtained in each counter.

(d) At radii not called out by a footnote value given are for measurements with the sphere oriented so that the diametral hole was in the east-west direction only.

(e) Measurements made with the sphere oriented so that the diametral hole was in the northsouth direction only.

(f) External to the sphere. 
Fundamental-FUND

ORSPHERE-FUND-EXP-001

CRIT-REAC-COEF-KIN-RRATE

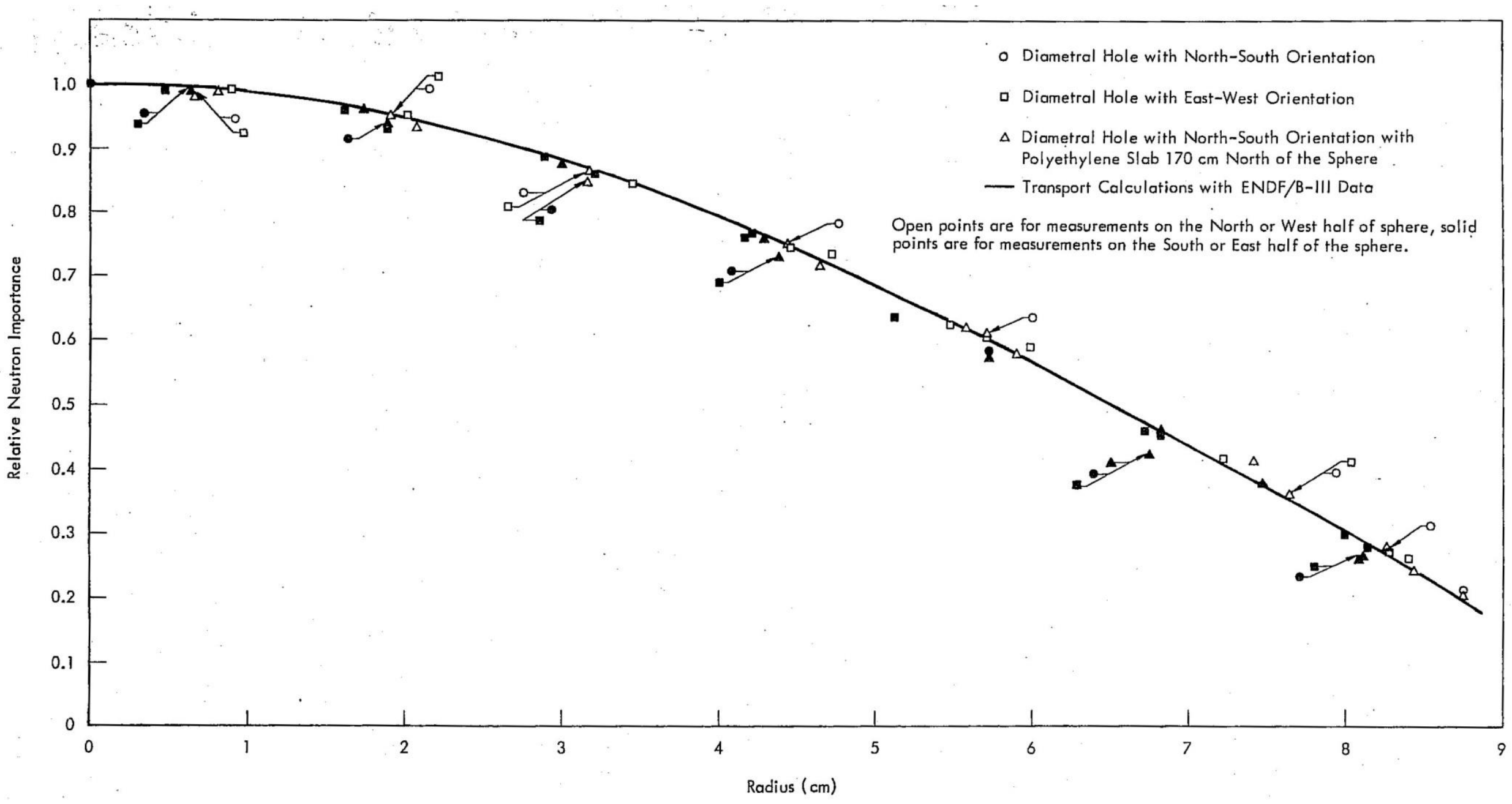

Figure 1.7-2. Relative Neutron Importance (Reference 8). 


\subsubsection{Relative Fission Density}

The measurement of the relative fission density in the ORSphere is described in Reference 8:

The relative spatial distribution of the fission density was measured by activating $0.330-\mathrm{cm}$ diameter uranium cylinders placed in the diametral hole and observing their resulting fission product gamma-ray activity with a pair of NaI scintillation detection systems. The cylinders were 0.635 or $0.318 \mathrm{~cm}$ long. The two detection systems were adjusted to have the same response with standard sources. Each activated cylinder was always counted simultaneously with a normalizing cylinder activated in the same irradiation at the center of the sphere. To minimize the effects of slow drifts in the response of the scintillation systems over the counting period, each pair of activated cylinders was counted in each detector and the average ratio of responses calculated.

As with the neutron importance measurements, the orientation effect and room return effect, simulated using a polyethylene slab, were evaluated and it was determined that the "the measured fission density distribution [is] independent of the orientation of the sphere or the presence of the polyethylene slab" (Reference 8). The results of the relative spatial distribution of the fission density measurements are given in Table 1.7-2 and shown in Figure 1.7-3.

Table 1.7-2. Relative Radial Fission Density (Reference 8).

\begin{tabular}{|c|c|c|c|}
\hline $\begin{array}{l}\text { Radius }{ }^{(a)} \\
(\mathrm{cm})\end{array}$ & $\begin{array}{l}\text { Average Relative } \\
\text { Fission Density }{ }^{(b)}\end{array}$ & $\begin{array}{c}\text { Radius } \\
(\mathrm{cm})\end{array}$ & $\begin{array}{l}\text { Average Relative } \\
\text { Fission Density }\end{array}$ \\
\hline-8.265 & $0.261 \pm 0.001$ & 0.635 & $0.996 \pm 0.001$ \\
\hline-7.633 & $0.354 \pm 0.001$ & 1.272 & $0.978 \pm 0.002$ \\
\hline-6.995 & $0.440 \pm 0.001$ & 1.908 & $0.956 \pm 0.003$ \\
\hline-6.355 & $0.519 \pm 0.001$ & 2.543 & $0.910 \pm 0.002$ \\
\hline-5.725 & $0.603 \pm 0.002$ & 3.180 & $0.872 \pm 0.003$ \\
\hline-5.088 & $0.672 \pm 0.003$ & 3.815 & $0.810 \pm 0.001$ \\
\hline-4.450 & $0.746 \pm 0.001$ & 4.450 & $0.742 \pm 0.002$ \\
\hline-3.815 & $0.810 \pm 0.003$ & 5.088 & $0.675 \pm 0.002$ \\
\hline-3.180 & $0.871 \pm 0.002$ & 5.725 & $0.600 \pm 0.001$ \\
\hline-2.54 & $0.910 \pm 0.003$ & 6.355 & $0.518 \pm 0.005$ \\
\hline-1.908 & $0.951 \pm 0.002$ & 6.995 & $0.438 \pm 0.002$ \\
\hline-1.272 & $0.978 \pm 0.002$ & 7.633 & $0.351 \pm 0.001$ \\
\hline-0.635 & $1.001 \pm 0.004$ & 8.265 & $0.257 \pm 0.002$ \\
\hline 0.0 & 1.000 & & \\
\hline
\end{tabular}

(a) Minus sign refers to values measured on the east or south half of the sphere.

(b) Average of all values for any radius [values averaged from measurements (i) with the sphere oriented so that the diametral hole was in the east-west direction, (ii) with the sphere oriented so that the diametral hole was in the east-west direction and with a 279$\times 173-\times 15.9-\mathrm{cm}$ polyethylene slab placed $170 \mathrm{~cm}$ east of the sphere center, and (iii) with the sphere oriented so that the diametral hole was in the north-south direction]. Error in values is precision based on repeated measurements. 


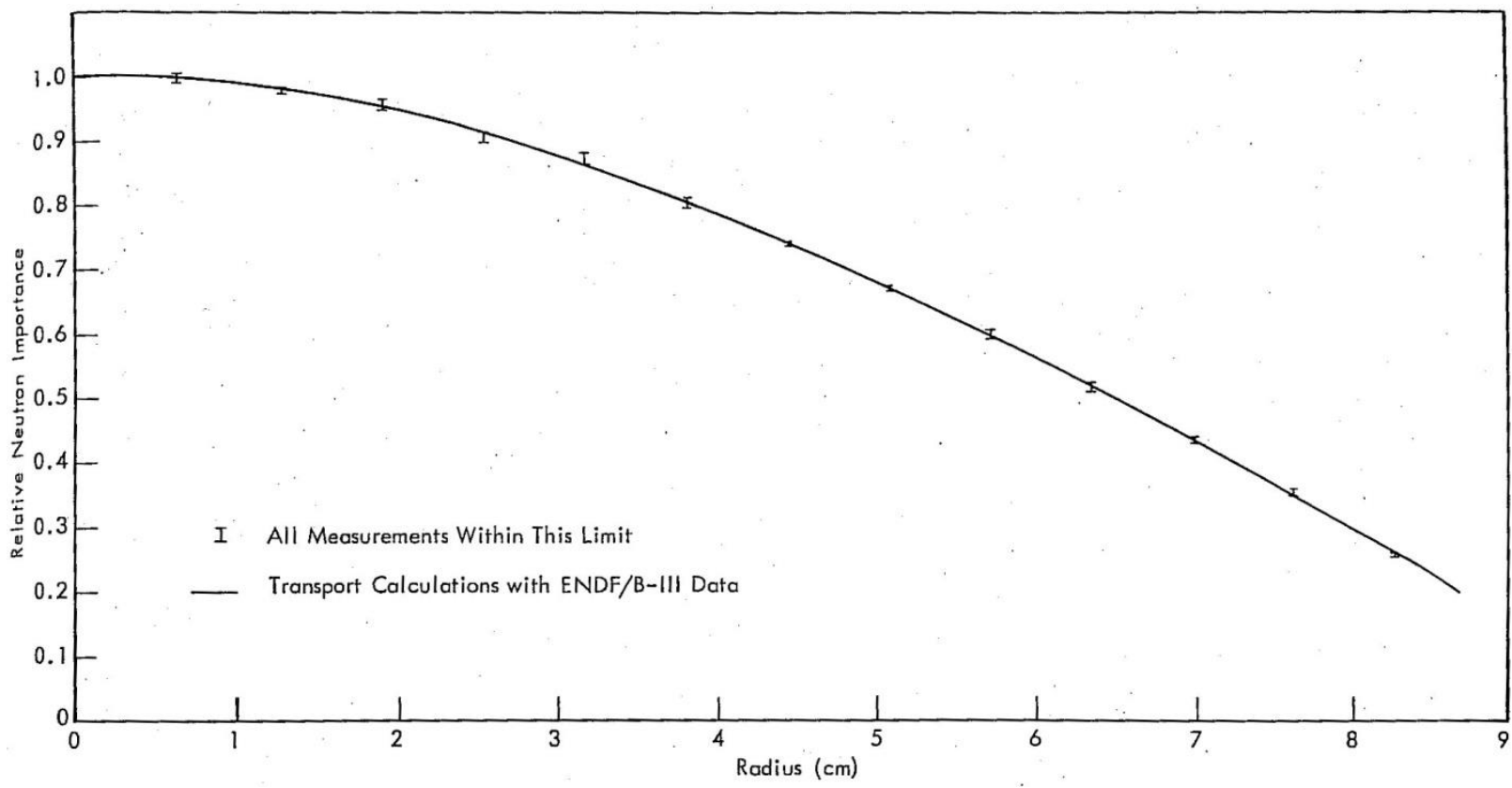

Figure 1.7-3. Relative Radial Fission Density (Reference 8).

\subsubsection{Material Data}

The uranium metal of the sphere is described in Section 1.3 of HEU-MET-FAST-100.

The material for the plugs and the activated cylinders was uranium metal, but the material would have been similar to that of the surrounding sphere. ${ }^{a}$

The source for the neutron importance measurements was a ${ }^{252} \mathrm{Cf}$ neutron source in a welded stainless steel cylinder. The source was a ${ }^{252} \mathrm{Cf}$ source, with a Maxwellian neutron spectrum and a temperature of $1.4 \mathrm{MeV}$. No further information regarding the source or the container was given.

\subsubsection{Temperature Data}

The temperature data for the sphere are given in Section 1.4 of HEU-MET-FAST-100.

\subsubsection{Additional Information Relevant to Reaction-Rate Distribution Measurements}

Additional information is not available.

\footnotetext{
${ }^{a}$ Personal email communication with J.T. Mihalczo, October 8. 2013.

${ }^{\mathrm{b}}$ L. Green, J.A. Mitchell, and N.M. Steen, "The Californium-252 Fission Neutron Spectrum from 0.5 to $13 \mathrm{MeV}$," Nucl. Sci. Eng., 50, 257, (1973).
} 


$$
\begin{gathered}
\text { NEA/NSC/DOC(2006)1 } \\
\text { Fundamental-FUND } \\
\text { ORSPHERE-FUND-EXP-001 } \\
\text { CRIT-REAC-COEF-KIN-RRATE }
\end{gathered}
$$

\subsection{Description of Power Distribution Measurements}

The power distribution is related to the relative fission density (Section 1.7).

\subsection{Description of Isotopic Measurements}

Isotopic measurements were not performed.

\subsection{Description of Other Miscellaneous Types of Measurements}

There were no additional miscellaneous measurements performed. 
NEA/NSC/DOC(2006)1

Fundamental-FUND

ORSPHERE-FUND-EXP-001

CRIT-REAC-COEF-KIN-RRATE

\subsection{EVALUATION OF EXPERIMENTAL DATA}

The measurements were evaluated using Monte Carlo N-Particle (MCNP) Version 5-1.60 and ENDF/BVII. $0^{\mathrm{b}}$ neutron cross section libraries. All models were calculated such that the statistical uncertainty in $\mathrm{k}_{\mathrm{eff}}, \sigma_{\mathrm{MC}}$, is less than or equal to \pm 0.00002 .

\subsection{Evaluation of Critical and/or Subcritical Configuration Data}

The criticality portion of this evaluation has been reviewed and approved by the International Criticality Safety Benchmark Evaluation Project (ICSBEP) and has been published under the following identifier: HEU-MET-FAST-100. ${ }^{\circ}$

\subsection{Evaluation of Buckling and Extrapolation Length Data}

Buckling and extrapolation-length measurements were not performed.

\subsection{Evaluation of Spectral Characteristics Data}

Spectral characteristics measurements were not performed.

\subsection{Evaluation of Reactivity Effects Data}

Various worth measurements were performed, including central void reactivity measurement, button worth measurements, and diametral filler rod worth measurements. The system reactivity was calculated from the system stable reactor period. The Inhour equation was used along with the delayed neutron parameters to convert the stable reactor period to reactivity in dollars. The reactivity of the system in two states, i.e. with and without the piece of material that is being evaluated, is compared to obtain a worth. These worth measurements were evaluated and judged to be acceptable benchmark data.

The geometry and material parameters were evaluated for the central void worth and the worth of the four, $1 / 8$ "-thick-uranium-buttons on the surface by perturbing the benchmark models. The uncertainty in an individual MCNP run was $\pm 0.00002 \mathrm{k}_{\text {eff. }}$ Two MCNP runs were required for a calculated worth measurement ( $\rho=\frac{k_{2}-k_{1}}{k_{2} k_{1}}$, where the worth is in units of $\Delta \mathrm{k}_{\mathrm{eff}}$ ). The statistical uncertainty corresponds to a statistical uncertainty in a worth of $\pm 0.00003 \Delta \mathrm{k}_{\text {eff }}$ or $\pm 0.43 \phi$; the statistical uncertainty in each $\mathrm{k}_{\text {eff }}$ is propagated appropriately. The effects of uncertainty in the evaluated geometry and material parameters of the central void reactivity and the worth of the surface buttons were found to be within the statistical uncertainty in the Monte Carlo calculation, $\pm 0.43 \sqrt{2} \notin$ for a one-sided uncertainty perturbation. The $\sqrt{2}$ factor is because the effect on the worth is a comparison of two worths, perturbed and unperturbed, each with a Monte Carlo statistical uncertainty of $0.43 \phi$.

An analysis of the effect of scaling and perturbing the isotopic abundances in the small central sphere was performed. The effect on the central sphere was chosen since the worth of mass, and thus also the effect of the uncertainties, is larger at the center of the sphere than the surface of the sphere. The uncertainty in the isotopic abundances are believed to have the largest effect on the worth measurements;

${ }^{a}$ F. B. Brown, R. F. Barrett, T. E. Booth, J. S. Bull, L. J. Cox, R. A. Forster, T. J. Goorley, R. D. Mosteller, S. E. Post, R. E. Prael, E. C. Selcow, A. Sood, and J. Sweezy, "MCNP Version 5," LA-UR-02-3935, Los Alamos National Laboratory (2002).

${ }^{\mathrm{b}}$ M. B. Chadwick, et al., "ENDF/B-VII.0: Next Generation Evaluated Nuclear Data Library for Nuclear Science and Technology," Nucl. Data Sheets, 107: 2931-3060 (2006).

c International Handbook of Evaluated Criticality Safety Benchmark Experiments, NEA/NSC/DOC(95)03, OECDNEA, Paris (2013). 
thus, the isotopics were perturbed for this analysis. Table 2.4-1 summarizes the results of this analysis. These results show that, even with a scaling factor of 300 , the effects on worth, due to uncertainty in ${ }^{234} U$ and ${ }^{236} \mathrm{U}$ (when scaled to $1 \sigma$ ) was approximately $0.001 \pm 0.001 \Delta \phi$ each, which is still within the scaled statistical uncertainty of the Monte Carlo calculations. The effect on worth of perturbing the ${ }^{235} \mathrm{U}$ enrichment was approximately $0.002 \pm 0.001 \Delta \phi$ (when scaled to $1 \sigma$ ); this is just above the noise of the Monte Carlo calculation. ${ }^{a}$ Based on this analysis, an uncertainty of $\pm 0.002 \notin$ was applied to all worth measurements to represent the uncertainty in the ${ }^{235} \mathrm{U}$ enrichment. Since the effects of uncertainty in impurity, mass, and dimensions are considered to be less than the calculated values for isotopic abundance of ${ }^{236} \mathrm{U}$ and ${ }^{234} \mathrm{U}$ of $0.001 \phi$, an effect of $\pm 0.001 \phi$ was applied to all worth measurements for uncertainty in each of those parameters.

Table 2.4-1. Analysis of Effect of Scaling and Perturbing on Calculated Uncertainty Effects. ${ }^{(a)}$

\begin{tabular}{|c|c|c|c|c|c|c|c|c|}
\hline Deviation & $\begin{array}{l}\Delta \rho \\
(\phi)\end{array}$ & \pm & $\sigma_{\mathrm{MC}}$ & $\begin{array}{l}\text { Scaling } \\
\text { Factor }\end{array}$ & $1 \sigma$ & $\begin{array}{l}\Delta \rho \\
(\phi)\end{array}$ & \pm & $\sigma_{\text {statistical }}$ \\
\hline \multicolumn{9}{|c|}{${ }^{234} \mathrm{U}^{(\mathrm{b})}$} \\
\hline+0.395 wt. $\%$ & -0.15 & \pm & 0.43 & 40 & $1 \%$ & -0.004 & \pm & 0.011 \\
\hline+0.593 wt. $\%$ & 0.61 & \pm & 0.43 & 60 & $1 \%$ & 0.010 & \pm & 0.007 \\
\hline+0.790 wt. $\%$ & 0.15 & \pm & 0.43 & 80 & $1 \%$ & 0.002 & \pm & 0.005 \\
\hline+0.988 wt. $\%$ & 0.61 & \pm & 0.43 & 100 & $1 \%$ & 0.006 & \pm & 0.004 \\
\hline+1.186 wt. $\%$ & 0.76 & \pm & 0.43 & 120 & $1 \%$ & 0.006 & \pm & 0.004 \\
\hline+2.964 wt. $\%$ & 0.31 & \pm & 0.43 & 300 & $1 \%$ & 0.001 & \pm & 0.001 \\
\hline \multicolumn{9}{|c|}{${ }^{235} \mathrm{U}^{(\mathrm{c})}$} \\
\hline \pm 0.708 wt. $\%$ & -0.46 & \pm & 0.43 & 40 & 0.0177 wt. $\%$ & -0.011 & \pm & 0.011 \\
\hline \pm 1.062 wt. $\%$ & 0.38 & \pm & 0.43 & 60 & 0.0177 wt. $\%$ & 0.006 & \pm & 0.007 \\
\hline \pm 1.416 wt. $\%$ & 0.00 & \pm & 0.43 & 80 & 0.0177 wt. $\%$ & 0.000 & \pm & 0.005 \\
\hline \pm 1.770 wt. $\%$ & -0.15 & \pm & 0.43 & 100 & 0.0177 wt. $\%$ & -0.002 & \pm & 0.004 \\
\hline \pm 2.124 wt. $\%$ & -0.15 & \pm & 0.43 & 120 & 0.0177 wt. $\%$ & -0.001 & \pm & 0.004 \\
\hline \pm 5.310 wt. $\%$ & 0.69 & \pm & 0.22 & 300 & 0.0177 wt. $\%$ & 0.002 & \pm & 0.001 \\
\hline \multicolumn{9}{|c|}{${ }^{236} \mathrm{U}^{(\mathrm{b})}$} \\
\hline+0.520 wt. $\%$ & 0.46 & \pm & 0.43 & 40 & 0.0130 wt. $\%$ & 0.011 & \pm & 0.011 \\
\hline+0.780 wt. $\%$ & 0.15 & \pm & 0.43 & 60 & 0.0130 wt. $\%$ & 0.003 & \pm & 0.007 \\
\hline+1.040 wt. $\%$ & 0.61 & \pm & 0.43 & 80 & 0.0130 wt. $\%$ & 0.008 & \pm & 0.005 \\
\hline+1.300 wt. $\%$ & 0.31 & \pm & 0.43 & 100 & 0.0130 wt. $\%$ & 0.003 & \pm & 0.004 \\
\hline+1.560 wt. $\%$ & 0.46 & \pm & 0.43 & 120 & 0.0130 wt. $\%$ & 0.004 & \pm & 0.004 \\
\hline+3.900 wt. $\%$ & 0.00 & \pm & 0.43 & 300 & 0.0130 wt. $\%$ & 0.000 & \pm & 0.001 \\
\hline
\end{tabular}

(a) This analysis was performed by John D. Bess of Idaho National Laboratory.

(b) The perturbation for ${ }^{234} \mathrm{U}$ and ${ }^{236} \mathrm{U}$ was a one-sided, positive perturbation. This allowed for a larger scaling factor to be used.

(c) The perturbation for ${ }^{235} \mathrm{U}$ was two-sided. The ${ }^{238} \mathrm{U}$ content, which was varied to maintain unity, was the limiting factor for the scaling factor.

\footnotetext{
${ }^{a}$ This analysis was performed by John D. Bess of Idaho National Laboratory on September 10, 2013.
} 
NEA/NSC/DOC(2006)1

Fundamental-FUND

ORSPHERE-FUND-EXP-001

CRIT-REAC-COEF-KIN-RRATE

\subsubsection{Delayed Neutron Parameters and Fission Fraction}

The delayed neutron parameters of Keepin et al. were used to convert stable reactor periods to system reactivity in dollars/cents. Fission fractions were also required and were originally "obtained from onedimensional $S_{n}$ neutron transport calculation with ENDF/B-VI cross sections for a delayed critical sphere" (see Table 1.4-1).

There is a given uncertainty in the Keepin delayed neutron parameters (Table 1.4-1). This uncertainty is judged to represent a random component of the overall uncertainty in the delayed neutron parameters. The systematic component of the uncertainty in the delayed neutron parameters is evaluated using an independent data set.

The effect of the random uncertainty in the Keepin delayed neutron parameters (Table 1.4-1) was evaluated by propagating the uncertainty in the Keepin data and a 5\% uncertainty on stable reactor period through the Inhour equation calculation. For many of the worth measurements it was found that the calculated propagated uncertainty is within the given measurement uncertainty. For a few of the worth measurements, the calculated uncertainty was found to be larger than the given measurement uncertainty; in those cases the calculated uncertainty is used. This convention is further discussed in Sections 2.4.2 through 2.4.4. In Table 2.4-5, Table 2.4-8, Table 2.4-9, and Table 2.4-10 the random component of the uncertainty is included in the experiment method uncertainty.

The systematic component of the overall uncertainty in the delayed neutron parameters was evaluated by repeating the Inhour equation calculation, for all worth measurements, using the delayed neutron parameters provided in the ABBN cross section library ${ }^{\mathrm{a}}$ that are derived from the delayed neutron parameters recommended by Spriggs, Campbell and Piksaikin. ${ }^{\mathrm{b}}$ The values are given in Table 2.4-2. The change in the worth using ABBN delayed neutron parameters versus the Keepin delayed neutron parameters is judged to be a bounding, systematic uncertainty effect due to uncertainty in the delayed neutron parameters. The average, $1 \sigma$ effect of using the ABBN delayed neutron parameters was an increase of $1.32 \%$ in the worth. This value is used for each worth measurement; see Table 2.4-5, Table 2.4-8, Table 2.4-9, and Table 2.4-10.

Table 2.4-2. Delayed Neutron Parameters.

\begin{tabular}{|c|c|c|c|c|c||}
\hline \multicolumn{6}{|c|}{ ABBN Delayed Neutron Parameters ${ }^{(a)}$} \\
\hline \multirow{2}{*}{ Group } & Decay Constant & \multicolumn{2}{|c|}{ Relative Yield ${ }^{236} \mathrm{U}$} & ${ }^{238} \mathrm{U}$ \\
\hline & & ${ }^{234} \mathrm{U}$ & ${ }^{235} \mathrm{U}$ & 0.02449 & 0.0084 \\
2 & 0.0124667 & 0.05485 & 0.03278 & 0.09797 & 0.104 \\
3 & 0.0282917 & 0.1566 & 0.15391 & 0.10797 & 0.0375 \\
4 & 0.0425244 & 0.10476 & 0.09135 & 0.12696 & 0.137 \\
5 & 0.133042 & 0.1823 & 0.19688 & 0.40988 & 0.294 \\
6 & 0.2924672 & 0.35475 & 0.33079 & 0.13696 & 0.198 \\
7 & 0.6664877 & 0.083 & 0.09025 & 0.08747 & 0.128 \\
8 & 1.634781 & 0.04618 & 0.08115 & 0.0083 & 0.0931 \\
\hline \hline
\end{tabular}

(a) These values are based on the ABBN cross section library and were provided by Yevgeniy Rozhikhin (IPPE).

\footnotetext{
${ }^{a}$ Values provided by Yevgeniy Rozhikhin, December 6, 2013.

${ }^{\mathrm{b}}$ G.D. Spriggs, J.M. Campbell, and V.M. Piksaikin, “An 8-Group Delayed Neutron Model Based on a Consistent Set of Half Lives," Progress in Nuclear Energy, 41, No. 1-4, 223-251 (2002).
} 
Additional method uncertainty in the determination of system reactivity is the uncertainty in the fission fraction. The fission fractions given in Table 1.4-1 were calculated using ENDF/B-VI cross section data. The benchmark model for the central void reactivity measurement was used to calculate the fission fraction per isotope from ENDF/B-VII.0 cross section libraries using MCNP5.1-60. The fission fraction obtained for ENDF/B-VII.0 cross section libraries is given in Table 2.4-3. The effect the change in fission fraction has on the calculated average for the central void reactivity is $0.0010 \Delta \phi$. It was found the effect was smaller for all other worth measurements thus $\pm 0.0010 \Delta \phi$ was applied to all worth measurement uncertainties to account for the effect of the fission fraction value.

Table 2.4-3. Fission Fraction Values.

\begin{tabular}{|c|c|c||}
\hline \multicolumn{3}{|c|}{ Delayed Neutron Parameters $^{(\mathrm{a})}$} \\
\hline \hline Isotope & $\begin{array}{c}\text { Fission Fractions } \\
\text { ENDF/B-VI }{ }^{(\mathrm{b})}\end{array}$ & $\begin{array}{c}\text { Fission Fractions } \\
\text { ENDF/B-VII.0 }^{(\mathrm{c})}\end{array}$ \\
\hline${ }^{234} \mathrm{U}$ & $0.8241 \%$ & $0.7876 \%$ \\
${ }^{235} \mathrm{U}$ & $98.1922 \%$ & $98.2357 \%$ \\
${ }^{236} \mathrm{U}$ & $0.0123 \%$ & $0.0166 \%$ \\
${ }^{238} \mathrm{U}$ & $0.9714 \%$ & $0.9601 \%$ \\
\hline $\begin{array}{c}\text { Average Calculated Central } \\
\text { Void Reactivity }{ }^{(\mathrm{a})}\end{array}$ & $9.1512 \varnothing$ & $9.1522 \varnothing$ \\
\hline \multicolumn{2}{|c|}{ Effect of Fission Fraction Value $(1 \sigma)$} & $0.0010 \Delta \phi$ \\
\hline \hline
\end{tabular}

(a) Because Keepin data for the delayed neutron parameters is only given for ${ }^{235} \mathrm{U}$ and ${ }^{238} \mathrm{U} 50 \%$ of the ${ }^{234} \mathrm{U}$ fission fraction and $50 \%$ of the ${ }^{236} \mathrm{U}$ were added to the ${ }^{235} \mathrm{U}$ and the other half were in ${ }^{238} \mathrm{U}$ for the Inhour calculations.

(b) The ENDF/B-VI fission fraction values were provided by the experimenter in Reference 3.

(c) The ENDF/B-VII fission fraction values were calculated with MCNP5 using the central void reactivity benchmark model. The fraction of weight gained by fission in each isotope was used to compute the fission fractions.

There is also an uncertainty in the treatment of the ${ }^{234} \mathrm{U}$ and ${ }^{236} \mathrm{U}$ isotopes. Because Keepin data for the delayed neutron parameters is only given for ${ }^{235} U$ and ${ }^{238} U$ "half the ${ }^{234} U$ fissions and half the ${ }^{236} U$ were [added to] ${ }^{235} \mathrm{U}$ and the other half were in ${ }^{238} \mathrm{U}$ " (Reference 3). The uncertainty effect of this assumption is evaluated by attributing $100 \%$ of the ${ }^{234} \mathrm{U}$ and ${ }^{236} \mathrm{U}$ fissions to first ${ }^{235} \mathrm{U}$ and then to ${ }^{236} \mathrm{U}$. This yields a change in the average calculated central void reactivity of $0.0306 \Delta \phi$. This perturbation of the fission fractions bounds the true uncertainty thus a scaling factor of $2 \sqrt{3}$ is used. This uncertainty is $0.0088 \Delta \phi$ and is given in Table 2.4-4. The effect was found to be smaller on all other worth measurements thus an uncertainty of $\pm 0.0088 \Delta \phi$ was applied to all worth measurement uncertainties to account for the effect of the fission fraction value. 
NEA/NSC/DOC(2006)1

Fundamental-FUND

ORSPHERE-FUND-EXP-001

CRIT-REAC-COEF-KIN-RRATE

Table 2.4-4. Uncertainty in Treatment of ${ }^{234} U$ and ${ }^{236} U$.

\begin{tabular}{|c|c|c|c|c|}
\hline \multicolumn{5}{|c|}{ Delayed Neutron Parameters } \\
\hline Isotope & Fission Fractions & $\begin{array}{l}\text { Fission Fraction used in } \\
\text { Calculation of } \\
\text { Benchmark Reactivity } \\
\end{array}$ & $\begin{array}{c}100 \%{ }^{234} \mathrm{U} \text { and }{ }^{236} \mathrm{U} \\
\text { Fissions Attributed to } \\
{ }^{235} \mathrm{U}\end{array}$ & $\begin{array}{c}100 \%{ }^{234} \mathrm{U} \text { and }{ }^{236} \mathrm{U} \\
\text { Fissions Attributed to } \\
{ }^{238} \mathrm{U}\end{array}$ \\
\hline${ }^{234} \mathrm{U}$ & $0.8241 \%$ & - & - & - \\
\hline${ }^{235} \mathrm{U}$ & $98.1922 \%$ & $98.6104 \%$ & $99.0286 \%$ & $98.1922 \%$ \\
\hline${ }^{236} \mathrm{U}$ & $0.0123 \%$ & - & - & - \\
\hline${ }^{238} \mathrm{U}$ & $0.9714 \%$ & $1.3896 \%$ & $0.9714 \%$ & $1.8078 \%$ \\
\hline \multicolumn{2}{|c|}{$\begin{array}{c}\text { Average Calculated Central } \\
\text { Void Reactivity }\end{array}$} & $9.1512 \varnothing$ & $9.1666 \varnothing$ & $9.1359 \varnothing$ \\
\hline \multicolumn{3}{|c|}{ Change in Average Central Void Reactivity } & \multicolumn{2}{|c|}{$0.0306 \Delta \phi$} \\
\hline \multicolumn{3}{|c|}{ Effect of $1 \sigma$ Uncertainty in Treatment of Fission Fraction } & \multicolumn{2}{|c|}{$0.0306 \Delta \phi / 2 \sqrt{3}=0.0088 \Delta \phi$} \\
\hline
\end{tabular}

\subsubsection{Central Void Reactivity Measurement}

Material Properties The isotopic abundances for the central sphere for the central void reactivity measurement were not explicitly given but is given as being the same as for the surrounding sphere. There are four sections of plugs needed for the central reactivity measurements (see Figure 1.4-1): (1) A long plug for the 0.504 -inch $(1.28016$-cm)-diameter diametral hole which surrounds the 0.460 -inch $(1.1684-\mathrm{cm})$-diameter sphere, $(2)$ a plug to fit the 0.136 -inch $(0.34544-\mathrm{cm})$-diameter section of the diametral hole, (3) a plug to fit the 0.386 -inch $(0.98044-\mathrm{cm})$-diameter surface hole along the diametral hole, and (4) a plug to fit the 0.504-inch $(1.28016-\mathrm{cm})$-diameter surface hole. The experimenter provided the monthly average isotopic compositions for the $\mathrm{Y}-12$ plant the month in which the parts were fabricated. Reference 2 provides an isotopic composition for "plugs for 0.500 -inch-diameter holes" (Table 1.4-11). The plugs for the 0.98044-cm- and 1.28016-cm-diameter surfaces holes and the 1.28016$\mathrm{cm}$-diameter diametral hole, including the 1.1684-cm-diameter sphere, would most likely have been fabricated at the same time. The isotopic abundances for the "plugs for the 0.500 -inch [1.27-cm]diameter holes" are believed to apply to these three plugs and the small sphere. The plug for the 0.34544-cm-diameter hole would have been a section of the diametral filler rod used in the critical assemblies (HEU-MET-FAST-100).

The uncertainty in the isotopic abundances would be the same as for the critical sphere (HEU-MET-FAST-100); the ${ }^{238} \mathrm{U}$ content is adjusted to maintain unity:

$$
\begin{array}{ll}
{ }^{234} \mathrm{U} & 1 \quad \%^{\mathrm{a}} \\
{ }^{235} \mathrm{U} & 0.0177 \text { wt.\% } \\
{ }^{236} \mathrm{U} & 0.0130 \text { wt.\% }
\end{array}
$$

The impurities for the material used for the central void reactivity was not provided. The average impurity content provided in Reference 1 (see Table 1.4-12 footnotes) was used for the small central sphere and all the other plugs used. This is the same average impurity content that is used for the diametral filler rod. The uncertainty in impurity measurements at the Y-12 plant at the time of the experiment was $\pm 20 \%$ for impurities measured above 10 micrograms $/ g$ - $U$ and $\pm 70 \%$ for impurities below 10 micrograms $/ \mathrm{g}-\mathrm{U} .^{\mathrm{b}}$ These were assumed to be bounding uncertainties.

Because the calculated effects of uncertainties in isotope abundance and impurities was within the statistical noise of the Monte Carlo calculations, even when using scaling factors, an uncertainty of

\footnotetext{
${ }^{\text {a }}$ It should be noted that the uncertainty for ${ }^{234} \mathrm{U}$ is $1 \%$ of the given weight percent. The uncertainty for ${ }^{235} \mathrm{U}$ and ${ }^{236} \mathrm{U}$ are given in units of weight percent.

${ }^{\mathrm{b}}$ J. T. Mihalczo, T. Gregory Schaaff, "Uncertainties in Masses, Dimensions, Impurities, and Isotopics of HEU Metal Used in Critical Experiments at ORCEF," ORNL/TM-2012/32, Oak Ridge National Laboratory (2012). 
NEA/NSC/DOC(2006)1

\section{Fundamental-FUND \\ ORSPHERE-FUND-EXP-001 \\ CRIT-REAC-COEF-KIN-RRATE}

$\pm 0.002 \varnothing$ was applied for the ${ }^{235} \mathrm{U}$ enrichment uncertainty and $\pm 0.001 \notin$ was applied for the isotopic abundance of ${ }^{234} \mathrm{U}$ and ${ }^{236} \mathrm{U}$ uncertainties. This is discussed in Section 2.4.0.

Geometry and Mass The dimensions and manufacturing tolerances for the long uranium plug and sphere placed in the 1.28016-cm-diameter diametral hole used for the central void reactivity measurement are given in Figure 1.4-2. The mass of the small uranium sphere was $15.614 \mathrm{~g}$. The uncertainty in the other dimensions for the long plug for the diametral hole would have negligible effect on the worth of the central void because they would remain constant when the small central sphere is added to and removed from the system.

All other holes are plugged for the central void reactivity measurements. The dimensions of these plugs are not given. The plugs for the 0.504-inch $(1.28016-\mathrm{cm})$ - and 0.386 -inch $(0.98044-\mathrm{cm})$-diameter surface holes were modeled as cylinders having a length of 1.000 inch $(2.54 \mathrm{~cm})$, to match the depth of the holes. The diameter of each plug was modeled such that the gap around the plug equaled the gap around the long plug in the diametral hole $([0.504-0.501] / 2$ inch, $0.00381 \mathrm{~cm})$. This yielded plug diameters of $1.27254 \mathrm{~cm}$ and $0.97282 \mathrm{~cm}$. The plug for the small, 0.136 -inch $(0.34544-\mathrm{cm})$-diameter hole linking the $0.98044-\mathrm{cm}$-diameter surface hole to the 1.28016-cm -diameter diametral hole was most likely identical in diameter and composition to the diametral hole filler rod used in HEU-MET-FAST-100 since the hole diameters are the same. Thus, the diameter for the plug was $0.328422 \mathrm{~cm}$. The dimensions of these plugs have a negligible effect on the worth measurements because they remain constant when the small central sphere is added to and removed from the system.

Because the calculated effects of the uncertainties in the small sphere diameter and mass were within the statistical noise of the Monte Carlo calculations and are considered to be less than the effect of the uncertainty in ${ }^{234} \mathrm{U}$ and ${ }^{236} \mathrm{U}$, which is scaled to a value of $\pm 0.001 \phi$, a value of $\pm 0.001 \phi$ was also applied for both the uncertainty in the small sphere diameter and mass.

Central Void Reactivity The central void reactivity was measured by comparing the system reactivity with and without a small sphere present at the center of the larger sphere. The average worth was obtained from 43 worth measurements between May 19, 1972 and August 10, 1972. The given worth in Reference 3 is $9.165 \pm 0.023 \phi$. If the variance weighted average of the daily averages and standard deviations for the values in Table 1.4-3 is recalculated a value of $9.16898 \pm 0.018 \not$ is obtained which is close to the published average. The published value is used for this evaluation.

If the Inhour equation results are re-calculated for the stable reactor periods in Table 1.4-2 the resulting average worth is $9.1434 \pm 0.018 \not$; the differences are believed to be due to rounding and both values are within $1 \sigma$ of each other. The given uncertainty of $\pm 0.023 \notin$ is used as the method uncertainty. Because multiple runs were performed, this uncertainty includes the effect of uncertainty in temperature, measurement technique, and reproducibility. The total uncertainty is summarized in Table 2.4-5. 
NEA/NSC/DOC(2006)1

Fundamental-FUND

ORSPHERE-FUND-EXP-001

CRIT-REAC-COEF-KIN-RRATE

Table 2.4-5. Central Void Reactivity Total Uncertainty.

\begin{tabular}{|c|c|c|c|c|}
\hline Uncertainty & $\phi$ & Uncertainty & & $\varnothing$ \\
\hline Experiment Method & $\begin{array}{c} \pm 0.0230 \\
\end{array}$ & ${ }^{234}$ U Abundance & 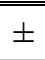 & 0.0010 \\
\hline Fission Fraction Values & \pm 0.0010 & ${ }^{235} \mathrm{U}$ Abundance & \pm & 0.0020 \\
\hline Treatment of ${ }^{234} \mathrm{U}$ and ${ }^{236} \mathrm{U}$ & \pm 0.0088 & ${ }^{236} \mathrm{U}$ Abundance & \pm & 0.0010 \\
\hline Delayed Neutron Parameter ${ }^{\text {(a) }}$ & \pm 0.1210 & Small Sphere Diameter & \pm & 0.0010 \\
\hline Small Sphere Mass & $\pm \quad 0.0010$ & & & \\
\hline
\end{tabular}

(a) This is the systematic component of the delayed neutron parameter uncertainty. The random component is included in the experiment method uncertainty (see Section 2.4.1).

\subsubsection{Button Worth Measurements}

Material Properties The uranium isotopic abundances for the buttons were given in Reference 1 and 2 (Table 1.4-11). The uncertainty in the abundances would be the same as for the critical sphere which is given above in Section 2.4.2.

The impurities for the uranium buttons was provided in Table 1.4-12. The uncertainty in impurity measurements at the Y-12 plant at the time of the experiment was $\pm 20 \%$ for impurities measured above 10 micrograms $/ \mathrm{g}-\mathrm{U}$ and $\pm 70 \%$ for impurities below $10 \mathrm{micrograms} / \mathrm{g}-\mathrm{U}{ }^{\mathrm{a}}{ }^{\mathrm{a}}$ These were assumed to be bounding uncertainties.

Because the calculated effects of the isotopic and impurity uncertainties for the uranium buttons were within the statistical noise of the Monte Carlo calculations, and are considered to be less than the effect of the uranium uncertainties at the center of the sphere, a value of $\pm 0.002 \notin$ was applied for the ${ }^{235} \mathrm{U}$ enrichment uncertainty and $\pm 0.001 \notin$ was applied for the isotopic abundance of ${ }^{234} \mathrm{U}$ and ${ }^{236} \mathrm{U}$ uncertainties.

The screws holding the buttons in place were stainless steel type 304 number 8-55 screws. The effect of the screw material on the worth of the buttons was evaluated but was within the statistical noise of the Monte Carlo calculation. The worth of one screw was approximated using the worth of the stainless steel button on the empty socket hole of the upper polar cap. Three stainless steel Type 304 buttons were worth $4.7228 \notin$ in the socket hole. Using the given button dimensions the worth per volume for the stainless steel was determined, $1.342 \notin$ per cubic centimeter. The volume of one screw was approximately $0.121 \mathrm{~cm}^{3}$ for the 0.635 -cm-thick buttons and $0.090 \mathrm{~cm}^{3}$ for the 0.3175 -cm-thick buttons. This corresponds to a worth per screw of $0.16 \varnothing$ and $0.12 \varnothing$ for the 0.635 and $0.3175 \mathrm{~cm}$ thick buttons, respectively. These values are assigned as bounding uncertainties for the screw material; the $1 \sigma$ uncertainties are $\pm 0.09 \phi$ for the 0.635 -cm-thick buttons and $\pm 0.07 \phi$ for the 0.3175 -cm-thick buttons. This uncertainty is not applied to the 4, 0.3175-cm-thick uranium buttons placed on the surface of the sphere. Because the worth of the four buttons was measured independently of the screws the uncertainty due to the screw material is negligible.

The aluminum buttons were aluminum Type 6061 and the steel buttons were stainless steel Type 304 . The aluminum and stainless steel compositions are given in Table 2.4-6 and Table 2.4-7; 'other' elements listed in Table 2.4-6 were not included in the model composition. The effect of replacing the aluminum Type 6061 with pure aluminum and switching the stainless steel Type 304 for stainless steel Type 316 is within the statistical uncertainty of the Monte Carlo calculation thus a $\pm 0.001 \notin$ uncertainty was

${ }^{\text {a }}$ J. T. Mihalczo, T. Gregory Schaaff, "Uncertainties in Masses, Dimensions, Impurities, and Isotopics of HEU Metal Used in Critical Experiments at ORCEF," ORNL/TM-2012/32, Oak Ridge National Laboratory (2012). 
arbitrarily applied for the material uncertainty, including both composition and impurity uncertainties, for the aluminum and stainless steel buttons.

Table 2.4-6. Type 6061 Aluminum Composition.

\begin{tabular}{|c|c|c|}
\hline Element & Standard Composition ${ }^{(\mathrm{a})(\mathrm{b})}$ & Model Composition \\
\hline Silicon & $0.40-0.80$ wt. $\%$ & 0.6 wt. $\%$ \\
\hline Iron & $<0.7$ wt. $\%$ & 0.35 wt. $\%$ \\
\hline Copper & $0.15-0.40$ wt. $\%$ & 0.275 wt. $\%$ \\
\hline Manganese & $<0.15$ wt. $\%$ & 0.075 wt. $\%$ \\
\hline Magnesium & $0.8-1.2$ wt. $\%$ & 1 wt. $\%$ \\
\hline Chromium & $0.04-0.35$ wt. $\%$ & 0.195 wt. $\%$ \\
\hline Zinc & $<0.25$ wt. $\%$ & 0.125 wt. $\%$ \\
\hline Titanium & $<0.15$ wt. $\%$ & 0.075 wt. $\%$ \\
\hline Other Elements Each & $<0.05$ wt. $\%$ & -- \\
\hline Total & $<0.15$ wt. $\%$ & -- \\
\hline Aluminum & Remainder & 97.305 wt. $\%$ \\
\hline Density $\left(\mathrm{g} / \mathrm{cm}^{3}\right)$ & 2.70 & 2.70 \\
\hline
\end{tabular}

(a) Where single units are shown, these indicate the maximum amounts permitted.

(b) ASTM Standard B308M, 2010, "Standard Specification for Aluminum-Alloy 6061-T6 Standard Structural Profiles,” ASTM International, West Conshohocken, PA, 2010.

Table 2.4-7. Type 304 Stainless Steel Composition.

\begin{tabular}{|c|c|c|}
\hline Element & $\begin{array}{c}\text { Standard } \\
\text { Composition }^{(\mathrm{a})(\mathrm{b})} \\
\end{array}$ & $\begin{array}{c}\text { Model } \\
\text { Composition } \\
\end{array}$ \\
\hline Iron, $\mathrm{Fe}$ & Balance & 69.9225 wt. $\%$ \\
\hline Carbon, C & 0.08 wt. $\%$ & 0.04 wt. $\%$ \\
\hline Manganese, Mn & 2.00 wt. $\%$ & 1.00 wt. $\%$ \\
\hline Silicon, Si & 1.00 wt. $\%$ & 0.50 wt. $\%$ \\
\hline Chromium, $\mathrm{Cr}$ & $18.0-20.0 \mathrm{wt} . \%$ & 19.00 wt. $\%$ \\
\hline Nickel, Ni & 8.0-11.0 wt.\% & 9.50 wt. $\%$ \\
\hline Phosphorus, $\mathrm{P}$ & 0.045 wt. $\%$ & 0.0225 wt. $\%$ \\
\hline Sulfur, S & 0.03 wt. $\%$ & 0.015 wt. $\%$ \\
\hline Density $\left(\mathrm{g} / \mathrm{cm}^{3}\right)$ & 8.00 & 8.00 \\
\hline
\end{tabular}

(a) ASTM Standard A 312/A 312M-09.

(b) Single values are maximum values.

Geometry and Mass The experimenter has stated that all buttons had the same diameters, smaller than the diameter of the button recesses, and varying thicknesses. In Reference 1 the diameter is given as 0.8720 inch and the experimenter has confirmed this as the correct diameter. Reference 3 gives the button diameter as 0.8750 inch but it is believed that this is an accidental swap of the button diameter with the button recess diameter. The outer diameter of the buttons is $0.872 \pm 0.001$ inch $(2.21488 \pm$ $0.00254 \mathrm{~cm})$ in the benchmark model. The inner diameter was 0.1770 inches $(0.44958 \mathrm{~cm})$. No uncertainty for the inner diameter was given but an uncertainty of $0.00254 \mathrm{~cm}$ was applied. The thicknesses of the buttons were $1 / 8$ inch, $0.3175 \mathrm{~cm}$, and $1 / 4$ inch, $0.635 \mathrm{~cm}$. The masses of the uranium buttons were 43.9 grams each for the 0.635 -cm-thick uranium buttons and 65.2 grams for three 0.3175 $\mathrm{cm}$-thick uranium buttons. The uncertainty in these masses would have been $0.1 \mathrm{~g}$; this is the uncertainty 
in mass as discussed in HEU-MET-FAST-100. The aluminum Type 6061 and stainless steel Type 304 buttons were modeled at nominal densities (see Table 2.4-6 and Table 2.4-7).

The placement of buttons on the surface of the sphere was not explicitly given; however, the experimenter has stated that the perturbed buttons were distributed between the upper and lower polar caps. The effect of button placement on worth was calculated by determining button worth if all buttons are placed close together on the upper polar cap and then buttons are placed at maximum spacing on the upper and lower polar caps. This applies only to the worth of the four uranium buttons and the worth per aluminum buttons measurements. The effect of button placement is within the statistical noise of the Monte Carlo and is judged to be negligible.

The holding screws for the surface buttons were modeled as having a radius to match the screw holes in the critical sphere, $0.175247 \mathrm{~cm}$. The geometry of the head of the screws is not known. The screws were modeled to be flush with the outer surface of the buttons, $1.25349-\mathrm{cm}$ and $0.93599-\mathrm{cm}$ long for the 0.635 -cm-thick and 0.3175 -cm-thick buttons, respectively. The effect of varying the dimensions of the screws was within the statistical uncertainty of the Monte Carlo calculations. It is judged that the uncertainty in the dimensions and density of the screws is within the $\pm 0.09 \notin$ and $\pm 0.06 \notin$ uncertainties derived in the above section for material properties.

Because the effect of the geometric uncertainties was within the statistical noise of the Monte Carlo calculations, even when using scaling factors where possible, an uncertainty of $\pm 0.001 \varnothing$ was applied for the dimensional and mass uncertainties for the buttons.

Worth of Buttons on the Sphere Surface When 16, 0.635-cm-thick uranium buttons are added to the 3.4220-inch-average-radius sphere (Case 2 in HEU-MET-FAST-100) the system reactivity is increased from $-23 \not$ to $+12.4 \not$. It is not known if these reactivities were obtained from a single run or from multiple runs or if the two reactivity measurements were performed on the same day or many days apart. In HEU-MET-FAST-100 an uncertainty of $\pm 2.0 \varnothing$ is applied to system reactivities which includes "assembly reproducibility, reactor period measurements uncertainty, and uncertainties in the delayed neutron parameters" (Reference 1). This uncertainty is applied to system reactivity for the sphere without any buttons, $-23 \pm 2.0 \notin$, and the sphere with 16 uranium buttons, $12.4 \pm 2 \notin$. This yields a worth for $16,0.635$-cm-thick uranium buttons of $35.4 \pm 2.828 \phi( \pm 2.0 \sqrt{2} \phi)$. The total uncertainty is summarized in Table 2.4-8.

The worth of four 0.3175 -cm-thick mass adjustment buttons is given as $6.1415 \pm 0.0834 \varnothing$. This is measured with 12 mass adjustment buttons plus an extra 4 holding screws on the reference sphere. Four uranium buttons are added to the sphere and, by comparing the reactivity, the worth of the four uranium mass adjustment buttons, without holding screws, is obtained. The worth was measured five times. If the Inhour results are re-calculated the resulting average is $6.1492 \pm 0.0403 \phi$; the differences are believed to be due to rounding and both values are within $1 \sigma$ of each other. The given uncertainty of $\pm 0.0834 \varnothing$ is used as the method uncertainty. Because multiple runs were performed this uncertainty includes the effect of uncertainty in temperature, measurement technique, and reproducibility. The multiple reactivity measurements used to obtain the worth were all performed one after another and the changes made to the sphere, i.e. the addition of buttons, were small. This meant that when the difference between reactivities was taken to obtain the worth, many of the systematic uncertainties that contributed to the larger uncertainty on the $16,0.635$-cm-thick uranium buttons worth were negligible. The total uncertainty is summarized in Table 2.4-8.

The worth of one 0.3175 -cm-thick aluminum button, including the holding screw, on the surface of the sphere was measured as being $0.7058 \pm 0.0104 \phi$. The worth per button was measured for five experimental runs with either three or four aluminum buttons added to the sphere with 12 or 13 uranium buttons placed in the remaining mass adjustment button recesses. If the Inhour results are re-calculated the resulting average is $0.7017 \pm 0.0046 \varnothing$ per aluminum button; the differences are believed to be due to rounding and both values are within $1 \sigma$ of each other. The given uncertainty of $\pm 0.0104 \phi$ is used as the method uncertainty. Because multiple runs were performed, this uncertainty includes the effect of 
uncertainty in temperature, measurement technique, and reproducibility. The total uncertainty is summarized in Table 2.4-8.

Table 2.4-8. Uncertainty in Worth of Button(s) on Surface of Sphere.

\begin{tabular}{|c|c|c|c|c|}
\hline \multicolumn{5}{|c|}{ Sixteen 0.635-cm-thick Uranium Buttons ${ }^{(\mathrm{a})}$} \\
\hline Uncertainty & $\varnothing$ & Uncertainty & & $\varnothing$ \\
\hline Experiment Method & \pm 2.8284 & Button Dimensions & \pm & 0.0010 \\
\hline Fission Fraction Values & \pm 0.0010 & ${ }^{234} \mathrm{U}$ Abundance & \pm & 0.0010 \\
\hline Treatment of ${ }^{234} \mathrm{U}$ and ${ }^{236} \mathrm{U}$ & \pm 0.0088 & ${ }^{235} \mathrm{U}$ Abundance & \pm & 0.0020 \\
\hline Delayed Neutron Parameter ${ }^{(b)}$ & \pm 0.4673 & ${ }^{236} \mathrm{U}$ Abundance & \pm & 0.0010 \\
\hline Button Mass & \pm 0.0010 & Holding Screws ${ }^{(c)}$ & \pm & 0.0900 \\
\hline \multicolumn{5}{|c|}{ Total $\pm 2.8682 \not c$} \\
\hline \multicolumn{5}{|c|}{ Four 0.3175-cm-thick Uranium Buttons ${ }^{(\mathrm{d})}$} \\
\hline Uncertainty & $\not$ & Uncertainty & & $\varnothing$ \\
\hline Experiment Method & \pm 0.0834 & ${ }^{234} \mathrm{U}$ Abundance & \pm & 0.0010 \\
\hline Fission Fraction Values & \pm 0.0010 & ${ }^{235} \mathrm{U}$ Abundance & \pm & 0.0020 \\
\hline Treatment of ${ }^{234} \mathrm{U}$ and ${ }^{236} \mathrm{U}$ & \pm 0.0088 & ${ }^{236} \mathrm{U}$ Abundance & \pm & 0.0010 \\
\hline Delayed Neutron Parameter ${ }^{(b)}$ & \pm 0.0811 & Button Dimensions & \pm & 0.0010 \\
\hline Button Mass & $\pm \quad 0.0010$ & & & \\
\hline \multicolumn{5}{|c|}{ Total $\pm 0.1167 \not$} \\
\hline \multicolumn{5}{|c|}{ One 0.3175-cm-thick Aluminum Button ${ }^{(a)}$} \\
\hline Uncertainty & $\phi$ & Uncertainty & & $\phi$ \\
\hline Experiment Method & $\pm \quad 0.0104$ & Aluminum Composition & \pm & 0.0010 \\
\hline Fission Fraction Values & $\pm \quad 0.0010$ & Button Density & \pm & 0.0010 \\
\hline Treatment of ${ }^{234} U$ and ${ }^{236} U$ & \pm 0.0088 & Button Dimensions & \pm & 0.0010 \\
\hline Delayed Neutron Parameter ${ }^{(b)}$ & \pm 0.0093 & Holding Screws ${ }^{(\mathrm{c})}$ & \pm & 0.0600 \\
\hline
\end{tabular}

(a) The worth of these buttons includes the worth of the holding screws.

(b) This is the systematic component of the delayed neutron parameter uncertainty. The random component is included in the experiment method uncertainty (see Section 2.4.1).

(c) This uncertainty includes that material, dimensions, and density of the holding screws.

(d) The worth of these buttons was measured independent of the holding screws. 


\section{NEA/NSC/DOC(2006)1 \\ Fundamental-FUND \\ ORSPHERE-FUND-EXP-001 \\ CRIT-REAC-COEF-KIN-RRATE}

Worth of Buttons in Empty Socket Hole of Upper Polar Cap Three 0.3175-cm-thick uranium buttons with a total mass of 65.2 grams were placed in the empty socket hole of the upper polar cap. The measured reactivity worth of these three uranium buttons is $7.86 \pm 0.04 \not$. Five experimental runs in which the system reactivity was determined with the buttons in place and then again with the buttons removed were performed to get the average worth. If the Inhour results are re-calculated, the resulting average is $7.81 \pm 0.0734 \not$. This calculated average is lower than the given average by $0.05 \phi$, which is within the calculated uncertainty in the value. It is not known why the calculated average deviates from the given average by more than the other worth measurements. The uncertainty in the calculated average $( \pm 0.0734 \not)$, since it is larger than the given uncertainty, is used as the method uncertainty. Because multiple runs were performed, this uncertainty includes the effect of uncertainty in temperature, measurement technique, and reproducibility. The total uncertainty is summarized in Table 2.4-9.

Three 0.3175 -cm-thick stainless steel Type 304 buttons had a worth of $4.7228 \pm 0.0420 \notin$ when placed in the empty socket hole of the upper polar cap. Five experimental runs were performed. If the Inhour results are re-calculated, the resulting average is $4.7032 \pm 0.0246 \phi$; the differences are believed to be due to rounding and both values are within $1 \sigma$ of each other. The given uncertainty of $\pm 0.0420 \notin$ is used as the method uncertainty. Because multiple runs were performed, this uncertainty includes the effect of uncertainty in temperature, measurement technique, and reproducibility. The total uncertainty is summarized in Table 2.4-9.

Three 0.3175 -cm-thick aluminum Type 6061 buttons, modeled at nominal density, placed in the empty socket hole of the upper polar cap had a measured worth of $3.1259 \pm 0.0358 \phi$. If the Inhour results are re-calculated, the resulting average is $3.1266 \pm 0.0608 \phi$; the differences between the given and calculated averages are believed to be due to rounding and both values are within $1 \sigma$ of each other. The uncertainty in the calculated average $( \pm 0.0608 \not)$ ), since it is larger than the given uncertainty, is used as the method uncertainty. Because multiple runs were performed, this uncertainty includes the effect of uncertainty in temperature, measurement technique, and reproducibility. The total uncertainty is summarized in Table 2.4-9. 
NEA/NSC/DOC(2006)1

Fundamental-FUND

ORSPHERE-FUND-EXP-001

CRIT-REAC-COEF-KIN-RRATE

Table 2.4-9. Uncertainty in Worth of Button in the Empty Socket Hole.

\begin{tabular}{|c|c|c|c|c|}
\hline \multicolumn{5}{|c|}{ Three 0.3175-cm-thick Uranium Buttons } \\
\hline Uncertainty & $\phi$ & Uncertainty & & $\phi$ \\
\hline Experiment Method & \pm 0.0734 & ${ }^{234} \mathrm{U}$ Abundance & \pm & 0.0010 \\
\hline Fission Fraction Values & \pm 0.0010 & ${ }^{235} \mathrm{U}$ Abundance & \pm & 0.0020 \\
\hline Treatment of ${ }^{234} \mathrm{U}$ and ${ }^{236} \mathrm{U}$ & \pm 0.0088 & ${ }^{236} \mathrm{U}$ Abundance & \pm & 0.0010 \\
\hline Delayed Neutron Parameter ${ }^{(a)}$ & \pm 0.1038 & Button Dimensions & \pm & 0.0010 \\
\hline Button Mass & $\pm \quad 0.001$ & & & \\
\hline \multicolumn{5}{|c|}{ Total $\pm 0.1274 \not c$} \\
\hline \multicolumn{5}{|c|}{ Three 0.3175-cm-thick Stainless Steel Buttons } \\
\hline Uncertainty & $\phi$ & Uncertainty & & $\varnothing$ \\
\hline Experiment Method & \pm 0.0420 & Steel Composition & \pm & 0.0010 \\
\hline Fission Fraction Values & \pm 0.0010 & Button Density & \pm & 0.0010 \\
\hline Treatment of ${ }^{234} \mathrm{U}$ and ${ }^{236} \mathrm{U}$ & \pm 0.0088 & Button Dimensions & \pm & 0.0010 \\
\hline Delayed Neutron Parameter ${ }^{\text {(a) }}$ & \pm 0.0623 & & & \\
\hline \multicolumn{5}{|c|}{ Total $\pm 0.0757 \not$} \\
\hline \multicolumn{5}{|c|}{ Three 0.3175-cm-thick Aluminum Buttons } \\
\hline Uncertainty & $\varnothing$ & Uncertainty & & $\phi$ \\
\hline Experiment Method & \pm 0.0608 & Aluminum Composition & \pm & 0.0010 \\
\hline Fission Fraction Values & \pm 0.0010 & Button Density & \pm & 0.0010 \\
\hline Treatment of ${ }^{234} \mathrm{U}$ and ${ }^{236} \mathrm{U}$ & \pm 0.0088 & Button Dimensions & \pm & 0.0010 \\
\hline Delayed Neutron Parameter ${ }^{(a)}$ & \pm 0.0413 & & & \\
\hline \multicolumn{5}{|c|}{ Total $\pm 0.0741 \not c$} \\
\hline
\end{tabular}

(a) This is the systematic component of the delayed neutron parameter uncertainty. The random component is included in the experiment method uncertainty (see Section 2.4.1).

\subsubsection{Diametral Filler Rod Measurements}

Material Properties The isotopic abundances for the diametral filler rod are given in Table 1.4-11). The uncertainty in the abundances is the same as for the critical sphere (HEU-MET-FAST-100); values are given in Section 2.4.2.

The impurity data for the diametral filler rod was not provided. The average impurity content provided in Reference 1 (see Table 1.4-12 footnotes) was used for the diametral filler rod. The uncertainty in impurity measurements at the Y-12 plant at the time of the experiment was $\pm 20 \%$ for impurities measured above 10 micrograms $/ \mathrm{g}-\mathrm{U}$ and $\pm 70 \%$ for impurities below 10 micrograms $/ \mathrm{g}-\mathrm{U}$. ${ }^{\mathrm{a}}$ These were assumed to be bounding uncertainties.

The effect of perturbing the isotopic abundances and impurities in the diametral filler rod was within the statistical noise of the Monte Carlo calculations, even when using scaling factors; an uncertainty of $\pm 0.002 \varnothing$ was applied for the ${ }^{235} \mathrm{U}$ uncertainty and $\pm 0.001 \varnothing$ was applied for the ${ }^{234} \mathrm{U}$ and ${ }^{236} \mathrm{U}$ uncertainties. This is discussed in Section 2.4.0.

${ }^{a}$ J. T. Mihalczo, T. Gregory Schaaff, "Uncertainties in Masses, Dimensions, Impurities, and Isotopics of HEU Metal Used in Critical Experiments at ORCEF," ORNL/TM-2012/32, Oak Ridge National Laboratory (2012). 


\section{Fundamental-FUND \\ ORSPHERE-FUND-EXP-001 \\ CRIT-REAC-COEF-KIN-RRATE}

Geometry and Mass The geometry and mass for the diametral filler rod is the same as for the diametral filler rod for the critical sphere (HEU-MET-FAST-100). The diametral filler rod was modeled as one 28.163 gram uranium metal rod with a diameter of $0.328442 \mathrm{~cm}$ and a length of $17.82953 \mathrm{~cm}$. The uncertainty in the mass and dimensions of the diametral filler rod were evaluated for the critical sphere and found to have a negligible effect. ${ }^{a}$

Diametral Filler Rod Worth The diametral filler rod has a measured worth of $11.2340 \pm 0.0717 \not$. The value of $11.23 \pm 0.07 \varnothing$ given in Reference 1 and 2 has been rounded from the values given in the experimenter's notes. The non-rounded value is used for the benchmark model. The worth is an average of five runs with and without the diametral filler rod present in the diametral hole of the critical sphere. If the Inhour results are re-calculated, the resulting average is $11.173 \pm 0.078 \phi$; the differences are believed to be due to rounding and both values are within $1 \sigma$ of each other. The uncertainty in the calculated average $( \pm 0.078 \not)$, since it is larger than the given uncertainty, is used as the method uncertainty. Because multiple runs were performed, this uncertainty includes the effect of uncertainty in temperature, measurement technique, and reproducibility. The total uncertainty is summarized in Table 2.4-10.

Table 2.4-10. Diametral Filler Rod Uncertainty.

\begin{tabular}{|c|c|c|c|}
\hline Uncertainty & $\phi$ & Uncertainty & $\bar{\phi}$ \\
\hline Experiment Method & $\pm \quad 0.0780$ & ${ }^{234} \mathrm{U}$ Abundance & $\pm \quad 0.0010$ \\
\hline Fission Fraction Values & $\pm \quad 0.0010$ & ${ }^{235} \mathrm{U}$ Abundance & $\pm \quad 0.0020$ \\
\hline Treatment of ${ }^{234} \mathrm{U}$ and ${ }^{236} \mathrm{U}$ & \pm 0.0088 & ${ }^{236} \mathrm{U}$ Abundance & $\pm \quad 0.0010$ \\
\hline $\begin{array}{l}\text { Delayed Neutron } \\
\text { Parameter }^{\text {(a) }}\end{array}$ & $\pm \quad 0.1483$ & $\begin{array}{l}\text { Diametral Filler Rod } \\
\text { Dimensions }^{\text {(a) }}\end{array}$ & NEG \\
\hline $\begin{array}{l}\text { Diametral Filler Rod } \\
\text { Mass }^{\text {(a) }}\end{array}$ & $\pm \quad \mathrm{NEG}$ & & \\
\hline
\end{tabular}

(a) These uncertainties were evaluated in HEU-MET-FAST-100.

\subsection{Evaluation of Reactivity Coefficient Data}

The worth per gram of uranium on the surface of the sphere was determined using the system reactivity change between the two critical spheres described in HEU-MET-FAST-100. Because the two spheres are nearly identical the uncertainties in the two spheres evaluated in HEU-MET-FAST-100 are highly correlated. While the material and dimensional uncertainties have an effect upon individual system reactivities, they have a negligible effect on the surface mass worth because the worth is a change in system reactivity of two highly correlated spheres. Thus, only the uncertainty of the reactivity measurement of $2.0 \notin$ is applicable; the uncertainty of the reactivity measurement includes assembly reproducibility $( \pm 0.3 \notin)$, reactor period measurements uncertainties, and uncertainties in the delayed neutron parameter.

The given change in system reactivity, as shown in Table 2.5-1, is used to derive the worth per gram of surface material. The system reactivity corrected for the tilt in the larger sphere is used. The mass of each sphere is also given in Table 2.5-1. The uncertainty in the mass is the uncertainty in mass for each section added together in quadrature. The uncertainty in the center section and upper polar cap were $\pm 0.01 \mathrm{~g}$ for each sphere. The uncertainty in the mass of the diametral filler rod was $\pm 0.014 \mathrm{~g}$ for each sphere. The uncertainty in the mass of the bottom section of sphere was $\pm 1 \mathrm{~g}$ for the $8.80491-\mathrm{cm}-$ average-radius sphere and $\pm 0.01 \mathrm{~g}$ for the 8.74268 -cm-average-radius sphere. To obtain the uncertainty

\footnotetext{
${ }^{a}$ This determination was completed in HEU-MET-FAST-100. The effect of the uncertainty in the diametral filler rod was determined using the effect on $\mathrm{k}_{\mathrm{eff}}$ and negligibility was set at less than $0.00001 \Delta \mathrm{k}_{\mathrm{eff}}$. 
in the worth per gram of surface material the measurement uncertainty in the system reactivity, $\pm 2.0 \phi$, and the uncertainty in the masses are propagated to get a $\pm 0.003 \notin$ per gram uncertainty.

Table 2.5-1. Worth per Gram of Surface Material

\begin{tabular}{|c|c|c|c|}
\hline & System Reactivity & \multicolumn{2}{|c|}{ Mass } \\
\hline 8.80491-cm-Average-Radius Sphere & $73.1 \pm 2.6 \phi^{(\mathrm{a})}$ & $53,475.983$ & $\pm \quad 1.017 \mathrm{~g}$ \\
\hline 8.74268-cm-Average-Radius Sphere & $-23.4 \pm 2.0 \varnothing$ & $52,350.943$ & $0.210 \mathrm{~g}$ \\
\hline Change & $96.5 \pm 2.83 \varnothing$ & $1,125.04$ & $\pm \quad 1.038 \mathrm{~g}$ \\
\hline Worth per Gram of Sur & ce Material & 0.003 & c per gram \\
\hline
\end{tabular}

(a) This uncertainty includes a $1.67 \notin$ uncertainty in the tilt angle between the center and lower plates. This tilt is not present in the $8.74268-\mathrm{cm}$-average-radius sphere.

\subsection{Evaluation of Kinetics Measurements Data}

\subsubsection{Delayed Neutron Fraction}

Two methods of measuring the effective delayed neutron fraction, $\beta_{\text {eff, }}$ were tested with ORSphere. The first used the central void reactivity and the second used time correlation measurements with californium- 252 yielding $\beta_{\text {eff }}$ values of $0.00657 \pm 0.00002$ and $0.00602 \pm 0.00008$, respectively. The $0.00602 \pm 0.00008$ value from the time correlation measurements is rejected due to the "improper theoretical formulation for correcting point kinetics for spatial effects" that is cited in Reference 5.

The $0.00657 \pm 0.00002 \beta_{\text {eff }}$ value is the ratio of the calculated worth of the central void, $6.02 \pm 0.01 \times 10^{-4}$ $\Delta \mathrm{k}$, and the measured central void worth, $9.165 \pm 0.023 \notin$. This method is similar to methods used by Gordon Hansen to determine $\beta_{\text {eff }}$ at Los Alamos National Laboratory., ${ }^{\mathrm{a}, \mathrm{b}}$ The $0.0066 \beta_{\text {eff }}$ value for Godiva given by the experimenter is believed to have been obtained by measuring the "increment between delayed and prompt critical" for surface mass of the sphere. ${ }^{\circ}$

It should be noted that the uncertainty in the central void worth was evaluated in Section 2.4.2 and the uncertainty in the value was found to be $\pm 0.123 \notin$. The uncertainty accounts for uncertainty in the fission fraction values, uncertainty in the delayed neutron parameters, treatment of the ${ }^{234} U$ and ${ }^{236} U$ in the Inhour equations, and the sphere geometry, mass, and material properties in addition to the experimental method uncertainty. This uncertainty in the measured central void worth is the driving uncertainty in the $\beta_{\text {eff }}$ value. The increase in the worth uncertainty increases the $\beta_{\text {eff }}$ uncertainty from 0.000016 to 0.000089 .

Hansen's method is highly dependent on the calculated $\Delta \mathrm{k}$ reactivity of the central void. The calculated worth of the central void in units of $\Delta \mathrm{k}$ was obtained by the experimenter using $\mathrm{S}_{n}$ transport theory, extrapolated to infinite order $\mathrm{S}_{n}$, with a precision of less than $10^{-7} \Delta \mathrm{k}$. ONEDANT and XSDRNPM codes with Hansen-Roach and ENDF/B-VI cross section libraries were used. This method is only valid for worth measurements that can be very accurately measured and very accurately modeled. There also must be uniformity in the composition such that deficiencies in the nuclear data will cancel when the reactivity is calculated by taking the difference between the reference and perturbed models. To determine the accuracy of the calculated reactivity the benchmark model for the central void measurement (see Section 3.4) and the Case 2 simple benchmark model for HEU-MET-FAST-100 were used to recalculate the reactivity in units of $\Delta \mathrm{k}$. The models with and without the 0.5482 -cm-radius

\footnotetext{
${ }^{a}$ Personal phone communication with J.T. Mihalczo, November 14, 2013.

${ }^{\mathrm{b}}$ G.E. Hansen, C. Maier, "Material Replacement Experiments: Theory and Measurements for the Lady Godiva Assembly," LA-1525 (1953). It should be noted that this report gives a $\beta_{\text {eff }}$ value of 0.0068 .

c G.E. Hansen, "Status of Computational and Experimental Correlations for Los Alamos Fast-Neutron Critical Assemblies," Physics of Fast and Intermediate Reactors, Proc. Of a Seminar, Vol. 1, p. 453, IAEA, (1962). 
sphere at the center of the main sphere yielding the system $\mathrm{k}_{\text {eff }}$ with, $\mathrm{k}_{1}$, and without, $\mathrm{k}_{2}$, the sphere present. The reactivity of the sphere was then calculated, $\rho(\Delta k)=\left(k_{1}-k_{2}\right) / k_{1} \cdot k_{2} \cdot \beta_{\text {eff }}$ was then

calculated using the benchmark central void worth of $9.165 \pm 0.123 \notin$ (see Section 2.4.2). Table 2.6-1 shows the results for the calculations using various codes and cross sections. From these results it can be seen that regardless of code and cross section used to calculate the reactivity of the central void in units of $\Delta \mathrm{k}$ the resulting $\beta_{\text {eff }}$ is the same within the uncertainty. However, it can also be seen that in order to determine $\beta_{\text {eff }}$ with a reasonable uncertainty the worth measurement must be of a material volume whose reactivity can be calculated with a small uncertainty.

Using deterministic methods the worth is re-calculated using ENDF/B-V.0, ENDF/B-VI.0 and ENDF.BVII.0. The average re-calculated worth is $6.06 \times 10^{-4} \Delta \mathrm{k}$ which is $0.4 \mathrm{pcm}$ above the given calculated worth of $6.02 \pm 0.01 \times 10^{-4}$. The $0.4 \mathrm{pcm}$ difference is used as the bounding uncertainty in the calculated central void reactivity $\left(0.23 \mathrm{pcm} 1 \sigma\right.$ uncertainty). According to expert judgment ${ }^{\mathrm{a}}$ the uncertainties in nuclear data could contribute approximately $0.5 \%$ to the relative reactivity uncertainty for fast high enriched non-reflected uranium systems. It is the judgment of the evaluator that by re-calculating using the three ENDF/B libraries the spread in the calculated reactivity due to discrepancies in nuclear data is accounted for and $0.23 \mathrm{pcm}$ uncertainty in the calculated central void reactivity accounts for nuclear data sensitivities. The increase in the uncertainty in the calculated central void reactivity increases the $\beta_{\text {eff }}$ uncertainty to 0.000092 .

\footnotetext{
${ }^{a}$ Personal email communication with E. Ivanov, February 3, 2015.
} 
NEA/NSC/DOC(2006)1

Fundamental-FUND

ORSPHERE-FUND-EXP-001

CRIT-REAC-COEF-KIN-RRATE

Table 2.6-1. Calculation of $\beta_{\text {eff }}$ using Various Method to Calculate the Void Reactivity Effect.

\begin{tabular}{|c|c|c|c|c|c|c|c|c|}
\hline Code & $\begin{array}{l}\text { Cross } \\
\text { Section }\end{array}$ & \multicolumn{3}{|c|}{$\rho(\Delta k)$} & \multicolumn{3}{|c|}{$\beta_{\mathrm{eff}}^{(\mathrm{e})}$} & $\frac{\beta_{e f f}-\beta_{e f f}^{\text {given }}}{\sigma_{\beta}+\sigma_{\beta}^{\text {given }}}(\mathrm{g})$ \\
\hline \multicolumn{2}{|c|}{ "Given (Ref. 3) } & 0.000602 & \pm & $0.000002^{(\mathrm{f})}$ & 0.00657 & $\overline{ \pm}$ & 0.00009 & - \\
\hline $\mathrm{MCNP}^{(\mathrm{a})}$ & ENDF/B-VII.0 & 0.000618 & \pm & 0.000011 & 0.00675 & \pm & 0.00015 & 0.75 \\
\hline MCNP5 $^{(\mathrm{b})}$ & JEFF-3.1 & 0.00065 & \pm & 0.00003 & 0.00706 & \pm & 0.00033 & 1.17 \\
\hline $\mathrm{MCNP}^{(\mathrm{b})}$ & JENDL-3.3 & 0.00058 & \pm & 0.00003 & 0.00632 & \pm & 0.00032 & -0.61 \\
\hline $\operatorname{MONK}^{(\mathrm{c})}$ & JEFF-3.1 & 0.00056 & \pm & 0.00009 & 0.00611 & \pm & 0.00099 & -0.43 \\
\hline $\operatorname{MONK}^{(\mathrm{c})}$ & ENDF/B-VII.0 & 0.00053 & \pm & 0.00009 & 0.00578 & \pm & 0.00099 & -0.73 \\
\hline XSDRNPM $^{(\mathrm{d})}$ & ENDF/B-VII.0-238g & 0.000605 & \pm & $10^{-8}$ & 0.00661 & \pm & 0.00009 & 0.22 \\
\hline XSDRNPM $^{(\mathrm{d})}$ & ENDF/B-VI.0-238g & 0.000608 & \pm & $10^{-8}$ & 0.00664 & \pm & 0.00009 & 0.39 \\
\hline XSDRNPM $^{(\mathrm{d})}$ & ENDF/B-V.0-238g & 0.000605 & \pm & $10^{-8}$ & 0.00660 & \pm & 0.00009 & 0.17 \\
\hline
\end{tabular}

(a) Results obtained using 500,000 histories for 2650 cycles, skipping the first 150 cycles.

(b) Results provided by John D. Bess from INL. Results obtained using 500000 histories for 2650 cycles, skipping the first 150 cycles.

(c) Results provided by James Dyrda from AWE. Results obtained using 30 settling stages plus 20000 normal stages, 1000 super histories per stage and 10 generations per super-history.

(d) Results provided by John D. Bess from Idaho National Laboratory $\left(\mathrm{S}_{\mathrm{N}}=512\right.$, convergence $\left.=10^{-9}\right)$. Standard SCALE settings were used.

(e) $\beta_{\text {eff }}$ was calculated using the benchmark central void worth of $9.165 \pm 0.123 \phi$.For the Monte Carlo calculations of reactivity, the dominant uncertainty in $\beta_{\text {eff }}$ is the uncertainty in the calculated reactivity. For the deterministic calculations of the reactivity, the dominant uncertainty in $\beta_{\text {eff }}$ is the uncertainty in the benchmark central void worth measurement (see Section 2.4.2 for the contributions to that uncertainty).

(f) The given uncertainty in the calculated reactivity of 0.000001 is increased to 0.000002 to account for additional uncertainty in the calculation.

(g) This ratio of the difference of the calculated $\beta_{\text {eff }}$ from the given $\beta_{\text {eff }}$ over the sum of the two uncertainties gives an idea of the agreement between the two $\beta_{\text {eff }}$ values.

Because $\beta_{\text {eff }}$ is a property of the system as a whole this method can be applied to any worth measurement taken for the system. This method is repeated for the uranium button worth measurements. Results are given in Table 2.6-2. Although there is a large variation in the $\beta_{\text {eff }}$, they are the same to within the $3 \sigma$ uncertainty. These worth measurements were not as precisely measured and the worth cannot be as accurately calculated. 
Table 2.6-2. Calculation of $\beta_{\text {eff }}$ using Various Surface Worth Measurements.

\begin{tabular}{|c|c|c|c|c|c|c|c|c|}
\hline & \multicolumn{7}{|c|}{$\beta_{\text {eff }}^{\text {given }}=0.00657 \pm 0.00009^{(\mathrm{a})}$} & $\beta_{\text {eff }}-\beta_{\text {eff }}^{\text {given }}$ \\
\hline & \multicolumn{2}{|c|}{$\begin{array}{l}\text { Given Worth } \\
(\varnothing)\end{array}$} & \multicolumn{2}{|c|}{$\begin{array}{c}\rho(\Delta k)^{(\mathrm{c})} \\
10^{3} \\
\end{array}$} & \multicolumn{3}{|c|}{$\begin{array}{l}\beta_{\text {eff }} \\
10^{3} \\
\end{array}$} & $\begin{array}{c}\sigma_{\beta}+\sigma_{\beta}^{\text {given }} \\
\text { (b) }\end{array}$ \\
\hline $\begin{array}{l}\text { 16, } 0.635-\mathrm{cm} \text {-thick Uranium } \\
\text { Buttons on Sphere Surface }\end{array}$ & 35.4 & \pm 2.868 & 2.862 & \pm 0.0028 & 8.085 & \pm & 0.66 & 2.02 \\
\hline $\begin{array}{l}\text { 4, } 0.3175-\mathrm{cm} \text {-thick Uranium } \\
\text { Buttons on Sphere Surface }\end{array}$ & 6.1415 & \pm 0.1167 & 0.43 & 0.0028 & 7.005 & \pm & 0.48 & 0.76 \\
\hline $\begin{array}{l}3,0.3175 \text {-cm-thick Uranium } \\
\text { Buttons in Socket Hole }\end{array}$ & 7.86 & \pm 0.1274 & 0.54 & \pm 0.0028 & 6.89 & \pm & 0.38 & 0.69 \\
\hline Surface Material Worth & 96.5 & 2.83 & 5.89 & 0.028 & 6.10 & \pm & 0.18 & -2.34 \\
\hline
\end{tabular}

(a) It should be noted that this value is derived using a small void region at the center of the core.

(b) This ratio of the difference of the calculated $\beta_{\text {eff }}$ from the given $\beta_{\text {eff }}$ over the sum of the two uncertainties gives an idea of the agreement between the two $\beta_{\text {eff }}$ values.

(c) Change in reactivity was calculated using MCNP5 and ENDF/B-VII.0 neutron cross section libraries.

Based on these two studies it can be determined that this method is valid, although, it should be limited to use for worth measurements that are very accurately measured, with a uniform composition, and whose worth can also be calculated very accurately.

The final experimental uncertainty in the delayed neutron fraction was increased from 0.00002 to 0.00009 to account for increase in the uncertainty in the central void reactitivy from $\pm 0.023 \phi$ to \pm 0.123 $\phi$, and additional uncertainty in the calculated reactivity, increased from $\pm 0.1 \mathrm{pcm}$ to $\pm 0.23 \mathrm{pcm}$.

\subsubsection{Prompt Neutron Decay Constant ${ }^{\mathrm{a}}$}

The prompt neutron decay constant, $\alpha$, is the asymptotic inverse reactor period or the logarithmic rate of change of the neutron population as is written in Equation 2.6.1.

Equation

2.6.1

$$
\alpha=\frac{1}{n(t)} \frac{d n}{d t}
$$

The value of $\alpha$ is reported as $1.1061 \pm 0.0009 \mu \mathrm{sec}^{-1}$. The value is reported in Table $1.6-1$ as a positive value but the prompt neutron decay constant is negative for systems below prompt critical. ${ }^{\mathrm{b}}$ The given uncertainty is from the statistics of the 538 measurements performed. It is much lower than the uncertainty given for GODIVA, $1.10 \pm 0.01 \mu \mathrm{sec}^{-1}$ (Reference 6 and 7). However, many of the 538 measurements were correlated and taking the deviation of the variance weighted average fails to account for possible systematic uncertainties. To account for this the $\pm 0.0009 \mu \mathrm{sec}^{-1}$ uncertainty was increased by the square root of the number of measurements and then divided by the square root of the number of independent source/detector configurations $( \pm 0.0009 \cdot \sqrt{538} / \sqrt{7})$. This yields a final experimental uncertainty of $\pm 0.0079 \mu \sec ^{-1}$ for the prompt neutron decay constant, $\alpha$.

\subsubsection{Mean Neutron Generation Time}

Although the mean neutron generation time, $\Lambda$, was not reported by the experimenter, it can be derived from the independently measured delayed neutron fraction, $\beta_{\text {eff, }}$ and the prompt neutron decay constant,

\footnotetext{
${ }^{a}$ Special thanks to Dr. Brian C. Kiedrowski of Los Alamos National Laboratory whose advice and input was integral to the formulation of the prompt neutron decay constant evaluation.

b J.D. Orndoff, "Prompt Neutron Periods of Metal Critical Assemblies," Nucl. Sci. and Eng., 2, 450 (1957). 
$\alpha$. Using the point kinetics Equation 2.6.2. and Equation 2.6.1, $\alpha$ can be approximated as Equation 2.6.3 when delayed neutrons can be neglected.

$\begin{aligned} & \text { Equation } \\ & 2.6 .2 \\ & \begin{array}{l}\text { Equation } \\ 2.6 .3\end{array} \\ & \frac{d c_{i}(t)}{d t}=\frac{\beta_{i}}{\Lambda} n(t)-\lambda_{i} c_{i}(t), i=1, \ldots, 6 \\ & \Lambda\end{aligned}$

Where $n$ is the neutron density; $\beta_{i}, \lambda_{i}$, and $c_{i}$ are related to the delayed neutron precursor groups and are not a factor in this formulation; $\rho$ is the reactivity of the system in units of $\Delta \mathrm{k} ; \beta_{\text {eff }}$ is the effective delayed neutron fraction; and $\Lambda$ is the mean generation time or neutron reproduction time. Equation 2.6.3 can be used to derive the mean generation time.

Equation

2.6.4

$$
\Lambda=l=\frac{\rho-\beta_{e f f}}{\alpha}
$$

In Equation 2.6.4 the mean generation time is equal to the prompt neutron lifetime ${ }^{\mathrm{a}}, l$, and the reactivity, $\rho$, is zero because the system is at delayed critical. The three terms affecting the mean generation time are each independently measured:

$$
\begin{aligned}
& \beta_{\text {eff }}=0.00657 \pm 0.00009 \\
& \rho=0 \pm 2 \varnothing \\
& \alpha=-1.1061 \pm 0.0079 \mu \mathrm{sec}^{-1} .
\end{aligned}
$$

These values yield a value for $\Lambda$ of $0.00594 \mu \mathrm{sec}$ or 5.94 nanosec. The uncertainties can be propagated using Equation 2.6.4 to obtain an uncertainty of \pm 0.15 nanosec.

\subsection{Evaluation of Reaction-Rate Distributions}

\subsubsection{Relative Neutron Importance}

The radial distribution of the relative neutron importance was measured by the changes in count rate in external $\mathrm{BF}_{3}$ counters as a source is passed through the diametral hole of the sphere normalized to the count rate when the source is at the center of the sphere. The 8.74268-cm-average-radius sphere was used (Case 2 in HEU-MET-FAST-100). Three $\mathrm{BF}_{3}$ counters were used at locations shown in Figure 1.7-1. The source was a ${ }^{252} \mathrm{Cf}$ source, with a Maxwellian neutron spectrum and a temperature of $1.4 \mathrm{MeV}$.

It should be noted that the experimental setup is measuring count rate using $\mathrm{BF}_{3}$ detectors which use a $(n, \alpha)$ reaction and not total flux. Because the system was a fast system, spectrum changes as the $\mathrm{Cf}$ source was passed through the diametral hole would have been minimal and the $\mathrm{BF}_{3}$ count rate measurements would be proportional to the total flux and thus it is judged that the relative neutron importance is not biased by the use of $\mathrm{BF}_{3}$ detectors. However, to be more precise what the experimenter calls the relative neutron importance will now be called relative neutron importance for $\mathrm{BF}_{3}$ detector response and a Cf source.

The experimenter evaluated the effect of sphere position and orientation, room return, detector location, and source centering in the container. The effect of all these was found to be negligible. The uncertainties given in Table 1.7-1 are "precision[s] based on repeated measurement" (Reference 8). These uncertainties are taken to be the measurement uncertainties.

a J.J. Dudersstadt, "Nuclear Reactor Analysis,” John, Wiley \& Sons, reprinting of (1976) edition. 
A rounding uncertainty of one in the last significant digit was applied to all relative neutron importance for $\mathrm{BF}_{3}$ detector response and a $\mathrm{Cf}$ source measurements. This uncertainty was taken to be a bounding uncertainty with a uniform distribution. The $1 \sigma$ rounding uncertainty was $\pm 0.001 / \sqrt{3}$ or 0.00057 .

The effect of sphere radius, uranium isotopic composition, sphere mass, and source position were evaluated using MCNP5.1.60 and ENDF/B-VII.0 neutron cross section library and the simple benchmark model. The uranium isotopic composition uncertainty effect was non-negligible; the sphere radius and mass and source position uncertainty effects were negligible. An uncertainty was judged to be negligible if the $1 \sigma$ effect was less than the rounding uncertainty $( \pm 0.00057)$.

The uncertainty in the sphere radius was the same as for the critical benchmark model, $2.54 \times 10^{-4} \mathrm{~cm}$ $(1 \sigma)$ (HEU-MET-FAST-100). The effect was evaluated by perturbing the sphere radius by $10 \sigma$ above and below the benchmark sphere radius using the simple benchmark model. The difference between the high and low radius perturbed models over two yields the $10 \sigma$ uncertainty effect. The effect is then scaled to the $1 \sigma$ effect. The sphere mass was conserved when the sphere radius was adjusted. The effect of the uncertainty in the sphere radius on the relative neutron importance for $\mathrm{BF}_{3}$ detector response and a $\mathrm{Cf}$ source was negligible.

The uncertainty in the uranium isotopic composition was the same as for the critical benchmark model (HEU-MET-FAST-100). The effect of the ${ }^{235} \mathrm{U}$ uncertainty was evaluated and the maximum uncertainty effect was $0.15 \%$. It was judged that because this uncertainty was sufficiently small and because the uncertainty effect on the critical benchmark model of the ${ }^{234} U$ and ${ }^{236} U$ content was smaller than the effect of the ${ }^{235} \mathrm{U}$ enrichment that the effect of the ${ }^{234} \mathrm{U}$ and ${ }^{236} \mathrm{U}$ content would be negligible for the relative neutron importance for $\mathrm{BF}_{3}$ detector response and a $\mathrm{Cf}$ source. The uncertainty in ${ }^{235} \mathrm{U}$ enrichment was $\pm 0.0177 \mathrm{wt} . \%(1 \sigma)$. The effect was evaluated using a similar approach to that used for the sphere radius. The ${ }^{238} \mathrm{U}$ content was adjusted to maintain unity. The maximum uncertainty effect of $0.15 \%$ was applied to all measurement points.

The uncertainty in the sphere mass was the same as for the total mass uncertainty for the 8.74268 -cmaverage-radius sphere of the surface worth coefficient measurements, $0.21 \mathrm{~g}$ (Table 2.5-1). The effect was evaluated using a similar approach to that used for the sphere radius. When the sphere mass was adjusted the sphere radius was held constant. The effect of the uncertainty in the sphere mass on the relative neutron importance for $\mathrm{BF}_{3}$ detector response and a $\mathrm{Cf}$ source was negligible.

The uncertainty in the source position was taken to be $\pm 0.001 \mathrm{~cm}$, which is one in the last significant digit of the given source location. The source position was perturbed by $3 \sigma$ in the simple benchmark model. However, the results of the calculation were meaningless because they were not larger than the statistical uncertainty. Rather than increasing the scaling factor the slope of the relative neutron importance for $\mathrm{BF}_{3}$ detector response and a $\mathrm{Cf}$ source was used. The slope of each measurement point, $n_{i}$, was determined using the following equation:

$$
n_{i}=\frac{y_{i+1}-y_{i-1}}{x_{i+1}-x_{i-1}} \cdot \sigma_{x}
$$

where $y_{i}$ is the measured relative neutron importance for $\mathrm{BF}_{3}$ detector response and a $\mathrm{Cf}$ source, $x_{i}$ is the measured source location, and $\sigma_{x}$ is the position uncertainty. This method does not yield a value for the end point measurements. The effect of the source position uncertainty was negligible. This agrees with the experimental findings that the source position in the source container has a negligible effect.

An additional uncertainty to account for the normalization was also included. Because the measured count rates were normalized to the count rate when the source was at the center of the sphere, the uncertainty in all points is multiplied by $\sqrt{2}$. Since the same uncertainty value is applied to all measurement points this simplified approach is justified. There is no uncertainty associated with the normalization point. 


\section{NEA/NSC/DOC(2006)1 \\ Fundamental-FUND \\ ORSPHERE-FUND-EXP-001 \\ CRIT-REAC-COEF-KIN-RRATE}

The uncertainties in the relative neutron importance for $\mathrm{BF}_{3}$ detector response and a $\mathrm{Cf}$ source are summarized in Table 2.7-1. The total uncertainty is given in Table 2.7-2.

It should be noted that these measurements are the relative neutron importance for $\mathrm{BF}_{3}$ detector response and a Cf source. The results are only a trend in the data and are not absolute. This is why the uncertainty effects are very small or negligible; the effect washes out when the normalization is performed.

Table 2.7-1. Summary of Experimental Uncertainty in

Relative Neutron Importance for $\mathrm{BF}_{3}$ Detector

Response and a Cf Source.

\begin{tabular}{|lcc|}
\hline \multicolumn{1}{|c}{ Uncertainty } & & Effect \\
\hline Sphere Radius & \pm & NEG \\
$\begin{array}{l}\text { Uranium Isotopic } \\
\text { composition }\end{array}$ & \pm & $0.15 \%$ \\
\hline Sphere Mass & \pm & NEG \\
\hline Source Position & \pm & NEG \\
\hline$\quad$ Total & \pm & $0.15 \% \sqrt{ } 2^{(a)}$ \\
\hline Rounding & \pm & $0.001 / \sqrt{ } 3$ \\
\hline \hline
\end{tabular}

(a) The $\sqrt{2}$ accounts for the added uncertainty from the normalization. 
NEA/NSC/DOC(2006)1

Fundamental-FUND

ORSPHERE-FUND-EXP-001

CRIT-REAC-COEF-KIN-RRATE

Table 2.7-2. Relative Neutron Importance for $\mathrm{BF}_{3}$ Detector Response and a $\mathrm{Cf}$ Source Experimental Uncertainty.

\begin{tabular}{|c|c|c|cc||}
\hline $\begin{array}{c}\text { Radius } \\
(\mathrm{cm})\end{array}$ & \multicolumn{2}{|c|}{$\begin{array}{c}\text { Relative } \\
\text { Neutron Importance }\end{array}$} & $\begin{array}{c}\text { Radius } \\
(\mathrm{cm})\end{array}$ & $\begin{array}{c}\text { Relative } \\
\text { Neutron Importance }\end{array}$ \\
\hline-8.138 & $0.278 \pm 0.0031$ & 0 & 1 & $-^{(\mathrm{a})}$ \\
\hline-8.105 & $0.267 \pm 0.0022$ & 0.660 & $0.986 \pm 0.0024$ \\
\hline-8.100 & $0.289 \pm 0.0013$ & 0.805 & $0.985 \pm 0.0029$ \\
\hline-8.004 & $0.299 \pm 0.0013$ & 0.904 & $0.992 \pm 0.0024$ \\
\hline-7.480 & $0.379 \pm 0.0022$ & 1.905 & $0.951 \pm 0.0029$ \\
\hline-6.833 & $0.464 \pm 0.0023$ & 2.024 & $0.956 \pm 0.0023$ \\
\hline-6.825 & $0.458 \pm 0.0032$ & 2.078 & $0.932 \pm 0.0029$ \\
\hline-6.759 & $0.425 \pm 0.0023$ & 3.175 & $0.864 \pm 0.0022$ \\
\hline-6.731 & $0.468 \pm 0.0032$ & 3.449 & $0.848 \pm 0.0900$ \\
\hline-5.730 & $0.578 \pm 0.0024$ & 4.445 & $0.750 \pm 0.0020$ \\
\hline-5.583 & $0.620 \pm 0.0025$ & 4.646 & $0.716 \pm 0.0019$ \\
\hline-5.484 & $0.624 \pm 0.0025$ & 4.722 & $0.737 \pm 0.0019$ \\
\hline-5.428 & $0.633 \pm 0.0033$ & 5.712 & $0.608 \pm 0.0017$ \\
\hline-4.392 & $0.729 \pm 0.0034$ & 5.895 & $0.576 \pm 0.0017$ \\
\hline-4.288 & $0.759 \pm 0.0020$ & 5.994 & $0.589 \pm 0.0017$ \\
\hline-4.221 & $0.770 \pm 0.0026$ & 7.216 & $0.418 \pm 0.0015$ \\
\hline-4.166 & $0.761 \pm 0.0026$ & 7.419 & $0.414 \pm 0.0023$ \\
\hline-3.208 & $0.860 \pm 0.0022$ & 7.650 & $0.364 \pm 0.0014$ \\
\hline-3.170 & $0.849 \pm 0.0021$ & 8.273 & $0.277 \pm 0.0013$ \\
\hline-3.012 & $0.875 \pm 0.0022$ & 8.400 & $0.264 \pm 0.0013$ \\
\hline-2.891 & $0.886 \pm 0.0028$ & 8.443 & $0.243 \pm 0.0013$ \\
\hline-1.900 & $0.936 \pm 0.0023$ & 8.590 & $0.230 \pm 0.0013$ \\
\hline-1.740 & $0.956 \pm 0.0037$ & 8.618 & $0.224 \pm 0.0012$ \\
\hline-1.618 & $0.958 \pm 0.0029$ & 8.745 & $0.204 \pm 0.0021$ \\
\hline-0.632 & $0.987 \pm 0.0024$ & 9.091 & $0.165 \pm 0.0012$ \\
\hline-0.470 & $0.992 \pm 0.0022$ & & & \pm \\
\hline \hline
\end{tabular}

(a) There is no uncertainty associated with the normalization point.

\subsubsection{Relative Fission Density}

The relative fission density measurement was the activation of uranium cylinders inserted through the diametral hole of the sphere normalized to a corresponding activation of a cylinder at the center of the sphere. The uranium activation cylinders were $0.330 \mathrm{~cm}$ in diameter and 0.635 or $0.318 \mathrm{~cm}$ long. The 8.74268-cm-average-radius sphere was used (Case 2 in HEU-MET-FAST-100). The experimenter evaluated the effect of the sphere orientation and room return on the relative fission density measurements. It was found that the effect of both is negligible. The uncertainties given in Table 1.7-2 are based on multiple measurements and are taken to be the measurement uncertainties.

A rounding uncertainty of one in the last significant digit was applied to all relative fission densities. This uncertainty was taken to be a bounding uncertainty with a uniform distribution. The $1 \sigma$ rounding uncertainty was $\pm 0.001 / \sqrt{ } 3$ or 0.00057 . 
NEA/NSC/DOC(2006)1

\section{Fundamental-FUND \\ ORSPHERE-FUND-EXP-001 \\ CRIT-REAC-COEF-KIN-RRATE}

The effect of the uranium activation cylinder position, diameter, and length, the uranium isotopic composition, and the uranium mass were evaluated using MCNP5.1.60 and ENDF/B-VII.0 neutron cross section library and the simple benchmark model. The effect of all these uncertainties was negligible except for the cylinder position which was $0.40 \%$. An uncertainty was judged to be negligible if the $1 \sigma$ effect was less than the rounding uncertainty $( \pm 0.00057)$.

The uncertainty in the cylinder position was taken to be $\pm 0.01 \mathrm{~cm}$. Most of the cylinder positions were given to three decimals; however, for two measurements the position was only given to two. Because the uncertainty in position was taken to be one in the last significant digit, the larger $0.01 \mathrm{~cm}$ value was applied to all data points. The method of evaluation was the same as for the position uncertainty for the relative neutron importance for $\mathrm{BF}_{3}$ detector response and a $\mathrm{Cf}$ source (Section 2.7.1). The maximum effect of $\pm 0.41 \%$ was applied to all measurement points.

The cylinder length was given as being either 0.635 or $0.318 \mathrm{~cm}$ long. It is not specified what length of cylinder was used for each measurement point. For the benchmark model a length of $0.318 \mathrm{~cm}$ was used. The uncertainty in cylinder length was evaluated by using a $0.635 \mathrm{~cm}$ cylinder. The effect of cylinder length on the relative fission density is negligible.

The diameter of the cylinder was given as $0.330 \mathrm{~cm}$. The effect was evaluated by perturbing the diameter cylinder by $10 \sigma$ above and below the benchmark value using the detailed benchmark model. The difference between the high and low perturbed models divided by two yields the $10 \sigma$ uncertainty effect. The effect is then scaled to the $1 \sigma$ effect. The effect of the uncertainty in the cylinder diameter on the relative fission density was negligible.

The uranium isotopic composition was evaluated in the same manner as for the relative neutron importance for $\mathrm{BF}_{3}$ detector response and a Cf source (Section 2.7.1). The effect of the uncertainty in ${ }^{235} \mathrm{U}$ enrichment on the relative fission density was negligible.

The effect of the mass of the sphere was evaluated in the same manner as for the relative neutron importance for $\mathrm{BF}_{3}$ detector response and a Cf source (Section 2.7.1). The effect of the uncertainty in the sphere mass on the relative fission density was negligible.

An additional uncertainty to account for the normalization was also included. Because the measured activations were normalized to the activation at the center of the sphere, the uncertainty in all points is multiplied by $\sqrt{2}$. Since the same uncertainty value is applied to all measurement points this simplified approach is justified. There is no uncertainty associated with the normalization point.

The uncertainties in the relative fission density are summarized in Table 2.7-3. The total uncertainties are given in Table 2.7-4.

It should be noted that these measurements are the relative fission density. The results are only a trend in the data and are not absolute. This is why the uncertainty effects are very small or negligible; the effect washes out when the normalization is done. 


\section{NEA/NSC/DOC(2006)1 \\ Fundamental-FUND \\ ORSPHERE-FUND-EXP-001 \\ CRIT-REAC-COEF-KIN-RRATE}

Table 2.7-3. Summary of Experimental Uncertainty in Fission Density.

\begin{tabular}{|lcc|}
\hline \multicolumn{1}{|c}{ Uncertainty } & & Effect \\
\hline Cylinder Position & \pm & $0.40 \%$ \\
\hline Cylinder Diameter & \pm & NEG \\
\hline Cylinder Length & \pm & NEG \\
\hline $\begin{array}{l}\text { Uranium Isotopic } \\
\text { composition }\end{array}$ & \pm & NEG \\
\hline Sphere Mass & \pm & NEG \\
Source Position & \pm & NEG \\
\hline \multicolumn{1}{|c|}{ Total } & \pm & $0.40 \% \sqrt{ } 2^{(\mathrm{a})}$ \\
\hline Rounding & \pm & $0.001 / \sqrt{ } 3$ \\
\hline \hline
\end{tabular}

(a) The $\sqrt{2}$ accounts for the added uncertainty from the normalization.

Table 2.7-4. Relative Radial Fission Density Uncertainty.

\begin{tabular}{|c|c|c|c|c|}
\hline $\begin{array}{c}\text { Radius } \\
(\mathrm{cm})\end{array}$ & $\begin{array}{c}\text { Relative } \\
\text { Fission Density }\end{array}$ & $\begin{array}{c}\text { Radius } \\
(\mathrm{cm})\end{array}$ & $\begin{array}{c}\text { Relative } \\
\text { Fission Density }\end{array}$ \\
\hline \hline-8.265 & $0.261 \pm 0.0019$ & 0.635 & $0.996 \pm 0.0058$ \\
\hline-7.633 & $0.354 \pm 0.0023$ & 1.272 & $0.978 \pm 0.0059$ \\
\hline-6.995 & $0.440 \pm 0.0027$ & 1.908 & $0.956 \pm 0.0062$ \\
-6.355 & $0.519 \pm 0.0032$ & 2.543 & $0.910 \pm 0.0056$ \\
-5.725 & $0.603 \pm 0.0040$ & 3.180 & $0.872 \pm 0.0058$ \\
-5.088 & $0.672 \pm 0.0049$ & 3.815 & $0.810 \pm 0.0047$ \\
\hline-4.450 & $0.746 \pm 0.0044$ & 4.450 & $0.742 \pm 0.0047$ \\
-3.815 & $0.810 \pm 0.0055$ & 5.088 & $0.675 \pm 0.0043$ \\
\hline-3.180 & $0.871 \pm 0.0053$ & 5.725 & $0.600 \pm 0.0036$ \\
\hline-2.54 & $0.910 \pm 0.0060$ & 6.355 & $0.518 \pm 0.0058$ \\
-1.908 & $0.951 \pm 0.0058$ & 6.995 & $0.438 \pm 0.0032$ \\
-1.272 & $0.978 \pm 0.0059$ & 7.633 & $0.351 \pm 0.0023$ \\
-0.635 & $1.001 \pm 0.0070$ & 8.265 & $0.257 \pm 0.0025$ \\
\hline 0 & 1 & $-(\mathrm{a})$ & & \\
\hline \hline
\end{tabular}

(a) There is no uncertainty associated with the normalization point. 


$$
\begin{gathered}
\text { NEA/NSC/DOC(2006)1 } \\
\text { Fundamental-FUND } \\
\text { ORSPHERE-FUND-EXP-001 } \\
\text { CRIT-REAC-COEF-KIN-RRATE }
\end{gathered}
$$

\subsection{Evaluation of Power Distribution Data}

Power distribution measurements were not performed.

\section{$2.9 \quad$ Evaluation of Isotopic Measurements}

Isotopic measurements were not performed.

\subsection{Evaluation of Other Miscellaneous Types of Measurements}

Other miscellaneous types of measurements were not performed. 
NEA/NSC/DOC(2006)1

Fundamental-FUND

ORSPHERE-FUND-EXP-001

CRIT-REAC-COEF-KIN-RRATE

\subsection{BENCHMARK SPECIFICATIONS}

Models of the experiments were created using MCNP5 with ENDF/B-VII.0 neutron cross section libraries. Models were run in MCNP5 such that the statistical uncertainty $(1 \sigma)$ of $\mathrm{k}_{\text {eff }}$ was not more than 0.00002 .

\subsection{Benchmark-Model Specifications for Critical and/or Subcritical Measurements}

The criticality portion of this evaluation has been reviewed and approved by the International Criticality Safety Benchmark Evaluation Project (ICSBEP) and has been published under the following identifier: HEU-MET-FAST-100. ${ }^{\mathrm{a}}$

\subsection{Benchmark-Model Specifications for Buckling and Extrapolation-Length Measurements}

Buckling and extrapolation-length measurements were not performed.

\subsection{Benchmark-Model Specifications for Spectral Characteristics Measurements}

Spectral characteristic measurements were not performed.

\subsection{Benchmark-Model Specifications for Reactivity Effects Measurements}

\subsubsection{Description of the Benchmark Model Simplifications}

The as-built model and the detailed model of the 8.74268 -cm-average-radius sphere (Case 2) were used as the base model for the worth measurements. Changes made to the base model for each worth measurement are described in Section 3.4.2 and 3.4.3. The simplification biases and corrections applied to obtain the base detailed model are (1) the room return and air bias, (2) the effect of removing the stainless steel table of the vertical lift machine, (3) the measured correction for the upper support structure, (5) the measured correction for the support rod and upper socket, (6) the measured correction for the center and lower support structure, and (7) the measured temperature correction. These simplifications are described in more detail in HEU-MET-FAST-100. A worth measurement is a result of a change in the system reactivity. It is judged that the aforementioned simplifications have negligible effects on the worth measurements because the structure, which is removed in the base detailed benchmark model, is constant and is not changed when changes are made to the system.

The benchmark model for the worth measurements of the three buttons in the empty socket hole did not include the mass adjustment buttons on the surface of the sphere. This simplification was within the statistical noise of the Monte Carlo calculation. The simplification bias introduced by not including the mass adjustment buttons on the surface of the sphere in the benchmark models was judged to be negligible because the buttons were on the surface of the sphere and were present both when the three buttons were added to and removed from the empty socket hole of the upper polar cap.

There were no additional simplification biases for the worth measurements.

\footnotetext{
${ }^{a}$ International Handbook of Evaluated Criticality Safety Benchmark Experiments, NEA/NSC/DOC(95)03, OECDNEA, Paris (2013). 


\section{NEA/NSC/DOC(2006)1 \\ Fundamental-FUND \\ ORSPHERE-FUND-EXP-001 \\ CRIT-REAC-COEF-KIN-RRATE}

\subsubsection{Dimensions}

The benchmark models for the worth measurement are based on the detailed critical benchmark model for the $8.742395-\mathrm{cm}$-average-radius sphere (detailed Case 2 benchmark model in HEU-MET-FAST-100). The dimensions for this model are given in Figure 3.4-1, Figure 3.4-2, and Figure 3.4-3. These figures are provided for reference; HEU-MET-FAST-100 should be referenced for a full description. Changes to each section of sphere for individual measurements are described in Section 3.4.2.1 through 3.4.2.3.

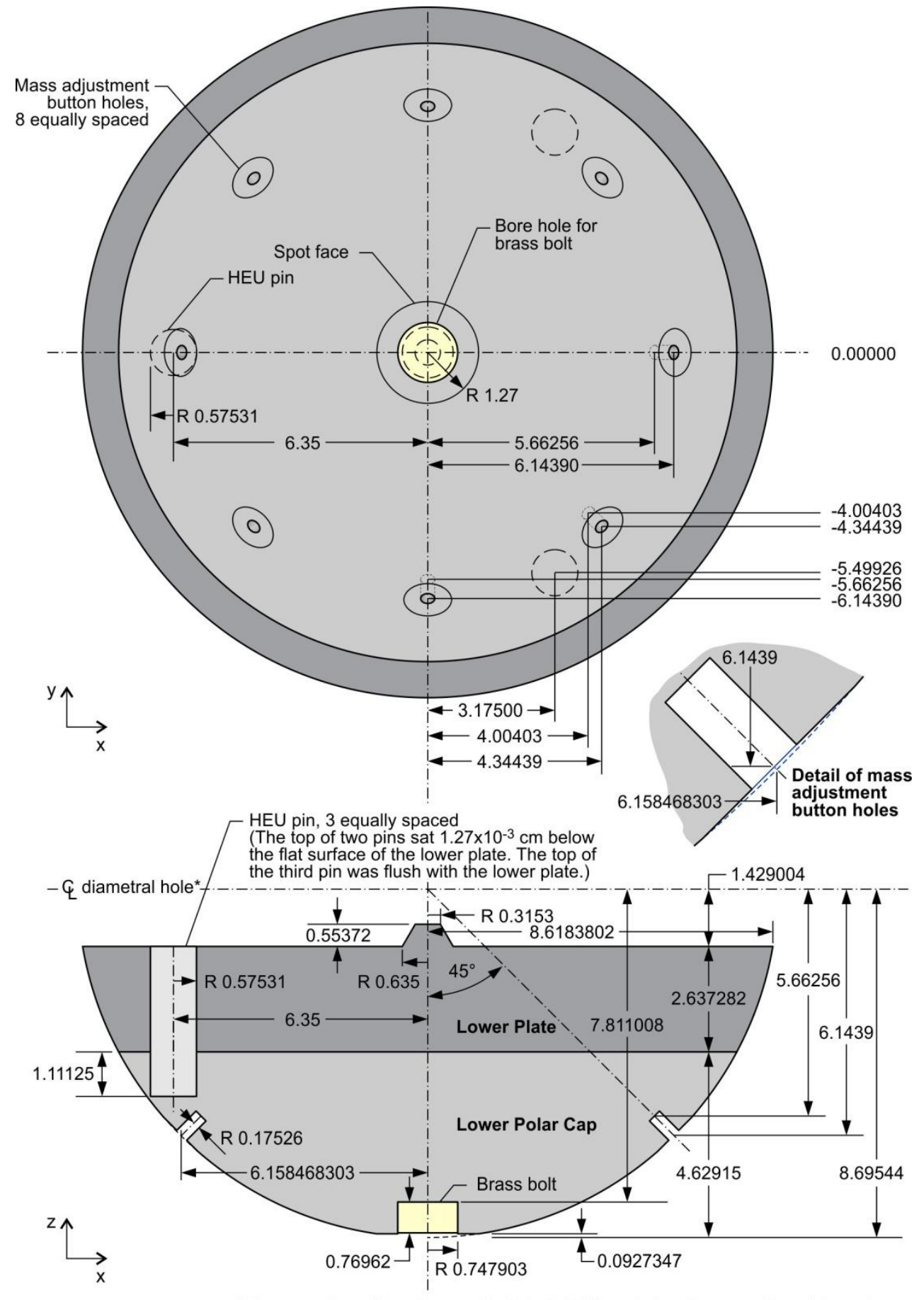

*The centerline of the diametral hole is $0.0508 \mathrm{~cm}$ below the centerline of the sphere Dimensions in cm

Figure 3.4-1. Bottom Section of Sphere for Base Model for Worth Measurements. 
NEA/NSC/DOC(2006)1

Fundamental-FUND

ORSPHERE-FUND-EXP-001

CRIT-REAC-COEF-KIN-RRATE
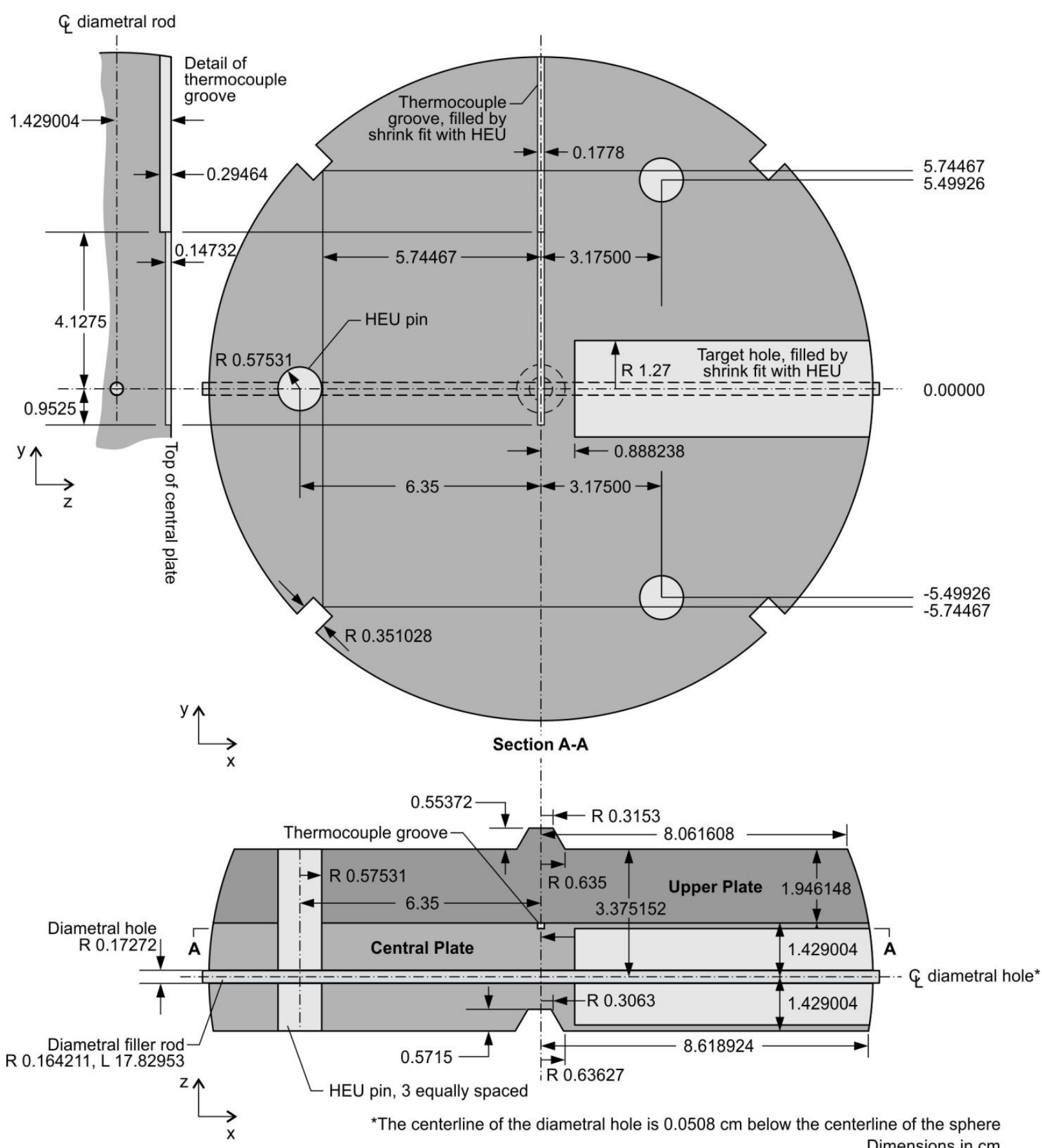

Figure 3.4-2. Center Section of Sphere for Base Model for Worth Measurements. 
NEA/NSC/DOC(2006)1

Fundamental-FUND

ORSPHERE-FUND-EXP-001

CRIT-REAC-COEF-KIN-RRATE

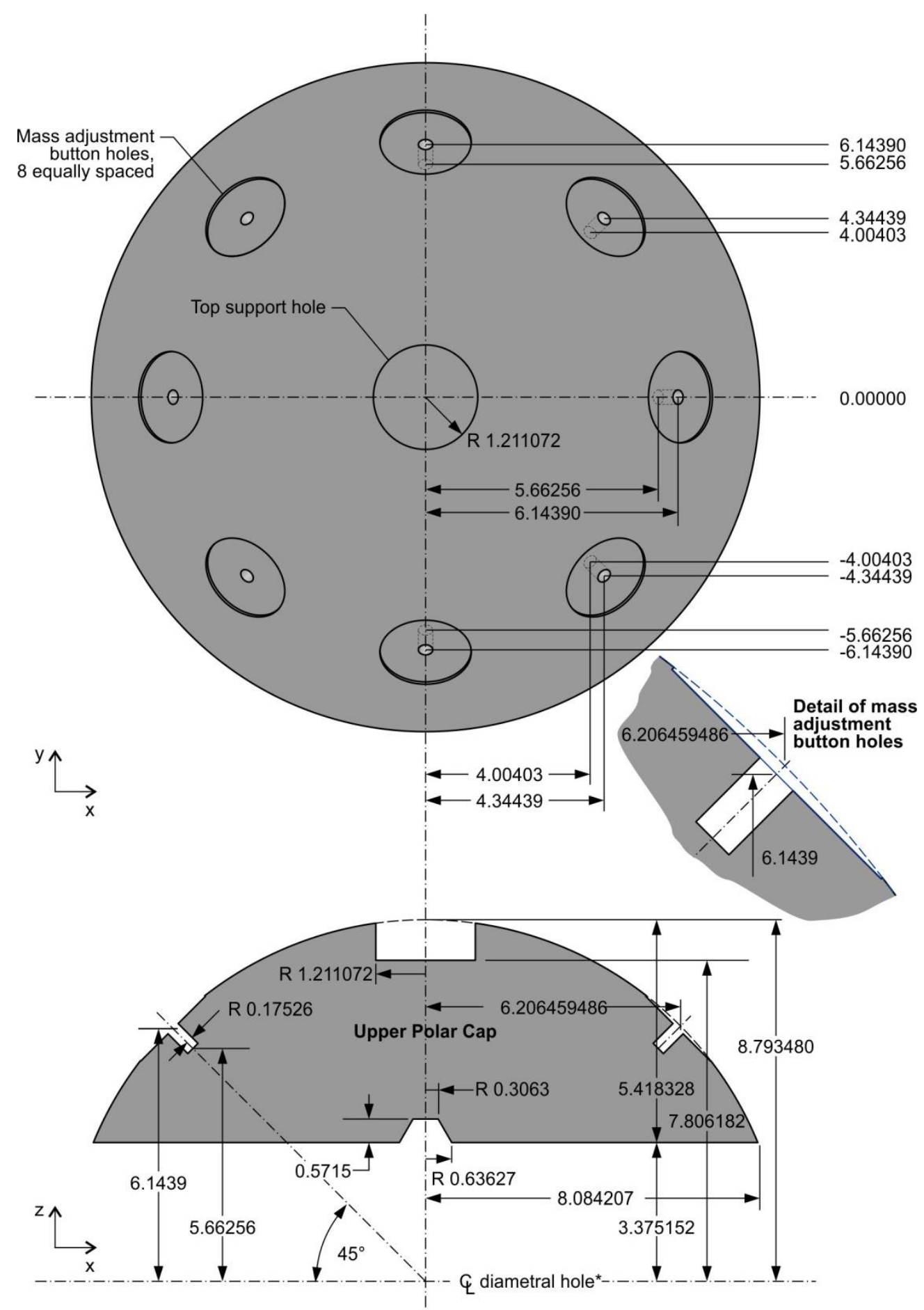

${ }^{*}$ The centerline of the diametral hole is $0.0508 \mathrm{~cm}$ below the centerline of the sphere Dimensions in $\mathrm{cm}$

Figure 3.4-3. Upper Polar Cap for Base Model for Worth Measurements. 


\section{NEA/NSC/DOC(2006)1 \\ Fundamental-FUND \\ ORSPHERE-FUND-EXP-001 \\ CRIT-REAC-COEF-KIN-RRATE}

\subsubsection{Central Void Reactivity}

For the central void reactivity measurements, the center plate of the Case 2 core was modified. Sections of the diametral hole were drilled to a larger diameter and a surface hole was added. These holes are plugged in the benchmark model for the central void reactivity. A $0.5842-\mathrm{cm}$-radius sphere at the center of the larger sphere is added to and removed from the benchmark model to determine the central void reactivity. The modified central plate and plugs used for the central void reactivity benchmark model are shown in Figure 3.4-4. The bottom section and upper polar cap are the same as for the critical benchmark model, Figure 3.4-1 and Figure 3.4-3.

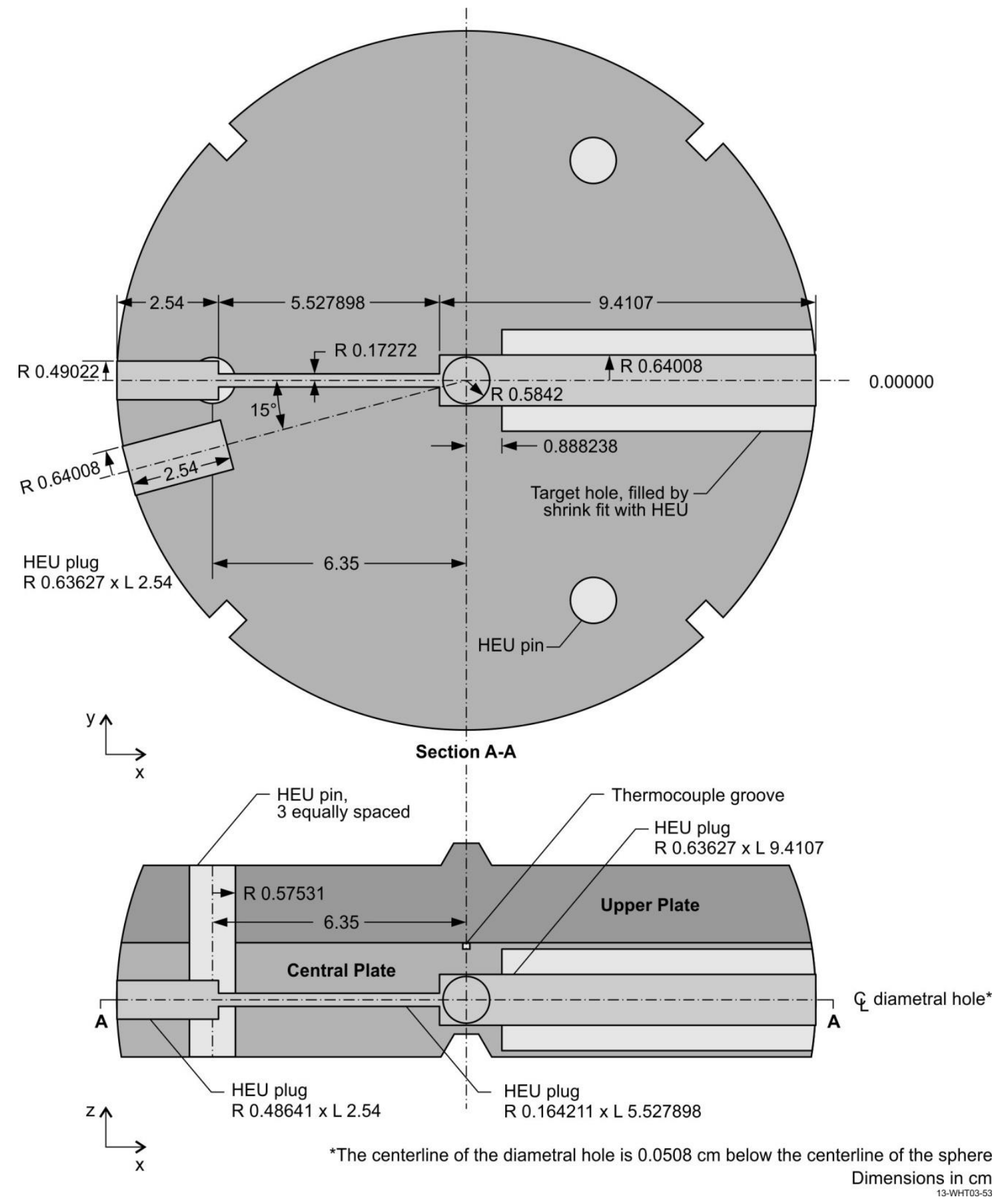

Figure 3.4-4. Modified Center Plate and HEU Plugs for the Central Void Reactivity Measurement. 
NEA/NSC/DOC(2006)1

Fundamental-FUND

ORSPHERE-FUND-EXP-001

CRIT-REAC-COEF-KIN-RRATE

\subsubsection{Button Worth Measurements}

The benchmark models for the button worth measurements are shown in Figure 3.4-1, Figure 3.4-2, and Figure 3.4-3. For the benchmark models for the button worth measurements, mass adjustment buttons are added to the surface of the sphere, as shown in Figure 3.4-5 and Figure 3.4-6, and placed in the empty socket hole of the upper polar cap, as shown in Figure 3.4-7.

For the worth of the 16, 0.635-cm-thick mass adjustment buttons, no buttons or screws are present for the reference benchmark model. The reference benchmark model is identical to the critical detailed benchmark model for Case 2 of HEU-MET-FAST-100. For the perturbed benchmark model 16, 0.635$\mathrm{cm}$-thick $\times 1.10744-\mathrm{cm}-\mathrm{OR} \times 0.22479$-cm-IR buttons are added to the 16 mass adjustment recesses with $16,0.175247$-cm-radius $\times 1.25349$-cm-long screws. The difference between the reactivity of the reference and perturbed benchmark model yields the worth of $16,0.635-\mathrm{cm}$-thick uranium buttons with holding screws.

For the worth of the 4, 0.3175-cm-thick uranium mass adjustment buttons the reference benchmark model has $12,0.3175$-cm-thick $\times 1.10744-\mathrm{cm}-\mathrm{OR} \times 0.22479$-cm-IR uranium mass adjustment buttons and $16,0.175247$-cm-radius $\times 0.93599$-cm-long holding screws on the mass adjustment button recesses. The mass adjustment button recesses B1 and B5 in Figure 3.4-5 and T3 and T7 in Figure 3.4-6 did not have uranium buttons but did have holding screws in the reference benchmark model; all other mass adjustment button recesses held a uranium button. For the perturbed benchmark model the $0.3175-\mathrm{cm}-$ thick uranium buttons are added to the four empty mass adjustment button recesses. The difference between the reactivity of the base and perturbed benchmark model yields the worth of 4, 0.3175-cm-thick uranium buttons independent of the holding screws.

The worth of one 0.3175 -cm-thick aluminum button was measured by: determining the worth of three and four aluminum buttons, including the worth of the holding screws; dividing by the number of aluminum buttons, yielding multiple worth per aluminum button values: and then averaging the results to get an average worth per aluminum buttons. The reference benchmark models had 12 and 13, 0.3175$\mathrm{cm}$-thick $\times 1.10744$-cm-OR $\times 0.22479$-cm-IR uranium buttons with 12 and 130.175247 -cm-radius $\times$ $0.93599-\mathrm{cm}$-long holding screws. For the perturbed benchmark model three or four 0.3175 -cm-thick $\times$ $1.10744-\mathrm{cm}$-OR $\times 0.22479$-cm-IR aluminum buttons with 0.175247 -cm-radius $\times 0.93599$-cm-long holding screws are placed in the empty mass adjustment button recesses. The aluminum buttons are placed in location $\mathrm{B} 1, \mathrm{~T} 3$, and $\mathrm{T} 7$ for the three buttons and $\mathrm{B} 1, \mathrm{~B} 5, \mathrm{~T} 3$, and $\mathrm{T} 7$ for the four buttons, see Figure 3.4-5 and Figure 3.4-6. The difference between the reactivity of the reference and perturbed benchmark models yields the worth of 3 and 4, 0.3175-cm-thick aluminum buttons including the holding screws. The worth is then divided by the number of buttons, yielding two worth per aluminum button values, and the results are averaged to determine the benchmark worth per aluminum button.

For the worth of 3 mass adjustment buttons in the empty socket hole of the upper polar cap the reference benchmark model is identical to the Case 2 critical sphere detailed benchmark model of HEU-MET-FAST-100, shown for reference in Figure 3.4-1, Figure 3.4-2, and Figure 3.4-3. Three buttons were stacked in the socket hole of the upper polar cap for the perturbed benchmark model as shown in Figure 3.4-7. Three aluminum buttons, three uranium buttons, and three stainless steel buttons were placed in the socket hole. The difference between the reactivity of the reference benchmark model and the perturbed benchmark models for each button type yields the worth of the buttons in the socket hole.

The mass of the 0.635 -cm-thick $\times 1.10744$-cm-OR $\times 0.22479$-cm-IR uranium buttons was given as 43.9 $\mathrm{g}$ each. The $0.635-\mathrm{cm}$-thick uranium buttons have a density of $18.71428 \mathrm{~g} / \mathrm{cm}^{3}$ in the benchmark models.

The mass of three, 0.3175 -cm-thick $\times 1.10744-\mathrm{cm}-\mathrm{OR} \times 0.22479-\mathrm{cm}$-IR uranium buttons was given as $65.2 \mathrm{~g}$ for three buttons. The 0.3175 -cm-thick uranium buttons have a density of $18.52956 \mathrm{~g} / \mathrm{cm}^{3}$ in the benchmark models.

The aluminum Type 6061 buttons and stainless steel Type 304 holding screws and buttons are modeled at nominal compositions as given in Table 2.4-6 and Table 2.4-7. 
NEA/NSC/DOC(2006)1

Fundamental-FUND

ORSPHERE-FUND-EXP-001

CRIT-REAC-COEF-KIN-RRATE

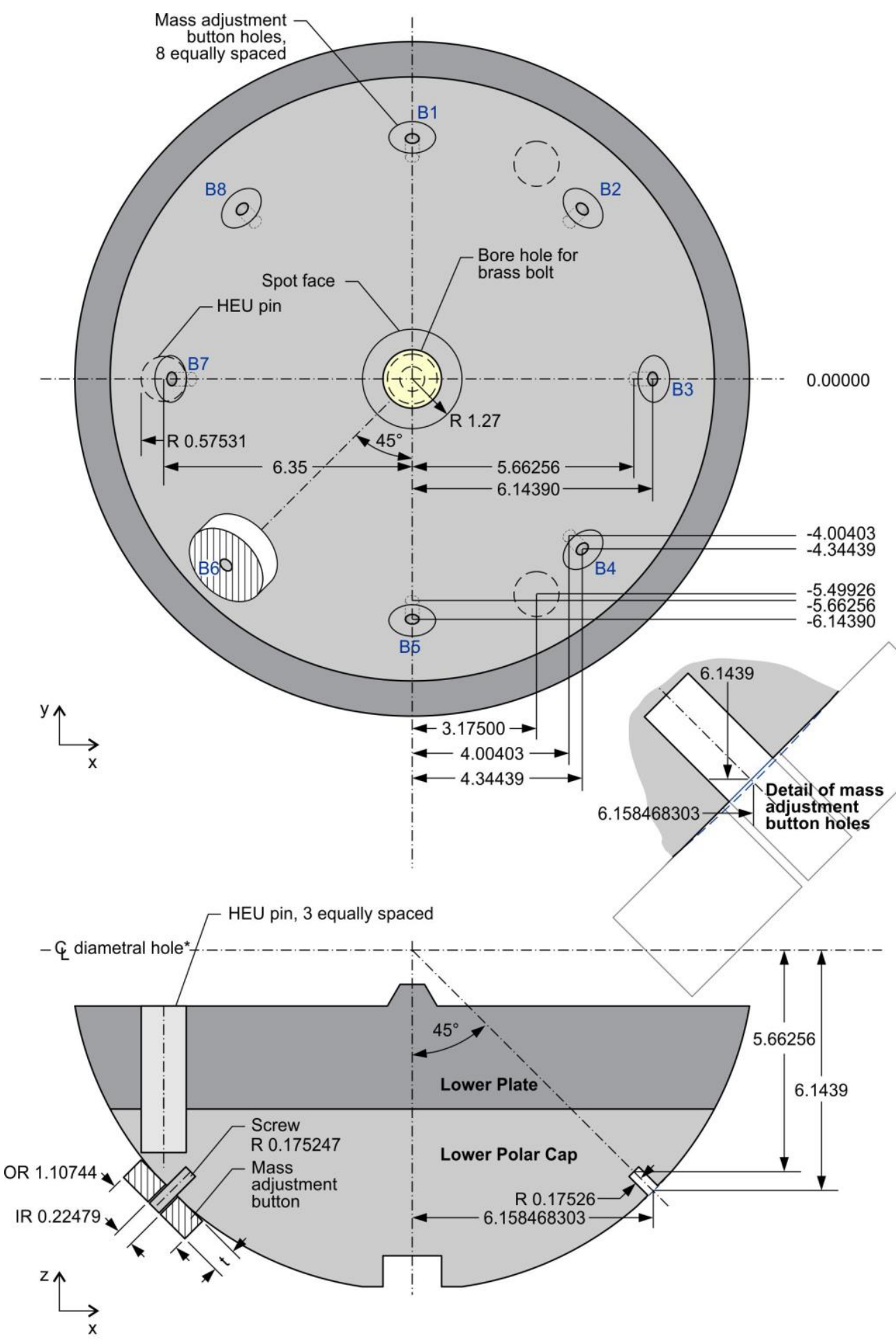

*The centerline of the diametral hole is $0.0508 \mathrm{~cm}$ below the centerline of the sphere Dimensions in $\mathrm{cm}$

Figure 3.4-5. General Button Placement on Lower Polar Cap. 
NEA/NSC/DOC(2006)1

Fundamental-FUND

ORSPHERE-FUND-EXP-001

CRIT-REAC-COEF-KIN-RRATE

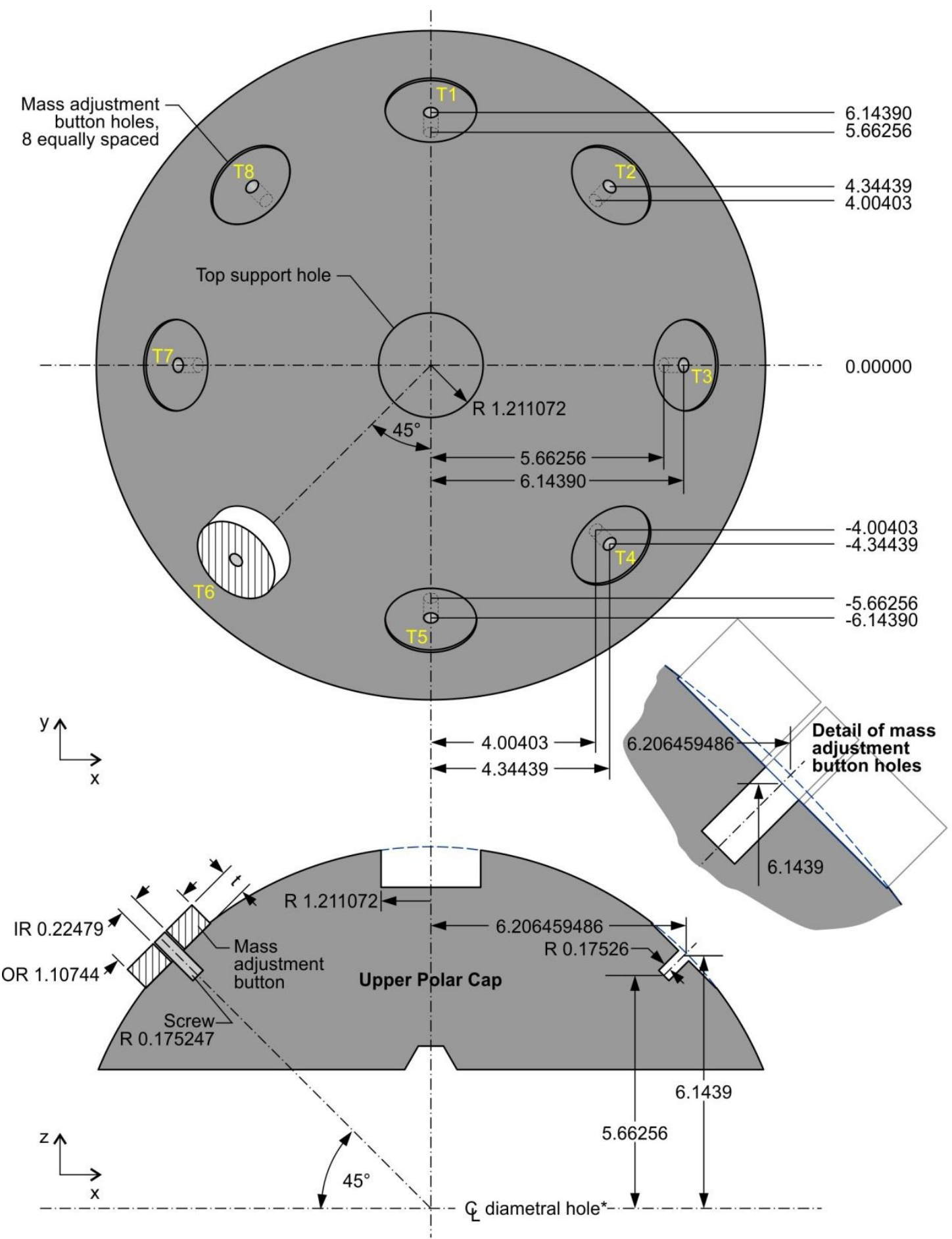

*The centerline of the diametral hole is $0.0508 \mathrm{~cm}$ below the centerline of the sphere

Dimensions in cm

Figure 3.4-6. General Button Placement on Upper Polar Cap. 


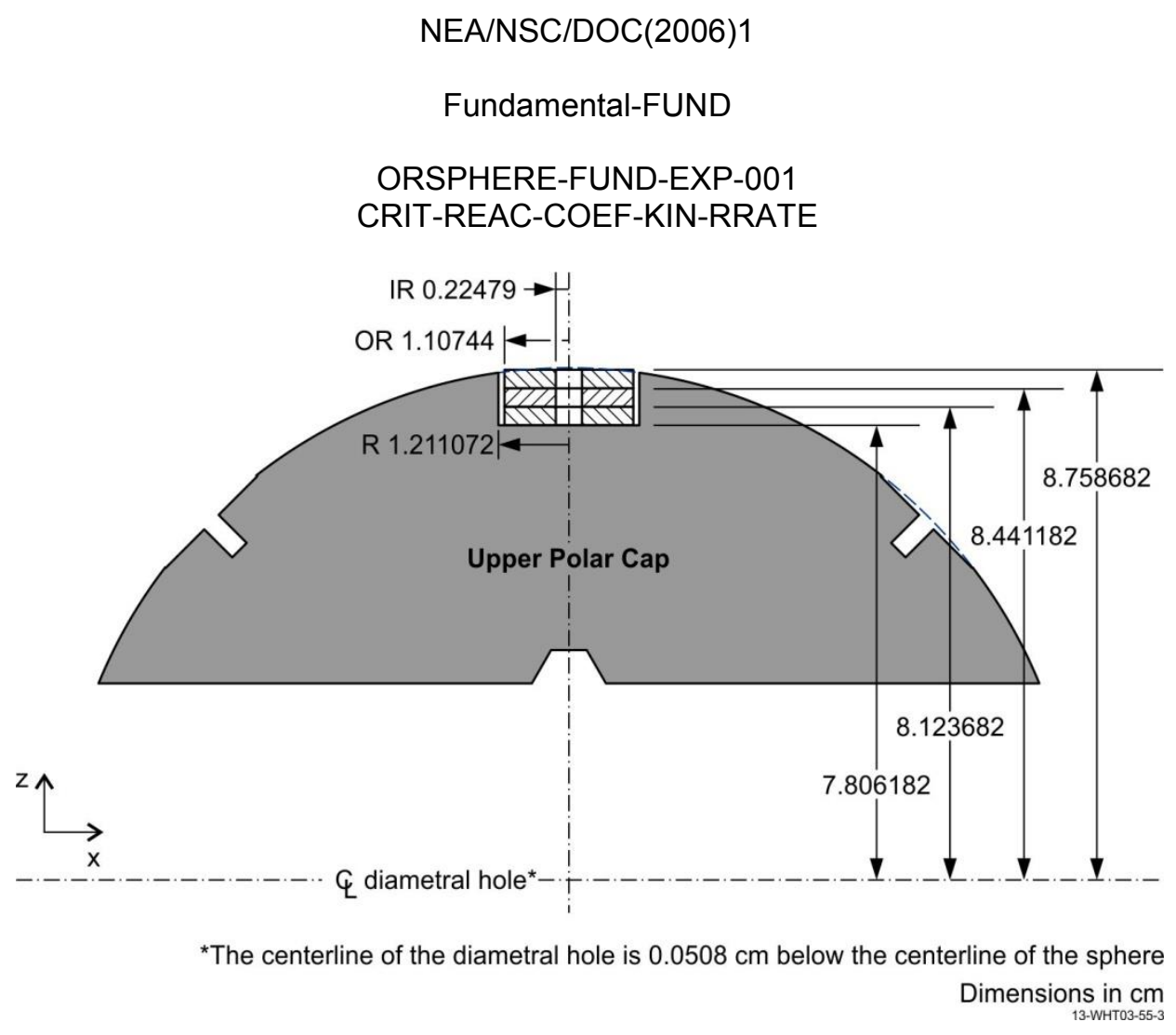

Figure 3.4-7. Button Placement in Empty Socket Hole of Upper Polar Cap.

\subsubsection{Diametral Filler Rod Worth Measurements}

The reference benchmark model was identical to the critical sphere shown in Figure 3.4-1, Figure 3.4-2, and Figure 3.4-3. For the perturbed benchmark model the diametral filler rod, whose dimensions are given in Figure 3.4-2, was removed. The difference between the base reference and perturbed benchmark models yields the worth of the diametral filler rod.

\subsubsection{Material Data}

The material data for the bottom, center, and upper section of the sphere of the Case 2 core are given in HEU-MET-FAST-100.

The material data for the central void reactivity measurement are given in Table 3.4-1.

The material data for the $0.635-\mathrm{cm}$-thick and $0.3175-\mathrm{cm}$-thick uranium buttons are given in Table 3.4-2.

The material data for the stainless steel holding screws and buttons are given in Table 3.4-3.

The material data for the aluminum buttons are given in Table 3.4-4.

The material data for the diametral filler rod is the same as for the $0.164211-\mathrm{cm}$-radius plug for the diametral hole section given in Table 3.4-1. 


\section{NEA/NSC/DOC(2006)1 \\ Fundamental-FUND \\ ORSPHERE-FUND-EXP-001 \\ CRIT-REAC-COEF-KIN-RRATE}

Table 3.4-1. Atom Densities for Plugs and Sphere for Central Void Reactivity Measurement.

\begin{tabular}{||ccccc||}
\hline \multirow{2}{*}{$\begin{array}{c}\text { Element/ } \\
\text { Isotope }\end{array}$} & $\begin{array}{c}\text { 0.63627-cm-Radius } \\
\text { Plug for Diametral } \\
\text { Hole Section and } \\
\text { Small Sphere }\end{array}$ & $\begin{array}{c}\text { 0.164211-cm-Radius } \\
\text { Plug for Diametral } \\
\text { Hole Section }\end{array}$ & $\begin{array}{c}\text { 0.48641-cm-Radius } \\
\text { Plug for Diametral } \\
\text { Hole Section }\end{array}$ & $\begin{array}{c}\text { 0.63627-cm-Radius } \\
\text { Plug for Surface } \\
\text { Hole }\end{array}$ \\
\hline \hline U Total & $4.7850 \mathrm{E}-02$ & $4.7722 \mathrm{E}-02$ & $4.7850 \mathrm{E}-02$ & $4.7850 \mathrm{E}-02$ \\
${ }^{234} \mathrm{U}$ & $4.7509 \mathrm{E}-04$ & $4.7738 \mathrm{E}-04$ & $4.7509 \mathrm{E}-04$ & $4.7509 \mathrm{E}-04$ \\
${ }^{235} \mathrm{U}$ & $4.4608 \mathrm{E}-02$ & $4.4485 \mathrm{E}-02$ & $4.4608 \mathrm{E}-02$ & $4.4608 \mathrm{E}-02$ \\
${ }^{236} \mathrm{U}$ & $2.1264 \mathrm{E}-04$ & $2.1446 \mathrm{E}-04$ & $2.1264 \mathrm{E}-04$ & $2.1264 \mathrm{E}-04$ \\
\hline${ }^{238} \mathrm{U}$ & $2.5539 \mathrm{E}-03$ & $2.5450 \mathrm{E}-03$ & $2.5539 \mathrm{E}-03$ & $2.5539 \mathrm{E}-03$ \\
\hline $\mathrm{Al}$ & $2.0866 \mathrm{E}-06$ & $2.0810 \mathrm{E}-06$ & $2.0866 \mathrm{E}-06$ & $2.0866 \mathrm{E}-06$ \\
\hline $\mathrm{Si}$ & $4.8109 \mathrm{E}-05$ & $4.7981 \mathrm{E}-05$ & $4.8109 \mathrm{E}-05$ & $4.8109 \mathrm{E}-05$ \\
\hline $\mathrm{Mn}$ & $3.7851 \mathrm{E}-06$ & $3.7751 \mathrm{E}-06$ & $3.7851 \mathrm{E}-06$ & $3.7851 \mathrm{E}-06$ \\
\hline $\mathrm{Ni}$ & $6.3270 \mathrm{E}-06$ & $6.3102 \mathrm{E}-06$ & $6.3270 \mathrm{E}-06$ & $6.3270 \mathrm{E}-06$ \\
\hline $\mathrm{Cr}$ & $4.9991 \mathrm{E}-07$ & $4.9858 \mathrm{E}-07$ & $4.9991 \mathrm{E}-07$ & $4.9991 \mathrm{E}-07$ \\
\hline $\mathrm{Cu}$ & $1.4609 \mathrm{E}-06$ & $1.4570 \mathrm{E}-06$ & $1.4609 \mathrm{E}-06$ & $1.4609 \mathrm{E}-06$ \\
\hline $\mathrm{B}$ & $3.1245 \mathrm{E}-07$ & $3.1162 \mathrm{E}-07$ & $3.1245 \mathrm{E}-07$ & $3.1245 \mathrm{E}-07$ \\
\hline $\mathrm{C}$ & $1.5749 \mathrm{E}-04$ & $1.5707 \mathrm{E}-04$ & $1.5749 \mathrm{E}-04$ & $1.5749 \mathrm{E}-04$ \\
\hline $\mathrm{O}$ & $1.4075 \mathrm{E}-05$ & $1.4038 \mathrm{E}-05$ & $1.4075 \mathrm{E}-05$ & $1.4075 \mathrm{E}-05$ \\
\hline $\mathrm{N}$ & $2.4117 \mathrm{E}-05$ & $2.4052 \mathrm{E}-05$ & $2.4117 \mathrm{E}-05$ & $2.4117 \mathrm{E}-05$ \\
\hline $\mathrm{Total}$ & $4.8108 \mathrm{E}-02$ & $4.7980 \mathrm{E}-02$ & $4.8108 \mathrm{E}-02$ & $4.8108 \mathrm{E}-02$ \\
\hline
\end{tabular}




\section{NEA/NSC/DOC(2006)1 \\ Fundamental-FUND \\ ORSPHERE-FUND-EXP-001 \\ CRIT-REAC-COEF-KIN-RRATE}

Table 3.4-2. Atom Densities for Uranium Buttons.

\begin{tabular}{|ccc|}
\hline & \multicolumn{2}{c|}{ Atom Density (atom/b-cm) } \\
\cline { 2 - 3 } $\begin{array}{c}\text { Element/ } \\
\text { Isotope }\end{array}$ & $\begin{array}{c}0.635-\mathrm{cm}-\text { Thick } \\
\text { Uranium Buttons }\end{array}$ & $\begin{array}{c}0.3175 \text {-cm-Thick } \\
\text { Uranium Buttons }\end{array}$ \\
\hline \hline U Total & $4.7885 \mathrm{E}-02$ & $4.7412 \mathrm{E}-02$ \\
${ }^{234} U$ & $4.7382 E-04$ & $4.6914 E-04$ \\
\hline${ }^{235} U$ & $4.4674 E-02$ & $4.4233 E-02$ \\
${ }^{236} U$ & $1.7149 E-05$ & $1.6979 E-05$ \\
\hline${ }^{238} U$ & $2.7202 E-03$ & $2.6934 E-03$ \\
\hline $\mathrm{Be}$ & $6.2518 \mathrm{E}-09$ & $6.1901 \mathrm{E}-09$ \\
\hline $\mathrm{Li}$ & $1.6235 \mathrm{E}-07$ & $1.6074 \mathrm{E}-07$ \\
\hline $\mathrm{Al}$ & $8.3527 \mathrm{E}-07$ & $8.2703 \mathrm{E}-07$ \\
\hline $\mathrm{Si}$ & $8.0244 \mathrm{E}-05$ & $7.9452 \mathrm{E}-05$ \\
\hline $\mathrm{Mn}$ & $4.1546 \mathrm{E}-06$ & $4.1136 \mathrm{E}-06$ \\
\hline $\mathrm{Ni}$ & $6.9447 \mathrm{E}-06$ & $6.8761 \mathrm{E}-06$ \\
\hline $\mathrm{Cr}$ & $5.4871 \mathrm{E}-07$ & $5.4329 \mathrm{E}-07$ \\
\hline $\mathrm{Cu}$ & $1.6035 \mathrm{E}-06$ & $1.5877 \mathrm{E}-06$ \\
\hline $\mathrm{B}$ & $2.0846 \mathrm{E}-07$ & $2.0640 \mathrm{E}-07$ \\
\hline $\mathrm{C}$ & $9.5604 \mathrm{E}-08$ & $9.4660 \mathrm{E}-08$ \\
\hline $\mathrm{O}$ & $1.4058 \mathrm{E}-06$ & $1.3919 \mathrm{E}-06$ \\
\hline $\mathrm{N}$ & $2.8708 \mathrm{E}-04$ & $2.8425 \mathrm{E}-04$ \\
\hline $\mathrm{Total}$ & $1.4086 \mathrm{E}-05$ & $1.3947 \mathrm{E}-05$ \\
\hline
\end{tabular}

Table 3.4-3. Atom Densities for Stainless Steel Screws and Buttons.

\begin{tabular}{|cc||}
\hline & Atom Density $($ atom $/ \mathrm{b}-\mathrm{cm})$ \\
\cline { 2 - 2 } Element & Stainless Steel Type 304 \\
\hline \hline $\mathrm{Fe}$ & $6.0319 \mathrm{E}-02$ \\
$\mathrm{C}$ & $1.6044 \mathrm{E}-04$ \\
\hline $\mathrm{Mn}$ & $8.7693 \mathrm{E}-04$ \\
\hline $\mathrm{Si}$ & $8.5768 \mathrm{E}-04$ \\
\hline $\mathrm{Cr}$ & $1.7604 \mathrm{E}-02$ \\
\hline $\mathrm{Ni}$ & $7.7983 \mathrm{E}-03$ \\
\hline $\mathrm{P}$ & $3.4997 \mathrm{E}-05$ \\
\hline $\mathrm{S}$ & $2.2534 \mathrm{E}-05$ \\
\hline Total & $8.7674 \mathrm{E}-02$ \\
\hline
\end{tabular}




\section{NEA/NSC/DOC(2006)1 \\ Fundamental-FUND \\ ORSPHERE-FUND-EXP-001 \\ CRIT-REAC-COEF-KIN-RRATE}

Table 3.4-4. Atom Densities for Aluminum Buttons.

\begin{tabular}{|cc||}
\hline & Atom Density (atom/b-cm) \\
\cline { 2 - 2 } Element & Aluminum Type 6061 \\
\hline \hline $\mathrm{Al}$ & $5.8638 \mathrm{E}-02$ \\
\hline $\mathrm{Cr}$ & $6.0978 \mathrm{E}-05$ \\
\hline $\mathrm{Cu}$ & $7.0365 \mathrm{E}-05$ \\
\hline $\mathrm{Fe}$ & $1.0190 \mathrm{E}-04$ \\
\hline $\mathrm{Mg}$ & $6.6898 \mathrm{E}-04$ \\
\hline $\mathrm{Mn}$ & $2.2197 \mathrm{E}-05$ \\
$\mathrm{Si}$ & $3.4736 \mathrm{E}-04$ \\
\hline $\mathrm{Ti}$ & $2.5469 \mathrm{E}-05$ \\
\hline $\mathrm{Zn}$ & $3.1082 \mathrm{E}-05$ \\
\hline Total & $5.9967 \mathrm{E}-02$ \\
\hline \hline
\end{tabular}

\subsubsection{Temperature Data}

The benchmark models for the worth measurements are evaluated at room temperature (294 K).

\subsubsection{Experimental and Benchmark-Model Reactivity Effect Parameters}

The various worth measurements with uncertainties, as derived in Section 2.4, are summarized in Table 3.4-5.

Table 3.4-5. Benchmark Worth Values.

\begin{tabular}{|c|c|c|c|}
\hline & \multicolumn{3}{|c|}{ Worth $(\varnothing)$} \\
\hline Central Void & 9.165 & \pm & 0.123 \\
\hline $\begin{array}{l}16,0.635-\mathrm{cm} \text {-thick Uranium } \\
\text { Buttons on Sphere Surface }\end{array}$ & 35.4 & \pm & 2.868 \\
\hline $\begin{array}{l}\text { 4, } 0.3175-\mathrm{cm} \text {-thick Uranium } \\
\text { Buttons on Sphere Surface }\end{array}$ & 6.1415 & \pm & 0.117 \\
\hline $\begin{array}{l}1,0.3175 \text {-cm-thick Aluminum } \\
\text { Button on Sphere Surface }\end{array}$ & 0.7058 & + & 0.062 \\
\hline $\begin{array}{l}\text { 3, } 0.3175 \text {-cm-thick Uranium } \\
\text { Buttons in Socket Hole }\end{array}$ & 7.86 & - & 0.127 \\
\hline $\begin{array}{l}\text { 3, 0.3175-cm-thick Stainless Steel } \\
\text { Buttons in Socket Hole }\end{array}$ & 4.7228 & \pm & 0.076 \\
\hline $\begin{array}{l}\text { 3, } 0.3175 \text {-cm-thick Aluminum } \\
\text { Buttons in Socket Hole }\end{array}$ & 3.1259 & \pm & 0.074 \\
\hline Diametral Filler Rod & 11.2340 & \pm & 0.168 \\
\hline
\end{tabular}




\subsection{Benchmark-Model Specifications for Reactivity Coefficient Measurements}

\subsubsection{Description of the Benchmark-Model Simplifications}

There are two benchmark models for the worth per gram of uranium on the surface of the sphere. The first was based on the Case 1 detailed benchmark model in HEU-MET-FAST-100; the tilt between the lower and center plates was removed. This was done by moving the small volume of pin protruding above the upper surface of the lower plate into the remaining volume of the pin. This slightly increased the density of the pin. The tilt was then removed so the center plate sat flush on the lower plate. The second benchmark model was identical to the Case 2 detailed benchmark model in HEU-MET-FAST-100. Detailed models of the spheres were created with MCNP5 with ENDF/B-VII.0 neutron cross section libraries. Various simplifications were made to the two spheres to create detailed benchmark models from the as-built models. These simplifications are described in detail in HEU-MET-FAST-100. Because the two spheres are nearly identical, the benchmark-model simplifications are highly correlated and the effect of the system simplifications on the change in system reactivity is negligible.

\subsubsection{Dimensions}

The dimensions for the two critical spheres are given as Case 1 for the 8.80491-cm-average-radius sphere and as Case 2 for the 8. 74268-cm-average-radius sphere in HEU-MET-FAST-100. The 8.80491-cmaverage-radius sphere is modified so the pin no longer protrudes above the upper surface of the lower plate but is flush with it and the tilt is removed. This is done by moving the $6.0746 \times 10^{-3} \mathrm{~cm}^{3}$ volume above the surface of the plate into the $3.89776 \mathrm{~cm}^{3}$ below the surface of the sphere. This increases the density from $18.8013 \mathrm{~g} / \mathrm{cm}^{3}$ to $18.8306 \mathrm{~g} / \mathrm{cm}^{3}$. Only one pin is affected; all other pins and surrounding material do not change. No change is made to the 8.74268 -cm-average-radius sphere.

There is a change in mass of 1,125.04 grams between the two spheres.

\subsubsection{Material Data}

The materials for the two critical spheres, except for the pin in the lower section that is shaved to remove the tilt, are given as Case 1 for the 8.80491-cm-average-radius sphere and as Case 2 for the $8.74268-\mathrm{cm}-$ average-radius sphere in HEU-MET-FAST-100. The pin that protrudes above the surface of the lower plate has an increased density and the material data are given in Table 3.5-1. 
NEA/NSC/DOC(2006)1

Fundamental-FUND

ORSPHERE-FUND-EXP-001

CRIT-REAC-COEF-KIN-RRATE

Table 3.5-1. Material Data for Shaved Pin for

8.80491-cm-Average-Radius Sphere.

\begin{tabular}{|c|c|}
\hline & Atom Density (atom/b-cm) \\
\hline $\begin{array}{l}\text { Element/ } \\
\text { Isotope }\end{array}$ & Shaved Pin $(x=-6.35, y=0)$ \\
\hline U Total & 4.8195E-02 \\
\hline${ }^{234} U$ & $4.8211 E-04$ \\
\hline${ }^{235} \mathrm{U}$ & $4.4926 E-02$ \\
\hline${ }^{236} U$ & $2.1658 E-04$ \\
\hline${ }^{238} U$ & $2.5702 E-03$ \\
\hline $\mathrm{Be}$ & - \\
\hline $\mathrm{Li}$ & - \\
\hline $\mathrm{Al}$ & $2.1016 \mathrm{E}-06$ \\
\hline $\mathrm{Si}$ & 4.8457E-05 \\
\hline $\mathrm{Mn}$ & $3.8124 \mathrm{E}-06$ \\
\hline $\mathrm{Ni}$ & $6.3727 \mathrm{E}-06$ \\
\hline $\mathrm{Cr}$ & $5.0352 \mathrm{E}-07$ \\
\hline $\mathrm{Cu}$ & $1.4714 \mathrm{E}-06$ \\
\hline B & $3.1471 \mathrm{E}-07$ \\
\hline Co & - \\
\hline $\mathrm{Ca}$ & - \\
\hline $\mathrm{C}$ & $1.5863 \mathrm{E}-04$ \\
\hline $\mathrm{O}$ & $1.4177 \mathrm{E}-05$ \\
\hline $\mathrm{N}$ & 2.4291E-05 \\
\hline Total & $4.8455 \mathrm{E}-02$ \\
\hline
\end{tabular}

\subsubsection{Temperature Data}

The benchmark models for the two spheres are evaluated at room temperature (294 K).

\subsubsection{Experimental and Benchmark-Model Reactivity Coefficient Measurements}

The benchmark worth per gram of uranium surface material is $0.086 \pm 0.003 \not$.

\subsection{Benchmark-Model Specifications for Kinetics Measurements}

\subsubsection{Description of the Benchmark Model Simplifications}

\subsubsection{Effective Delayed Neutron Fraction}

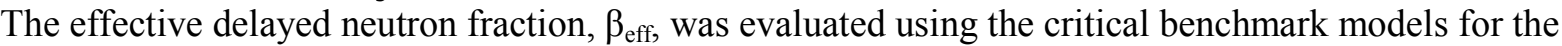
two spheres described in HEU-MET-FAST-100. The effect on the $\beta_{\text {eff }}$ value of the simplifications made to the as-built model to get the detailed benchmark models for the critical sphere was evaluated using MCNP5 and ENDF/B-VII.0 neutron cross section libraries and was found to be negligible. 
NEA/NSC/DOC(2006)1

Fundamental-FUND

ORSPHERE-FUND-EXP-001

CRIT-REAC-COEF-KIN-RRATE

\subsubsection{Prompt Neutron Decay Constant}

The prompt neutron decay constant, $\alpha$, was measured using the smaller, Case 2, sphere from HEU-MET-FAST-100, but with a variable number of uranium buttons to bring the system to delayed critical. The system reactivity for the numerous measurements varied between $\pm 0.5 \phi$. The reactivity for the prompt neutron decay constant benchmark value must also be at exactly delayed critical. Because no single system configuration was given for exactly delayed critical the simple critical benchmark model for Case 2 of HEU-MET-FAST-100 was corrected to delayed critical. The model was corrected using the worth per gram of surface material worth coefficient, see Section 3.5.5.

The simple benchmark model of the Case 2 critical assembly of HEU-MET-FAST-100 had a radius of $8.72995881 \mathrm{~cm}$ and mass of $52,350.943 \mathrm{~g}$ which corresponds to a volume of $2,786.924436 \mathrm{~cm}^{3}$ and density of $18.78448598 \mathrm{~g} / \mathrm{cm}^{3}$. . The worth per gram of surface material was $0.086 \pm 0.003 \phi / \mathrm{g}$; which converts to $5.65 \pm 0.21 \times 10^{-6} \Delta \mathrm{k}_{\text {eff }} / \mathrm{g}$. The benchmark $\mathrm{k}_{\text {eff }}$ of the simple benchmark model is $0.9966 \pm$ 0.0007 . Because the reactivity measurement uncertainty of $2.0 \notin$ was included in the sphere and the worth per gram of surface material uncertainties, the uncertainty in the sphere was reduced from 0.0007 to 0.00069 so as to not double count the reactivity measurement uncertainty. This uncertainty includes all material, dimensional and bias uncertainty in the sphere model. In order to bring the system to exactly delayed critical $603.8015 \pm 125.526$ grams of material must be added to the sphere. This mass is added by increasing the sphere volume, i.e. radius, and maintaining constant density. The volume is increased by $32.1436 \pm 6.7953 \mathrm{~cm}^{3}$ and a final radius of $8.76339 \pm 0.00692 \mathrm{~cm}$. If $\alpha$ is calculated using the benchmark model with the sphere radius perturbed by $\pm 0.00692 \mathrm{~cm}$ the change in $\alpha$ is $\pm 0.1068 \mu \mathrm{sec}^{-1}$. This is taken to be the bias uncertainty. When added with the experimental uncertainty of $\pm 0.0079 \mu \mathrm{sec}^{-1}$ the benchmark uncertainty is $\pm 0.1071 \mu \mathrm{sec}^{-1}$.

\subsubsection{Mean Neutron Generation Time}

The benchmark model for the mean neutron generation time or prompt neutron lifetime, since the system was at delayed critical, was identical to the benchmark model for the prompt neutron decay constant. When the bias uncertainty in the sphere radius discussed in Section 3.6.1.2 is taken into account the uncertainty in $\Lambda$ is increased from \pm 0.15 nanosec for the experimental uncertainty to \pm 0.59 nanosec for the benchmark uncertainty.

\subsubsection{Dimensions}

\subsubsection{Effective Delayed Neutron Fraction}

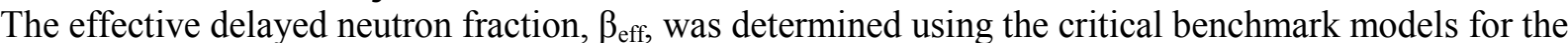
two spheres. The dimensions are described in HEU-MET-FAST-100.

\subsubsection{Prompt Neutron Decay Constant}

The benchmark model for the prompt neutron decay constant was similar to the simple benchmark model of the $8.74268-\mathrm{cm}$-core but was corrected to delayed critical. The benchmark model was a solid, homogenous sphere of radius $8.76328034 \mathrm{~cm}$.

\subsubsection{Mean Neutron Generation Time}

The benchmark model for the mean neutron generation time was identical to the prompt neutron decay constant benchmark model (Section 3.6.2.2).

\subsubsection{Material Data}

\subsubsection{Effective Delayed Neutron Fraction}

The effective delayed neutron fraction, $\beta_{\text {eff, }}$ was determined using the critical benchmark models for the two spheres. The material data for the spheres are given in HEU-MET-FAST-100.

\footnotetext{
${ }^{a}$ It should be noted that a high number of decimals are reported here for the purpose of calculation reproducibility. For calculations no rounding was performed until the end of the calculation.
} 


\section{NEA/NSC/DOC(2006)1 \\ Fundamental-FUND \\ ORSPHERE-FUND-EXP-001 \\ CRIT-REAC-COEF-KIN-RRATE}

\subsubsection{Prompt Neutron Decay Constant}

The atom densities of the sphere were identical to those for the Case 2 simple benchmark model of HEU-MET-FAST-100. The atom densities are given in Table 3.6-1.

Table 3.6-1.Uranium Atom Densities. ${ }^{(a)}$

\begin{tabular}{|c|c|}
\hline $\begin{array}{l}\text { Element/ } \\
\text { Isotope }\end{array}$ & $\begin{array}{l}\text { Atom Density } \\
\text { (atom/b-cm) }\end{array}$ \\
\hline U Total & $4.8075 \mathrm{E}-02$ \\
\hline${ }^{234} U$ & $4.7568 E-04$ \\
\hline${ }^{235} U$ & $4.4838 E-02$ \\
\hline${ }^{236} U$ & $2.1938 E-05$ \\
\hline${ }^{238} U$ & $2.7390 E-03$ \\
\hline $\mathrm{Si}$ & $4.9746 \mathrm{E}-05$ \\
\hline B & $3.4357 \mathrm{E}-07$ \\
\hline $\mathrm{C}$ & $1.5920 \mathrm{E}-04$ \\
\hline Total & $4.8284 \mathrm{E}-02$ \\
\hline
\end{tabular}

(a) When impurities were removed they were replaced with void.

\subsubsection{Mean Neutron Generation Time}

The atom densities of the sphere were identical to those for the prompt neutron decay constant. The atom densities are given in Table 3.6-1.

\subsubsection{Temperature Data}

The benchmark models temperature for effective delayed neutron fraction, prompt neutron decay constant, and mean neutron generation time are all room temperature (294 K).

\subsubsection{Experimental and Benchmark-Model Kinetics Measurements}

\subsubsection{Effective Delayed Neutron Fraction}

The benchmark value for the effective delayed neutron fraction, $\beta_{\text {eff }}$ of the core with central void is $0.00657 \pm 0.00009$.

\subsubsection{Prompt Neutron Decay Constant}

The benchmark value for the prompt neutron decay constant, $\alpha$, is $1.1061 \pm 0.1071 \mu \mathrm{sec}^{-1}$.

\subsubsection{Mean Neutron Generation Time}

The benchmark value for the mean neutron generation time, $\Lambda$, is $5.94 \pm 0.59$ nanosec. Because the system is at delayed critical the prompt neutron lifetime, $l$, is equal to $\Lambda$. 


\subsection{Benchmark-Model Specifications for Reaction-Rate Distribution Measurements}

\subsubsection{Description of the Benchmark Model Simplifications}

\subsubsection{Relative Neutron Importance}

Simplification biases were evaluated using the critical benchmark models for 8.74268 -cm-average-radius sphere in HEU-MET-FAST-100 (Case 2). The source was a solid ${ }^{252} \mathrm{Cf}$ source, within a $0.315-\mathrm{cm}-$ diameter $\times 0.961-\mathrm{cm}-$ long welded stainless-steel cylinder, passed through the diametral hole of the sphere. The source material was not modeled explicitly but rather modeled as an isotropic point source. The counters were three $\mathrm{BF}_{3}$ counters located at $(0,-295,-249.5) ;(295,0,-249.5)$; and $(0,-295,-249.5)$. Results from the three detectors were averaged. There was not sufficient information to explicitly model the $\mathrm{BF}_{3}$ counters; therefore the relative count rates were taken to be representative of the relative neutron importance for $\mathrm{BF}_{3}$ detector response and a $\mathrm{Cf}$ source. The relative neutron importance for $\mathrm{BF}_{3}$ response and a $\mathrm{Cf}$ source is the relative response of detectors to a change in neutron flux, normalized to the flux when the $\mathrm{Cf}$ source is at the center of the sphere, where the $\mathrm{BF}_{3}$ detectors are using a $(n, \alpha)$ reaction. The simplification bias for the relative neutron importance was calculated for the identical simplifications as were done for the critical benchmark models (HEU-MET-FAST-100, Section 3.1.1 and 3.1.2).

Additionally, the detailed benchmark model was modeled in MCNP6 with different spectra and it was found that the effect of changing the source was negligible. A bias in the relative neutron importance for $\mathrm{BF}_{3}$ detector response and a $\mathrm{Cf}$ source is considered negligible if it is less than the statistical uncertainty of the Monte Carlo calculation. For biases that are negligible, the bias uncertainty is preserved; as can be seen in Table 3.7-1. The biases in the detailed and simple benchmark models for the relative neutron importance for $\mathrm{BF}_{3}$ detector response and a Cf source are given in Table 3.7-1.

Table 3.7-1. Simplification Bias of the Relative Neutron Importance for $\mathrm{BF}_{3}$ Detector Response and a Cf Source.

\begin{tabular}{|c|c|r||}
\hline Radius & $\begin{array}{c}\text { Detailed Benchmark } \\
\text { Model Simplification } \\
\text { Bias }\end{array}$ & $\begin{array}{c}\text { Simple Benchmark } \\
\text { Model Simplification } \\
\text { Bias }\end{array}$ \\
\hline-8.138 & NEG \pm 0.0027 & NEG \pm 0.0027 \\
-8.105 & NEG \pm 0.0027 & NEG \pm 0.0028 \\
-8.100 & $0.003 \pm 0.0027$ & NEG \pm 0.0027 \\
-8.004 & NEG \pm 0.0027 & NEG \pm 0.0027 \\
-7.480 & $0.008 \pm 0.0032$ & $0.0067 \pm 0.0032$ \\
-6.833 & NEG \pm 0.0038 & NEG \pm 0.0038 \\
-6.825 & NEG \pm 0.0040 & NEG \pm 0.0040 \\
-6.759 & NEG \pm 0.0039 & NEG \pm 0.0039 \\
\hline-6.731 & $0.010 \pm 0.0039$ & $0.0086 \pm 0.0039$ \\
\hline-5.730 & NEG \pm 0.0047 & NEG \pm 0.0047 \\
\hline-5.583 & $0.013 \pm 0.0047$ & $0.0082 \pm 0.0047$ \\
-5.484 & $0.012 \pm 0.0049$ & NEG \pm 0.0049 \\
-5.428 & NEG \pm 0.0050 & NEG \pm 0.0050 \\
\hline-4.392 & $0.006 \pm 0.0057$ & NEG \pm 0.0057 \\
\hline-4.288 & $0.007 \pm 0.0057$ & NEG \pm 0.0057 \\
\hline-4.221 & NEG \pm 0.0059 & NEG \pm 0.0059 \\
\hline-4.166 & NEG \pm 0.0058 & NEG \pm 0.0058 \\
-3.208 & $0.017 \pm 0.0063$ & $0.0118 \pm 0.0063$ \\
-3.170 & $0.027 \pm 0.0064$ & $0.0147 \pm 0.0063$ \\
\hline
\end{tabular}


NEA/NSC/DOC(2006)1

Fundamental-FUND

ORSPHERE-FUND-EXP-001

CRIT-REAC-COEF-KIN-RRATE

Table 3.7-1 (cont'd). Simplification Bias of the Relative Neutron Importance for $\mathrm{BF}_{3}$ Detector Response and a Cf Source.

\begin{tabular}{|c|c|c|}
\hline Radius & $\begin{array}{c}\text { Detailed Benchmark } \\
\text { Model Simplification } \\
\text { Bias } \\
\end{array}$ & $\begin{array}{c}\text { Simple Benchmark } \\
\text { Model Simplification } \\
\text { Bias } \\
\end{array}$ \\
\hline-3.012 & $0.016 \pm 0.0063$ & $0.0075 \pm 0.0063$ \\
\hline-2.891 & $0.016 \pm 0.0065$ & $0.0094 \pm 0.0065$ \\
\hline-1.900 & $\mathrm{NEG} \pm 0.0070$ & $\mathrm{NEG} \pm 0.0070$ \\
\hline-1.740 & $0.023 \pm 0.0070$ & $0.0117 \pm 0.0069$ \\
\hline-1.618 & $0.009 \pm 0.0071$ & $\mathrm{NEG} \pm 0.0071$ \\
\hline-0.632 & $0.022 \pm 0.0072$ & $0.0123 \pm 0.0072$ \\
\hline-0.470 & $0.011 \pm 0.0073$ & $\mathrm{NEG} \pm 0.0073$ \\
\hline 0 & $\mathrm{NEG}^{(\mathrm{a})}$ & $\mathrm{NEG}^{(\mathrm{a})}$ \\
\hline 0.660 & $0.018 \pm 0.0073$ & $0.0169 \pm 0.0073$ \\
\hline 0.805 & $\mathrm{NEG} \pm 0.0074$ & $\mathrm{NEG} \pm 0.0074$ \\
\hline 0.904 & $0.018 \pm 0.0072$ & $0.0117 \pm 0.0072$ \\
\hline 1.905 & $0.023 \pm 0.0071$ & $0.0228 \pm 0.0071$ \\
\hline 2.024 & $0.031 \pm 0.0071$ & $0.0193 \pm 0.0071$ \\
\hline 2.078 & $0.012 \pm 0.0072$ & $\mathrm{NEG} \pm 0.0072$ \\
\hline 3.175 & $0.008 \pm 0.0068$ & $\mathrm{NEG} \pm 0.0068$ \\
\hline 3.449 & $0.017 \pm 0.0066$ & $0.0115 \pm 0.0066$ \\
\hline 4.445 & $0.018 \pm 0.0062$ & $0.0149 \pm 0.0061$ \\
\hline 4.646 & $0.018 \pm 0.0061$ & $\mathrm{NEG} \pm 0.0061$ \\
\hline 4.722 & $0.014 \pm 0.0060$ & $0.0125 \pm 0.0060$ \\
\hline 5.712 & $0.016 \pm 0.0054$ & $0.0160 \pm 0.0054$ \\
\hline 5.895 & $0.007 \pm 0.0054$ & $\mathrm{NEG} \pm 0.0053$ \\
\hline 5.994 & $0.011 \pm 0.0052$ & $\mathrm{NEG} \pm 0.0052$ \\
\hline 7.216 & $\mathrm{NEG} \pm 0.0043$ & $\mathrm{NEG} \pm 0.0043$ \\
\hline 7.419 & $0.017 \pm 0.0041$ & $0.0084 \pm 0.0041$ \\
\hline 7.650 & $0.007 \pm 0.0040$ & $\mathrm{NEG} \pm 0.0040$ \\
\hline 8.273 & $0.005 \pm 0.0035$ & $0.0065 \pm 0.0035$ \\
\hline 8.400 & $0.012 \pm 0.0033$ & $0.0099 \pm 0.0033$ \\
\hline 8.443 & $0.004 \pm 0.0034$ & $0.0059 \pm 0.0034$ \\
\hline 8.590 & $\mathrm{NEG} \pm 0.0033$ & $\mathrm{NEG} \pm 0.0033$ \\
\hline 8.618 & $0.015 \pm 0.0031$ & $0.0116 \pm 0.0031$ \\
\hline 8.745 & $0.004 \pm 0.0031$ & $\mathrm{NEG} \pm 0.0031$ \\
\hline 9.091 & $0.005 \pm 0.0026$ & $\mathrm{NEG} \pm 0.0026$ \\
\hline
\end{tabular}

(a) There is no bias or uncertainty associated with the normalization point of the trend.

\subsubsection{Relative Fission Density}

Simplification biases for the relative fission density were evaluated using the critical benchmark models for 8.74268-cm-average-radius sphere in HEU-MET-FAST-100 (Case 2). The fission density was measured through the diametral hole of the sphere. The uranium activation cylinders were not modeled explicitly but rather the neutron flux through the center of the sphere was calculated. The simplification 


\section{NEA/NSC/DOC(2006)1 \\ Fundamental-FUND \\ ORSPHERE-FUND-EXP-001 \\ CRIT-REAC-COEF-KIN-RRATE}

bias for the relative fission density was calculated for the identical simplifications as were done for the critical benchmark models (HEU-MET-FAST-100, Section 3.1.1 and 3.1.2). A bias in the relative fission density is considered negligible if it is less than the statistical uncertainty of the Monte Carlo calculation. For biases that are negligible, the bias uncertainty is preserved; as can be seen in Table 3.7-2. The biases in the detailed and simple benchmark models for the relative fission density are given in Table 3.7-2.

Table 3.7-2. Simplification Bias of the Relative Radial Fission Density Uncertainty.

\begin{tabular}{|c|c|c|}
\hline Radius $^{(a)}$ & $\begin{array}{c}\text { Detailed Benchmark } \\
\text { Model Simplification } \\
\text { Bias } \\
\end{array}$ & $\begin{array}{c}\text { Simple Benchmark } \\
\text { Model Simplification } \\
\text { Bias } \\
\end{array}$ \\
\hline-8.265 & NEG \pm 0.0000 & $-0.001 \pm 0.0000$ \\
\hline-7.633 & $\mathrm{NEG} \pm 0.0001$ & $-0.001 \pm 0.0001$ \\
\hline-6.995 & $\mathrm{NEG} \pm 0.0001$ & $-0.002 \pm 0.0001$ \\
\hline-6.355 & NEG \pm 0.0001 & $\mathrm{NEG} \pm 0.0001$ \\
\hline-5.725 & $\mathrm{NEG} \pm 0.0001$ & $\mathrm{NEG} \pm 0.0001$ \\
\hline-5.088 & $\mathrm{NEG} \pm 0.0001$ & NEG \pm 0.0001 \\
\hline-4.450 & $\mathrm{NEG} \pm 0.0001$ & $\mathrm{NEG} \pm 0.0001$ \\
\hline-3.815 & $\mathrm{NEG} \pm 0.0001$ & $\mathrm{NEG} \pm 0.0001$ \\
\hline-3.180 & $\mathrm{NEG} \pm 0.0001$ & $\mathrm{NEG} \pm 0.0001$ \\
\hline-2.54 & $\mathrm{NEG} \pm 0.0001$ & $\mathrm{NEG} \pm 0.0001$ \\
\hline-1.908 & $\mathrm{NEG} \pm 0.0001$ & $\mathrm{NEG} \pm 0.0001$ \\
\hline-1.272 & $\mathrm{NEG} \pm 0.0001$ & $\mathrm{NEG} \pm 0.0001$ \\
\hline-0.635 & $\mathrm{NEG} \pm 0.0001$ & $\mathrm{NEG} \pm 0.0001$ \\
\hline 0 & $\mathrm{NEG}^{(\mathrm{a})}$ & $\mathrm{NEG}^{(\mathrm{a})}$ \\
\hline 0.635 & $\mathrm{NEG} \pm 0.0001$ & $\mathrm{NEG} \pm 0.0001$ \\
\hline 1.272 & $\mathrm{NEG} \pm 0.0001$ & NEG \pm 0.0001 \\
\hline 1.908 & $\mathrm{NEG} \pm 0.0001$ & $\mathrm{NEG} \pm 0.0001$ \\
\hline 2.543 & $\mathrm{NEG} \pm 0.0001$ & $\mathrm{NEG} \pm 0.0001$ \\
\hline 3.180 & $\mathrm{NEG} \pm 0.0001$ & $\mathrm{NEG} \pm 0.0001$ \\
\hline 3.815 & $\mathrm{NEG} \pm 0.0001$ & $\mathrm{NEG} \pm 0.0001$ \\
\hline 4.450 & $\mathrm{NEG} \pm 0.0001$ & $\mathrm{NEG} \pm 0.0001$ \\
\hline 5.088 & $\mathrm{NEG} \pm 0.0001$ & $\mathrm{NEG} \pm 0.0001$ \\
\hline 5.725 & $\mathrm{NEG} \pm 0.0001$ & $-0.001 \pm 0.0001$ \\
\hline 6.355 & $\mathrm{NEG} \pm 0.0001$ & $-0.001 \pm 0.0001$ \\
\hline 6.995 & $\mathrm{NEG} \pm 0.0001$ & $-0.001 \pm 0.0001$ \\
\hline 7.633 & $\mathrm{NEG} \pm 0.0001$ & $-0.001 \pm 0.0000$ \\
\hline 8.265 & $\mathrm{NEG} \pm 0.0000$ & $-0.002 \pm 0.0000$ \\
\hline
\end{tabular}

(a) There is no bias or uncertainty associated with the normalization point of the trend.

\subsubsection{Dimensions}

\subsubsection{Relative Neutron Importance}

The simple and detailed benchmark models are identical to the simple and detailed critical benchmark models for the 8.74268-cm-average-radius sphere in HEU-MET-FAST-100 (Case 2). The source was 


\section{NEA/NSC/DOC(2006)1 \\ Fundamental-FUND \\ ORSPHERE-FUND-EXP-001 \\ CRIT-REAC-COEF-KIN-RRATE}

modeled as a $1.4 \mathrm{MeV}$ isotropic point source with a Maxwellian distribution at the appropriate radius along the center line of the sphere; this was the diametral filler rod in the detailed benchmark model.

\subsubsection{Relative Fission Density}

The simple and detailed benchmark models are identical to the simple and detailed critical benchmark models for the 8.74268-cm-average-radius sphere in HEU-MET-FAST-100 (Case 2). The fission rate measurements are over a $0.330 \mathrm{~cm}$-diameter $\times 0.318$-cm-long volume at the appropriate radius along the center line of the sphere; this was the diametral filler rod in the detailed benchmark model.

\subsubsection{Material Data}

\subsubsection{Relative Neutron Importance}

The simple and detailed benchmark models are identical to the simple and detailed critical benchmark models for the 8.74268-cm-average-radius sphere in HEU-MET-FAST-100 (Case 2).

\subsubsection{Relative Fission Density}

The simple and detailed benchmark models are identical to the simple and detailed critical benchmark models for the 8.74268-cm-average-radius sphere in HEU-MET-FAST-100 (Case 2).

\subsubsection{Temperature Data}

The benchmark model temperature for the relative neutron importance for $\mathrm{BF}_{3}$ detector response and a Cf source and relative fission density is room temperature $(294 \mathrm{~K})$ for both the simple and detailed models.

\subsubsection{Experimental and Benchmark-Model Reaction Rate Measurements}

\subsubsection{Relative Neutron Importance}

The benchmark values for the relative neutron importance for $\mathrm{BF}_{3}$ detector response and a $\mathrm{Cf}$ source are found by applying the biases in Table 3.7-1 to the experimental results. The uncertainty in the benchmark model is found by adding, in quadrature, the uncertainty in the experimental results, discussed in Section 2.7, and the bias uncertainty given in Table 3.7-1. The benchmark results are given in Table 3.7-3 and plotted in Figure 3.7-1.

Table 3.7-3. Benchmark Relative Neutron Importance for $\mathrm{BF}_{3}$ Detector Response and a Cf Source.

\begin{tabular}{||c|c|c||}
\hline Radius & $\begin{array}{c}\text { Detailed Benchmark } \\
\text { Model Value }\end{array}$ & $\begin{array}{c}\text { Simple Benchmark } \\
\text { Model Value }\end{array}$ \\
\hline \hline-8.138 & $0.278 \pm 0.004$ & $0.278 \pm 0.004$ \\
-8.105 & $0.267 \pm 0.003$ & $0.267 \pm 0.003$ \\
-8.100 & $0.292 \pm 0.003$ & $0.289 \pm 0.003$ \\
-8.004 & $0.299 \pm 0.003$ & $0.299 \pm 0.003$ \\
-7.480 & $0.387 \pm 0.004$ & $0.386 \pm 0.004$ \\
-6.833 & $0.464 \pm 0.004$ & $0.464 \pm 0.004$ \\
-6.825 & $0.458 \pm 0.005$ & $0.458 \pm 0.005$ \\
-6.759 & $0.425 \pm 0.004$ & $0.425 \pm 0.004$ \\
-6.731 & $0.478 \pm 0.005$ & $0.477 \pm 0.005$ \\
\hline-5.730 & $0.578 \pm 0.005$ & $0.578 \pm 0.005$ \\
\hline-5.583 & $0.633 \pm 0.005$ & $0.628 \pm 0.005$ \\
\hline-5.484 & $0.636 \pm 0.005$ & $0.624 \pm 0.005$ \\
\hline
\end{tabular}


NEA/NSC/DOC(2006)1

Fundamental-FUND

ORSPHERE-FUND-EXP-001

CRIT-REAC-COEF-KIN-RRATE

Table 3.7-3 (cont'd). Benchmark Relative Neutron Importance for $\mathrm{BF}_{3}$ Detector Response and a Cf Source.

\begin{tabular}{|c|c|c|}
\hline Radius & $\begin{array}{c}\text { Detailed Benchmark } \\
\text { Model Value }\end{array}$ & $\begin{array}{c}\text { Simple Benchmark } \\
\text { Model Value }\end{array}$ \\
\hline-5.428 & $0.633 \pm 0.006$ & $0.633 \pm 0.006$ \\
\hline-4.392 & $0.735 \pm 0.006$ & $0.729 \pm 0.006$ \\
\hline-4.288 & $0.766 \pm 0.006$ & $0.759 \pm 0.006$ \\
\hline-4.221 & $0.770 \pm 0.006$ & $0.770 \pm 0.006$ \\
\hline-4.166 & $0.761 \pm 0.006$ & $0.761 \pm 0.006$ \\
\hline-3.208 & $0.877 \pm 0.006$ & $0.872 \pm 0.006$ \\
\hline-3.170 & $0.876 \pm 0.006$ & $0.864 \pm 0.006$ \\
\hline-3.012 & $0.891 \pm 0.006$ & $0.883 \pm 0.006$ \\
\hline-2.891 & $0.902 \pm 0.007$ & $0.895 \pm 0.007$ \\
\hline-1.900 & $0.936 \pm 0.007$ & $0.936 \pm 0.007$ \\
\hline-1.740 & $0.979 \pm 0.008$ & $0.968 \pm 0.008$ \\
\hline-1.618 & $0.967 \pm 0.007$ & $0.958 \pm 0.007$ \\
\hline-0.632 & $1.009 \pm 0.007$ & $0.999 \pm 0.007$ \\
\hline-0.470 & $1.003 \pm 0.007$ & $0.992 \pm 0.007$ \\
\hline 0 & $1.000^{(\mathrm{a})}$ & $1.000^{(\mathrm{a})}$ \\
\hline 0.660 & $1.004 \pm 0.007$ & $1.003 \pm 0.007$ \\
\hline 0.805 & $0.985 \pm 0.008$ & $0.985 \pm 0.008$ \\
\hline 0.904 & $1.010 \pm 0.007$ & $1.004 \pm 0.007$ \\
\hline 1.905 & $0.974 \pm 0.007$ & $0.974 \pm 0.007$ \\
\hline 2.024 & $0.987 \pm 0.007$ & $0.975 \pm 0.007$ \\
\hline 2.078 & $0.944 \pm 0.007$ & $0.932 \pm 0.007$ \\
\hline 3.175 & $0.872 \pm 0.007$ & $0.864 \pm 0.007$ \\
\hline 3.449 & $0.865 \pm 0.090$ & $0.859 \pm 0.090$ \\
\hline 4.445 & $0.768 \pm 0.006$ & $0.765 \pm 0.006$ \\
\hline 4.646 & $0.734 \pm 0.006$ & $0.716 \pm 0.006$ \\
\hline 4.722 & $0.751 \pm 0.006$ & $0.750 \pm 0.006$ \\
\hline 5.712 & $0.624 \pm 0.005$ & $0.624 \pm 0.005$ \\
\hline 5.895 & $0.583 \pm 0.005$ & $0.576 \pm 0.005$ \\
\hline 5.994 & $0.600 \pm 0.005$ & $0.589 \pm 0.005$ \\
\hline 7.216 & $0.418 \pm 0.004$ & $0.418 \pm 0.004$ \\
\hline 7.419 & $0.431 \pm 0.005$ & $0.422 \pm 0.005$ \\
\hline 7.650 & $0.371 \pm 0.004$ & $0.364 \pm 0.004$ \\
\hline 8.273 & $0.282 \pm 0.004$ & $0.284 \pm 0.004$ \\
\hline 8.400 & $0.276 \pm 0.003$ & $0.274 \pm 0.003$ \\
\hline 8.443 & $0.247 \pm 0.004$ & $0.249 \pm 0.004$ \\
\hline 8.590 & $0.230 \pm 0.003$ & $0.230 \pm 0.003$ \\
\hline 8.618 & $0.239 \pm 0.003$ & $0.236 \pm 0.003$ \\
\hline 8.745 & $0.208 \pm 0.004$ & $0.204 \pm 0.004$ \\
\hline 9.091 & $0.170 \pm 0.003$ & $0.165 \pm 0.003$ \\
\hline
\end{tabular}

(a) There is no bias or uncertainty associated with the normalization point of the trend. 
NEA/NSC/DOC(2006)1

Fundamental-FUND

ORSPHERE-FUND-EXP-001

CRIT-REAC-COEF-KIN-RRATE

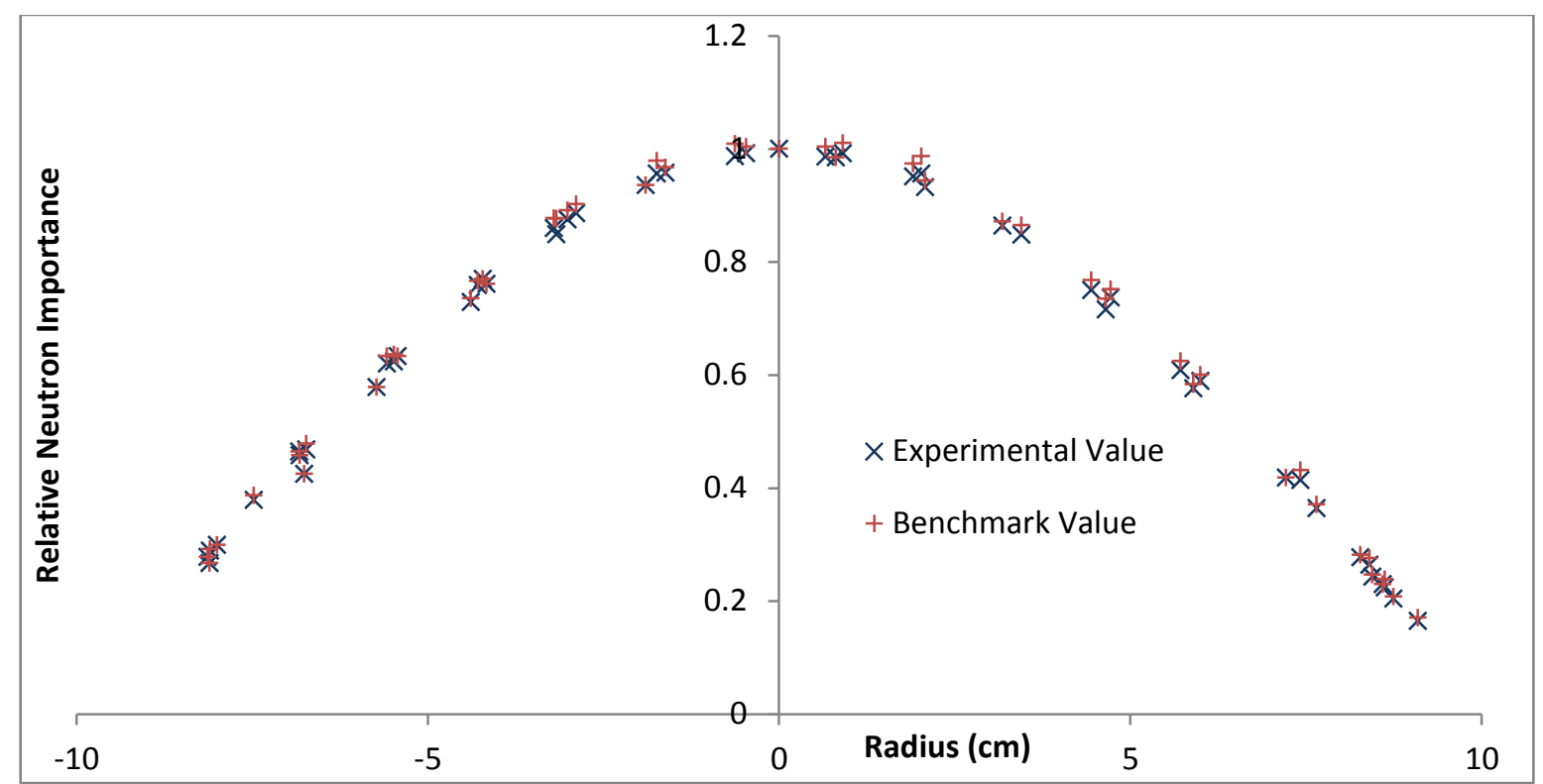

Figure 3.7-1. Experimental and Benchmark Relative Neutron Importance for $\mathrm{BF}_{3}$ Detector Response and a Cf Source. 


\section{NEA/NSC/DOC(2006)1 \\ Fundamental-FUND \\ ORSPHERE-FUND-EXP-001 \\ CRIT-REAC-COEF-KIN-RRATE}

\subsubsection{Relative Fission Density}

The benchmark values for the relative fission density are found by applying the biases in Table 3.7-2 to the experimental results. The uncertainty in the benchmark model is found by adding, in quadrature, the uncertainty in the experimental results, discussed in Section 2.7, and the bias uncertainty given in Table 3.7-2. The benchmark results are given in Table 3.7-4 and plotted in Figure 3.7-2.

Table 3.7-4. Relative Radial Fission Density Uncertainty.

\begin{tabular}{|c|c|c|}
\hline Radius $^{(a)}$ & $\begin{array}{c}\text { Detailed Benchmark } \\
\text { Model Value }\end{array}$ & $\begin{array}{c}\text { Simple Benchmark } \\
\text { Model Value }\end{array}$ \\
\hline-8.265 & $0.261 \pm 0.002$ & $0.260 \pm 0.002$ \\
\hline-7.633 & $0.354 \pm 0.002$ & $0.353 \pm 0.002$ \\
\hline-6.995 & $0.440 \pm 0.003$ & $0.438 \pm 0.003$ \\
\hline-6.355 & $0.519 \pm 0.003$ & $0.519 \pm 0.003$ \\
\hline-5.725 & $0.603 \pm 0.004$ & $0.603 \pm 0.004$ \\
\hline-5.088 & $0.672 \pm 0.005$ & $0.672 \pm 0.005$ \\
\hline-4.450 & $0.746 \pm 0.004$ & $0.746 \pm 0.004$ \\
\hline-3.815 & $0.810 \pm 0.006$ & $0.810 \pm 0.006$ \\
\hline-3.180 & $0.871 \pm 0.005$ & $0.871 \pm 0.005$ \\
\hline-2.54 & $0.910 \pm 0.006$ & $0.910 \pm 0.006$ \\
\hline-1.908 & $0.951 \pm 0.006$ & $0.951 \pm 0.006$ \\
\hline-1.272 & $0.978 \pm 0.006$ & $0.978 \pm 0.006$ \\
\hline-0.635 & $1.001 \pm 0.007$ & $1.001 \pm 0.007$ \\
\hline 0 & $1^{(\mathrm{a})}$ & $1^{(\mathrm{a})}$ \\
\hline 0.635 & $0.996 \pm 0.006$ & $0.996 \pm 0.006$ \\
\hline 1.272 & $0.978 \pm 0.006$ & $0.978 \pm 0.006$ \\
\hline 1.908 & $0.956 \pm 0.006$ & $0.956 \pm 0.006$ \\
\hline 2.543 & $0.910 \pm 0.006$ & $0.910 \pm 0.006$ \\
\hline 3.180 & $0.872 \pm 0.006$ & $0.872 \pm 0.006$ \\
\hline 3.815 & $0.810 \pm 0.005$ & $0.810 \pm 0.005$ \\
\hline 4.450 & $0.742 \pm 0.005$ & $0.742 \pm 0.005$ \\
\hline 5.088 & $0.675 \pm 0.004$ & $0.675 \pm 0.004$ \\
\hline 5.725 & $0.600 \pm 0.004$ & $0.599 \pm 0.004$ \\
\hline 6.355 & $0.518 \pm 0.006$ & $0.517 \pm 0.006$ \\
\hline 6.995 & $0.438 \pm 0.003$ & $0.437 \pm 0.003$ \\
\hline 7.633 & $0.351 \pm 0.002$ & $0.350 \pm 0.002$ \\
\hline 8.265 & $0.257 \pm 0.003$ & $0.255 \pm 0.003$ \\
\hline
\end{tabular}

(a) There is no bias or uncertainty associated with the normalization point of the trend. 
NEA/NSC/DOC(2006)1

Fundamental-FUND

ORSPHERE-FUND-EXP-001

CRIT-REAC-COEF-KIN-RRATE

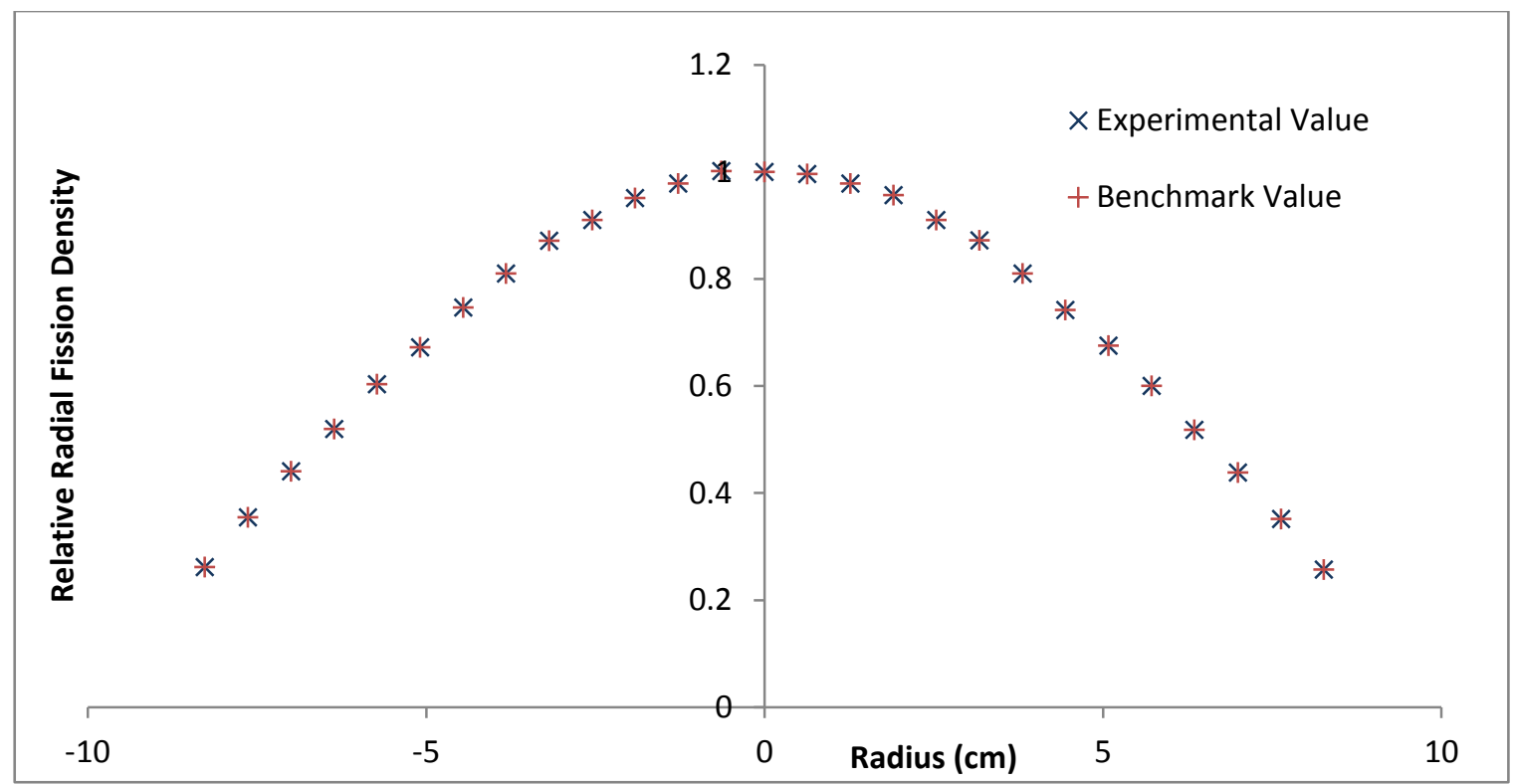

Figure 3.7-2. Experimental and Benchmark Relative Fission Density.

\subsection{Benchmark-Model Specifications for Power Distribution Measurements}

Power distribution measurements were not performed.

\subsection{Benchmark-Model Specifications for Isotopic Measurements}

Isotopic measurements were not performed.

\subsection{Benchmark-Model Specifications for Other Miscellaneous Types of Measurements}

Other miscellaneous types of measurements were not performed. 


\subsection{RESULTS OF SAMPLE CALCULATIONS}

\subsection{Results of Calculations of the Critical or Subcritical Configurations}

The criticality portion of this evaluation has been reviewed and approved by the International Criticality Safety Benchmark Evaluation Project (ICSBEP) and has been published under the following identifier: HEU-MET-FAST-100. ${ }^{a}$

\subsection{Results of Buckling and Extrapolation Length Calculations}

Buckling and extrapolation-length measurements were not performed.

\subsection{Results of Spectral-Characteristics Calculations}

Spectral-characteristic measurements were not performed.

\subsection{Results of Reactivity-Effects Calculations}

The worth measurements were evaluated using models as described in Section 3.4 with MCNP5-1.60 and ENDF/B-VII.0 neutron cross section libraries. Models were run using 500000 histories per cycle for 2650 cycles, skipping the first 150 cycles. The benchmark worths and sample calculation results are given in Table 4.4-1. It should be noted that calculated worths that deviate from the benchmark worths by more than three sigma of the benchmark uncertainty are still within three sigma for the uncertainty inherent to the Monte Carlo calculation.

a International Handbook of Evaluated Criticality Safety Benchmark Experiments, NEA/NSC/DOC(95)03, OECDNEA, Paris (2013). 


\section{NEA/NSC/DOC(2006)1}

Fundamental-FUND

\section{ORSPHERE-FUND-EXP-001} CRIT-REAC-COEF-KIN-RRATE

Table 4.4-1. Benchmark Worth Values.

\begin{tabular}{|c|c|c|c|c|c|c|c|c|c|}
\hline \multirow[b]{2}{*}{ Central Void } & \multicolumn{2}{|c|}{$\begin{array}{c}\text { Benchmark } \\
\text { Worth }(\varnothing)\end{array}$} & \multicolumn{3}{|c|}{$\begin{array}{c}\text { MCNP5 } \\
\text { ENDF/B-VII.0 } \\
(\text { a) } \\
(\text { c) }\end{array}$} & \multirow{2}{*}{$\frac{\frac{C-E^{(\mathrm{b})}}{E}}{2.70 \%}$} & \multirow{2}{*}{$\begin{array}{l}\mathrm{C} / \mathrm{E}^{(\mathrm{b})} \\
\text { Ratio } \\
0.973\end{array}$} & \multirow{2}{*}{$\begin{array}{c}\begin{array}{c}\# \\
\text { of } \sigma^{(c)}\end{array} \\
2.01\end{array}$} & \multirow{2}{*}{$\begin{array}{c}{ }^{\#} \\
\text { of } \sigma_{\mathrm{MC}}^{(\mathrm{d})} \\
1.49\end{array}$} \\
\hline & $9.165=$ & 0.123 & 9.4123 & \pm & $0.1659^{(\mathrm{e})}$ & & & & \\
\hline $\begin{array}{l}\text { 16, } 0.635-\mathrm{cm} \text {-thick Uranium } \\
\text { Buttons on Sphere Surface }\end{array}$ & $35.4=$ & 2.868 & 43.5627 & \pm & 0.4508 & $23.06 \%$ & 0.813 & 2.85 & 18.11 \\
\hline $\begin{array}{l}4,0.3175-\mathrm{cm} \text {-thick Uranium } \\
\text { Buttons on Sphere Surface }\end{array}$ & $6.1415=$ & 0.117 & 6.0050 & \pm & $0.1638^{(\mathrm{e})}$ & $-2.22 \%$ & 1.023 & -1.17 & -0.83 \\
\hline $\begin{array}{l}\text { 1, } 0.3175-\mathrm{cm} \text {-thick Aluminum } \\
\text { Button on Sphere Surface }\end{array}$ & 0.7058 & 0.062 & 0.7813 & \pm & $0.0569^{(\mathrm{f})}$ & $10.70 \%$ & 0.903 & 1.21 & 1.33 \\
\hline $\begin{array}{l}\text { 3, 0.3175-cm-thick Uranium } \\
\text { Buttons in Socket Hole }\end{array}$ & $7.86=$ & 0.127 & 8.2442 & \pm & 0.6114 & $4.89 \%$ & 0.953 & 3.02 & 0.63 \\
\hline $\begin{array}{l}\text { 3, 0.3175-cm-thick Stainless } \\
\text { Steel Buttons in Socket Hole }\end{array}$ & $4.7228=$ & 0.076 & 4.7339 & \pm & 0.4322 & $0.23 \%$ & 0.998 & 0.15 & 0.03 \\
\hline $\begin{array}{l}\text { 3, 0.3175-cm-thick Aluminum } \\
\text { Buttons in Socket Hole }\end{array}$ & 3.1259 & 0.074 & 3.6652 & \pm & 0.4321 & $17.25 \%$ & 0.853 & 7.29 & 1.25 \\
\hline Diametral Filler Rod & $11.234=$ & 0.168 & 10.8532 & \pm & 0.4336 & $-3.39 \%$ & 1.035 & -2.27 & -0.88 \\
\hline
\end{tabular}

(a) Because of the large statistical uncertainty in the sample calculation these results are truncated to fewer decimal points.

(b) "E" is the experimental benchmark value. "C" is the calculated value.

(c) This value shows how far the calculated worth deviates from the benchmark worth in terms of the benchmark worth uncertainty. (C-E)/ $\sigma$

(d) This value shows how close the calculated worth are to the benchmark worth in terms of the statistical uncertainty of the Monte Carlo calculation. (C$\mathrm{E}) / \sigma_{\mathrm{MC}}$

(e) For this calculated worth seven runs with different random numbers were performed and a variance weighted average of all results was taken.

(f) For this calculated worth seven runs with different random numbers were performed and a variance weighted average of all results was taken. The statistical uncertainty was also reduced because it was divided by the number of buttons, 3 or 4 


\section{NEA/NSC/DOC(2006)1 \\ Fundamental-FUND \\ ORSPHERE-FUND-EXP-001 \\ CRIT-REAC-COEF-KIN-RRATE}

\subsection{Results of Reactivity Coefficient Calculations}

The worth per gram of uranium surface material benchmark models is described in Section 3.5. The models were created and run in MCNP5-1.60 and MCNP6-1.0 using ENDF/B-VII.0 neutron cross section libraries and MCNP6-1.0 using ENDF/B-VII.1 . For each model 500,000 histories per cycle were used for 2650 cycles, skipping the first 150 cycles. The benchmark and sample calculation worth per gram of uranium surface material are given in Table 4.5-1. The [(C-E)/E] for the sample calculation result is $-7.2 \%,-7.8 \%$ and $-8.1 \%$ below the benchmark value; this corresponds to 2.44 to $2.76 \sigma$ below the benchmark value. The benchmark $\beta_{\text {eff }}$ value of $0.00657 \pm 0.00009$ was used to convert reactivity from units of $\Delta \mathrm{k}$ to units of $\phi$.

Table 4.5-1. Sample Calculation of Worth per Gram of Surface Material using MCNP5-1.60 and ENDF/B-VII.0.

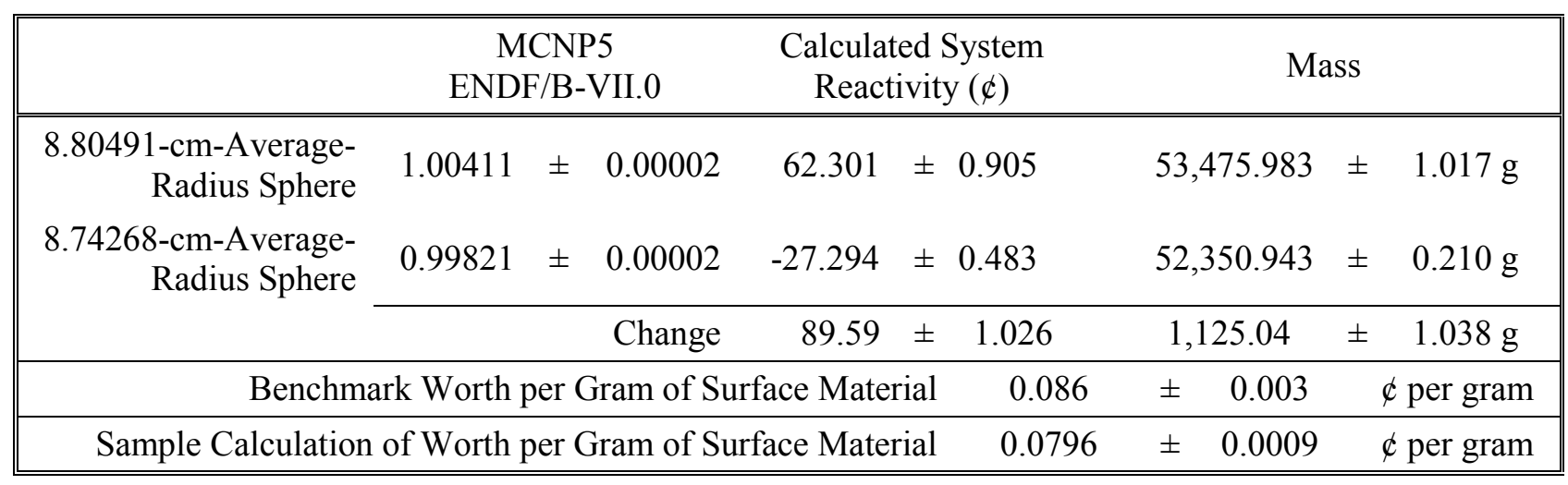

Table 4.5-2. Sample Calculation of Worth per Gram of Surface Material using MCNP6-1.0 and ENDF/B-VII.0.

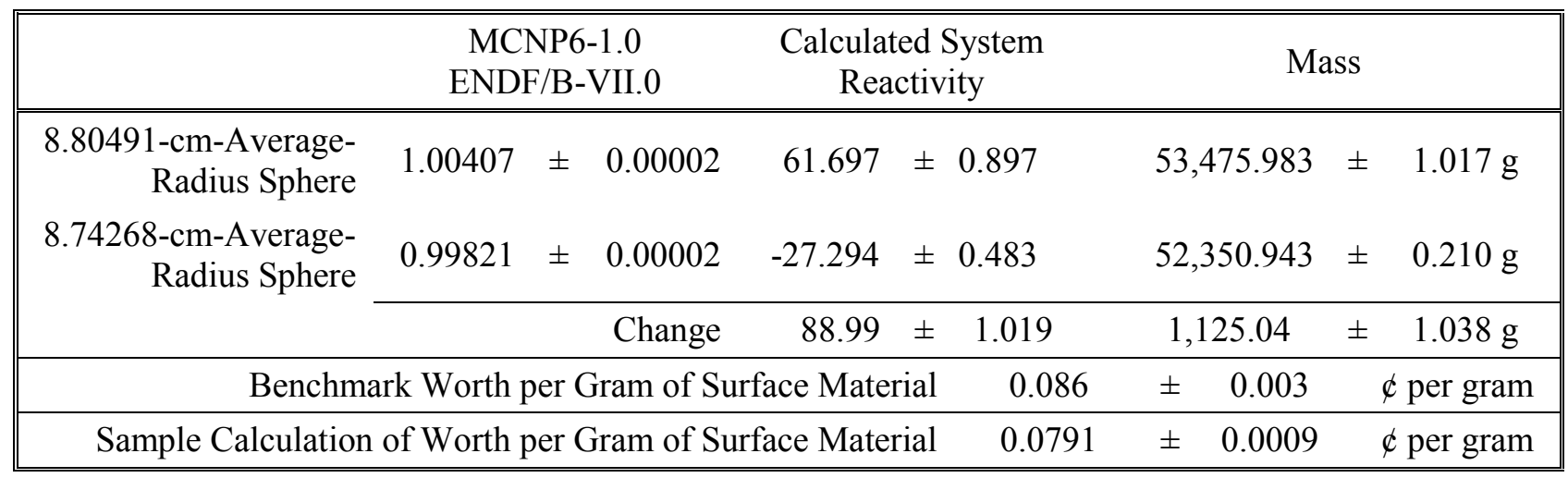


NEA/NSC/DOC(2006)1

Fundamental-FUND

ORSPHERE-FUND-EXP-001

CRIT-REAC-COEF-KIN-RRATE

Table 4.5-3. Sample Calculation of Worth per Gram of Surface Material using MCNP6-1.0 and ENDF/B-VII.1.

\begin{tabular}{|c|c|c|c|c|c|c|c|}
\hline & \multicolumn{2}{|c|}{$\begin{array}{c}\text { MCNP6-1.0 } \\
\text { ENDF/B-VII.1 }\end{array}$} & \multicolumn{2}{|c|}{$\begin{array}{c}\text { Calculated System } \\
\text { Reactivity }\end{array}$} & \multicolumn{3}{|c|}{ Mass } \\
\hline $\begin{array}{r}\text { 8.80491-cm-Average- } \\
\text { Radius Sphere }\end{array}$ & 1.00402 & $\pm \quad 0.00002$ & 60.942 & \pm 0.897 & $53,475.983$ & \pm & $1.017 \mathrm{~g}$ \\
\hline \multirow[t]{2}{*}{$\begin{array}{r}\text { 8.74268-cm-Average- } \\
\text { Radius Sphere }\end{array}$} & 0.99818 & $\pm \quad 0.00002$ & -27.294 & \pm 0.483 & $52,350.943$ & \pm & $0.210 \mathrm{~g}$ \\
\hline & & Change & 88.69 & \pm 1.013 & $1,125.04$ & \pm & $1.038 \mathrm{~g}$ \\
\hline \multicolumn{4}{|c|}{ Benchmark Worth per Gram of Surface Material } & 0.086 & 0.003 & & per gram \\
\hline \multicolumn{4}{|c|}{ Sample Calculation of Worth per Gram of Surface Material } & 0.0788 & \pm 0.0009 & & per gram \\
\hline
\end{tabular}

\subsection{Results of Kinetics Parameter Calculations}

\subsubsection{Delayed Neutron Fraction}

The $\beta_{\text {eff }}$ value was calculated for the benchmark models described in Section 3.6 using two methods. The first method used $k_{\text {prompt }}$, calculated by MCNP5, and compared it to $k_{\text {eff }}$ to calculate $\beta_{\text {eff }}\left(\beta_{\text {eff }}=1-\right.$ $\mathrm{k}_{\text {prompt }} / \mathrm{k}_{\mathrm{eff}}$ ). ${ }^{\mathrm{a}}$ The second method used MCNP5 to calculate $\beta_{\mathrm{eff}}$ directly using adjoint-weighted methods capabilities in MCNP5-1.60. ${ }^{\mathrm{b}}$ Both methods used ENDF/B-VII.0 neutron cross section libraries. The results of the two methods for the two critical benchmark models is given in Table 4.6-1.

Table 4.6-1. Sample Calculation Results for Delayed Neutron Fraction.

\begin{tabular}{|lcccccccccc|}
\hline \multirow{3}{*}{ Method 11 } & & & & & & & $\beta_{\text {eff }}$ & & $(C-E) / E^{(\mathrm{a})}$ \\
& Case 1 & $\mathrm{k}_{\text {prompt }}$ & 0.99721 & \pm & 0.00002 & 0.00650 & \pm & 0.00003 & $-0.46 \%$ \\
& Case 2 & $\mathrm{k}_{\text {eff }}$ & 1.00373 & \pm & 0.00002 & 0.00654 & \pm & 0.00003 & $-1.11 \%$ \\
Method 2 2 & Case 1 & $\mathrm{k}_{\text {prompt }}$ & 0.99172 & \pm & 0.00002 & 0.00650 & \pm & 0.00003 & $-0.37 \%$ \\
& Case 2 & $\mathrm{k}_{\text {eff }}$ & 0.99821 & \pm & 0.00002 & 0.00654 & \pm & 0.00003 & $-1.02 \%$ \\
\hline
\end{tabular}

(a) "E" is the expected or benchmark value. "C" is the calculated value.

\subsubsection{Prompt Neutron Decay Constant}

The prompt neutron decay constant, $\alpha$, was calculated for the prompt neutron decay constant benchmark model described in Section 3.6 using the adjoint-weighted methods capabilities in MCNP5-1.60. This yields the three variables in Equation 2.6.3, $\rho$ (in the form of $\mathrm{k}_{\mathrm{eff}}$ ), $\beta_{\mathrm{eff}}$, and $\Lambda$ needed to calculate $\alpha$. These values are given in Table 4.6.2.

\footnotetext{
${ }^{a}$ R. K. Meulekamp and S. C. van der Marck, "Calculating the Effective Delayed Neutron Fraction with Monte Carlo," Nucl. Sci. Eng., 152, 142-148 (2006).

${ }^{\text {b }}$ B.C. Kiedrowski, et al., "MCNP5-1.60 Feature Enhancements and Manual Clarifications," LA-UR-10-06217, Los Alamos National Laboratory (2010).
} 
Table 4.6-2. Sample Calculation Results for Prompt Neutron Decay Constant.

\begin{tabular}{|c|c|c|c|c|c|c|}
\hline $\mathrm{k}_{\mathrm{eff}}$ & 1.00141 & $\pm \quad 0.00002$ & Benchmark $\alpha(\mu \mathrm{s})$ & -1.1061 & & 0.1071 \\
\hline$\beta_{\text {eff }}$ & 0.00647 & \pm 0.00003 & Calculated $\alpha(\mu \mathrm{s})$ & -0.8842 & \pm & 0.0902 \\
\hline$\Lambda(\mathrm{ns})$ & 5.72499 & $\pm \quad 0.00297$ & \multicolumn{3}{|c|}{$(C-E) / E^{(\mathrm{a})}$} & $-20 \%$ \\
\hline
\end{tabular}

(a) " $E$ " is the expected or benchmark value. "C" is the calculated value.

The calculated $\alpha$ is approximately $20 \%$ below the benchmark value. This is very far outside the range of the benchmark uncertainty; however, it is within $3 \sigma$ for the calculated value uncertainty.

The model used for these calculation results is the benchmark model, which has been adjusted to delayed critical. The expected $\mathrm{k}_{\text {eff }}$ is 1.0000 , but, as can be seen in Table $4.6-2$, the calculated $\mathrm{k}_{\text {eff }}$ is approximately $0.14 \%$ high due to calculational bias. The $\mathrm{k}_{\mathrm{eff}}$ contributes a non-zero value for the reactivity in Equation 2.6.4. It is of interested to note that, if the calculational bias is ignored and the reactivity is set to zero the calculated $\alpha$ becomes $-1.1301 \mu \mathrm{sec}$ which is $2 \%$ above the benchmark value.

\subsubsection{Mean Generation Time}

The mean generation time, $\Lambda$, was calculated for the prompt neutron decay constant benchmark model described in Section 3.6 using the adjoint-weighted methods capabilities in MCNP5-1.60. The calculated value is $5.72499 \pm 0.00297$ nanosec, which is $-3.6 \%$ below the benchmark value of $5.94 \pm 0.14$ nanosec.

\subsection{Results of Reaction-Rate Distribution Calculations}

\subsubsection{Relative Neutron Importance}

The relative neutron importance for $\mathrm{BF}_{3}$ detector response and a $\mathrm{Cf}$ source was calculated using the models described in Section 3.7 with MCNP5-1.60 and ENDF/B-VII.0 neutron cross section libraries. The source was modeled as isotropic point sources distributed across the center line of the sphere. A Maxwellian source distribution with a temperature of $1.4 \mathrm{MeV}$ was used. The flux at the detectors was modeled using a point detector tally (F5). The SCX tally treatment was used. An SCX tally treatment bins tally results based on the location of the original source neutron in the source distribution. The tally results for the three detectors were averaged. The model was run for $250,000,000$ particle histories. The sample calculation results are given in Table 4.7-1 for the detailed benchmark model and Table 4.7-2 for the simple benchmark model. The deviation between the calculated values and benchmark model values is quite variable and rather large, especially at the edges of the sphere. The cause for this deviation is unknown. 
NEA/NSC/DOC(2006)1

Fundamental-FUND

ORSPHERE-FUND-EXP-001

CRIT-REAC-COEF-KIN-RRATE

Table 4.7-1. Sample Calculation Results for the Relative Neutron Importance for $\mathrm{BF}_{3}$

Detector Response and a Cf Source, Detailed Model. MCNP5-1.60, ENDF/B-VII.0.

\begin{tabular}{|c|c|c|c|c|c|c|c|}
\hline \multirow{2}{*}{$\begin{array}{c}\text { Radius } \\
-8.138\end{array}$} & \multicolumn{3}{|c|}{$\begin{array}{c}\text { Detailed Benchmark } \\
\text { Model Value }\end{array}$} & \multicolumn{2}{|c|}{$\begin{array}{c}\text { Sample Calculation } \\
\text { Results }^{\text {(a) }}\end{array}$} & \multirow{2}{*}{$\frac{(\mathrm{C}-\mathrm{E}) / \mathrm{E}^{(\mathrm{b})}}{-19.93 \%}$} & \multirow{2}{*}{$\frac{(\mathrm{C}-\mathrm{E}) / \sigma^{(\mathrm{c})}}{-13.52}$} \\
\hline & 0.278 & \pm & 0.004 & 0.223 & \pm 0.001 & & \\
\hline-8.105 & 0.267 & \pm & 0.003 & 0.224 & \pm 0.001 & $-16.18 \%$ & -12.54 \\
\hline-8.100 & 0.292 & \pm & 0.003 & 0.227 & \pm 0.001 & $-22.12 \%$ & -22.28 \\
\hline-8.004 & 0.299 & \pm & 0.003 & 0.236 & \pm 0.001 & $-20.93 \%$ & -21.18 \\
\hline-7.480 & 0.387 & \pm & 0.004 & 0.314 & \pm 0.001 & $-18.95 \%$ & -19.12 \\
\hline-6.833 & 0.464 & \pm & 0.004 & 0.396 & \pm 0.001 & $-14.69 \%$ & -15.66 \\
\hline-6.825 & 0.458 & \pm & 0.005 & 0.403 & \pm 0.001 & $-12.08 \%$ & -11.02 \\
\hline-6.759 & 0.425 & \pm & 0.004 & 0.407 & \pm 0.001 & $-4.12 \%$ & -3.94 \\
\hline-6.731 & 0.478 & \pm & 0.005 & 0.414 & \pm 0.001 & $-13.41 \%$ & -13.01 \\
\hline-5.730 & 0.578 & \pm & 0.005 & 0.539 & \pm 0.002 & $-6.83 \%$ & -7.64 \\
\hline-5.583 & 0.633 & \pm & 0.005 & 0.561 & \pm 0.002 & $-11.40 \%$ & -14.01 \\
\hline-5.484 & 0.636 & \pm & 0.005 & 0.576 & \pm 0.002 & $-9.50 \%$ & -11.33 \\
\hline-5.428 & 0.633 & \pm & 0.006 & 0.577 & \pm 0.002 & $-8.81 \%$ & -9.58 \\
\hline-4.392 & 0.735 & \pm & 0.006 & 0.705 & \pm 0.002 & $-4.16 \%$ & -4.75 \\
\hline-4.288 & 0.766 & \pm & 0.006 & 0.714 & \pm 0.002 & $-6.81 \%$ & -8.91 \\
\hline-4.221 & 0.770 & \pm & 0.006 & 0.722 & \pm 0.002 & $-6.18 \%$ & -7.63 \\
\hline-4.166 & 0.761 & \pm & 0.006 & 0.725 & \pm 0.002 & $-4.67 \%$ & -5.79 \\
\hline-3.208 & 0.877 & \pm & 0.006 & 0.828 & \pm 0.002 & $-5.55 \%$ & -7.57 \\
\hline-3.170 & 0.876 & \pm & 0.006 & 0.835 & \pm 0.002 & $-4.75 \%$ & -6.44 \\
\hline-3.012 & 0.891 & \pm & 0.006 & 0.840 & \pm 0.002 & $-5.68 \%$ & -7.86 \\
\hline-2.891 & 0.902 & \pm & 0.007 & 0.854 & \pm 0.002 & $-5.32 \%$ & -7.07 \\
\hline-1.900 & 0.936 & \pm & 0.007 & 0.930 & \pm 0.003 & $-0.60 \%$ & -0.79 \\
\hline-1.740 & 0.979 & \pm & 0.008 & 0.943 & \pm 0.003 & $-3.65 \%$ & -4.71 \\
\hline-1.618 & 0.967 & \pm & 0.007 & 0.946 & \pm 0.003 & $-2.12 \%$ & -2.78 \\
\hline-0.632 & 1.009 & \pm & 0.007 & 0.989 & \pm 0.003 & $-2.02 \%$ & -2.80 \\
\hline-0.470 & 1.003 & \pm & 0.007 & 0.990 & \pm 0.003 & $-1.30 \%$ & -1.79 \\
\hline 0 & \multicolumn{3}{|c|}{1.000} & \multicolumn{2}{|c|}{1} & - & - \\
\hline 0.660 & 1.004 & \pm & 0.007 & 0.999 & \pm 0.003 & $-0.50 \%$ & -0.68 \\
\hline 0.805 & 0.985 & \pm & 0.008 & 1.001 & \pm 0.003 & $1.61 \%$ & 2.06 \\
\hline 0.904 & 1.010 & \pm & 0.007 & 0.997 & \pm 0.003 & $-1.27 \%$ & -1.76 \\
\hline 1.905 & 0.974 & \pm & 0.007 & 0.978 & \pm 0.003 & $0.41 \%$ & 0.54 \\
\hline 2.024 & 0.987 & \pm & 0.007 & 0.980 & \pm 0.003 & $-0.70 \%$ & -0.96 \\
\hline 2.078 & 0.944 & \pm & 0.007 & 0.973 & \pm 0.003 & $3.06 \%$ & 3.86 \\
\hline 3.175 & 0.872 & \pm & 0.007 & 0.909 & \pm 0.003 & $4.35 \%$ & 5.47 \\
\hline 3.449 & 0.865 & \pm & 0.090 & 0.886 & \pm 0.002 & $2.46 \%$ & 0.24 \\
\hline 4.445 & 0.768 & \pm & 0.006 & 0.799 & \pm 0.002 & $4.09 \%$ & 5.01 \\
\hline 4.646 & 0.734 & \pm & 0.006 & 0.791 & \pm 0.002 & $7.75 \%$ & 9.11 \\
\hline 4.722 & 0.751 & \pm & 0.006 & 0.773 & \pm 0.002 & $2.87 \%$ & 3.55 \\
\hline 5.712 & 0.624 & \pm & 0.005 & 0.669 & \pm 0.002 & $7.27 \%$ & 8.29 \\
\hline
\end{tabular}


NEA/NSC/DOC(2006)1

Fundamental-FUND

ORSPHERE-FUND-EXP-001

CRIT-REAC-COEF-KIN-RRATE

Table 4.7-1 (cont'd). Sample Calculation Results for the Relative Neutron Importance for $\mathrm{BF}_{3}$ Detector Response and a Cf Source, Detailed Model. MCNP5-1.60, ENDF/B-VII.0.

\begin{tabular}{||c|ccc|cc|c|c||}
\hline Radius & \multicolumn{2}{|c|}{$\begin{array}{c}\text { Detailed Benchmark } \\
\text { Model Value }\end{array}$} & \multicolumn{2}{|c|}{$\begin{array}{c}\text { Sample Calculation } \\
\text { Results }^{(\mathrm{a})}\end{array}$} & $(\mathrm{C}-\mathrm{E}) / \mathrm{E}^{(\mathrm{b})}$ & $(\mathrm{C}-\mathrm{E}) / \sigma^{(\mathrm{c})}$ \\
\hline \hline 5.895 & 0.583 & \pm & 0.005 & 0.650 & \pm 0.002 & $11.34 \%$ & 12.08 \\
\hline 5.994 & 0.600 & \pm & 0.005 & 0.635 & \pm 0.002 & $5.78 \%$ & 6.50 \\
\hline 7.216 & 0.418 & \pm & 0.004 & 0.485 & \pm 0.002 & $15.94 \%$ & 14.84 \\
\hline 7.419 & 0.431 & \pm & 0.005 & 0.461 & \pm 0.002 & $6.96 \%$ & 6.49 \\
\hline 7.650 & 0.371 & \pm & 0.004 & 0.427 & \pm 0.001 & $15.27 \%$ & 13.52 \\
\hline 8.273 & 0.282 & \pm & 0.004 & 0.343 & \pm 0.001 & $21.93 \%$ & 16.81 \\
\hline 8.400 & 0.276 & \pm & 0.003 & 0.327 & \pm 0.001 & $18.72 \%$ & 14.84 \\
\hline 8.443 & 0.247 & \pm & 0.004 & 0.319 & \pm 0.001 & $29.20 \%$ & 20.22 \\
\hline 8.590 & 0.230 & \pm & 0.003 & 0.298 & \pm 0.001 & $29.42 \%$ & 19.51 \\
\hline 8.618 & 0.239 & \pm & 0.003 & 0.297 & \pm 0.001 & $24.29 \%$ & 17.38 \\
\hline 8.745 & 0.208 & \pm & 0.004 & 0.277 & \pm 0.001 & $33.40 \%$ & 18.67 \\
\hline 9.091 & 0.170 & \pm & 0.003 & 0.230 & \pm 0.001 & $34.81 \%$ & 20.53 \\
\hline
\end{tabular}

(a) Sample calculation models were run in source mode with 250,000,000 neutron particle histories.

(b) ' $\mathrm{E}$ ' is the expected or benchmark value. ' $\mathrm{C}$ ' is the calculated value.

(c) ' $\mathrm{E}$ ' is the expected or benchmark value. ' $\mathrm{C}$ ' is the calculated value. $\sigma$ is the benchmark model uncertainty. 
Table 4.7-2. Sample Calculation Results for the Relative Neutron Importance for $\mathrm{BF}_{3}$ Detector Response and a Cf Source, Simple Model. MCNP5-1.60, ENDF/B-VII.0

\begin{tabular}{|c|c|c|c|c|c|c|c|}
\hline \multirow{2}{*}{$\begin{array}{c}\text { Radius } \\
-8.138\end{array}$} & \multicolumn{3}{|c|}{$\begin{array}{c}\text { Simple Benchmark } \\
\text { Model Value }\end{array}$} & \multicolumn{2}{|c|}{$\begin{array}{c}\text { Sample Calculation } \\
\text { Results }^{(\mathrm{a})}\end{array}$} & \multirow{2}{*}{$\frac{(\mathrm{C}-\mathrm{E}) / \mathrm{E}^{(\mathrm{b})}}{-21.12 \%}$} & \multirow{2}{*}{$\frac{(\mathrm{C}-\mathrm{E}) / \sigma^{(\mathrm{c})}}{-14.34}$} \\
\hline & 0.278 & \pm & 0.004 & 0.219 & \pm 0.001 & & \\
\hline-8.105 & 0.267 & \pm & 0.003 & 0.223 & \pm 0.001 & $-16.57 \%$ & -12.82 \\
\hline-8.100 & 0.289 & \pm & 0.003 & 0.227 & \pm 0.001 & $-21.51 \%$ & -21.44 \\
\hline-8.004 & 0.299 & \pm & 0.003 & 0.237 & \pm 0.001 & $-20.86 \%$ & -21.05 \\
\hline-7.480 & 0.386 & \pm & 0.004 & 0.312 & \pm 0.001 & $-19.01 \%$ & -19.11 \\
\hline-6.833 & 0.464 & \pm & 0.004 & 0.394 & \pm 0.001 & $-15.02 \%$ & -16.03 \\
\hline-6.825 & 0.458 & \pm & 0.005 & 0.398 & \pm 0.001 & $-13.18 \%$ & -12.04 \\
\hline-6.759 & 0.425 & \pm & 0.004 & 0.407 & \pm 0.001 & $-4.13 \%$ & -3.94 \\
\hline-6.731 & 0.477 & \pm & 0.005 & 0.412 & \pm 0.001 & $-13.46 \%$ & -13.01 \\
\hline-5.730 & 0.578 & \pm & 0.005 & 0.535 & \pm 0.002 & $-7.41 \%$ & -8.30 \\
\hline-5.583 & 0.628 & \pm & 0.005 & 0.556 & \pm 0.002 & $-11.49 \%$ & -14.02 \\
\hline-5.484 & 0.624 & \pm & 0.005 & 0.566 & \pm 0.002 & $-9.23 \%$ & -10.82 \\
\hline-5.428 & 0.633 & \pm & 0.006 & 0.575 & \pm 0.002 & $-9.19 \%$ & -9.99 \\
\hline-4.392 & 0.729 & \pm & 0.006 & 0.698 & \pm 0.002 & $-4.22 \%$ & -4.77 \\
\hline-4.288 & 0.759 & \pm & 0.006 & 0.710 & \pm 0.002 & $-6.51 \%$ & -8.45 \\
\hline-4.221 & 0.770 & \pm & 0.006 & 0.717 & \pm 0.002 & $-6.93 \%$ & -8.56 \\
\hline-4.166 & 0.761 & \pm & 0.006 & 0.721 & \pm 0.002 & $-5.28 \%$ & -6.55 \\
\hline-3.208 & 0.872 & \pm & 0.006 & 0.823 & \pm 0.002 & $-5.58 \%$ & -7.56 \\
\hline-3.170 & 0.864 & \pm & 0.006 & 0.822 & \pm 0.002 & $-4.82 \%$ & -6.47 \\
\hline-3.012 & 0.883 & \pm & 0.006 & 0.832 & \pm 0.002 & $-5.73 \%$ & -7.87 \\
\hline-2.891 & 0.895 & \pm & 0.007 & 0.847 & \pm 0.002 & $-5.36 \%$ & -7.08 \\
\hline-1.900 & 0.936 & \pm & 0.007 & 0.921 & \pm 0.003 & $-1.58 \%$ & -2.08 \\
\hline-1.740 & 0.968 & \pm & 0.008 & 0.932 & \pm 0.003 & $-3.70 \%$ & -4.72 \\
\hline-1.618 & 0.958 & \pm & 0.007 & 0.937 & \pm 0.003 & $-2.20 \%$ & -2.85 \\
\hline-0.632 & 0.999 & \pm & 0.007 & 0.979 & \pm 0.003 & $-2.04 \%$ & -2.80 \\
\hline-0.470 & 0.992 & \pm & 0.007 & 0.983 & \pm 0.003 & $-0.87 \%$ & -1.18 \\
\hline 0 & & 1 & & & & - & - \\
\hline 0.660 & 1.003 & \pm & 0.007 & 0.998 & \pm 0.003 & $-0.50 \%$ & -0.68 \\
\hline 0.805 & 0.985 & \pm & 0.008 & 1.003 & \pm 0.003 & $1.84 \%$ & 2.36 \\
\hline 0.904 & 1.004 & \pm & 0.007 & 0.991 & \pm 0.003 & $-1.28 \%$ & -1.76 \\
\hline 1.905 & 0.974 & \pm & 0.007 & 0.978 & \pm 0.003 & $0.41 \%$ & 0.54 \\
\hline 2.024 & 0.975 & \pm & 0.007 & 0.968 & \pm 0.003 & $-0.71 \%$ & -0.96 \\
\hline 2.078 & 0.932 & \pm & 0.007 & 0.963 & \pm 0.003 & $3.38 \%$ & 4.21 \\
\hline 3.175 & 0.864 & \pm & 0.007 & 0.906 & \pm 0.003 & $4.88 \%$ & 6.09 \\
\hline 3.449 & 0.859 & \pm & 0.090 & 0.881 & \pm 0.002 & $2.48 \%$ & 0.24 \\
\hline 4.445 & 0.765 & \pm & 0.006 & 0.796 & \pm 0.002 & $4.10 \%$ & 5.02 \\
\hline 4.646 & 0.716 & \pm & 0.006 & 0.779 & \pm 0.002 & $8.75 \%$ & 10.05 \\
\hline 4.722 & 0.750 & \pm & 0.006 & 0.771 & \pm 0.002 & $2.88 \%$ & 3.55 \\
\hline 5.712 & 0.624 & \pm & 0.005 & 0.669 & \pm 0.002 & $7.27 \%$ & 8.28 \\
\hline 5.895 & 0.576 & \pm & 0.005 & 0.642 & \pm 0.002 & $11.54 \%$ & 12.15 \\
\hline
\end{tabular}


Table 4.7-2 (cont'd). Sample Calculation Results for the Relative Neutron Importance for $\mathrm{BF}_{3}$ Detector Response and a Cf Source, Simple Model. MCNP5-1.60, ENDF/B-VII.0

\begin{tabular}{|c|ccc|cr|c|c||}
\hline Radius & \multicolumn{2}{|c|}{$\begin{array}{c}\text { Simple Benchmark } \\
\text { Model Value }\end{array}$} & \multicolumn{2}{|c|}{$\begin{array}{c}\text { Sample Calculation } \\
\text { Results }^{(\mathrm{a})}\end{array}$} & $(\mathrm{C}-\mathrm{E}) / \mathrm{E}^{(\mathrm{b})}$ & $(\mathrm{C}-\mathrm{E}) / \sigma^{(\mathrm{c})}$ \\
\hline \hline 5.994 & 0.589 & \pm & 0.005 & 0.629 & \pm 0.002 & $6.75 \%$ & 7.47 \\
\hline 7.216 & 0.418 & \pm & 0.004 & 0.478 & \pm 0.002 & $14.26 \%$ & 13.29 \\
\hline 7.419 & 0.422 & \pm & 0.005 & 0.452 & \pm 0.002 & $7.10 \%$ & 6.50 \\
7.650 & 0.364 & \pm & 0.004 & 0.421 & \pm 0.001 & $15.69 \%$ & 13.67 \\
\hline 8.273 & 0.284 & \pm & 0.004 & 0.345 & \pm 0.001 & $21.77 \%$ & 16.77 \\
\hline 8.400 & 0.274 & \pm & 0.003 & 0.325 & \pm 0.001 & $18.85 \%$ & 14.85 \\
8.443 & 0.249 & \pm & 0.004 & 0.321 & \pm 0.001 & $28.92 \%$ & 20.17 \\
8.590 & 0.230 & \pm & 0.003 & 0.299 & \pm 0.001 & $30.03 \%$ & 19.87 \\
8.618 & 0.236 & \pm & 0.003 & 0.294 & \pm 0.001 & $24.61 \%$ & 17.40 \\
8.745 & 0.204 & \pm & 0.004 & 0.276 & \pm 0.001 & $35.51 \%$ & 19.50 \\
\hline 9.091 & 0.165 & \pm & 0.003 & 0.223 & \pm 0.001 & $35.34 \%$ & 20.25 \\
\hline
\end{tabular}

(a) Sample calculation models were run in source mode with $250,000,000$ neutron particle histories.

(b) ' $\mathrm{E}$ ' is the expected or benchmark value. ' $\mathrm{C}$ ' is the calculated value.

(c) ' $\mathrm{E}$ ' is the expected or benchmark value. ' $\mathrm{C}$ ' is the calculated value. $\sigma$ is the benchmark model uncertainty.

\subsubsection{Relative Fission Density}

The relative fission density was calculated using the models described in Section 3.7 with MCNP5-1.60 and ENDF/B-VII.0 neutron cross section libraries. The flux was calculated using a superimposed mesh tally over the center line of the sphere. The sample calculation results are given in Table 4.7-3 for the detailed benchmark model and Table 4.7-4 for the simple benchmark model. The deviation between the calculated values and benchmark model values is quite variable although all but one point is within $3 \sigma$. 
NEA/NSC/DOC(2006)1

Fundamental-FUND

ORSPHERE-FUND-EXP-001

CRIT-REAC-COEF-KIN-RRATE

Table 4.7-3. Sample Calculation Results for the Relative Fission Density, Detailed Model. MCNP5-1.60, ENDF/B-VII.0

\begin{tabular}{|c|ccc|cc|c|c|}
\hline Radius $^{(\mathrm{a})}$ & \multicolumn{2}{|c|}{$\begin{array}{c}\text { Detailed Benchmark } \\
\text { Model Value }\end{array}$} & \multicolumn{2}{|c|}{$\begin{array}{c}\text { Sample Calculation } \\
\text { Results }\end{array}$} & $(\mathrm{C}-\mathrm{E}) / \mathrm{E}^{(\mathrm{b})}$ & $(\mathrm{C}-\mathrm{E}) / \sigma^{(\mathrm{c})}$ \\
\hline-8.265 & 0.261 & \pm & 0.002 & 0.2579 & \pm 0.00003 & $-1.17 \%$ & -1.6 \\
\hline-7.633 & 0.354 & \pm & 0.002 & 0.3461 & \pm 0.00004 & $-2.23 \%$ & -3.4 \\
\hline-6.995 & 0.440 & \pm & 0.003 & 0.4319 & \pm 0.00004 & $-1.83 \%$ & -2.9 \\
\hline-6.355 & 0.519 & \pm & 0.003 & 0.5154 & \pm 0.00005 & $-0.70 \%$ & -1.2 \\
\hline-5.725 & 0.603 & \pm & 0.004 & 0.5946 & \pm 0.00006 & $-1.39 \%$ & -2.1 \\
\hline-5.088 & 0.672 & \pm & 0.005 & 0.6710 & \pm 0.00006 & $-0.15 \%$ & -0.2 \\
\hline-4.450 & 0.746 & \pm & 0.004 & 0.7424 & \pm 0.00007 & $-0.49 \%$ & -0.8 \\
\hline-3.815 & 0.810 & \pm & 0.006 & 0.8063 & \pm 0.00007 & $-0.46 \%$ & -0.7 \\
\hline-3.180 & 0.871 & \pm & 0.005 & 0.8627 & \pm 0.00008 & $-0.95 \%$ & -1.5 \\
\hline-2.54 & 0.910 & \pm & 0.006 & 0.9110 & \pm 0.00008 & $0.11 \%$ & 0.2 \\
\hline-1.908 & 0.951 & \pm & 0.006 & 0.9490 & \pm 0.00008 & $-0.21 \%$ & -0.3 \\
\hline-1.272 & 0.978 & \pm & 0.006 & 0.9775 & \pm 0.00009 & $-0.05 \%$ & -0.1 \\
\hline-0.635 & 1.001 & \pm & 0.007 & 0.9942 & \pm 0.00009 & $-0.68 \%$ & -1.0 \\
\hline 0 & & 1 & & & 1 & - & - \\
\hline 0.635 & 0.996 & \pm & 0.006 & 0.9945 & \pm 0.00009 & $-0.15 \%$ & -0.3 \\
\hline 1.272 & 0.978 & \pm & 0.006 & 0.9778 & \pm 0.00009 & $-0.02 \%$ & 0.0 \\
\hline 1.908 & 0.956 & \pm & 0.006 & 0.9497 & \pm 0.00008 & $-0.66 \%$ & -1.0 \\
\hline 2.543 & 0.910 & \pm & 0.006 & 0.9115 & \pm 0.00008 & $0.17 \%$ & 0.3 \\
\hline 3.180 & 0.872 & \pm & 0.006 & 0.8632 & \pm 0.00008 & $-1.01 \%$ & -1.5 \\
\hline 3.815 & 0.810 & \pm & 0.005 & 0.8061 & \pm 0.00007 & $-0.48 \%$ & -0.8 \\
\hline 4.450 & 0.742 & \pm & 0.005 & 0.7418 & \pm 0.00007 & $-0.02 \%$ & 0.0 \\
\hline 5.088 & 0.675 & \pm & 0.004 & 0.6707 & \pm 0.00006 & $-0.63 \%$ & -1.0 \\
\hline 5.725 & 0.600 & \pm & 0.004 & 0.5944 & \pm 0.00006 & $-0.93 \%$ & -1.6 \\
\hline 6.355 & 0.518 & \pm & 0.006 & 0.5154 & \pm 0.00005 & $-0.51 \%$ & -0.4 \\
\hline 6.995 & 0.438 & \pm & 0.003 & 0.4316 & \pm 0.00004 & $-1.46 \%$ & -2.0 \\
\hline 7.633 & 0.351 & \pm & 0.002 & 0.3463 & \pm 0.00004 & $-1.33 \%$ & -2.0 \\
\hline 8.265 & 0.257 & \pm & 0.003 & 0.2579 & \pm 0.00003 & $0.34 \%$ & 0.3 \\
\hline
\end{tabular}

(a) Sample calculation models were run in kcode mode with 500,000 histories for 2650 cycles, skipping the first 150 cycles.

(b) ' $\mathrm{E}$ ' is the expected or benchmark value. ' $\mathrm{C}$ ' is the calculated value.

(c) ' $\mathrm{E}$ ' is the expected or benchmark value. ' $\mathrm{C}$ ' is the calculated value. $\sigma$ is the benchmark model uncertainty. 
NEA/NSC/DOC(2006)1

Fundamental-FUND

ORSPHERE-FUND-EXP-001

CRIT-REAC-COEF-KIN-RRATE

Table 4.7-4. Sample Calculation Results for the Relative Fission Density, Simple Model. MCNP5-1.60, ENDF/B-VII.0

\begin{tabular}{||c|ccc|ccc|c|c||}
\hline Radius $^{\text {(a) }}$ & \multicolumn{2}{|c|}{$\begin{array}{c}\text { Simple Benchmark } \\
\text { Model Value }\end{array}$} & $\begin{array}{c}\text { Sample Calculation } \\
\text { Results }\end{array}$ & $(\mathrm{C}-\mathrm{E}) / \mathrm{E}^{(\mathrm{b})}$ & $(\mathrm{C}-\mathrm{E}) / \sigma^{(\mathrm{c})}$ \\
\hline \hline-8.265 & 0.260 & \pm & 0.002 & 0.2565 & \pm 0.00003 & $-1.27 \%$ & -1.8 \\
\hline-7.633 & 0.353 & \pm & 0.002 & 0.3453 & \pm 0.00004 & $-2.11 \%$ & -3.2 \\
\hline-6.995 & 0.438 & \pm & 0.003 & 0.4305 & \pm 0.00004 & $-1.74 \%$ & -2.8 \\
\hline-6.355 & 0.519 & \pm & 0.003 & 0.5144 & \pm 0.00005 & $-0.89 \%$ & -1.5 \\
\hline-5.725 & 0.603 & \pm & 0.004 & 0.5941 & \pm 0.00006 & $-1.47 \%$ & -2.2 \\
\hline-5.088 & 0.672 & \pm & 0.005 & 0.6700 & \pm 0.00006 & $-0.30 \%$ & -0.4 \\
\hline-4.450 & 0.746 & \pm & 0.004 & 0.7417 & \pm 0.00007 & $-0.57 \%$ & -1.0 \\
\hline-3.815 & 0.810 & \pm & 0.006 & 0.8058 & \pm 0.00007 & $-0.52 \%$ & -0.8 \\
\hline-3.180 & 0.871 & \pm & 0.005 & 0.8629 & \pm 0.00008 & $-0.92 \%$ & -1.5 \\
\hline-2.54 & 0.910 & \pm & 0.006 & 0.9110 & \pm 0.00008 & $0.11 \%$ & 0.2 \\
\hline-1.908 & 0.951 & \pm & 0.006 & 0.9496 & \pm 0.00008 & $-0.15 \%$ & -0.2 \\
\hline-1.272 & 0.978 & \pm & 0.006 & 0.9774 & \pm 0.00009 & $-0.06 \%$ & -0.1 \\
\hline-0.635 & 1.001 & \pm & 0.007 & 0.9936 & \pm 0.00009 & $-0.74 \%$ & -1.1 \\
\hline 0 & & 1 & & & 1 & - & - \\
\hline 0.635 & 0.996 & \pm & 0.006 & 0.9941 & \pm 0.00009 & $-0.19 \%$ & -0.3 \\
\hline 1.272 & 0.978 & \pm & 0.006 & 0.9764 & \pm 0.00009 & $-0.16 \%$ & -0.3 \\
\hline 1.908 & 0.956 & \pm & 0.006 & 0.9490 & \pm 0.00008 & $-0.73 \%$ & -1.1 \\
\hline 2.543 & 0.910 & \pm & 0.006 & 0.9107 & \pm 0.00008 & $0.08 \%$ & 0.1 \\
\hline 3.180 & 0.872 & \pm & 0.006 & 0.8627 & \pm 0.00008 & $-1.07 \%$ & -1.6 \\
\hline 3.815 & 0.810 & \pm & 0.005 & 0.8064 & \pm 0.00007 & $-0.45 \%$ & -0.8 \\
\hline 4.450 & 0.742 & \pm & 0.005 & 0.7413 & \pm 0.00007 & $-0.09 \%$ & -0.1 \\
\hline 5.088 & 0.675 & \pm & 0.004 & 0.6704 & \pm 0.00006 & $-0.68 \%$ & -1.1 \\
\hline 5.725 & 0.599 & \pm & 0.004 & 0.5934 & \pm 0.00006 & $-0.93 \%$ & -1.5 \\
\hline 6.355 & 0.517 & \pm & 0.006 & 0.5144 & \pm 0.00005 & $-0.46 \%$ & -0.4 \\
\hline 6.995 & 0.437 & \pm & 0.003 & 0.4309 & \pm 0.00004 & $-1.35 \%$ & -1.8 \\
\hline 7.633 & 0.350 & \pm & 0.002 & 0.3452 & \pm 0.00004 & $-1.31 \%$ & -2.0 \\
\hline 8.265 & 0.255 & \pm & 0.003 & 0.2566 & \pm 0.00003 & $0.45 \%$ & 0.4 \\
\hline
\end{tabular}

(a) Sample calculation models were run in kcode mode with 500,000 histories for 2650 cycles, skipping the first 150 cycles.

(b) ' $\mathrm{E}$ ' is the expected or benchmark value. ' $\mathrm{C}$ ' is the calculated value.

(c) ' $\mathrm{E}$ ' is the expected or benchmark value. ' $\mathrm{C}$ ' is the calculated value. $\sigma$ is the benchmark model uncertainty. 


$$
\begin{gathered}
\text { NEA/NSC/DOC(2006)1 } \\
\text { Fundamental-FUND } \\
\text { ORSPHERE-FUND-EXP-001 } \\
\text { CRIT-REAC-COEF-KIN-RRATE }
\end{gathered}
$$

\subsection{Results of Power Distribution Calculations}

Power distribution measurements were not performed.

\subsection{Results of Isotopic Calculations}

Isotopic measurements were not performed.

\subsection{Results of Calculations for Other Miscellaneous Types of Measurements}

Other miscellaneous types of measurements were not performed. 


\section{NEA/NSC/DOC(2006)1 \\ Fundamental-FUND \\ ORSPHERE-FUND-EXP-001 \\ CRIT-REAC-COEF-KIN-RRATE}

\subsection{REFERENCES}

1. J.T. Mihalczo, J. J. Lynn, J. R. Taylor, G. E. Hansen, and D. B. Pelowitz, "Delayed Critical ORNL Unreflected Uranium (93.20) Metal Sphere and the Pure Unreflected Uranium (93.80) Sphere Critical Mass," Ann. Nucl. Energy, 29, 525-560 (2002).

2. J.T. Mihaclzo, J. J. Lynn, J. R. Taylor, and G. E. Hansen, "Measurements with an Unreflected Uranium (93.2\%) Metal Sphere," PHYSOR 1993, Nashville, TN, September 19-23 (1993).

3. J.T. Mihalczo, J.J. Lynn, and J.R. Taylor, "The Central Void Reactivity in the Oak Ridge National Laboratory Enriched Uranium (93.2) Metal Sphere,” Nuc. Sci. and Eng., 130, 153-163 (1998).

4. J. T. Mihalczo, J. J. Lynn, and J. R. Taylor, "The Central Void Reactivity in the Oak Ridge Enriched Uranium (93.2) Metal Sphere,” ORNL/TM-13349, Oak Ridge National Laboratory (1997).

5. J. T. Mihalczo, "The Effective Delayed Neutron Fraction from Fission in an Unreflected Uranium Sphere from Time Correlation Measurements with Californium-252," Nucl. Sci. Eng., 60, 262-275 (1976).

6. J. T. Mihalczo, "Prompt Neutron Decay for Delayed Critical Bare and Natural-UraniumReflected Metal Spheres of Plutonium and Highly Enriched Uranium," Nucl. Tech., 175, 498508 (2011).

7. J.T. Mihalczo, "Propmt Neutron Decay for an unreflected and Unmoderated Uranium (HEU) Metal Sphere,” PHYSOR 1996, Mito, Japan, September 16-20, (1996).

8. J. T. Mihalczo, "Neutron Importance and Fission Density in Uranium-235-Enriched Uranium and Plutonium Metal Spheres,” Nucl. Sci. Eng., 56, 271-290 (1975). 


\author{
NEA/NSC/DOC(2006)1 \\ Fundamental-FUND \\ ORSPHERE-FUND-EXP-001 \\ CRIT-REAC-COEF-KIN-RRATE
}

\title{
APPENDIX A: COMPUTER CODES, CROSS SECTIONS, AND TYPICAL INPUT LISTINGS
}

Models were created using Monte Carlo n-Particle (MCNP), Version 5-1.60, and ENDF/B-VII.0 neutron cross section libraries. Models were run using 500000 histories per cycle for 2650 cycles, skipping the first 150 cycles. Isotopic abundances for all elements except uranium were taken from "Nuclides and Isotopes: Chart of the Nuclides," Sixteenth Edition, KAPL, 2002. The uranium is highly enriched in ${ }^{235} U$ and the isotopic abundances are given for the benchmark models in Section 3.

\section{A.1 Critical/Subcritical Configurations}

The criticality portion of this evaluation has been reviewed and approved by the International Criticality Safety Benchmark Evaluation Project (ICSBEP) and has been published under the following identifier: HEU-MET-FAST-100 .

\section{A.2 Buckling and Extrapolation Length Configurations}

Buckling and extrapolation-length measurements were not performed.

\section{A.3 Spectral-Characteristics Configurations}

Spectral Characteristic measurements were not performed.

\section{A.4 Reactivity-Effects Configurations}

\section{A.4.1 Name(s) of Code System(s) Used}

1. Monte Carlo n-Particle, Version 5.1.60 (MCNP5).

\section{A.4.2 Bibliographic References for the Codes Used}

1. F. B. Brown, R. F. Barrett, T. E. Booth, J. S. Bull, L. J. Cox, R. A. Forster, T. J. Goorley, R. D. Mosteller, S. E. Post, R. E. Prael, E. C. Selcow, A. Sood, and J. Sweezy, "MCNP Version 5," LA-UR-02-3935, Los Alamos National Laboratory (2002).

\section{A.4.3 Origin of Cross-section Data}

The evaluated neutron data file library ENDF/B-VII. $0^{\mathrm{b}}$ was utilized in the benchmark-model analysis.

\section{A.4.4 Spectral Calculations and Data Reduction Methods Used}

Not applicable.

\footnotetext{
a International Handbook of Evaluated Criticality Safety Benchmark Experiments, NEA/NSC/DOC(95)03, OECDNEA, Paris (2013).

b M. B. Chadwick, et al., "ENDF/B-VII.0: Next Generation Evaluated Nuclear Data Library for Nuclear Science and Technology," Nucl. Data Sheets, 107: 2931-3060 (2006).
} 
NEA/NSC/DOC(2006)1

Fundamental-FUND

ORSPHERE-FUND-EXP-001

CRIT-REAC-COEF-KIN-RRATE

\section{A.4.5 Number of Energy Groups or If Continuous-energy Cross Sections are Used in the Different Phases of Calculation}

1. Continuous-energy cross sections.

\section{A.4.6 Component Calculations}

Not applicable

\section{A.4.7 Other Assumptions and Characteristics}

Not applicable.

\section{A.4.8 Typical Input Listings for Each Code System Type}

The following sample input decks are provided:

MCNP5 Input Deck for Central Void Reactivity Benchmark Models

MCNP5 Input Deck for Surface Button Worth Benchmark Models

Benchmark Model 16, 0.635-cm-thick Uranium Buttons

Perturbed Benchmark Model for Worth of 4, 0.3175-cm-thick Buttons

MCNP5 Input Deck for Button Worth in Empty Socket Hole Benchmark Models

MCNP5 Input Deck for Diametral Filler Rod Worth Benchmark Models

MCNP5 Input Deck for Central Void Reactivity Benchmark Models:

Reference Benchmark Model

For the perturbed benchmark model the small 0.5842-cm-radius sphere (cell number 354) is removed.

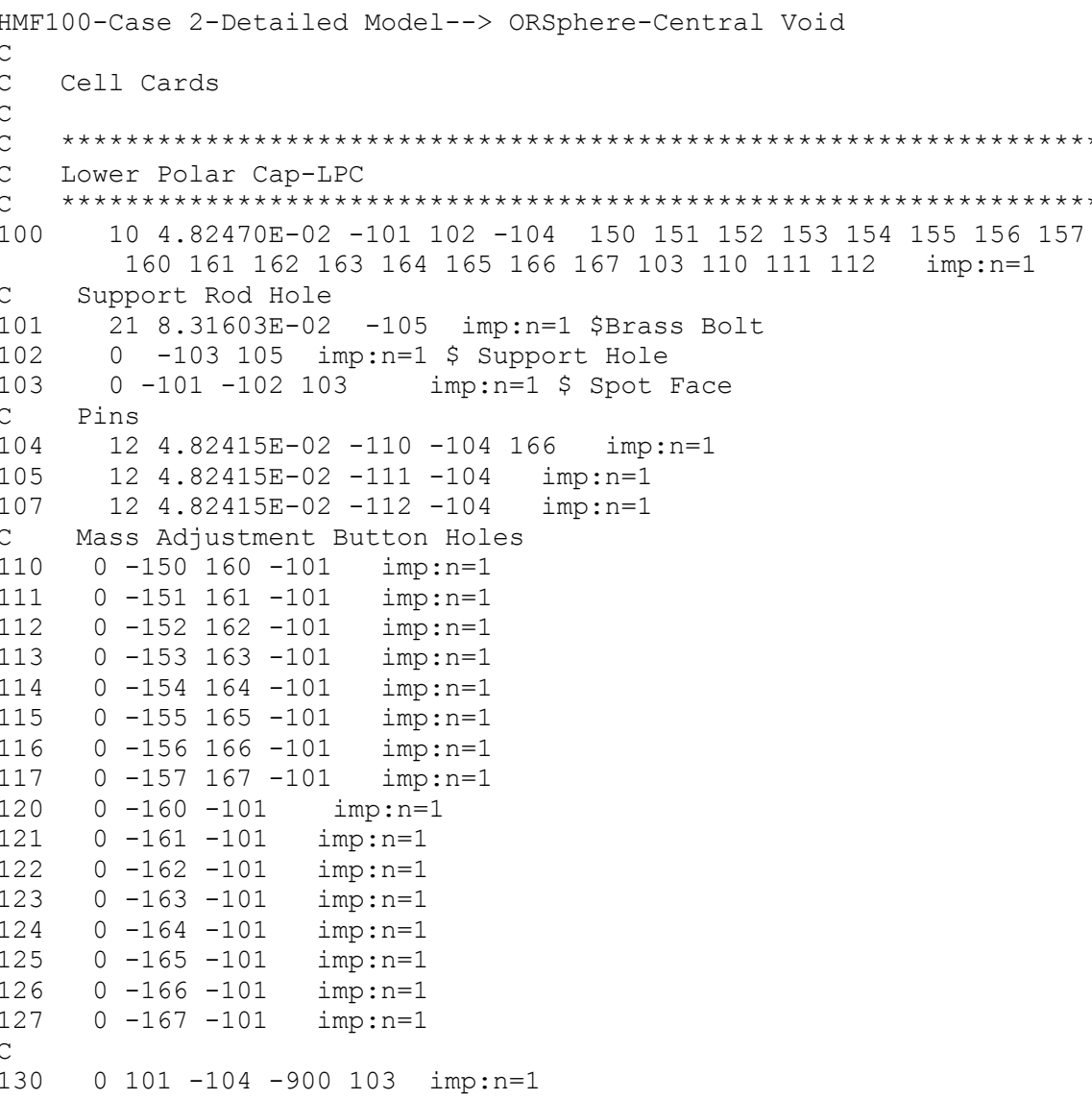


NEA/NSC/DOC(2006)1

Fundamental-FUND

ORSPHERE-FUND-EXP-001

CRIT-REAC-COEF-KIN-RRATE

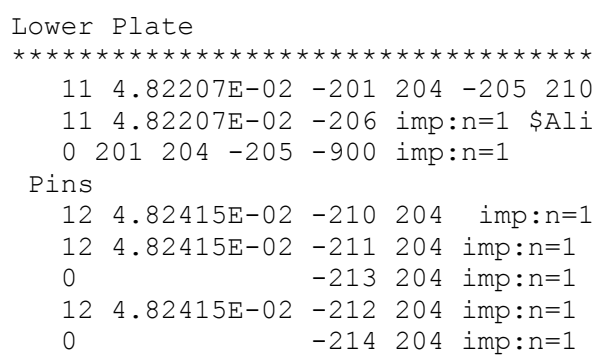


NEA/NSC/DOC(2006)1

Fundamental-FUND

ORSPHERE-FUND-EXP-001

CRIT-REAC-COEF-KIN-RRATE

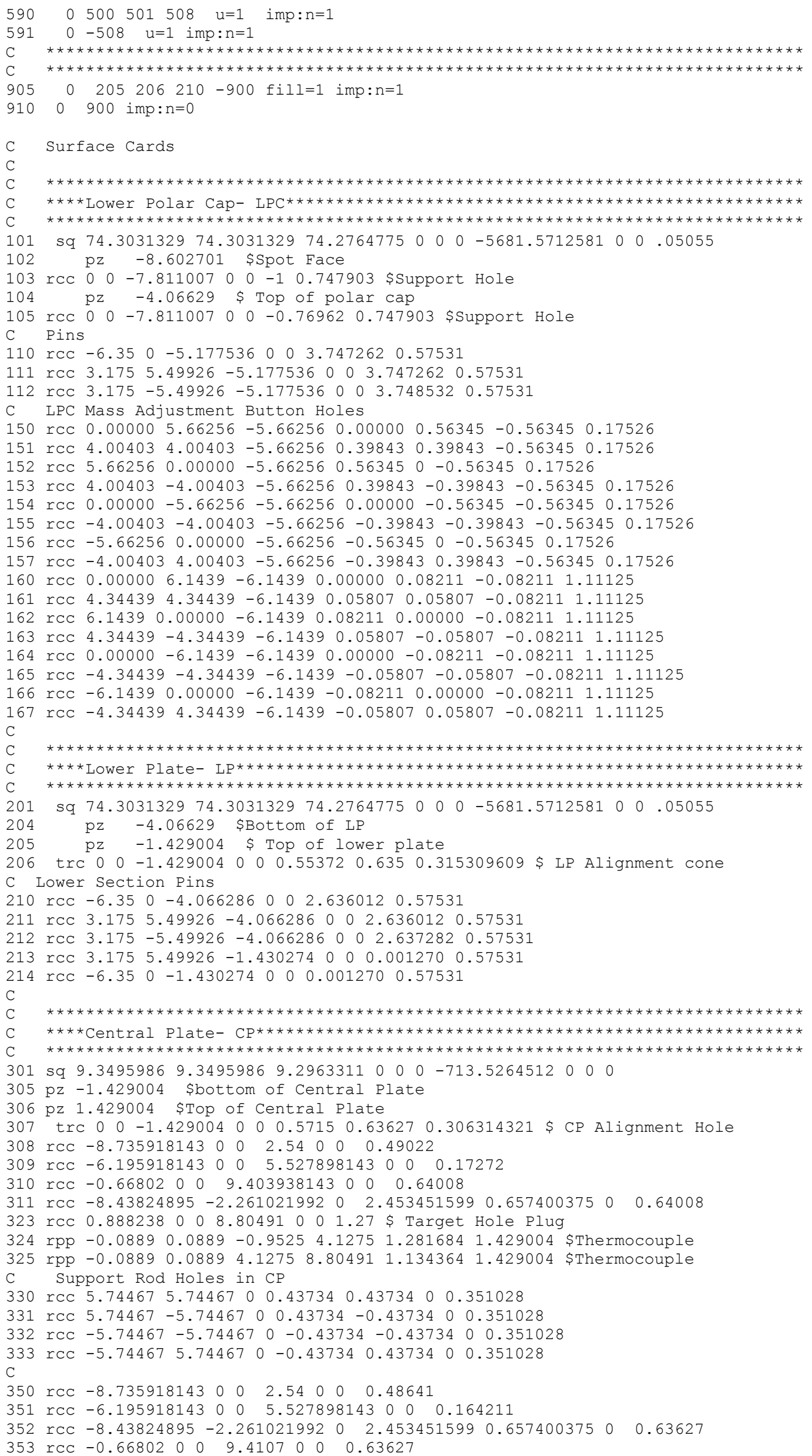

\section{Revision: 1}


NEA/NSC/DOC(2006)1

Fundamental-FUND

ORSPHERE-FUND-EXP-001

CRIT-REAC-COEF-KIN-RRATE

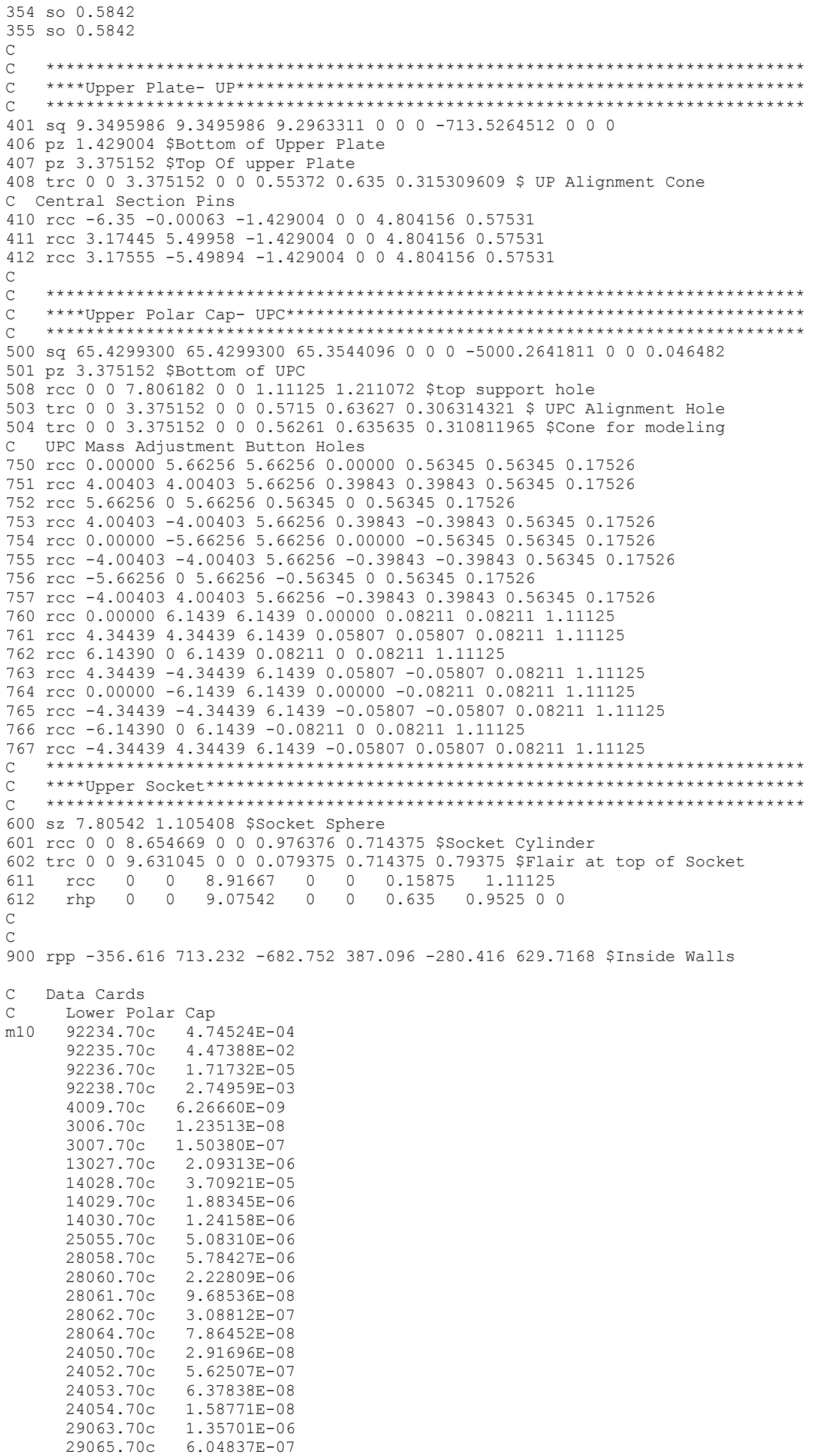

Revision: 1 
NEA/NSC/DOC(2006)1

Fundamental-FUND

ORSPHERE-FUND-EXP-001

CRIT-REAC-COEF-KIN-RRATE

\begin{tabular}{|c|c|c|}
\hline & $010.70 \mathrm{C}$ & $912 E-08$ \\
\hline & $5011.70 \mathrm{c}$ & $8.36873 \mathrm{E}-08$ \\
\hline & $27059.70 \mathrm{C}$ & $9.58303 \mathrm{E}-08$ \\
\hline & $20040.70 \mathrm{c}$ & $1.36604 \mathrm{E}-06$ \\
\hline & $20042.70 \mathrm{c}$ & $9.11719 \mathrm{E}-09$ \\
\hline & $20043.70 c$ & $1.90235 \mathrm{E}-09$ \\
\hline & $20044.70 \mathrm{c}$ & $2.93948 \mathrm{E}-0$ \\
\hline & $20046.70 \mathrm{c}$ & $5.63659 \mathrm{E}-1$ \\
\hline & $20048.70 \mathrm{c}$ & $2.63511 \mathrm{E}-0$ \\
\hline & $6000.70 \mathrm{c}$ & $1.68332 \mathrm{E}-04$ \\
\hline & $8016.70 \mathrm{c}$ & $1.40852 \mathrm{E}-05$ \\
\hline & $8017.70 \mathrm{C}$ & $3.43104 \mathrm{E}-08$ \\
\hline & $7014.70 \mathrm{c}$ & $2.41033 E-05$ \\
\hline & $7015.70 \mathrm{c}$ & $8.90279 E-08$ \\
\hline 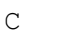 & Lower Plate & \\
\hline $\mathrm{m} 11$ & $92234.70 \mathrm{C}$ & $4.74733 \mathrm{E}-\mathrm{C}$ \\
\hline & $92235.70 \mathrm{c}$ & $4.47596 \mathrm{E}-0$ \\
\hline & $92236.70 \mathrm{c}$ & $1.71786 \mathrm{E}-0$ \\
\hline & $92238.70 \mathrm{c}$ & $2.73052 \mathrm{E}-0$ \\
\hline & $4009.70 c$ & $6.26450 \mathrm{E}-09$ \\
\hline & $3006.70 \mathrm{c}$ & $1.23472 \mathrm{E}-08$ \\
\hline & $3007.70 \mathrm{c}$ & $1.50329 \mathrm{E}-07$ \\
\hline & $13027.70 \mathrm{c}$ & $3.34789 \mathrm{E}-0$ \\
\hline & $14028.70 c$ & $4.63496 \mathrm{E}-0$ \\
\hline & $14029.70 \mathrm{c}$ & $2.35352 \mathrm{E}-0$ \\
\hline & $14030.70 \mathrm{c}$ & $1.55146 \mathrm{E}-0$ \\
\hline & $25055.70 c$ & $3.48963 \mathrm{E}-06$ \\
\hline & $28058.70 c$ & $3.97100 \mathrm{E}-0 \mathrm{E}$ \\
\hline & $28060.70 c$ & $1.52962 \mathrm{E}-0$ \\
\hline & $28061.70 \mathrm{C}$ & $6.64916 \mathrm{E}-08$ \\
\hline & $28062.70 c$ & $2.12004 \mathrm{E}-0$ \\
\hline & $28064.70 c$ & $5.39913 \mathrm{E}-0$ \\
\hline & $24050.70 c$ & $2.00254 \mathrm{E}-08$ \\
\hline & $24052.70 c$ & $3.86171 \mathrm{E}-0$ \\
\hline & $24053.70 c$ & $4.37887 \mathrm{E}-0$ \\
\hline & $24054.70 \mathrm{c}$ & $1.08999 \mathrm{E}-08$ \\
\hline & $29063.70 c$ & $9.31609 \mathrm{E}-07$ \\
\hline & $29065.70 \mathrm{c}$ & $4.15231 \mathrm{E}-0$ \\
\hline & $5010.70 c$ & $1.03921 \mathrm{E}-07$ \\
\hline & $5011.70 \mathrm{C}$ & $4.18296 \mathrm{E}-07$ \\
\hline & $27059.70 \mathrm{c}$ & $9.57982 \mathrm{E}-0$ \\
\hline & $20040.70 c$ & $1.36558 \mathrm{E}-06$ \\
\hline & $20042.70 c$ & $9.11413 \mathrm{E}-0$ \\
\hline & $20043.70 \mathrm{c}$ & $1.90171 \mathrm{E}-0$ \\
\hline & $20044.70 c$ & $2.93850 \mathrm{E}-08$ \\
\hline & $20046.70 c$ & $5.63470 \mathrm{E}-11$ \\
\hline & $20048.70 c$ & $2.63422 \mathrm{E}-0$ \\
\hline & $6000.70 \mathrm{c}$ & $1.33492 \mathrm{E}-04$ \\
\hline & $8016.70 c$ & $1.40805 \mathrm{E}-05$ \\
\hline & $8017.70 \mathrm{C}$ & $3.42989 \mathrm{E}-08$ \\
\hline & $7014.70 \mathrm{c}$ & $2.40952 \mathrm{E}-05$ \\
\hline & $7015.70 \mathrm{c}$ & $8.89980 \mathrm{E}-08$ \\
\hline & Pins for Lo & ver Part \\
\hline & $92234.70 \mathrm{C}$ & $4.79981 \mathrm{E}-04$ \\
\hline & $92235.70 \mathrm{c}$ & $4.47281 \mathrm{E}-0$ \\
\hline & $92236.70 \mathrm{c}$ & $2.15625 \mathrm{E}-0$ \\
\hline & $92238.70 \mathrm{c}$ & $2.55888 \mathrm{E}-03$ \\
\hline & $13027.70 \mathrm{c}$ & $2.09237 \mathrm{E}-0$ \\
\hline & $14028.70 \mathrm{c}$ & $4.44944 \mathrm{E}-0$ \\
\hline & $14029.70 \mathrm{c}$ & $2.25932 \mathrm{E}-0$ \\
\hline & $14030.70 \mathrm{c}$ & $1.48936 \mathrm{E}-0$ \\
\hline & $25055.70 \mathrm{C}$ & $3.79563 \mathrm{E}-0$ \\
\hline & $28058.70 c$ & $4.31922 \mathrm{E}-0$ \\
\hline & $28060.70 c$ & $1.66375 \mathrm{E}-0$ \\
\hline & $28061.70 \mathrm{c}$ & $7.23222 \mathrm{E}-0$ \\
\hline & $28062.70 c$ & $2.30595 \mathrm{E}-0$ \\
\hline & $28064.70 c$ & $5.87257 \mathrm{E}-0$ \\
\hline & $24050.70 \mathrm{c}$ & $2.17815 \mathrm{E}-0$ \\
\hline & $24052.70 c$ & $4.20034 \mathrm{E}-0$ \\
\hline & $24053.70 c$ & $4.76285 \mathrm{E}-0$ \\
\hline & $24054.70 c$ & $1.18557 \mathrm{E}-0$ \\
\hline & $29063.70 \mathrm{c}$ & $1.01330 \mathrm{E}-0$ \\
\hline & $29065.70 \mathrm{c}$ & $4.51642 \mathrm{E}-0$ \\
\hline & $5010.70 c$ & $6.23511 \mathrm{E}-08$ \\
\hline & $5011.70 \mathrm{c}$ & $2.50971 \mathrm{E}-07$ \\
\hline & 0000.70 & $1.57930 \mathrm{E}-0$ \\
\hline & م016 & $1.40801 \mathrm{E}-0$ \\
\hline
\end{tabular}

\$ Total 4.82470E-02 
NEA/NSC/DOC(2006)1

Fundamental-FUND

ORSPHERE-FUND-EXP-001

CRIT-REAC-COEF-KIN-RRATE

\begin{tabular}{|c|c|c|}
\hline & $\begin{array}{l}8017.70 \mathrm{C} \\
7014.70 \mathrm{C} \\
7015.70 \mathrm{c}\end{array}$ & $\begin{array}{l}3.42979 \mathrm{E}-08 \\
2.40946 \mathrm{E}-05 \\
8.89956 \mathrm{E}-08\end{array}$ \\
\hline C & $\begin{array}{l}\text { Central Pla } \\
92234.70 \mathrm{c} \\
92235.70 \mathrm{c} \\
92236.70 \mathrm{c} \\
92238.70 \mathrm{c} \\
4009.70 \mathrm{c} \\
3006.70 \mathrm{c} \\
3007.70 \mathrm{c} \\
13027.70 \mathrm{c} \\
14028.70 \mathrm{c} \\
14029.70 \mathrm{c} \\
14030.70 \mathrm{c} \\
25055.70 \mathrm{c} \\
28058.70 \mathrm{c} \\
28060.70 \mathrm{c} \\
28061.70 \mathrm{c} \\
28062.70 \mathrm{c} \\
28064.70 \mathrm{c} \\
24050.70 \mathrm{c} \\
24052.70 \mathrm{c} \\
24053.70 \mathrm{c} \\
24054.70 \mathrm{c} \\
29063.70 \mathrm{c} \\
29065.70 \mathrm{c} \\
5010.70 \mathrm{c} \\
5011.70 \mathrm{c} \\
27059.70 \mathrm{c} \\
20040.70 \mathrm{c} \\
20042.70 \mathrm{c} \\
20043.70 \mathrm{c} \\
20044.70 \mathrm{c} \\
20046.70 \mathrm{c} \\
20048.70 \mathrm{c} \\
6000.70 \mathrm{c} \\
8016.70 \mathrm{c} \\
8017.70 \mathrm{c} \\
7014.70 \mathrm{c} \\
7015.70 \mathrm{c}\end{array}$ & $\begin{array}{l}\text { 4.76368E-04 } \\
4.49131 \mathrm{E}-02 \\
1.72364 \mathrm{E}-05 \\
2.75010 \mathrm{E}-03 \\
6.28627 \mathrm{E}-09 \\
1.23901 \mathrm{E}-08 \\
1.50852 \mathrm{E}-07 \\
1.67976 \mathrm{E}-06 \\
7.44171 \mathrm{E}-05 \\
3.77872 \mathrm{E}-06 \\
2.49096 \mathrm{E}-06 \\
3.07172 \mathrm{E}-06 \\
3.49544 \mathrm{E}-06 \\
1.34644 \mathrm{E}-06 \\
5.85287 \mathrm{E}-08 \\
1.86615 \mathrm{E}-07 \\
4.75254 \mathrm{E}-08 \\
1.76272 \mathrm{E}-08 \\
3.39924 \mathrm{E}-07 \\
3.85446 \mathrm{E}-08 \\
9.59457 \mathrm{E}-09 \\
8.20042 \mathrm{E}-07 \\
3.65504 \mathrm{E}-07 \\
4.17130 \mathrm{E}-08 \\
1.67900 \mathrm{E}-07 \\
9.61312 \mathrm{E}-08 \\
1.37033 \mathrm{E}-06 \\
9.14582 \mathrm{E}-09 \\
1.90832 \mathrm{E}-09 \\
2.94871 \mathrm{E}-08 \\
5.65429 \mathrm{E}-11 \\
2.64338 \mathrm{E}-09 \\
1.49993 \mathrm{E}-04 \\
1.41294 \mathrm{E}-05 \\
3.44181 \mathrm{E}-08 \\
2.41790 \mathrm{E}-05 \\
8.93074 \mathrm{E}-08\end{array}$ \\
\hline & per Plate & \\
\hline & $\begin{array}{l}92234.70 c \\
92235.70 c \\
92236.70 c \\
92238.70 c \\
4009.70 c \\
3006.70 c \\
3007.70 c \\
13027.70 c \\
14028.70 c \\
14029.70 c \\
14030.70 c \\
25055.70 c \\
28058.70 c \\
28060.70 c \\
28061.70 c \\
28062.70 c \\
28064.70 c \\
24050.70 c \\
24052.70 c \\
24053.70 c \\
24054.70 c \\
29063.70 c \\
29065.70 c \\
5010.70 c \\
5011.70 c \\
27059.70 c \\
20040.70 c \\
20042.70 c \\
20043.70 c \\
20044.70 c \\
20046.70 c \\
20048.70 c \\
6000.70 c \\
8016.70 c \\
8017.70 c\end{array}$ & $\begin{array}{c}4.76471 \mathrm{E}-04 \\
4.49232 \mathrm{E}-02 \\
1.72432 \mathrm{E}-05 \\
2.74561 \mathrm{E}-03 \\
6.28700 \mathrm{E}-09 \\
1.23915 \mathrm{E}-08 \\
1.50869 \mathrm{E}-07 \\
1.67996 \mathrm{E}-06 \\
3.72129 \mathrm{E}-05 \\
1.88958 \mathrm{E}-06 \\
1.24562 \mathrm{E}-06 \\
2.08901 \mathrm{E}-06 \\
2.37718 \mathrm{E}-06 \\
9.15684 \mathrm{E}-07 \\
3.98041 \mathrm{E}-08 \\
1.26913 \mathrm{E}-07 \\
3.23210 \mathrm{E}-08 \\
1.19879 \mathrm{E}-08 \\
2.31175 \mathrm{E}-07 \\
2.62134 \mathrm{E}-08 \\
6.52506 \mathrm{E}-09 \\
5.57693 \mathrm{E}-07 \\
2.48571 \mathrm{E}-07 \\
6.25767 \mathrm{E}-08 \\
2.51879 \mathrm{E}-07 \\
9.61423 \mathrm{E}-08 \\
1.37049 \mathrm{E}-06 \\
9.14688 \mathrm{E}-09 \\
1.90854 \mathrm{E}-09 \\
2.94905 \mathrm{E}-08 \\
5.65495 \mathrm{E}-11 \\
2.64369 \mathrm{E}-09 \\
1.50011 \mathrm{E}-04 \\
1.41310 \mathrm{E}-05 \\
3.44221 \mathrm{E}-08\end{array}$ \\
\hline
\end{tabular}

\$ Total 4.82415E-02

$-4.82415 \mathrm{E}-02$ 
NEA/NSC/DOC(2006)1

Fundamental-FUND

ORSPHERE-FUND-EXP-001

CRIT-REAC-COEF-KIN-RRATE

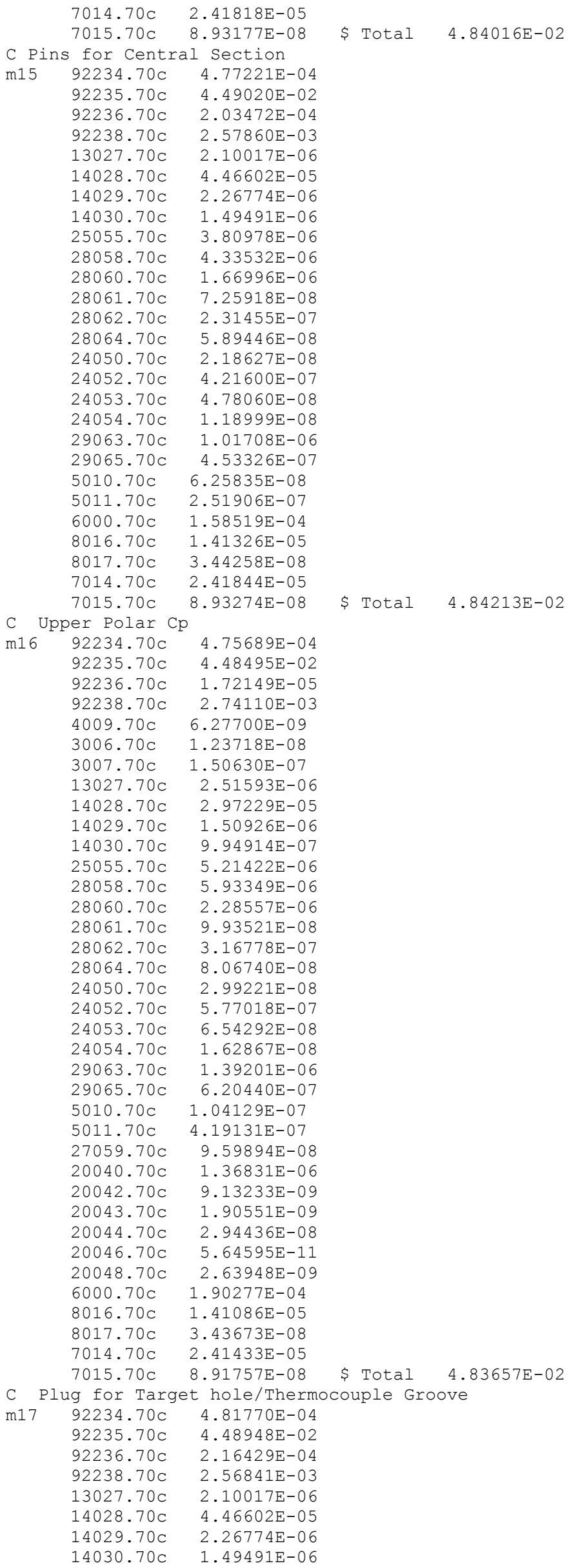

Revision: 1 
NEA/NSC/DOC(2006)1

Fundamental-FUND

ORSPHERE-FUND-EXP-001

CRIT-REAC-COEF-KIN-RRATE

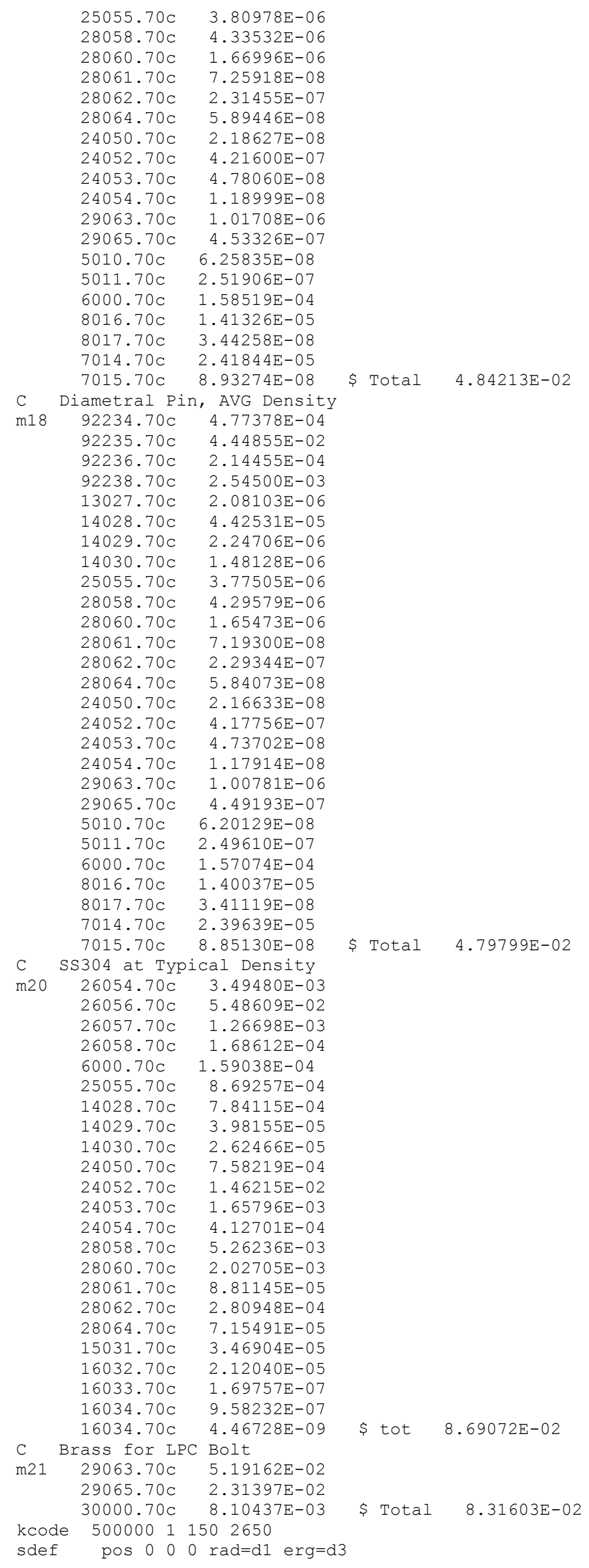

Revision: 1

Date: March 31, 2015

Page 110 of 169 
NEA/NSC/DOC(2006)1

Fundamental-FUND

ORSPHERE-FUND-EXP-001

CRIT-REAC-COEF-KIN-RRATE

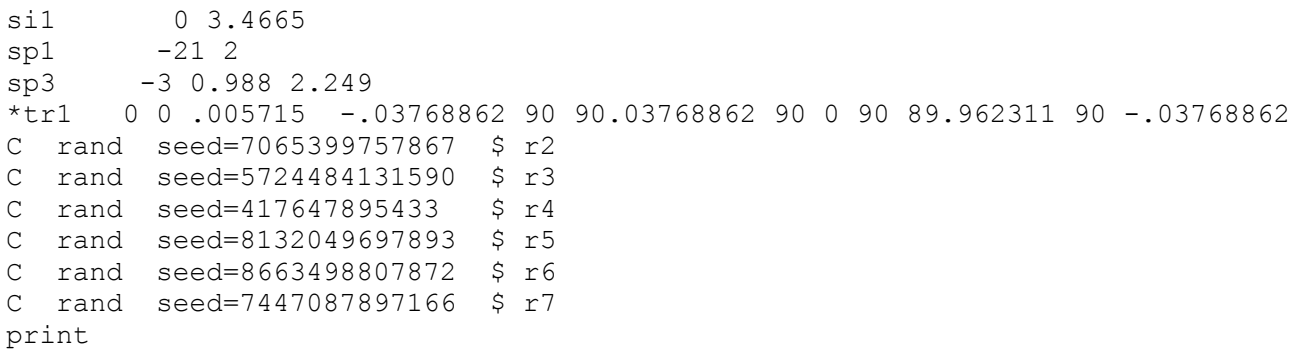

MCNP5 Input Deck for Surface Button Worth Benchmark Models:

Benchmark Model 16, 0.635-cm-thick Uranium Buttons

The reference benchmark model for this measurement had zero mass adjustment buttons and holding screws present. The buttons are modeled as cells $800-807$ and $850-857$. The holding screws are modeled as cells 110-117, $560-567,820-827$, and 870-877.

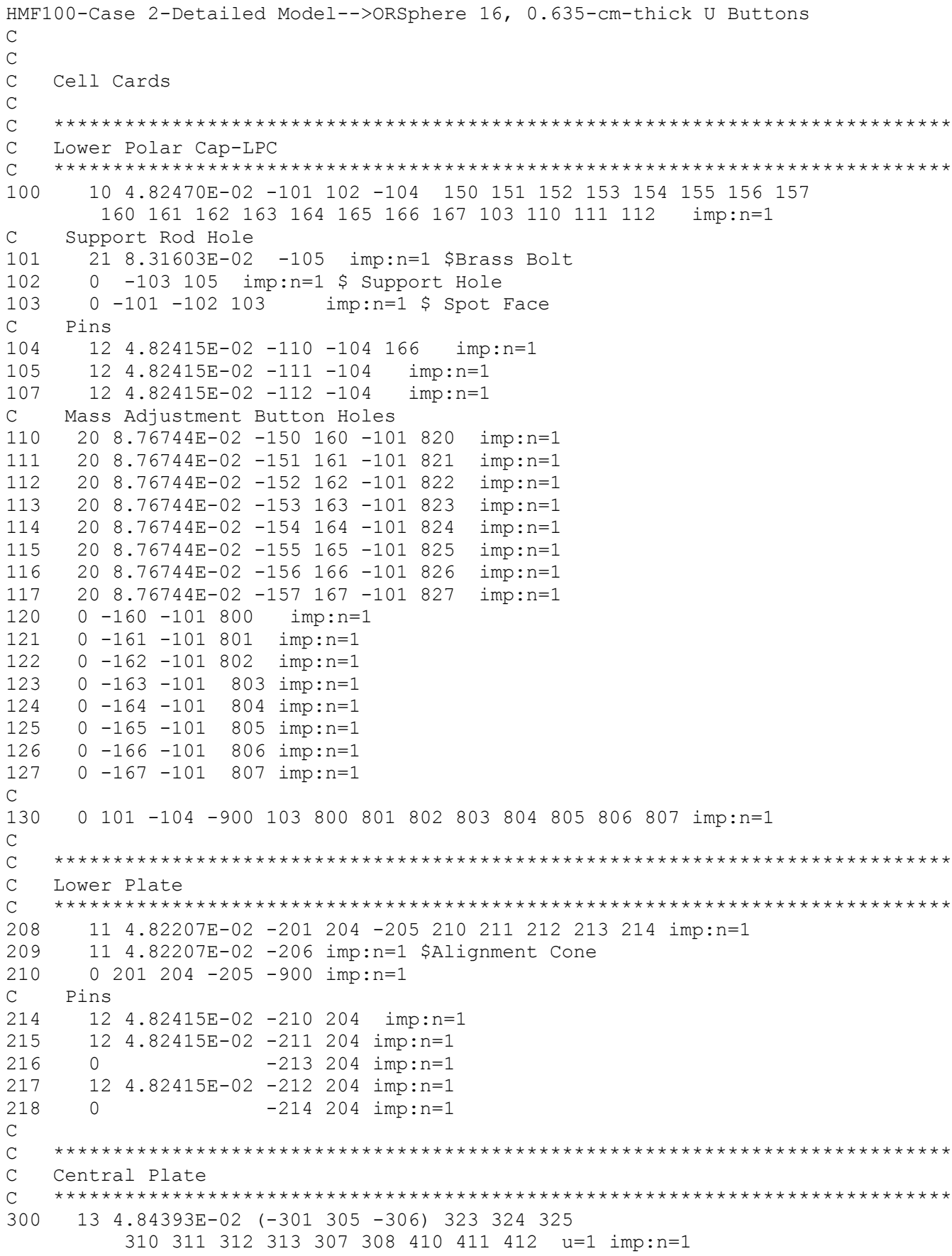

Revision: 1 
NEA/NSC/DOC(2006)1

Fundamental-FUND

\section{ORSPHERE-FUND-EXP-001}

CRIT-REAC-COEF-KIN-RRATE

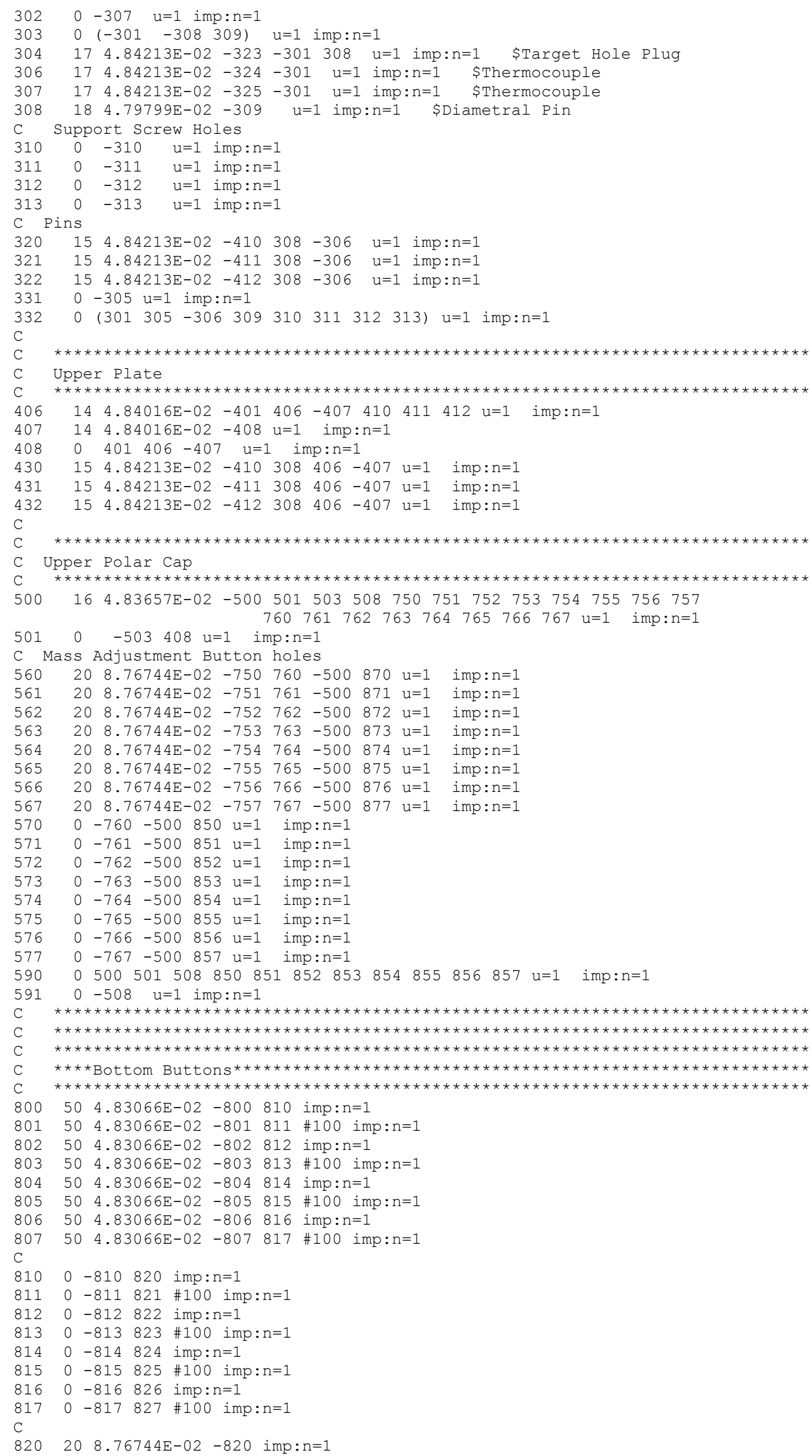

Revision: 1 
NEA/NSC/DOC(2006)1

Fundamental-FUND

ORSPHERE-FUND-EXP-001

CRIT-REAC-COEF-KIN-RRATE

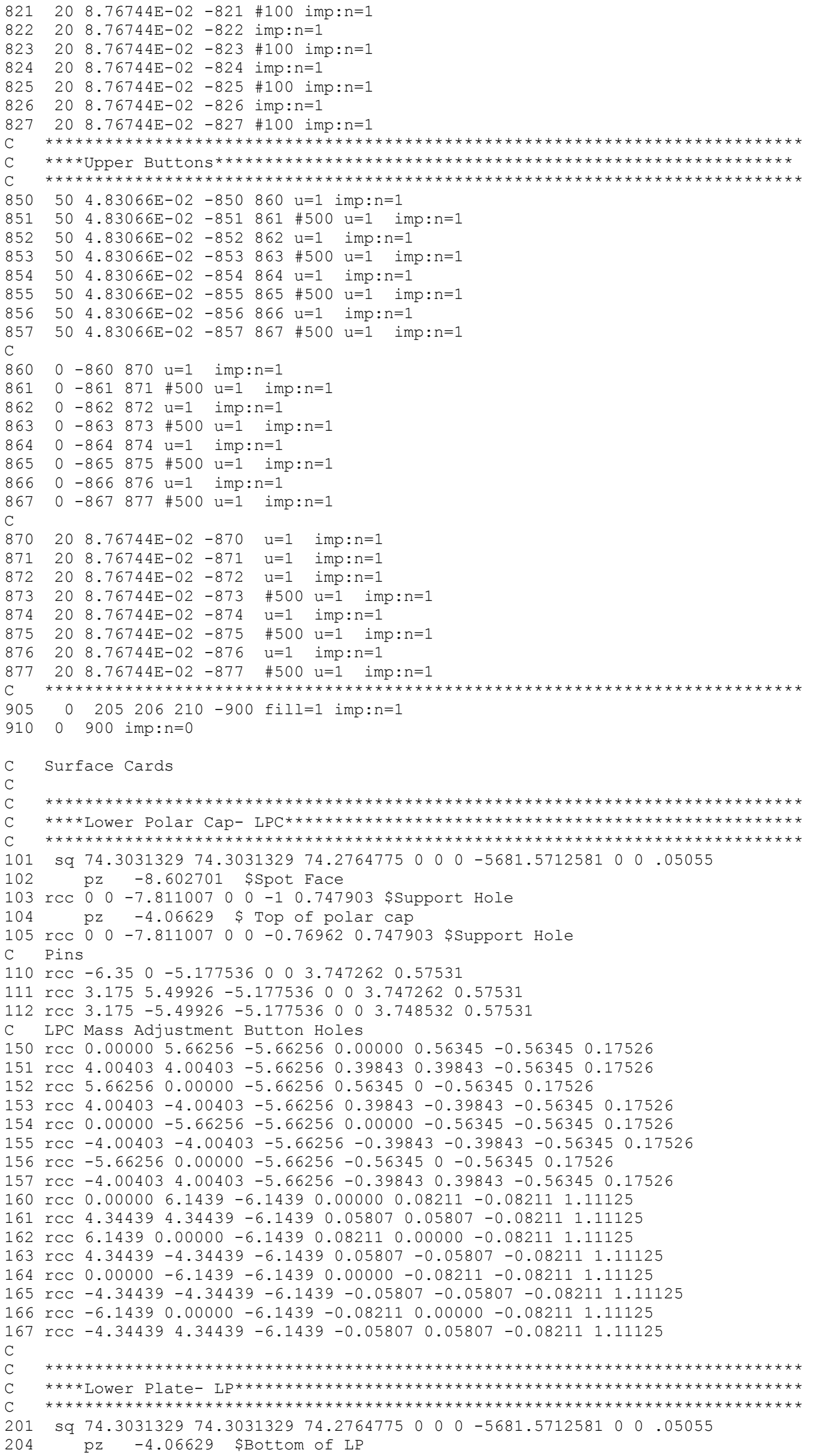

Revision: 1 
NEA/NSC/DOC(2006)1

\section{Fundamental-FUND}

\section{ORSPHERE-FUND-EXP-001 \\ CRIT-REAC-COEF-KIN-RRATE}

$205 \mathrm{pz}-1.429004$ \$ Top of lower plate

$206 \operatorname{trc} 0 \quad 0 \quad-1.429004000 .553720 .6350 .315309609$ \$ LP Alignment cone

C Lower Section Pins

210 rcc $-6.35 \quad 0 \quad-4.066286 \quad 0 \quad 0 \quad 2.636012 \quad 0.57531$

$211 \operatorname{rcc} 3.175 \quad 5.49926 \quad-4.066286 \quad 0 \quad 0 \quad 2.636012 \quad 0.57531$

$212 \operatorname{rcc} 3.175 \quad-5.49926-4.06628600002 .637282 \quad 0.57531$

$213 \operatorname{rcc} 3.175 \quad 5.49926-1.430274 \quad 0 \quad 0 \quad 0.001270 \quad 0.57531$

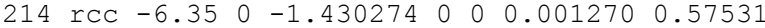

301 sq $9.34959869 .34959869 .29633110000-713.5264512000$

$305 \mathrm{pz}-1.429004$ \$bottom of Central Plate

$306 \mathrm{pz} 1.429004$ \$Top of Central Plate

307 trc $0 \quad 0 \quad-1.429004 \quad 0 \quad 0 \quad 0.57150 .63627 \quad 0.306314321$ \$ CP Alignment Hole

308 cx 0.17272 \$Diametral Hole

309 rcc -8.91476500017 .82953000 .164211 \$ Diametral Pin

323 rcc 0.8882380008 .804910001 .27 \$ Target Hole Plug

$324 \mathrm{rpp}-0.08890 .0889-0.95254 .1275 \quad 1.2816841 .429004$ \$Thermocouple

$325 \mathrm{rpp}-0.08890 .08894 .1275 \quad 8.80491 \quad 1.1343641 .429004$ \$Thermocouple

C Support Rod Holes in CP

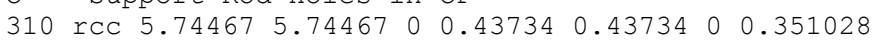

$\begin{array}{llllllllll}311 & \operatorname{rCc} & 5.74467 & -5.74467 & 0 & 0.43734 & -0.43734 & 0 & 0.351028\end{array}$

312 rCC $-5.74467-5.74467 \quad 0 \quad-0.43734 \quad-0.43734 \quad 0 \quad 0.351028$

313 rCC $-5.74467 \quad 5.74467 \quad 0 \quad-0.43734 \quad 0.43734 \quad 0 \quad 0.351028$

$\mathrm{C}$

C $\quad * * * t$ UPper Plate-UP

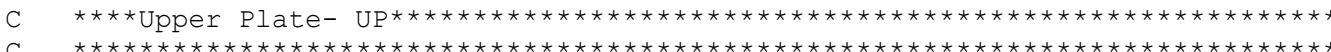

$401 \mathrm{sq} 9.34959869 .3495986 \quad 9.296331100000-713.52645120000$

$406 \mathrm{pz} 1.429004$ \$Bottom of Upper Plate

$407 \mathrm{pz} 3.375152$ \$Top of upper Plate

$408 \operatorname{trc} 0 \quad 0 \quad 3.375152000 .553720 .6350 .315309609$ \$ UP Alignment Cone

C Central Section Pins

410 rCC $-6.35-0.00063-1.429004 \quad 0 \quad 0 \quad 4.804156 \quad 0.57531$

$411 \operatorname{rcc} 3.17445 \quad 5.49958-1.429004 \quad 0 \quad 0 \quad 4.804156 \quad 0.57531$

$412 \operatorname{rcc} 3.17555-5.49894-1.4290040004 .804156 \quad 0.57531$

C

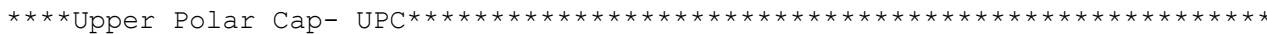

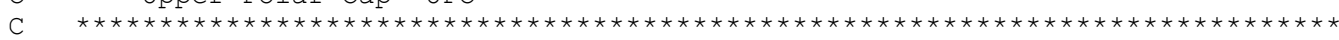

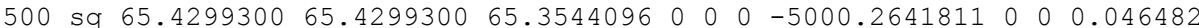

$501 \mathrm{pz} 3.375152$ \$Bottom of UPC

508 rec 0007.8061820001 .111251 .211072 \$top support hole

$503 \operatorname{trc} 0 \quad 0 \quad 3.375152000 .57150 .63627 \quad 0.306314321$ \$ UPC Alignment Hole

$504 \operatorname{trc} 003.375152000 .562610 .6356350 .310811965$ \$Cone for modeling

C UPC Mass Adjustment Button Holes

$\begin{array}{lllllllll}750 & \text { rcc } & 0.0000 & 5.6626 & 5.6626 & 0.0000000 & 0.5634551 & 0.5634551 & 0.17526\end{array}$

$\begin{array}{llllllllll}751 & \operatorname{rec} 4.0040 & 4.0040 & 5.6626 & 0.3984229 & 0.3984229 & 0.5634551 & 0.17526\end{array}$

$\begin{array}{lllllllllll}752 \operatorname{rcc} & 5.6626 & 0.0000 & 5.6626 & 0.5634551 & 0.0000000 & 0.5634551 & 0.17526\end{array}$

$\begin{array}{llllllllll}753 \operatorname{rcc} & 4.0040 & -4.0040 & 5.6626 & 0.3984229 & -0.3984229 & 0.5634551 & 0.17526\end{array}$

$\begin{array}{lllllllll}754 & \text { rCC } & 0.0000 & -5.6626 & 5.6626 & 0.0000000 & -0.5634551 & 0.5634551 & 0.17526\end{array}$

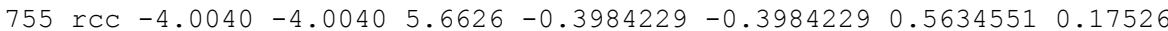

$\begin{array}{llllllllll}756 & \mathrm{rCC} & -5.6626 & 0.0000 & 5.6626 & -0.5634551 & 0.0000000 & 0.5634551 & 0.17526\end{array}$

$\begin{array}{llllllllll}757 & \mathrm{rCC} & -4.0040 & 4.0040 & 5.6626 & -0.3984229 & 0.3984229 & 0.5634551 & 0.17526\end{array}$ C

$\begin{array}{llllllllll}760 & \operatorname{rcc} & 0.0000 & 6.1439 & 6.1439 & 0.0000000 & 0.0821133 & 0.0821133 & 1.11125\end{array}$

$\begin{array}{llllllllll}761 & \text { rcc } & 4.3444 & 4.3444 & 6.1439 & 0.0580629 & 0.0580629 & 0.0821133 & 1.11125\end{array}$

$\begin{array}{llllllllll}762 & \operatorname{rcc} & 6.1439 & 0.0000 & 6.1439 & 0.0821133 & 0.0000000 & 0.0821133 & 1.11125\end{array}$

$\begin{array}{lllllllllll}763 \operatorname{rCC} & 4.3444 & -4.3444 & 6.1439 & 0.0580629 & -0.0580629 & 0.0821133 & 1.11125\end{array}$

$\begin{array}{lllllllll}764 & \operatorname{rcc} & 0.0000 & -6.1439 & 6.1439 & 0.0000000 & -0.0821133 & 0.0821133 & 1.11125\end{array}$

765 rCC $-4.3444-4.3444 \quad 6.1439-0.0580629-0.0580629 \quad 0.0821133 \quad 1.11125$

$\begin{array}{lllllllll}766 & \mathrm{rcc} & -6.1439 & 0.0000 & 6.1439 & -0.0821133 & 0.0000000 & 0.0821133 & 1.11125\end{array}$

767 rCC $-4.3444 \quad 4.3444 \quad 6.1439 \quad-0.0580629 \quad 0.0580629 \quad 0.0821133 \quad 1.11125$

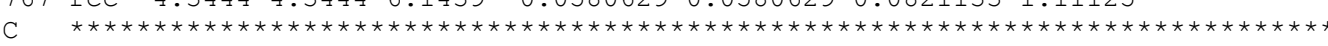

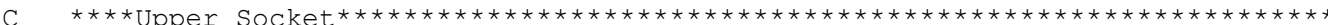

C

$600 \mathrm{sz} 7.805421 .105408$ \$Socket Sphere

601 rcc $000 \quad 8.654669000 .976376 \quad 0.714375 \quad$ \$Socket Cylinder

602 trc 009.631045000 .0793750 .7143750 .79375 \$Flair at top of Socket

$\begin{array}{lllllllll}611 & \mathrm{rcc} & 0 & 0 & 8.91667 & 0 & 0 & 0.15875 & 1.11125\end{array}$

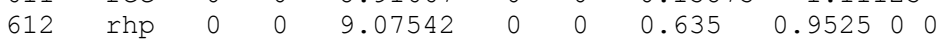

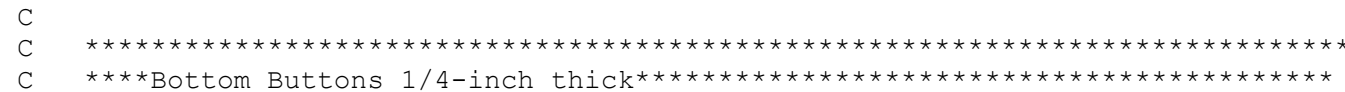

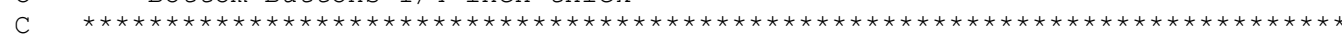

Revision: 1 
NEA/NSC/DOC(2006)1

\section{Fundamental-FUND}

\section{ORSPHERE-FUND-EXP-001 CRIT-REAC-COEF-KIN-RRATE}

C Button OD

$800 \operatorname{rcc} 0.00000 \quad 6.1439-6.14390 .00000 \quad 0.44901-0.44901 \quad 1.10744$

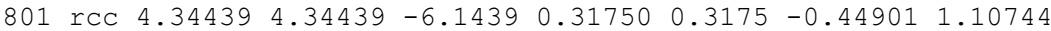

$802 \operatorname{rcc} 6.14390 \quad 0 \quad-6.1439 \quad 0.44901 \quad 0 \quad-0.44901 \quad 1.10744$

$803 \operatorname{rcc} 4.34439-4.34439-6.14390 .31750-0.3175-0.44901 \quad 1.10744$

804 rcc $0.00000-6.1439-6.14390 .00000-0.44901-0.44901 \quad 1.10744$

805 rcc $-4.34439-4.34439-6.1439-0.31750-0.3175-0.44901 \quad 1.10744$

$806 \operatorname{rcc}-6.14390 \quad 0 \quad-6.1439-0.4490100-0.44901 \quad 1.10744$

807 rCC $-4.34439 \quad 4.34439-6.1439-0.31750 \quad 0.3175-0.44901 \quad 1.10744$

C Button ID

810 rcc $0.00000 \quad 6.1439-6.14390 .00000 \quad 0.44901-0.44901 \quad 0.22479$

811 rcc $4.34439 \quad 4.34439-6.14390 .31750 \quad 0.3175-0.44901 \quad 0.22479$

$812 \operatorname{rcc} 6.14390 \quad 0 \quad-6.14390 .4490100 .44901 \quad 0.22479$

813 rcc $4.34439-4.34439-6.14390 .31750-0.3175-0.44901 \quad 0.22479$

814 rcc $0.00000-6.1439-6.14390 .00000-0.44901-0.449010 .22479$

815 rCC $-4.34439-4.34439-6.1439-0.31750-0.3175-0.44901 \quad 0.22479$

$816 r c c-6.14390 \quad 0 \quad-6.1439-0.44901 \quad 0 \quad-0.44901 \quad 0.22479$

817 rCC $-4.34439 \quad 4.34439-6.1439-0.31750 \quad 0.3175 \quad-0.449010 .22479$

C Screws

$820 \operatorname{rcc} 0.00000 \quad 6.1439-6.14390 .00000 \quad 0.44901-0.449010 .1752473$

821 rCC $4.34439 \quad 4.34439-6.14390 .31750 \quad 0.31750-0.449010 .1752473$

$822 \operatorname{rcc} 6.14390 \quad 0 \quad-6.1439 \quad 0.44901 \quad 0.00000-0.44901 \quad 0.1752473$

$823 \operatorname{rcc} 4.34439-4.34439-6.14390 .31750-0.31750-0.449010 .1752473$

$824 \operatorname{rcc} 0.00000-6.1439-6.14390 .00000-0.44901-0.449010 .1752473$

825 rCc $-4.34439-4.34439-6.1439-0.31750-0.31750-0.44901 \quad 0.1752473$

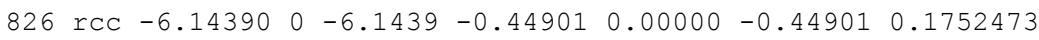

827 rCC $-4.344394 .34439-6.1439-0.31750 \quad 0.31750-0.449010 .1752473$

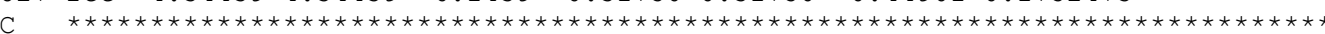

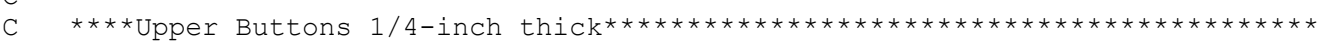

C

C Button OD

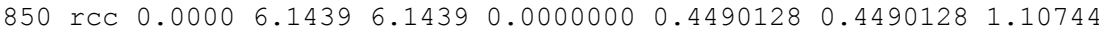

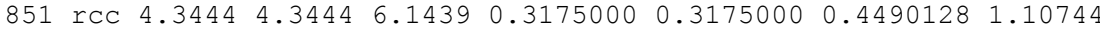

$852 \operatorname{rcc} 6.1439 \quad 0.0000 \quad 6.1439 \quad 0.4490128 \quad 0.0000000 \quad 0.4490128 \quad 1.10744$

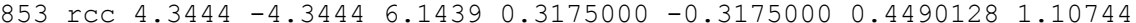

$854 \operatorname{rcc} 0.0000 \quad-6.1439 \quad 6.1439 \quad 0.0000000 \quad-0.4490128 \quad 0.4490128 \quad 1.10744$

855 rcc $-4.3444-4.3444 \quad 6.1439-0.3175000-0.3175000 \quad 0.4490128 \quad 1.10744$

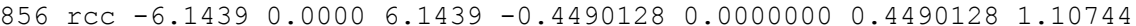

$857 \operatorname{rCC}-4.3444 \quad 4.3444 \quad 6.1439 \quad-0.3175000 \quad 0.3175000 \quad 0.4490128 \quad 1.10744$

C Button ID

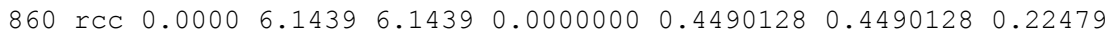

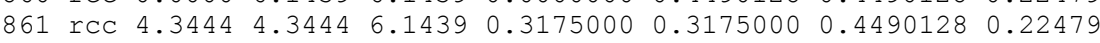

$862 \begin{array}{rccccccccc}6.1439 & 0.0000 & 6.1439 & 0.4490128 & 0.0000000 & 0.4490128 & 0.22479\end{array}$

$863 \operatorname{rcc} 4.3444 \quad-4.3444 \quad 6.1439 \quad 0.3175000 \quad-0.3175000 \quad 0.4490128 \quad 0.22479$

864 rec $0.0000-6.1439 \quad 6.14390 .0000000-0.4490128 \quad 0.4490128 \quad 0.22479$

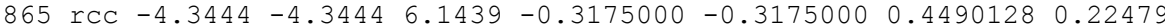

$866 r \mathrm{rc}-6.14390 .0000 \quad 6.1439-0.4490128 \quad 0.0000000 \quad 0.4490128 \quad 0.22479$

867 rcc $-4.3444 \quad 4.3444 \quad 6.1439 \quad-0.3175000 \quad 0.3175000 \quad 0.4490128 \quad 0.22479$

C Screws

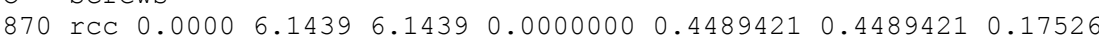

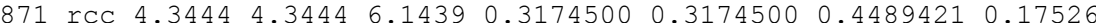

$872 \operatorname{rcc} 6.1439 \quad 0.0000 \quad 6.1439 \quad 0.4489421 \quad 0.0000000 \quad 0.4489421 \quad 0.17526$

$873 \operatorname{rcc} 4.3444 \quad-4.3444 \quad 6.1439 \quad 0.3174500 \quad-0.3174500 \quad 0.44894210 .17526$

874 rcc $0.0000-6.14396 .14390 .0000000-0.4489421 \quad 0.44894210 .17526$

875 rCC $-4.3444-4.3444 \quad 6.1439-0.3174500-0.3174500 \quad 0.44894210 .17526$

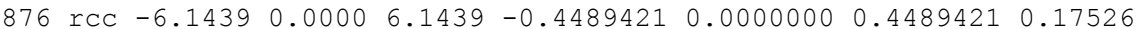

877 rCC $-4.3444 \quad 4.3444 \quad 6.1439 \quad-0.3174500 \quad 0.3174500 \quad 0.44894210 .17526$ $\mathrm{C}$

C

$900 \mathrm{rpp}-356.616713 .232-682.752 \quad 387.096-280.416 \quad 629.7168$ \$Inside Walls

C Data Cards

C Lower Polar Cap

m10 92234.70C $4.74524 \mathrm{E}-04$

$92235.70 \mathrm{C} \quad 4.47388 \mathrm{E}-02$

$92236.70 \mathrm{C} \quad 1.71732 \mathrm{E}-05$

$92238.70 \mathrm{C} \quad 2.74959 \mathrm{E}-03$

$4009.70 \mathrm{C} \quad 6.26660 \mathrm{E}-09$

$3006.70 \mathrm{C} \quad 1.23513 \mathrm{E}-08$

$3007.70 \mathrm{C} \quad 1.50380 \mathrm{E}-07$

$13027.70 \mathrm{C} \quad 2.09313 \mathrm{E}-06$

$14028.70 \mathrm{C} \quad 3.70921 \mathrm{E}-05$

$14029.70 \mathrm{C} \quad 1.88345 \mathrm{E}-06$

$14030.70 \mathrm{C} \quad 1.24158 \mathrm{E}-06$

$25055.70 \mathrm{C} \quad 5.08310 \mathrm{E}-06$

$28058.70 \mathrm{C} \quad 5.78427 \mathrm{E}-06$

$28060.70 \mathrm{C} \quad 2.22809 \mathrm{E}-06$ 
NEA/NSC/DOC(2006)1

Fundamental-FUND

ORSPHERE-FUND-EXP-001

CRIT-REAC-COEF-KIN-RRATE

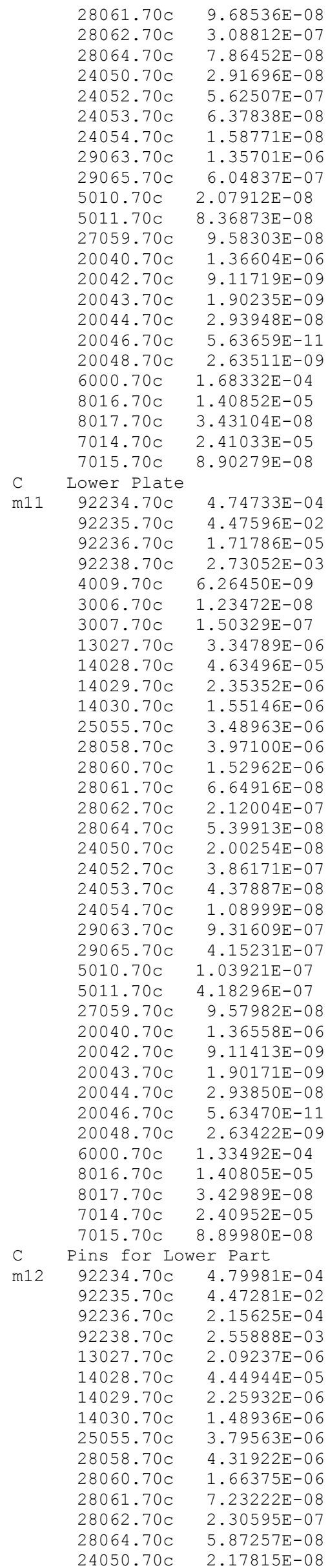

\$ Total 4.82470E-02 
NEA/NSC/DOC(2006)1

Fundamental-FUND

ORSPHERE-FUND-EXP-001

CRIT-REAC-COEF-KIN-RRATE

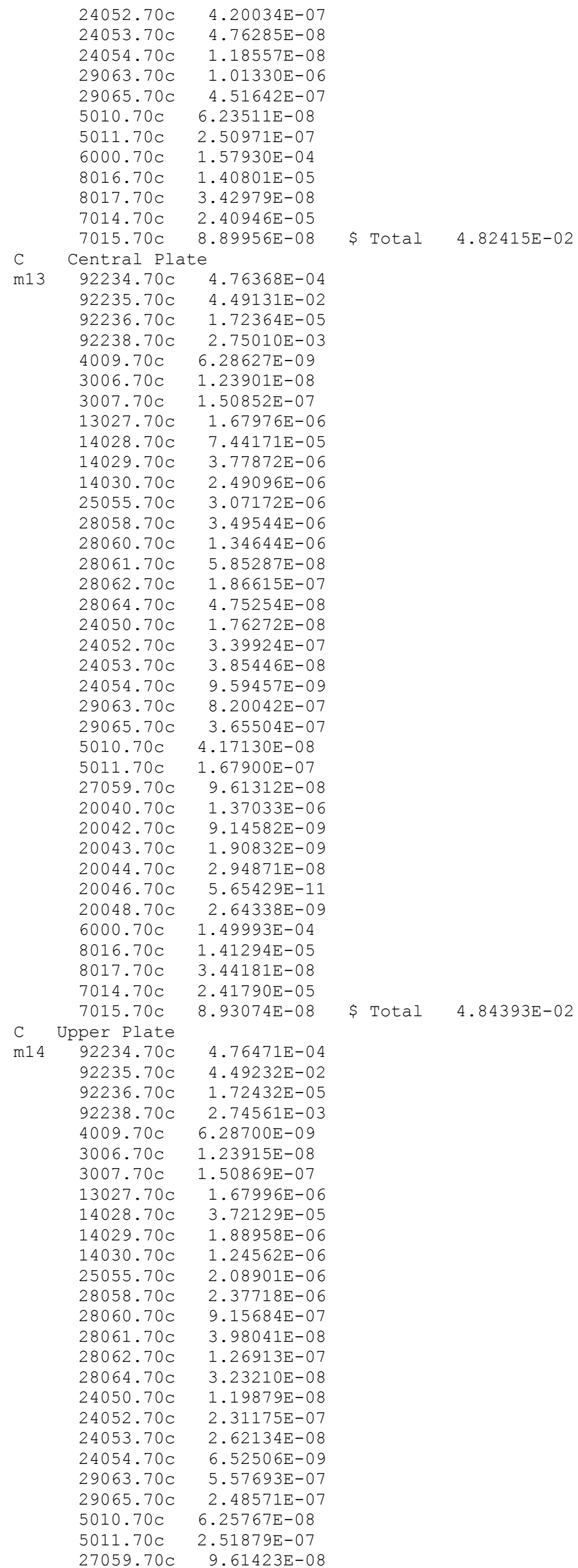

Revision: 1 
NEA/NSC/DOC(2006)1

Fundamental-FUND

ORSPHERE-FUND-EXP-001

CRIT-REAC-COEF-KIN-RRATE

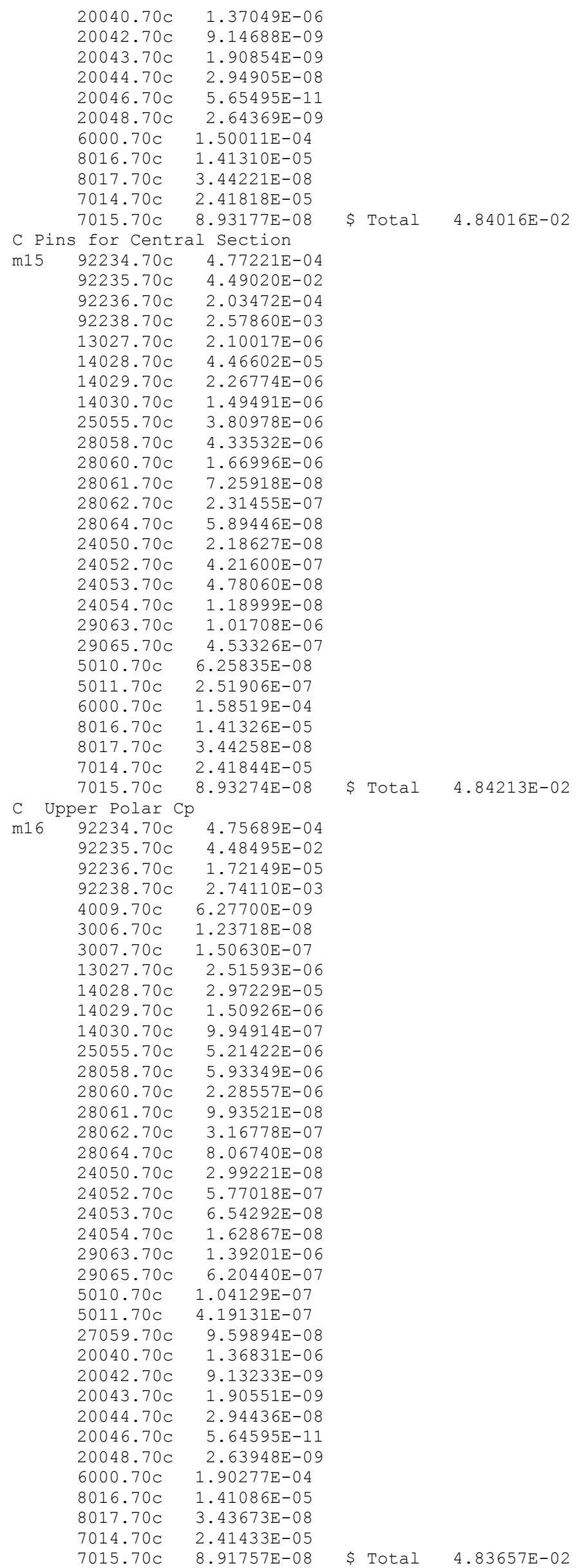

Revision: 1 
NEA/NSC/DOC(2006)1

Fundamental-FUND

ORSPHERE-FUND-EXP-001

CRIT-REAC-COEF-KIN-RRATE

C Plug for Target hole/Thermocouple Groove
$92234.70 \mathrm{C} \quad 4.81770 \mathrm{E}-04$
$92235.70 \mathrm{C} \quad 4.48948 \mathrm{E}-02$
$92236.70 \mathrm{C} \quad 2.16429 \mathrm{E}-04$
$92238.70 \mathrm{C} \quad 2.56841 \mathrm{E}-03$
$13027.70 \mathrm{C} \quad 2.10017 \mathrm{E}-06$
$14028.70 \mathrm{C} \quad 4.46602 \mathrm{E}-05$
$14029.70 \mathrm{C} \quad 2.26774 \mathrm{E}-06$
$14030.70 \mathrm{C} \quad 1.49491 \mathrm{E}-06$
$25055.70 \mathrm{C} \quad 3.80978 \mathrm{E}-06$
$28058.70 \mathrm{C} \quad 4.33532 \mathrm{E}-06$
$28060.70 \mathrm{C} \quad 1.66996 \mathrm{E}-06$
$28061.70 \mathrm{C} \quad 7.25918 \mathrm{E}-08$
$28062.70 \mathrm{C} \quad 2.31455 \mathrm{E}-07$
$28064.70 \mathrm{C} \quad 5.89446 \mathrm{E}-08$
$24050.70 \mathrm{C} \quad 2.18627 \mathrm{E}-08$
$24052.70 \mathrm{C} \quad 4.21600 \mathrm{E}-07$
$24053.70 \mathrm{C} \quad 4.78060 \mathrm{E}-08$
$24054.70 \mathrm{C} \quad 1.18999 \mathrm{E}-08$
$29063.70 \mathrm{C} \quad 1.01708 \mathrm{E}-06$
$29065.70 \mathrm{C} \quad 4.53326 \mathrm{E}-07$
$5010.70 \mathrm{c} \quad 6.25835 \mathrm{E}-08$
$5011.70 \mathrm{C} \quad 2.51906 \mathrm{E}-07$
$6000.70 \mathrm{C} \quad 1.58519 \mathrm{E}-04$
$8016.70 \mathrm{C} \quad 1.41326 \mathrm{E}-05$
$8017.70 \mathrm{C} \quad 3.44258 \mathrm{E}-08$
$7014.70 \mathrm{C} \quad 2.41844 \mathrm{E}-05$
7015.70C 8.93274E-08 \$ Total 4.84213E-02

C Diametral Pin, AVG Density

m18 92234.70c 4.77378E-04

$92235.70 \mathrm{C} \quad 4.44855 \mathrm{E}-02$

$92236.70 \mathrm{C} \quad 2.14455 \mathrm{E}-04$

$92238.70 \mathrm{C} \quad 2.54500 \mathrm{E}-03$

$13027.70 \mathrm{C} \quad 2.08103 \mathrm{E}-06$

$14028.70 \mathrm{C} \quad 4.42531 \mathrm{E}-05$

$14029.70 \mathrm{C} \quad 2.24706 \mathrm{E}-06$

$14030.70 \mathrm{C} \quad 1.48128 \mathrm{E}-06$

$25055.70 \mathrm{C} \quad 3.77505 \mathrm{E}-06$

$28058.70 \mathrm{C} \quad 4.29579 \mathrm{E}-06$

$28060.70 \mathrm{C} \quad 1.65473 \mathrm{E}-06$

$28061.70 \mathrm{C} \quad 7.19300 \mathrm{E}-08$

$28062.70 \mathrm{C} \quad 2.29344 \mathrm{E}-07$

$28064.70 \mathrm{C} \quad 5.84073 \mathrm{E}-08$

$24050.70 \mathrm{C} \quad 2.16633 \mathrm{E}-08$

$24052.70 \mathrm{C} \quad 4.17756 \mathrm{E}-07$

$24053.70 \mathrm{C} \quad 4.73702 \mathrm{E}-08$

$24054.70 \mathrm{C} \quad 1.17914 \mathrm{E}-08$

$29063.70 \mathrm{C} \quad 1.00781 \mathrm{E}-06$

$29065.70 \mathrm{C} \quad 4.49193 \mathrm{E}-07$

$5010.70 \mathrm{C} \quad 6.20129 \mathrm{E}-08$

$5011.70 \mathrm{C} \quad 2.49610 \mathrm{E}-07$

$6000.70 \mathrm{C} \quad 1.57074 \mathrm{E}-04$

$8016.70 \mathrm{C} \quad 1.40037 \mathrm{E}-05$

$8017.70 \mathrm{c} \quad 3.41119 \mathrm{E}-08$

$7014.70 \mathrm{C} \quad 2.39639 \mathrm{E}-05$

$7015.70 \mathrm{c} \quad 8.85130 \mathrm{E}-08$

C $\quad 0.25$ inch thick uranium button

m50 $92234.70 \mathrm{C} \quad 4.73822 \mathrm{E}-04$

$92235.70 \mathrm{C} \quad 4.46739 \mathrm{E}-02$

$92236.70 \mathrm{C} \quad 1.71486 \mathrm{E}-05$

$92238.70 \mathrm{C} \quad 2.72022 \mathrm{E}-03$

$4009.70 \mathrm{c} \quad 6.25177 \mathrm{E}-09$

$3006.70 \mathrm{C} \quad 1.23221 \mathrm{E}-08$

$3007.70 \mathrm{C} \quad 1.50024 \mathrm{E}-07$

$13027.70 \mathrm{C} \quad 8.35272 \mathrm{E}-07$

$14028.70 \mathrm{C} \quad 7.40087 \mathrm{E}-05$

$14029.70 \mathrm{C} \quad 3.75798 \mathrm{E}-06$

$14030.70 \mathrm{C} \quad 2.47729 \mathrm{E}-06$

$25055.70 \mathrm{C} \quad 4.15461 \mathrm{E}-06$

$28058.70 \mathrm{C} \quad 4.72771 \mathrm{E}-06$

$28060.70 \mathrm{C} \quad 1.82110 \mathrm{E}-06$

$28061.70 \mathrm{C} \quad 7.91622 \mathrm{E}-08$

$28062.70 \mathrm{C} \quad 2.52404 \mathrm{E}-07$

$28064.70 \mathrm{C} \quad 6.42798 \mathrm{E}-08$

$24050.70 \mathrm{C} \quad 2.38415 \mathrm{E}-08$

$24052.70 \mathrm{C} \quad 4.59759 \mathrm{E}-07$

$24053.70 \mathrm{C} \quad 5.21330 \mathrm{E}-08$

Revision: 1 
NEA/NSC/DOC(2006)1

Fundamental-FUND

ORSPHERE-FUND-EXP-001

CRIT-REAC-COEF-KIN-RRATE

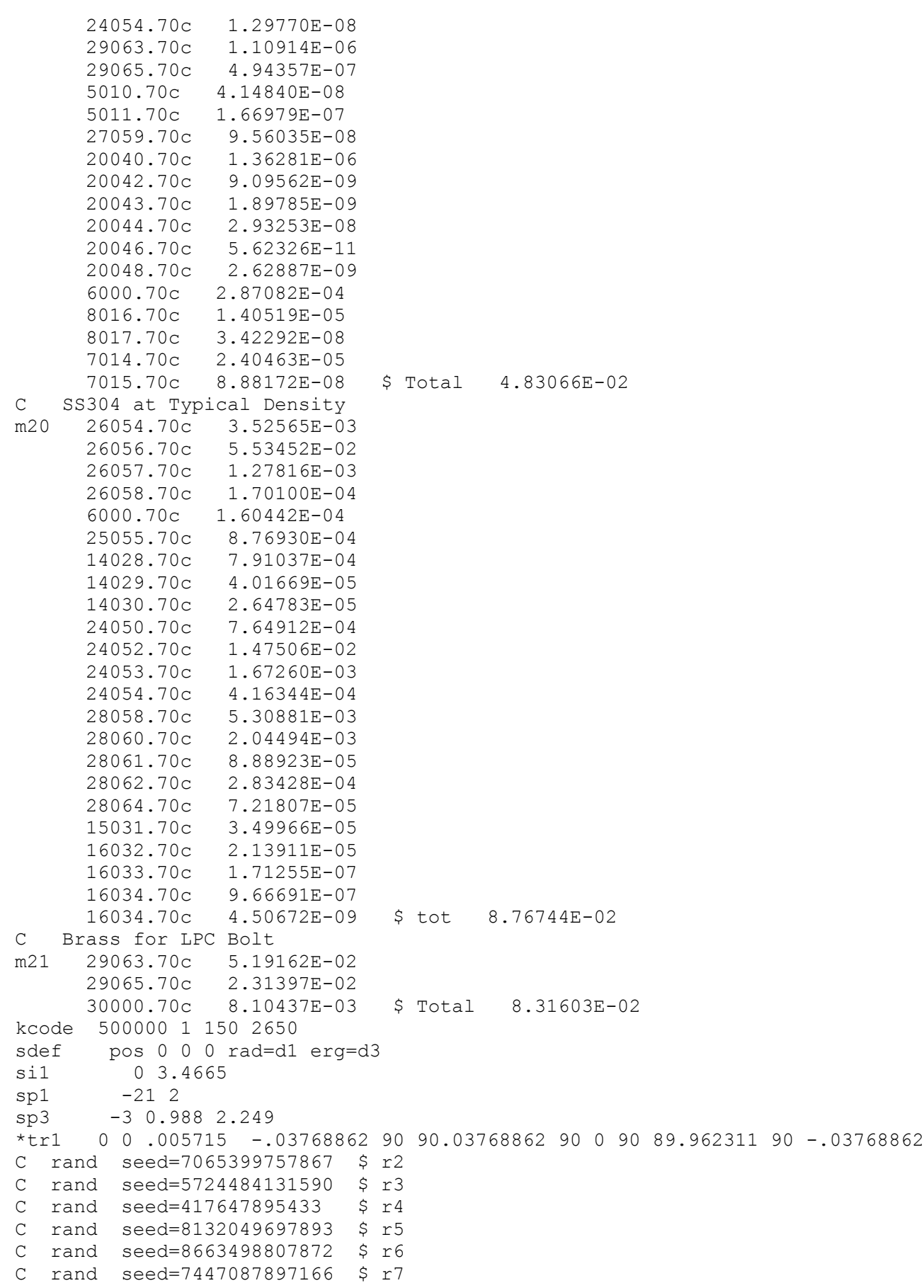

MCNP5 Input Deck for Surface Button Worth Benchmark Models:

Perturbed Benchmark Model for Worth of 4, 0.3175-cm-thick Buttons

4, 0.3175-cm-thick uranium buttons:

The perturbed benchmark model for this measurement is given below. The reference benchmark model had buttons B1 and B5 in Figure 3.4-5 and T3 and T7 in Figure 3.4-6 removed (cells 800, 804, 852, and 856) but the holding screws were not removed.

Worth per 0.3175-cm-thick aluminum button:

The worth per aluminum button was measured with the worth of three or four aluminum buttons. For the reference benchmark models 12 or 13, 0.3175 -cm-thick uranium buttons with holding screws were present; locations B1, T3, and T7 (cells 800, 850, and 856) for the three buttons and B1, B5, T3, and T7 (cells 800, 804, 850, and 856) for the four buttons, see Figure 3.4-5 and Figure 3.4-6. For the perturbed model three or four aluminum buttons (material $\mathrm{m} 50$ ) and holding screws were added to the empty locations. The 
NEA/NSC/DOC(2006)1

Fundamental-FUND

ORSPHERE-FUND-EXP-001

CRIT-REAC-COEF-KIN-RRATE

dimensions of the $0.3175-\mathrm{cm}$-thick aluminum buttons and holding screws were equal to the dimensions of the 0.3175 -cm-thick uranium buttons and holding screws. The cell cards in the below model can be easily modified to obtain the reference and perturbed benchmark models for this measurement.

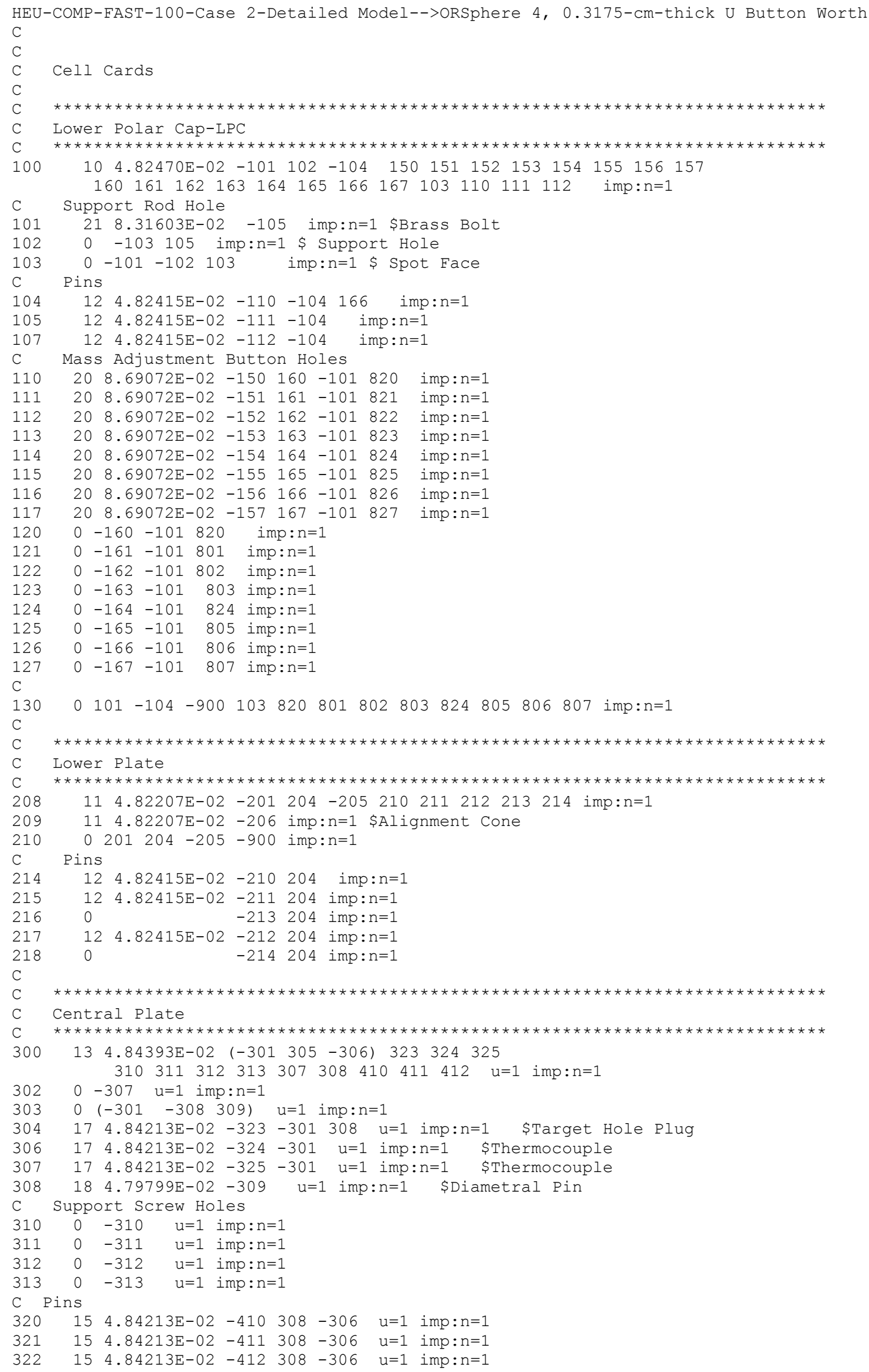

Revision: 1 
NEA/NSC/DOC(2006)1

Fundamental-FUND

ORSPHERE-FUND-EXP-001

CRIT-REAC-COEF-KIN-RRATE

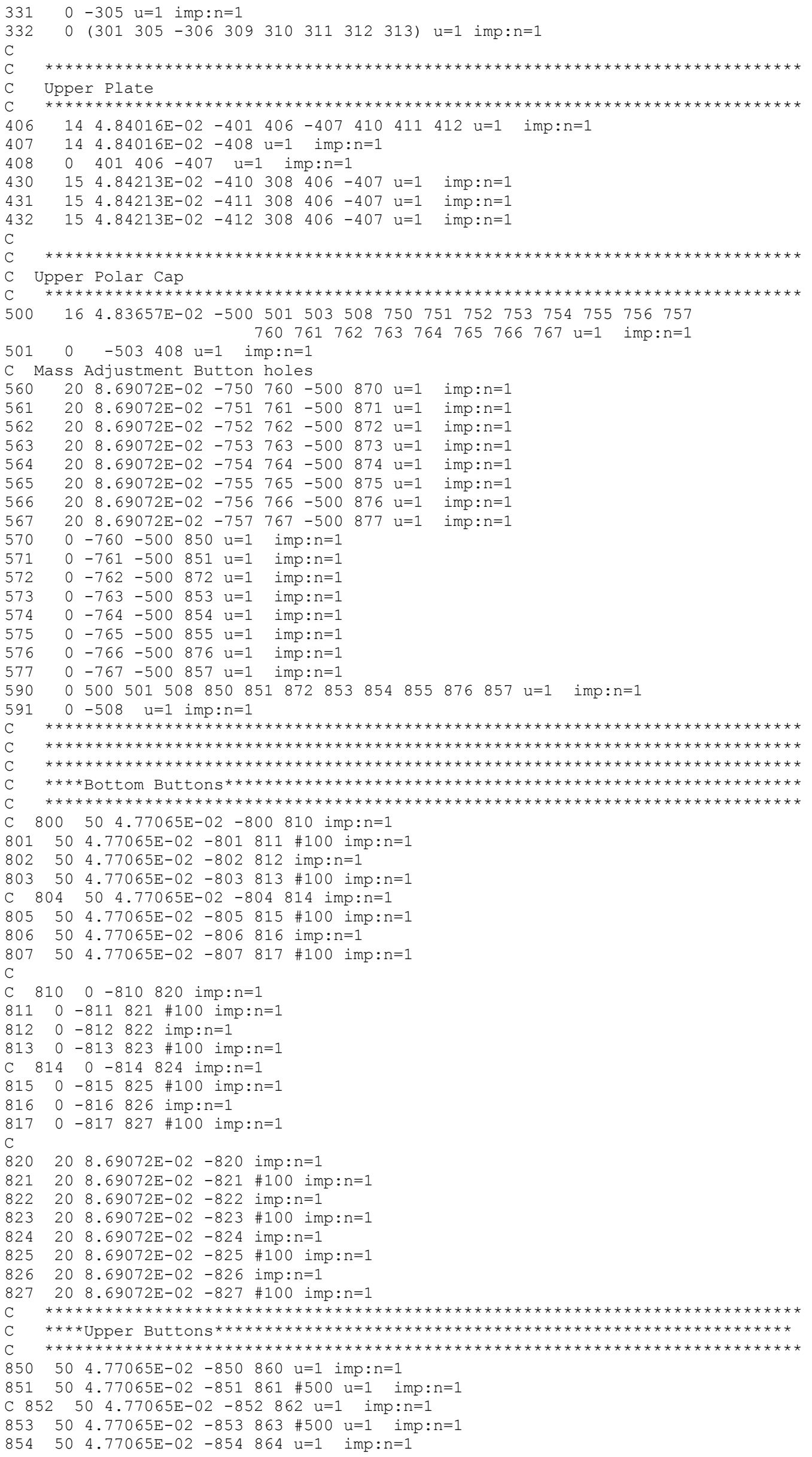

Revision: 1 
NEA/NSC/DOC(2006)1

\section{Fundamental-FUND}

\section{ORSPHERE-FUND-EXP-001 \\ CRIT-REAC-COEF-KIN-RRATE}

$855504.77065 \mathrm{E}-02-855865$ \#500 u=1 imp: $n=1$

C $856504.77065 \mathrm{E}-02-856866 \mathrm{u}=1$ imp: $\mathrm{n}=1$

$857504.77065 \mathrm{E}-02-857867$ \#500 u=1 imp:n=1

$860 \quad 0-860 \quad 870 u=1 \quad$ imp: $n=1$

$8610-861871$ \#500 u=1 imp:n=1

C $862 \quad 0 \quad-862872 u=1 \quad$ imp: $n=1$

$8630-863873$ \#500 u=1 imp: $n=1$

$864 \quad 0-864 \quad 874 \quad u=1 \quad$ imp $: n=1$

$8650-865875 \# 500 u=1$ imp: $n=1$

C $8660-866876 u=1 \quad$ imp: $n=1$

$8670-867877$ \#500 u=1 imp:n=1

$870208.69072 \mathrm{E}-02-870 \mathrm{u}=1$ imp: $\mathrm{n}=1$

$871208.69072 \mathrm{E}-02-871 \mathrm{u}=1$ imp: $n=1$

$872208.69072 \mathrm{E}-02-872 \mathrm{u}=1$ imp:n=1

$873208.69072 \mathrm{E}-02-873$ \#500 u=1 imp:n=1

$874208.69072 \mathrm{E}-02-874 \quad \mathrm{u}=1$ imp: $\mathrm{n}=1$

$875208.69072 \mathrm{E}-02-875$ \#500 u=1 imp:n=1

$876208.69072 \mathrm{E}-02-876 \mathrm{u}=1$ imp: $\mathrm{n}=1$

$877208.69072 \mathrm{E}-02-877 \quad \# 500 \mathrm{u}=1$ imp: $\mathrm{n}=1$

$9050205206210-900$ fill=1 imp:n=1

9100900 imp $: \mathrm{n}=0$

C Surface Cards

$\mathrm{C}$

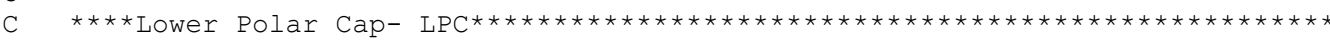

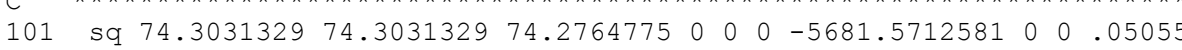

$102 \quad \mathrm{pz} \quad-8.602701$ \$Spot Face

103 rec $0 \quad 0 \quad-7.811007 \quad 0 \quad 0 \quad-1 \quad 0.747903$ \$Support Hole

$104 \quad \mathrm{pz}-4.06629$ \$ Top of polar cap

105 rcc $0 \quad 0 \quad-7.811007 \quad 0 \quad 0 \quad-0.769620 .747903$ \$Support Hole

C Pins

$110 \operatorname{rcc}-6.35 \quad 0 \quad-5.177536 \quad 0 \quad 0 \quad 3.747262 \quad 0.57531$

$111 \operatorname{rcc} 3.175 \quad 5.49926 \quad-5.177536 \quad 0 \quad 0 \quad 3.747262 \quad 0.57531$

$112 \operatorname{rcc} 3.175 \quad-5.49926-5.177536 \quad 0 \quad 0 \quad 3.748532 \quad 0.57531$

C LPC Mass Adjustment Button Holes

$150 \operatorname{rcc} 0.00000 \quad 5.66256-5.66256 \quad 0.00000 \quad 0.56345 \quad-0.563450 .17526$

$151 \operatorname{rcc} 4.00403 \quad 4.00403-5.66256 \quad 0.39843 \quad 0.39843-0.563450 .17526$

$152 \operatorname{rcc} 5.66256 \quad 0.00000 \quad-5.66256 \quad 0.56345 \quad 0 \quad-0.56345 \quad 0.17526$

$153 \operatorname{rcc} 4.00403-4.00403-5.66256 \quad 0.39843-0.39843-0.56345 \quad 0.17526$

$154 \operatorname{rcc} 0.00000-5.66256-5.66256 \quad 0.00000-0.56345-0.563450 .17526$

155 rcc $-4.00403-4.00403-5.66256-0.39843-0.39843-0.563450 .17526$

$156 \operatorname{rcc}-5.66256 \quad 0.00000-5.66256-0.563450-0.56345 \quad 0.17526$

$157 \mathrm{rcc}-4.00403 \quad 4.00403-5.66256-0.39843 \quad 0.39843-0.56345 \quad 0.17526$

$160 \operatorname{rcc} 0.00000 \quad 6.1439-6.14390 .00000 \quad 0.08211-0.08211 \quad 1.11125$

161 rcc $4.344394 .34439-6.14390 .05807 \quad 0.05807 \quad-0.08211 \quad 1.11125$

$162 \operatorname{rcc} 6.1439 \quad 0.00000-6.14390 .08211 \quad 0.00000-0.08211 \quad 1.11125$

$163 \operatorname{rcc} 4.34439-4.34439-6.14390 .05807-0.05807-0.082111 .11125$

$164 \operatorname{rcc} 0.00000-6.1439-6.1439 \quad 0.00000-0.08211-0.08211 \quad 1.11125$

165 rCc $-4.34439-4.34439-6.1439-0.05807-0.05807-0.082111 .11125$

$166 \operatorname{rcc}-6.14390 .00000-6.1439-0.082110 .00000-0.082111 .11125$

167 rCC $-4.344394 .34439-6.1439-0.05807 \quad 0.05807-0.08211 \quad 1.11125$

C

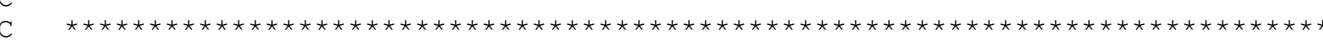

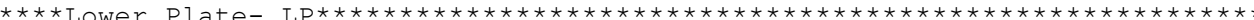

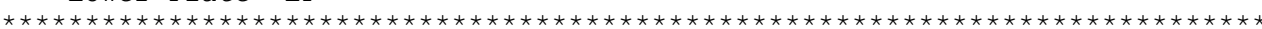

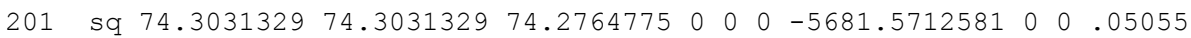

$204 \quad \mathrm{pz} \quad-4.06629$ \$Bottom of LP

205 pz -1.429004 \$ Top of lower plate

206 trc $0 \quad 0 \quad-1.429004000 .553720 .6350 .315309609$ \$ LP Alignment cone

C Lower Section Pins

210 rcc $-6.35 \quad 0 \quad-4.066286 \quad 0 \quad 0 \quad 2.636012 \quad 0.57531$

211 rcc $3.175 \quad 5.49926 \quad-4.066286 \quad 0 \quad 0 \quad 2.636012 \quad 0.57531$

$212 \operatorname{rcc} 3.175 \quad-5.49926-4.066286 \quad 0 \quad 0 \quad 2.637282 \quad 0.57531$

$213 \operatorname{rcc} 3.175 \quad 5.49926 \quad-1.430274 \quad 0 \quad 0 \quad 0.001270 \quad 0.57531$

$214 r \mathrm{rcc}-6.35 \quad 0 \quad-1.430274 \quad 0 \quad 0 \quad 0.001270 \quad 0.57531$

$\mathrm{C}$

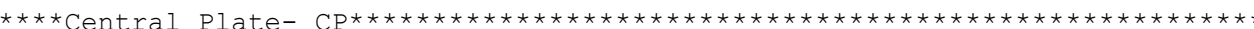

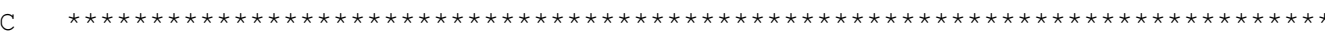

$301 \mathrm{sq} 9.34959869 .34959869 .296331100000-713.52645120000$

$305 \mathrm{pz}-1.429004$ \$bottom of Central Plate

$306 \mathrm{pz} 1.429004$ \$Top of Central Plate

Revision: 1 
NEA/NSC/DOC(2006)1

\section{Fundamental-FUND}

\section{ORSPHERE-FUND-EXP-001 \\ CRIT-REAC-COEF-KIN-RRATE}

307 trc $0 \quad 0 \quad-1.429004 \quad 0 \quad 0 \quad 0.57150 .63627 \quad 0.306314321$ \$ CP Alignment Hole

$308 \mathrm{Cx} 0.17272$ \$Diametral Hole

309 rcc $-8.914765000 \quad 17.82953000 .164211$ \$ Diametral Pin

323 rcc 0.8882380008 .804910001 .27 \$ Target Hole Plug

$324 \mathrm{rpp}-0.08890 .0889-0.9525 \quad 4.1275 \quad 1.281684 \quad 1.429004$ \$Thermocouple

$325 \mathrm{rpp}-0.08890 .08894 .1275 \quad 8.80491 \quad 1.1343641 .429004$ \$Thermocouple Support Rod Holes in CP

$\begin{array}{llllllllll}310 & \operatorname{rCC} & 5.74467 & 5.74467 & 0 & 0.43734 & 0.43734 & 0 & 0.351028\end{array}$

$\begin{array}{llllllllll}311 & \text { rCC } & 5.74467 & -5.74467 & 0 & 0.43734 & -0.43734 & 0 & 0.351028\end{array}$

312 rCC $-5.74467-5.74467 \quad 0 \quad-0.43734-0.43734 \quad 0 \quad 0.351028$

313 rCC $-5.74467 \quad 5.74467 \quad 0 \quad-0.43734 \quad 0.43734 \quad 0 \quad 0.351028$

$401 \mathrm{sq} 9.3495986 \quad 9.3495986 \quad 9.296331100000-713.5264512000$

$406 \mathrm{pz} 1.429004$ \$Bottom of Upper Plate

$407 \mathrm{pz} 3.375152$ \$Top of upper Plate

$408 \operatorname{trc} 0 \quad 0 \quad 3.375152000 .553720 .6350 .315309609$ \$ UP Alignment Cone

C Central Section Pins

410 rCc $-6.35-0.00063-1.429004 \quad 0 \quad 0 \quad 4.804156 \quad 0.57531$

411 rcc $3.17445 \quad 5.49958-1.429004 \quad 0 \quad 0 \quad 4.804156 \quad 0.57531$

$412 \operatorname{rcc} 3.17555-5.49894-1.4290040004 .804156 \quad 0.57531$

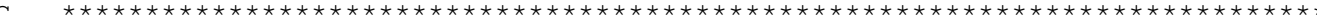

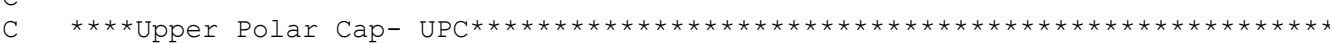

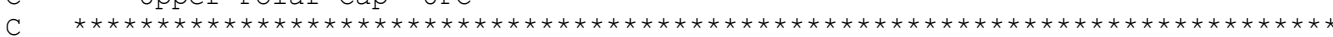

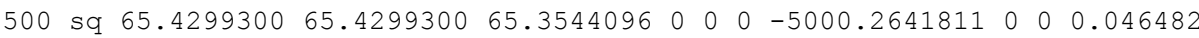

$501 \mathrm{pz} 3.375152$ \$Bottom of UPC

508 rcc 0007.8061820001 .111251 .211072 \$top support hole

$503 \operatorname{trc} 0 \quad 0 \quad 3.375152 \quad 0 \quad 0 \quad 0.5715 \quad 0.63627 \quad 0.306314321$ \$ UPC Alignment Hole

$504 \operatorname{trc} 0 \quad 0 \quad 3.375152000 .562610 .6356350 .310811965$ \$Cone for modeling

C UPC Mass Adjustment Button Holes

$\begin{array}{lllllllll}750 & \operatorname{rcc} & 0.0000 & 5.6626 & 5.6626 & 0.0000000 & 0.5634551 & 0.5634551 & 0.17526\end{array}$

$\begin{array}{lllllllll}751 & \text { rcc } & 4.0040 & 4.0040 & 5.6626 & 0.3984229 & 0.3984229 & 0.5634551 & 0.17526\end{array}$

$\begin{array}{llllllllll}752 \operatorname{rcc} & 5.6626 & 0.0000 & 5.6626 & 0.5634551 & 0.0000000 & 0.5634551 & 0.17526\end{array}$

$\begin{array}{lllllllll}753 & \text { rcc } 4.0040 & -4.0040 & 5.6626 & 0.3984229 & -0.3984229 & 0.5634551 & 0.17526\end{array}$

$\begin{array}{lllllllll}754 & \text { rCC } & 0.0000 & -5.6626 & 5.6626 & 0.0000000 & -0.5634551 & 0.5634551 & 0.17526\end{array}$

755 rCC $-4.0040-4.00405 .6626-0.3984229-0.39842290 .56345510 .17526$

$\begin{array}{llllllllll}756 r c c & -5.6626 & 0.0000 & 5.6626 & -0.5634551 & 0.0000000 & 0.5634551 & 0.17526\end{array}$

$\begin{array}{lllllllll}757 & \text { rCC } & -4.0040 & 4.0040 & 5.6626 & -0.3984229 & 0.3984229 & 0.5634551 & 0.17526\end{array}$

C

$\begin{array}{llllllllll}760 & \operatorname{rcc} & 0.0000 & 6.1439 & 6.1439 & 0.0000000 & 0.0821133 & 0.0821133 & 1.11125\end{array}$

$\begin{array}{llllllllll}761 & \operatorname{rCC} & 4.3444 & 4.3444 & 6.1439 & 0.0580629 & 0.0580629 & 0.0821133 & 1.11125\end{array}$

$\begin{array}{lllllllll}762 \operatorname{rcc} & 6.1439 & 0.0000 & 6.1439 & 0.0821133 & 0.0000000 & 0.0821133 & 1.11125\end{array}$

$\begin{array}{llllllllll}763 \operatorname{rcc} & 4.3444 & -4.3444 & 6.1439 & 0.0580629 & -0.0580629 & 0.0821133 & 1.11125\end{array}$

$\begin{array}{llllllllll}764 \operatorname{rcc} & 0.0000 & -6.1439 & 6.1439 & 0.0000000 & -0.0821133 & 0.0821133 & 1.11125\end{array}$

$\begin{array}{lllllllll}765 & \mathrm{rCC} & -4.3444 & -4.3444 & 6.1439 & -0.0580629 & -0.0580629 & 0.0821133 & 1.11125\end{array}$

$\begin{array}{llllllllll}766 & \text { rcc } & -6.1439 & 0.0000 & 6.1439 & -0.0821133 & 0.0000000 & 0.0821133 & 1.11125\end{array}$

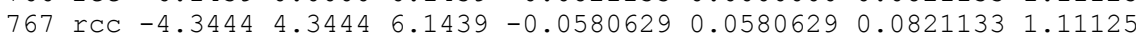

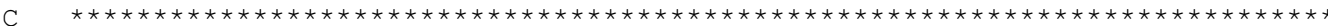

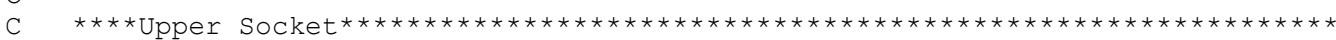

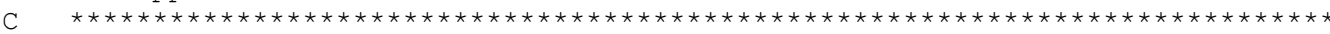

600 sz 7.805421 .105408 \$Socket Sphere

601 rec 0008.654669000 .9763760 .714375 \$Socket Cylinder

$602 \operatorname{trc} 0009.631045000 .0793750 .7143750 .79375$ \$Flair at top of Socket

$\begin{array}{llllllllll}611 & \text { rcc } & 0 & 0 & 8.91667 & 0 & 0 & 0.15875 & 1.11125 \\ 612 & \text { rhp } & 0 & 0 & 9.07542 & 0 & 0 & 0.635 & 0.9525 & 0\end{array}$

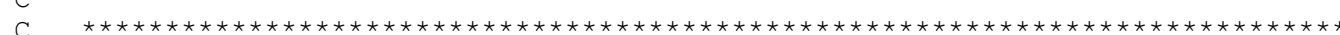

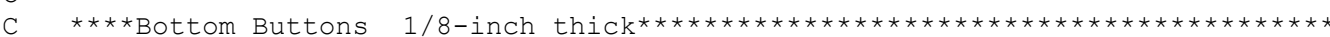

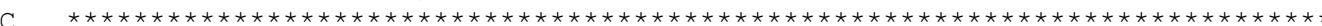

C Button OD

$800 \operatorname{rcc} 0.00000 \quad 6.1439-6.1439 \quad 0.00000 \quad 0.22451-0.22451 \quad 1.10744$

801 rcc $4.344394 .34439-6.14390 .15875 \quad 0.15875 \quad-0.22451 \quad 1.10744$

$802 \operatorname{rcc} 6.14390 \quad 0 \quad-6.1439 \quad 0.22451 \quad 0 \quad-0.22451 \quad 1.10744$

$803 \operatorname{rcc} 4.34439-4.34439-6.14390 .15875-0.15875-0.22451 \quad 1.10744$

$804 \operatorname{rCc} 0.00000-6.1439-6.14390 .00000-0.22451-0.22451 \quad 1.10744$

805 rcc $-4.34439-4.34439-6.1439-0.15875-0.15875-0.224511 .10744$

$806 \operatorname{rcc}-6.14390 \quad 0 \quad-6.1439-0.22451 \quad 0 \quad-0.22451 \quad 1.10744$

807 rCC $-4.344394 .34439-6.1439-0.15875 \quad 0.15875-0.22451 \quad 1.10744$

C Button ID

$810 \operatorname{rcc} 0.00000 \quad 6.1439-6.1439 \quad 0.00000 \quad 0.22451 \quad-0.22451 \quad 0.22479$

811 rcC $4.34439 \quad 4.34439 \quad-6.14390 .15875 \quad 0.15875 \quad-0.224510 .22479$

$812 \operatorname{rcc} 6.14390 \quad 0 \quad-6.1439 \quad 0.22451 \quad 0 \quad-0.22451 \quad 0.22479$

813 rcc $4.34439-4.34439-6.14390 .15875-0.15875-0.224510 .22479$

814 rCC $0.00000-6.1439-6.14390 .00000-0.22451-0.224510 .22479$

Revision: 1 
NEA/NSC/DOC(2006)1

\section{Fundamental-FUND}

\section{ORSPHERE-FUND-EXP-001 \\ CRIT-REAC-COEF-KIN-RRATE}

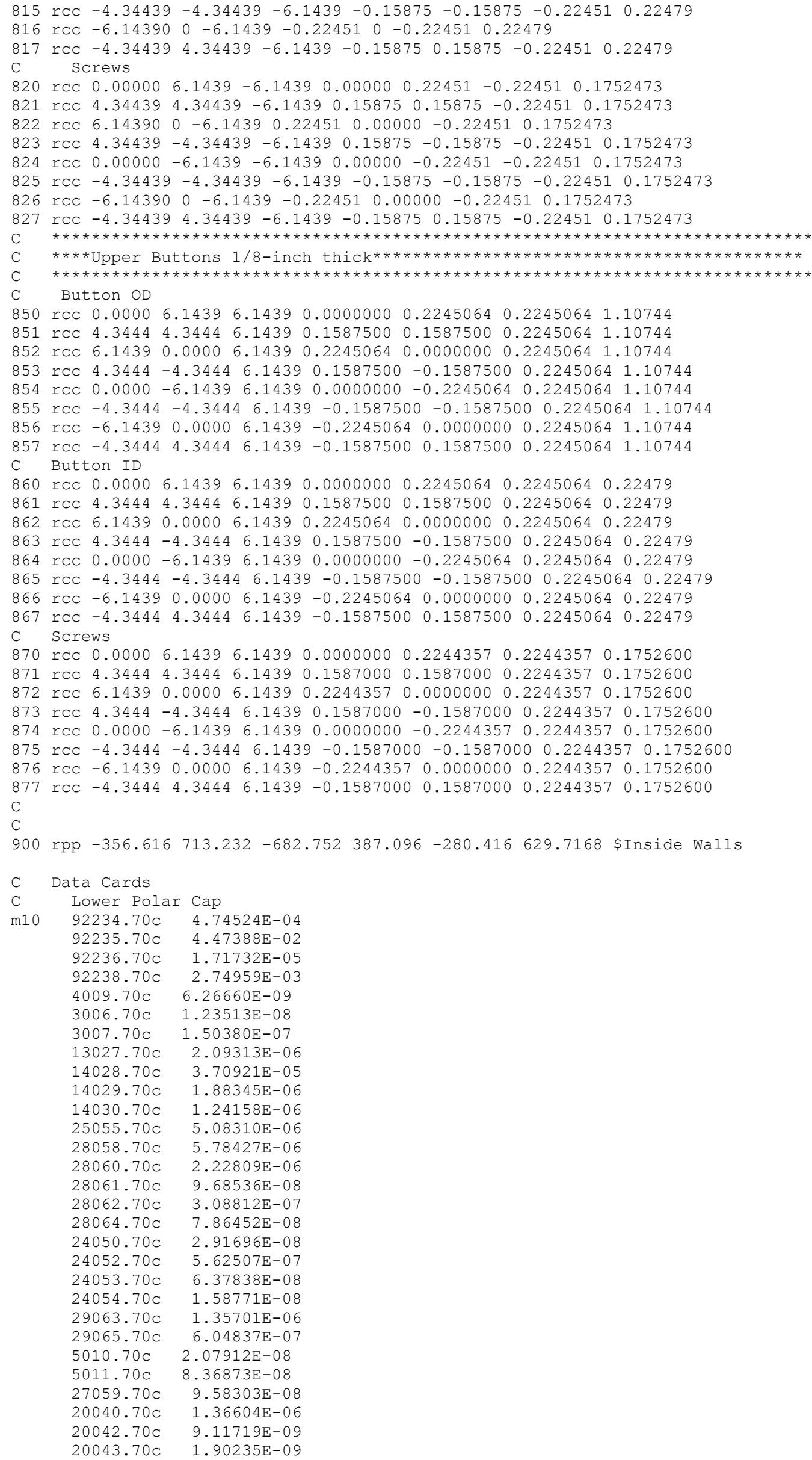


NEA/NSC/DOC(2006)1

Fundamental-FUND

ORSPHERE-FUND-EXP-001

CRIT-REAC-COEF-KIN-RRATE

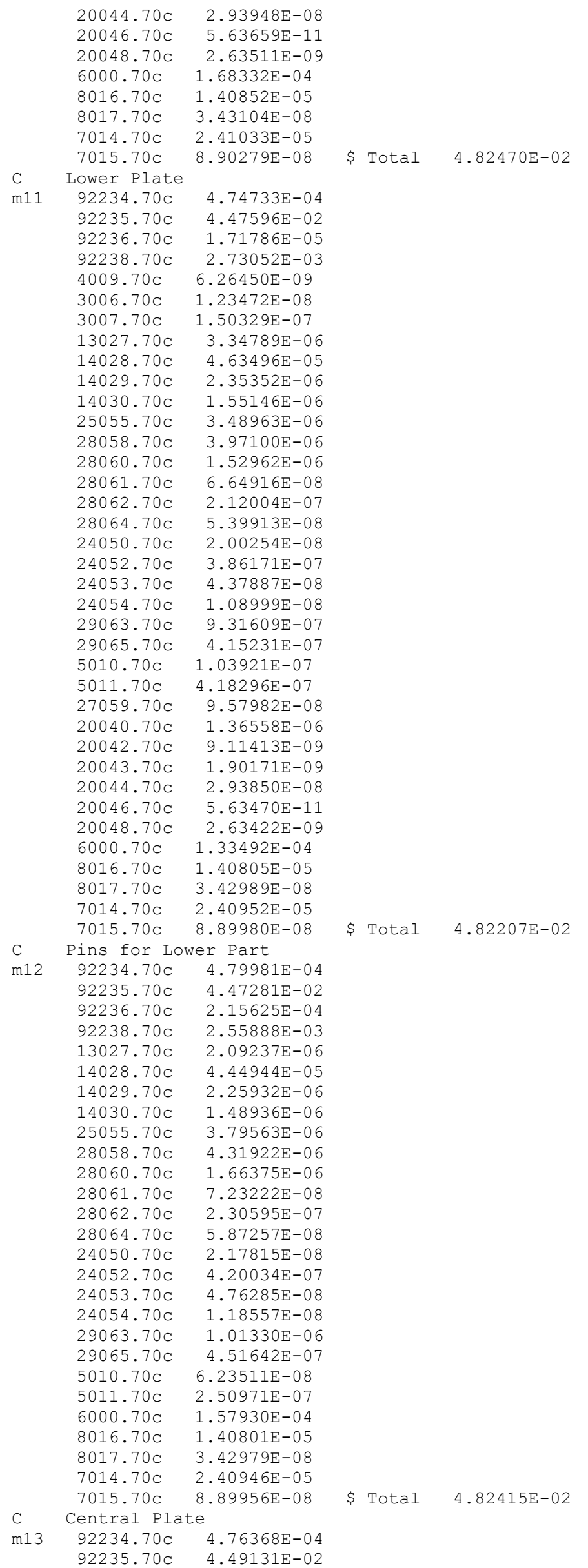

Revision: 1 
NEA/NSC/DOC(2006)1

Fundamental-FUND

ORSPHERE-FUND-EXP-001

CRIT-REAC-COEF-KIN-RRATE

$92236.70 \mathrm{C}$

$92238.70 \mathrm{C}$

$4009.70 \mathrm{C}$

$3006.70 \mathrm{c}$

$3007.70 \mathrm{C}$

$13027.70 \mathrm{C}$

$14028.70 \mathrm{C}$

$14029.70 \mathrm{C}$

$14030.70 \mathrm{C}$

$25055.70 \mathrm{C}$

$28058.70 \mathrm{C}$

$28060.70 \mathrm{C}$

$28061.70 \mathrm{C}$

$28062.70 \mathrm{C}$

$28064.70 \mathrm{C}$

$24050.70 \mathrm{C}$

$24052.70 \mathrm{c}$

$24053.70 \mathrm{C}$

$24054.70 \mathrm{C}$

$29063.70 \mathrm{C}$

$29065.70 \mathrm{C}$

$5010.70 \mathrm{C}$

$5011.70 \mathrm{C}$

$27059.70 \mathrm{C}$

$20040.70 \mathrm{c}$

$20042.70 \mathrm{C}$

$20043.70 \mathrm{C}$

$20044.70 \mathrm{C}$

$20046.70 \mathrm{C}$

$20048.70 \mathrm{C}$

$6000.70 \mathrm{c}$

$8016.70 \mathrm{c}$

$8017.70 \mathrm{c}$

$7014.70 \mathrm{C}$

$7015.70 \mathrm{c}$

C

m14 92234.70 C

$92235.70 \mathrm{C}$

$92236.70 \mathrm{C}$

$92238.70 \mathrm{C}$

$4009.70 \mathrm{C}$

$3006.70 \mathrm{C}$

$3007.70 \mathrm{C}$

$13027.70 \mathrm{C}$

$14028.70 \mathrm{C}$

$14029.70 \mathrm{C}$

$14030.70 \mathrm{C}$

$25055.70 \mathrm{C}$

$28058.70 \mathrm{C}$

$28060.70 \mathrm{C}$

$28061.70 \mathrm{C}$

$28062.70 \mathrm{C}$

$28064.70 \mathrm{C}$

$24050.70 \mathrm{c}$

$24052.70 \mathrm{C}$

$24053.70 \mathrm{C}$

$24054.70 \mathrm{C}$

$29063.70 \mathrm{C}$

$29065.70 \mathrm{C}$

$5010.70 \mathrm{C}$

$5011.70 \mathrm{C}$

$27059.70 \mathrm{c}$

$20040.70 \mathrm{C}$

$20042.70 \mathrm{C}$

$20043.70 \mathrm{c}$

$20044.70 \mathrm{C}$

$20046.70 \mathrm{C}$

$20048.70 \mathrm{c}$

$6000.70 \mathrm{c}$

$8016.70 \mathrm{C}$

$8017.70 \mathrm{c}$

$7014.70 \mathrm{c}$

$7015.70 \mathrm{C}$

C Pins for Cent

m15 92234.70c

$92235.70 \mathrm{C}$

$92236.70 \mathrm{C}$
1.72364E-05

2. $75010 \mathrm{E}-03$

$6.28627 \mathrm{E}-09$

1.23901E-08

1. $50852 \mathrm{E}-07$

1. $67976 \mathrm{E}-06$

7. $44171 \mathrm{E}-05$

3. $77872 \mathrm{E}-06$

$2.49096 \mathrm{E}-06$

3. $07172 \mathrm{E}-06$

3. $49544 \mathrm{E}-06$

1. $34644 \mathrm{E}-06$

$5.85287 \mathrm{E}-08$

$1.86615 \mathrm{E}-07$

4. $75254 \mathrm{E}-08$

1. $76272 \mathrm{E}-08$

3. $39924 \mathrm{E}-07$

3. $85446 \mathrm{E}-08$

9.59457E-09

8. $20042 \mathrm{E}-07$

3. $65504 \mathrm{E}-07$

$4.17130 \mathrm{E}-08$

$1.67900 \mathrm{E}-07$

9. $61312 \mathrm{E}-08$

1. $37033 \mathrm{E}-06$

9. $14582 \mathrm{E}-09$

1. $90832 \mathrm{E}-09$

2. $94871 \mathrm{E}-08$

$5.65429 \mathrm{E}-11$

2. $64338 \mathrm{E}-09$

1. $49993 \mathrm{E}-04$

1. $41294 \mathrm{E}-05$

3. $44181 \mathrm{E}-08$

2. $41790 \mathrm{E}-05$

8.93074E-08

4. $76471 \mathrm{E}-04$

4. 49232E-02

1. $72432 \mathrm{E}-05$

$2.74561 \mathrm{E}-03$

$6.28700 \mathrm{E}-09$

1. $23915 \mathrm{E}-08$

$1.50869 \mathrm{E}-07$

1. $67996 \mathrm{E}-06$

3. $72129 \mathrm{E}-05$

$1.88958 \mathrm{E}-06$

1. $24562 \mathrm{E}-06$

$2.08901 \mathrm{E}-06$

2.37718E-06

$9.15684 \mathrm{E}-07$

$3.98041 \mathrm{E}-08$

1. $26913 \mathrm{E}-07$

3. $23210 \mathrm{E}-08$

1. $19879 \mathrm{E}-08$

2. $31175 \mathrm{E}-07$

2. $62134 \mathrm{E}-08$

$6.52506 \mathrm{E}-09$

$5.57693 \mathrm{E}-07$

$2.48571 \mathrm{E}-07$

$6.25767 \mathrm{E}-08$

2. $51879 \mathrm{E}-07$

9. $61423 \mathrm{E}-08$

1. $37049 \mathrm{E}-06$

$9.14688 \mathrm{E}-09$

1. $90854 \mathrm{E}-09$

2. $94905 \mathrm{E}-08$

$5.65495 \mathrm{E}-11$

2. $64369 \mathrm{E}-09$

1. $50011 \mathrm{E}-04$

1. $41310 \mathrm{E}-05$

3. $44221 \mathrm{E}-08$

2. $41818 \mathrm{E}-05$

8. $93177 \mathrm{E}-08$

al Section

4. 77221E-04

4. $49020 \mathrm{E}-02$

$2.03472 \mathrm{E}-04$

\$ Total 4.84393E-02

\$ Total 4.84016E-02

Revision: 1

Date: March 31, 2015 
NEA/NSC/DOC(2006)1

Fundamental-FUND

ORSPHERE-FUND-EXP-001

CRIT-REAC-COEF-KIN-RRATE

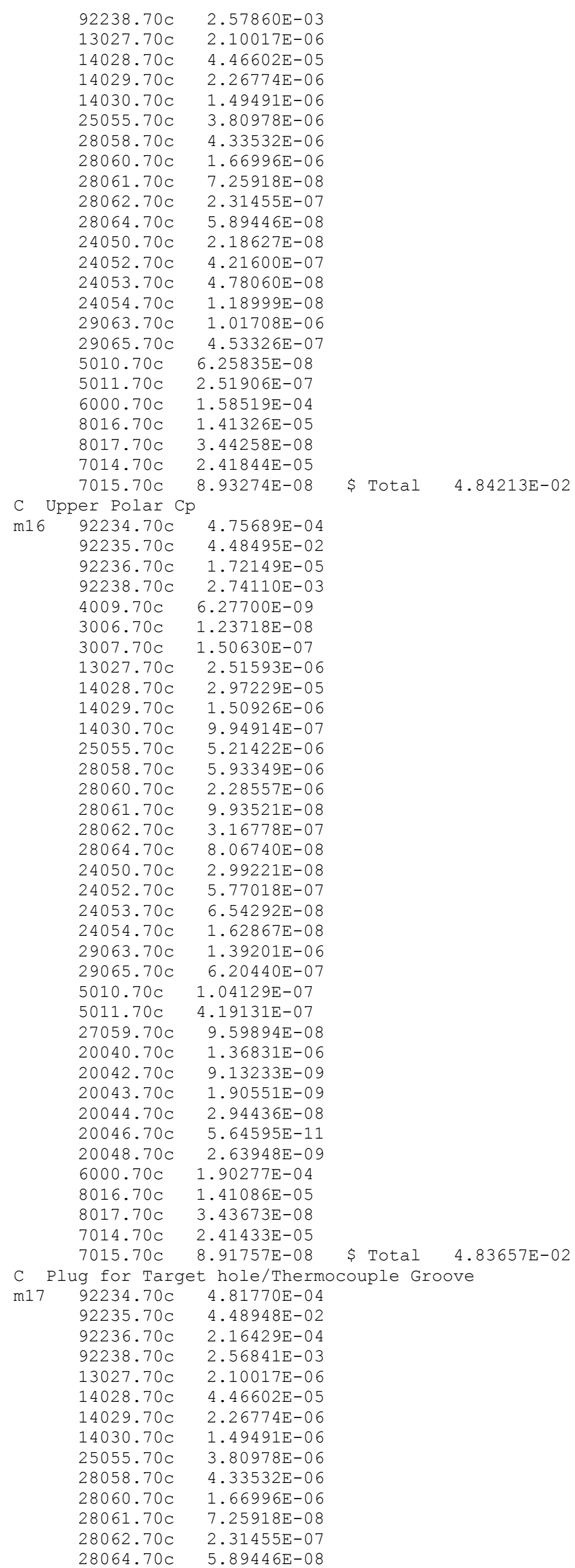

Revision: 1 
NEA/NSC/DOC(2006)1

Fundamental-FUND

ORSPHERE-FUND-EXP-001

CRIT-REAC-COEF-KIN-RRATE

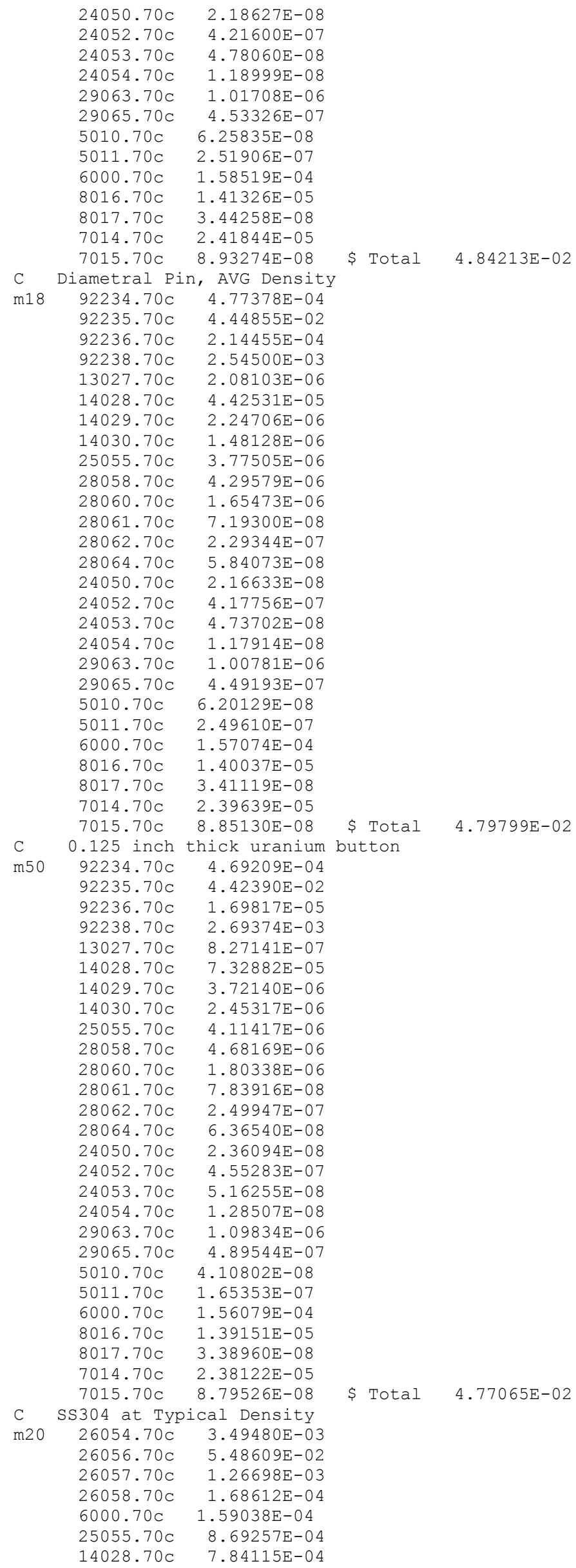

Revision: 1 
NEA/NSC/DOC(2006)1

Fundamental-FUND

ORSPHERE-FUND-EXP-001

CRIT-REAC-COEF-KIN-RRATE

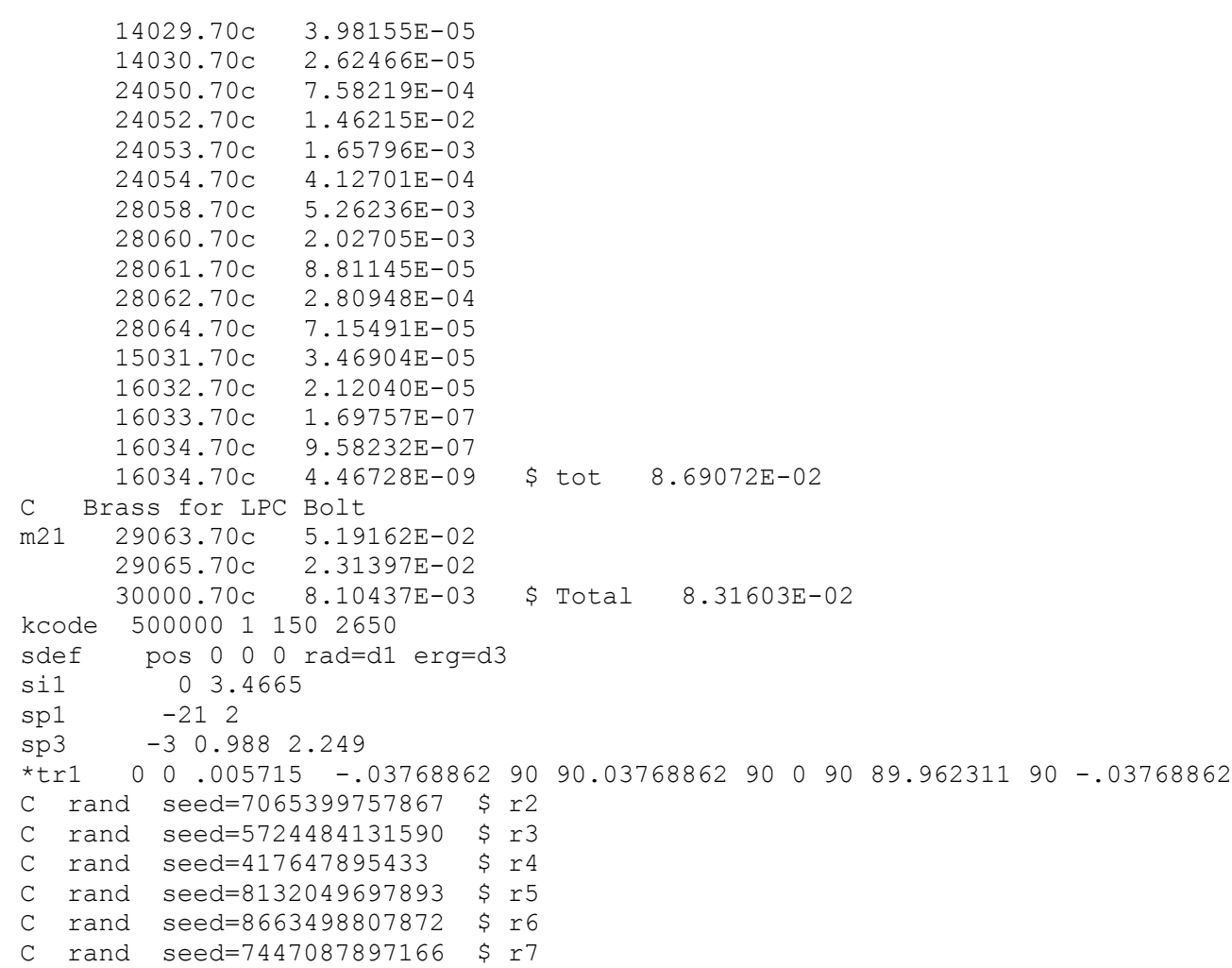

MCNP5 Input Deck for Button Worth in Empty Socket Hole Benchmark Models:

Perturbed Benchmark Model for Worth of 3, 0.3175-cm-thick Buttons in Socket Hole

3, 0.3175-cm-thick uranium buttons in empty socket hole:

The perturbed benchmark model for this measurement is given below. The reference benchmark model had the three buttons in the socket hole removed (cell 580-582).

3, 0.3175-cm-thick aluminum buttons in empty socket hole:

The perturbed benchmark model for this measurement is the same as the model given below but the three buttons in the socket hole were aluminum (material m30, cell 580-582). The reference benchmark model was the same and had the three buttons in the socket hole removed (cell 580-582).

3, 0.3175-cm-thick stainless steel buttons in empty socket hole:

The perturbed benchmark model for this measurement is the same as the model given below but the three buttons in the socket hole were stainless steel (material m20, cell 580-582). The reference benchmark model was the same and had the three buttons in the socket hole removed (cell 580-582).

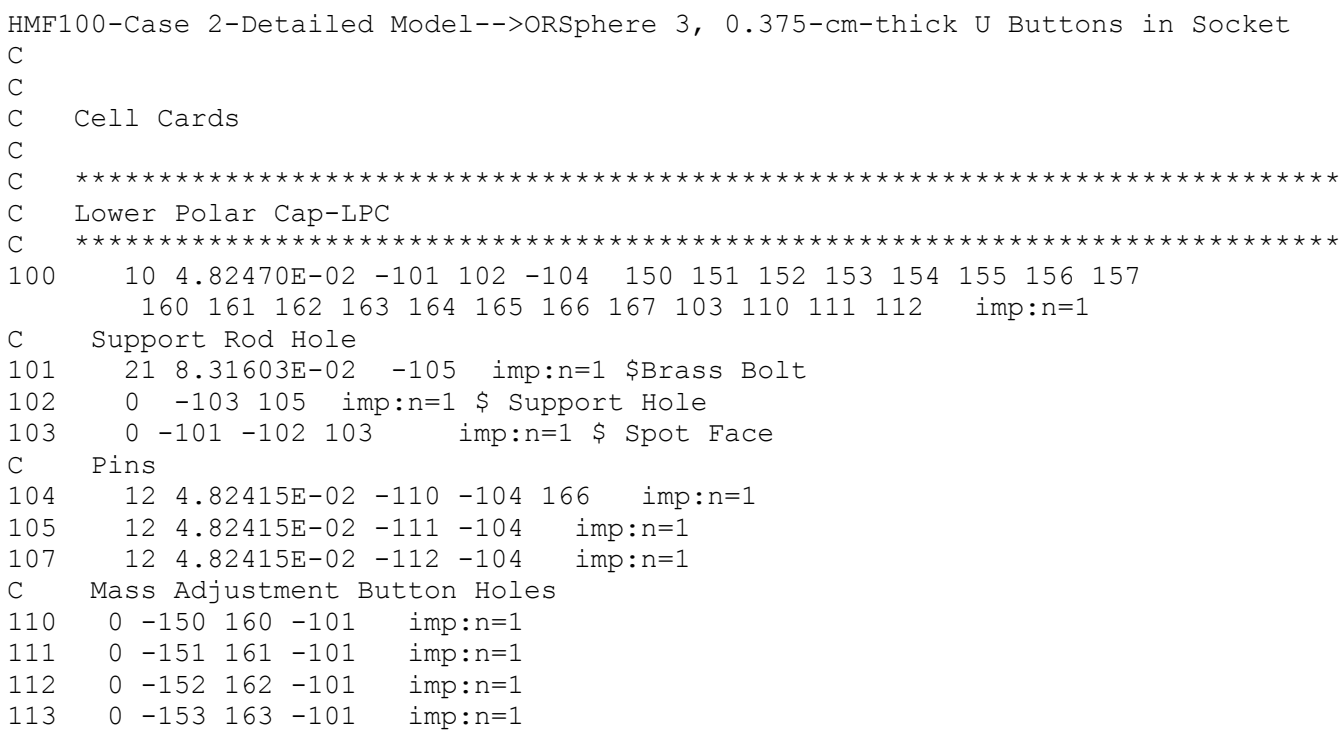

Revision: 1 
NEA/NSC/DOC(2006)1

Fundamental-FUND

ORSPHERE-FUND-EXP-001

CRIT-REAC-COEF-KIN-RRATE

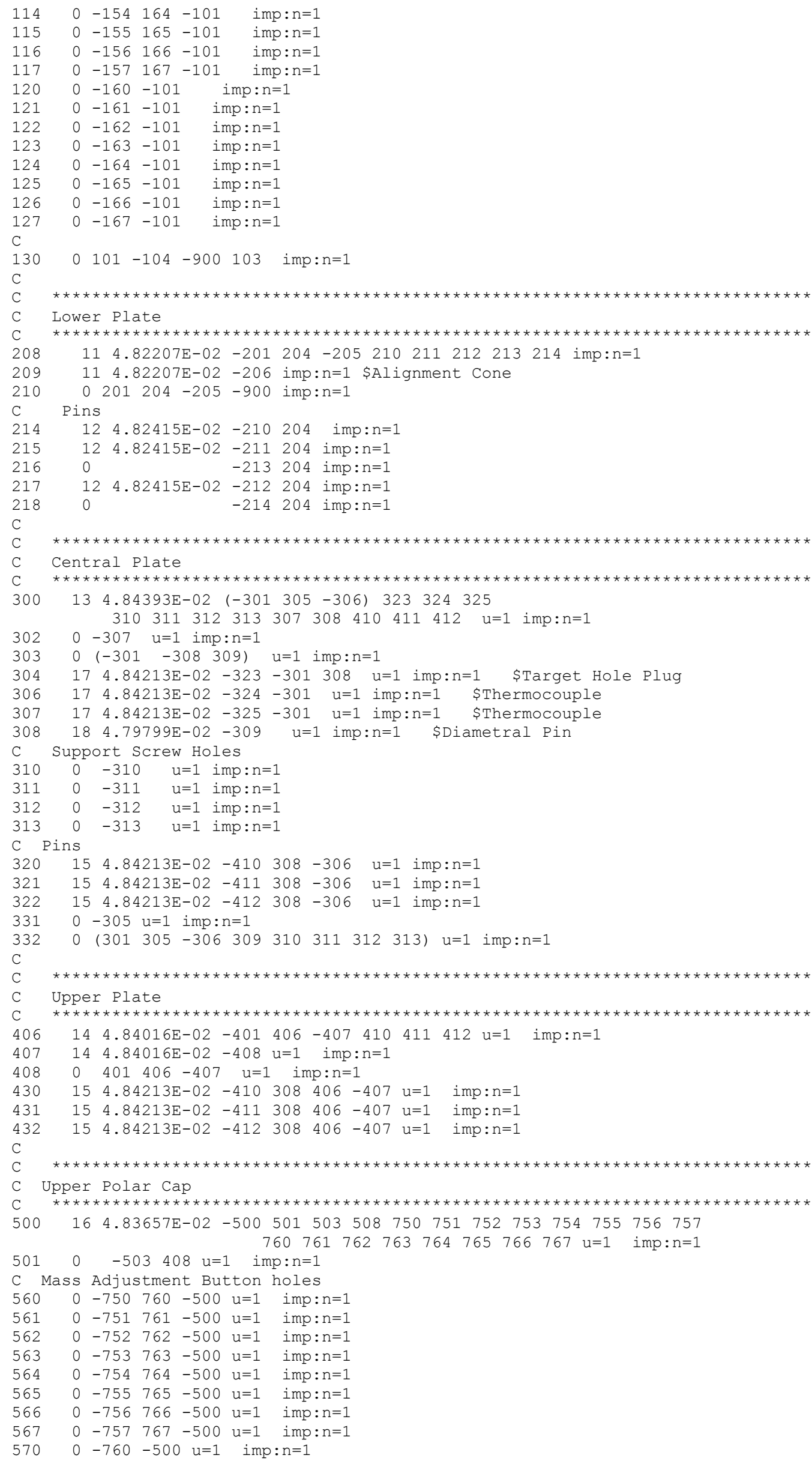

Revision: 1 
NEA/NSC/DOC(2006)1

Fundamental-FUND

ORSPHERE-FUND-EXP-001

CRIT-REAC-COEF-KIN-RRATE

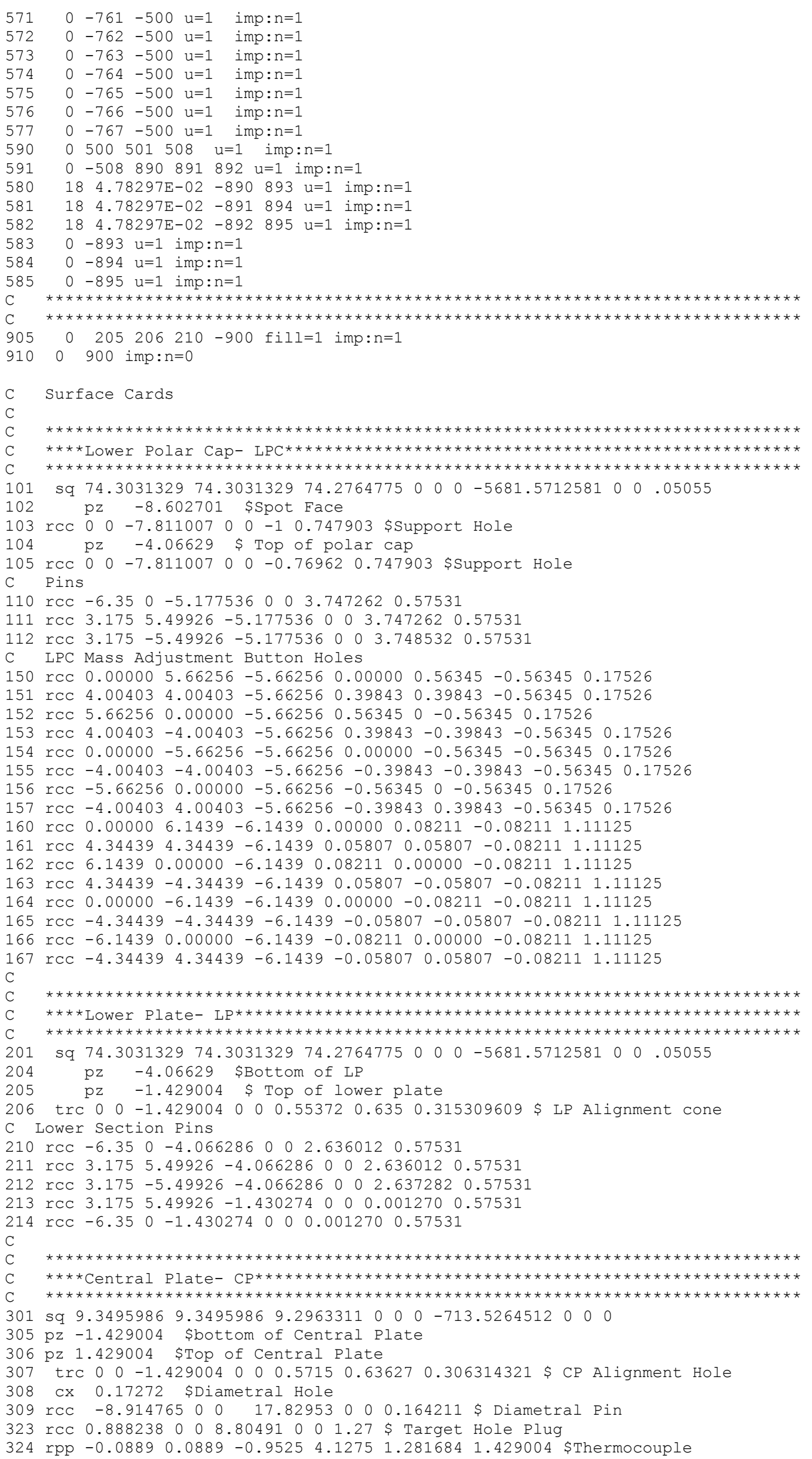

Revision: 1 
NEA/NSC/DOC(2006)1

\section{Fundamental-FUND}

\section{ORSPHERE-FUND-EXP-001 \\ CRIT-REAC-COEF-KIN-RRATE}

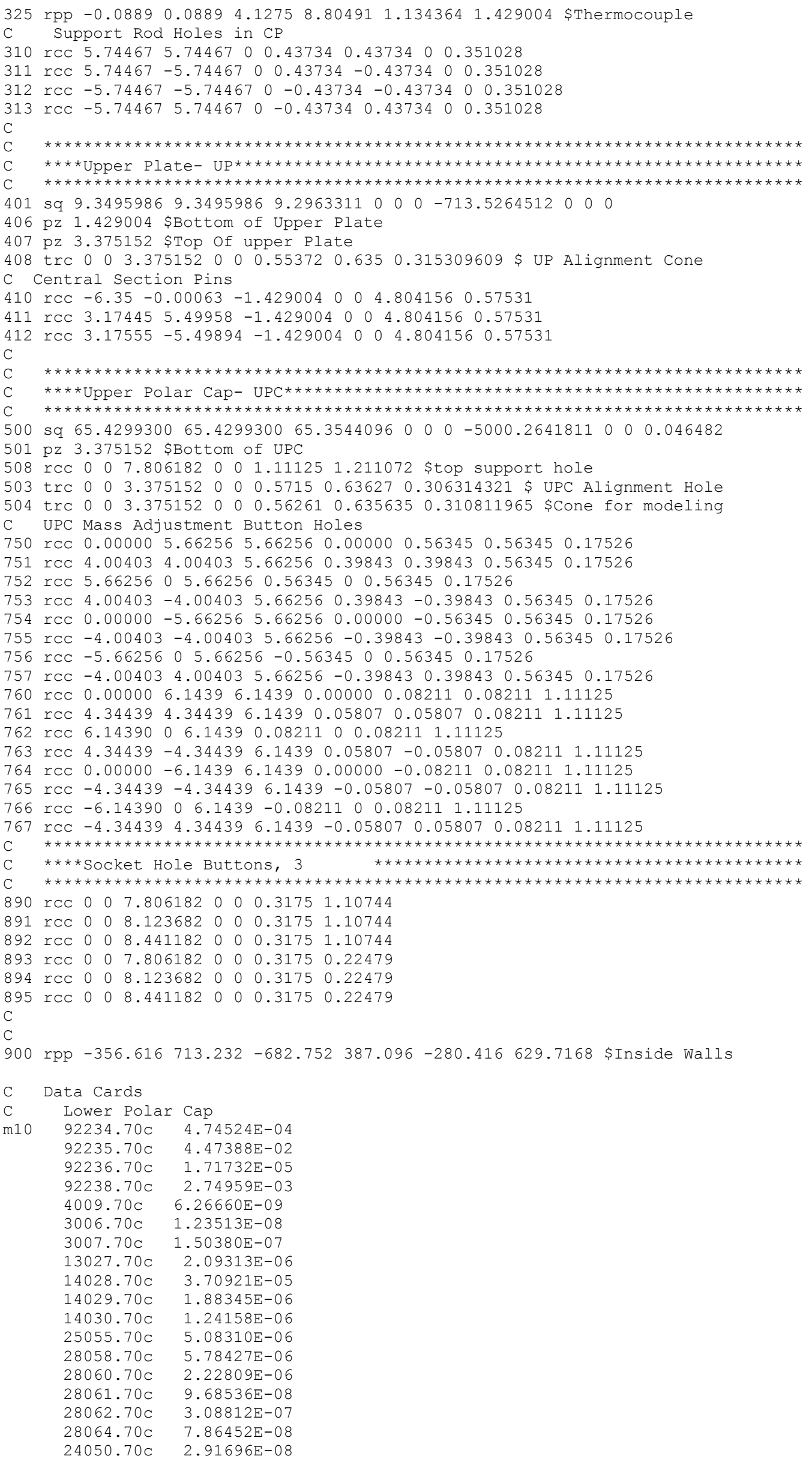

Revision: 1 
NEA/NSC/DOC(2006)1

Fundamental-FUND

ORSPHERE-FUND-EXP-001

CRIT-REAC-COEF-KIN-RRATE

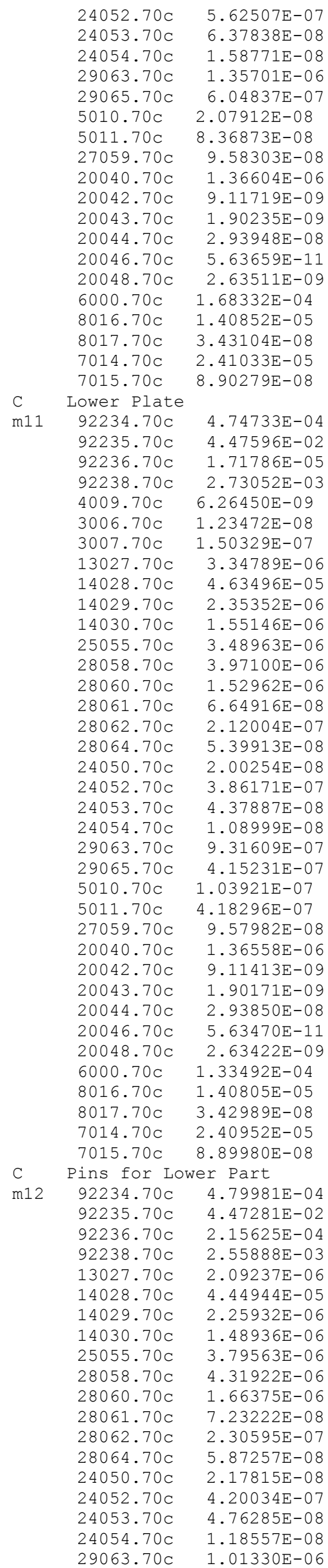

\$ Total 4.82470E-02 
NEA/NSC/DOC(2006)1

Fundamental-FUND

ORSPHERE-FUND-EXP-001

CRIT-REAC-COEF-KIN-RRATE

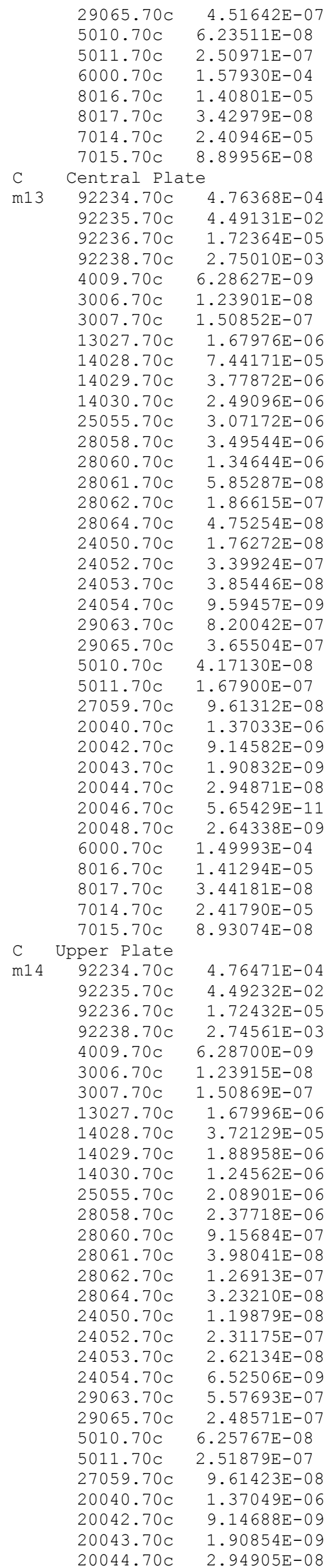

Revision: 1 
NEA/NSC/DOC(2006)1

Fundamental-FUND

ORSPHERE-FUND-EXP-001

CRIT-REAC-COEF-KIN-RRATE

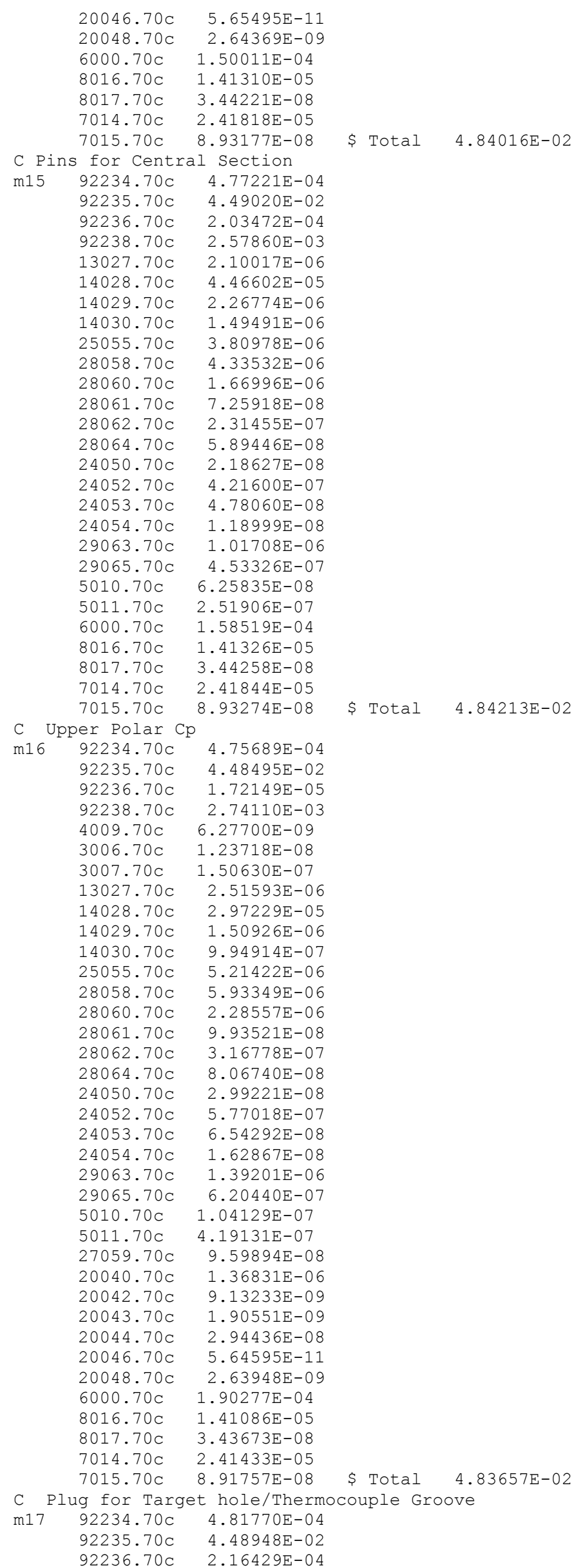

Revision: 1 
NEA/NSC/DOC(2006)1

Fundamental-FUND

ORSPHERE-FUND-EXP-001

CRIT-REAC-COEF-KIN-RRATE

$92238.70 \mathrm{C}$ $13027.70 \mathrm{C}$ $14028.70 \mathrm{C}$ $14029.70 \mathrm{c}$ $14030.70 \mathrm{C}$ $25055.70 \mathrm{C}$ $28058.70 \mathrm{c}$ $28060.70 \mathrm{C}$ $28061.70 \mathrm{C}$ $28062.70 \mathrm{C}$ $28064.70 \mathrm{C}$ $24050.70 c$ $24052.70 \mathrm{C}$ $24053.70 \mathrm{C}$ $24054.70 \mathrm{C}$ $29063.70 \mathrm{C}$ $29065.70 \mathrm{C}$ $5010.70 \mathrm{c}$

$5011.70 \mathrm{c}$ $6000.70 \mathrm{c}$ $8016.70 \mathrm{c}$ $8017.70 \mathrm{c}$ $7014.70 \mathrm{c}$ $7015.70 \mathrm{c}$

$2.56841 \mathrm{E}-03$

2. $10017 \mathrm{E}-06$

4. $46602 \mathrm{E}-05$

2. 26774E-0 6

1. $49491 \mathrm{E}-06$

3. $80978 E-06$

4. $33532 \mathrm{E}-06$

1. $66996 \mathrm{E}-06$

7. 25918E-08

2. $31455 \mathrm{E}-07$

5. $89446 \mathrm{E}-08$

$2.18627 \mathrm{E}-08$

4. $21600 \mathrm{E}-07$

$4.78060 \mathrm{E}-08$

1. $18999 \mathrm{E}-08$

1. $01708 \mathrm{E}-06$

4. 53326E-07

6. $25835 \mathrm{E}-08$

2. 51906E-07

1. 58519E-04

1. $41326 \mathrm{E}-05$

3. $44258 \mathrm{E}-08$

2. $41844 \mathrm{E}-05$

8. $93274 \mathrm{E}-08$

4. $69144 \mathrm{E}-04$

$4.42329 \mathrm{E}-02$

1. $69793 \mathrm{E}-05$

2. $69337 \mathrm{E}-03$

$6.19006 \mathrm{E}-09$

1. $22004 \mathrm{E}-08$

1. $48543 \mathrm{E}-07$

$8.27027 \mathrm{E}-07$

7. $32781 \mathrm{E}-05$

3. $72089 \mathrm{E}-06$

2. $45283 \mathrm{E}-06$

4.11360E-06

4. $68104 \mathrm{E}-06$

1. $80313 \mathrm{E}-06$

7. $83808 \mathrm{E}-08$

2. $49912 \mathrm{E}-07$

6. $36453 \mathrm{E}-08$

2. $36061 \mathrm{E}-08$

4. 55221E-07

5. $16184 \mathrm{E}-08$

1. $28489 \mathrm{E}-08$

1. $09819 \mathrm{E}-06$

4.89477E-07

4.10746E-08

1. $65330 \mathrm{E}-07$

9.46598E-08

1. $34936 \mathrm{E}-06$

9.00583E-09

$1.87912 \mathrm{E}-09$

$2.90358 \mathrm{E}-08$

$5.56775 \mathrm{E}-11$

2. $60292 E-09$

2. $84248 \mathrm{E}-04$

$1.39131 \mathrm{E}-05$

3. $38913 \mathrm{E}-08$

2. $38089 \mathrm{E}-05$

$8.79405 \mathrm{E}-08$

C SS304 at Typical Density

m20 26054.70c $\quad 3.52565 \mathrm{E}-03$

$26056.70 \mathrm{C} \quad 5.53452 \mathrm{E}-02$

$26057.70 \mathrm{C} \quad 1.27816 \mathrm{E}-03$

$26058.70 \mathrm{C} \quad 1.70100 \mathrm{E}-04$

$6000.70 \mathrm{C} \quad 1.60442 \mathrm{E}-04$

$25055.70 \mathrm{C} \quad 8.76930 \mathrm{E}-04$

$14028.70 \mathrm{C} \quad 7.91037 \mathrm{E}-04$

$14029.70 \mathrm{C} \quad 4.01669 \mathrm{E}-05$

$14030.70 \mathrm{C} \quad 2.64783 \mathrm{E}-05$

$24050.70 \mathrm{C} \quad 7.64912 \mathrm{E}-04$

$24052.70 \mathrm{C} \quad 1.47506 \mathrm{E}-02$

$24053.70 \mathrm{C} \quad 1.67260 \mathrm{E}-03$

$24054.70 \mathrm{C} \quad 4.16344 \mathrm{E}-04$

$28058.70 \mathrm{C} \quad 5.30881 \mathrm{E}-03$
\$ Total 4.84213E-02
\$ Total 4.78297E-02

Revision: 1 
NEA/NSC/DOC(2006)1

Fundamental-FUND

ORSPHERE-FUND-EXP-001

CRIT-REAC-COEF-KIN-RRATE

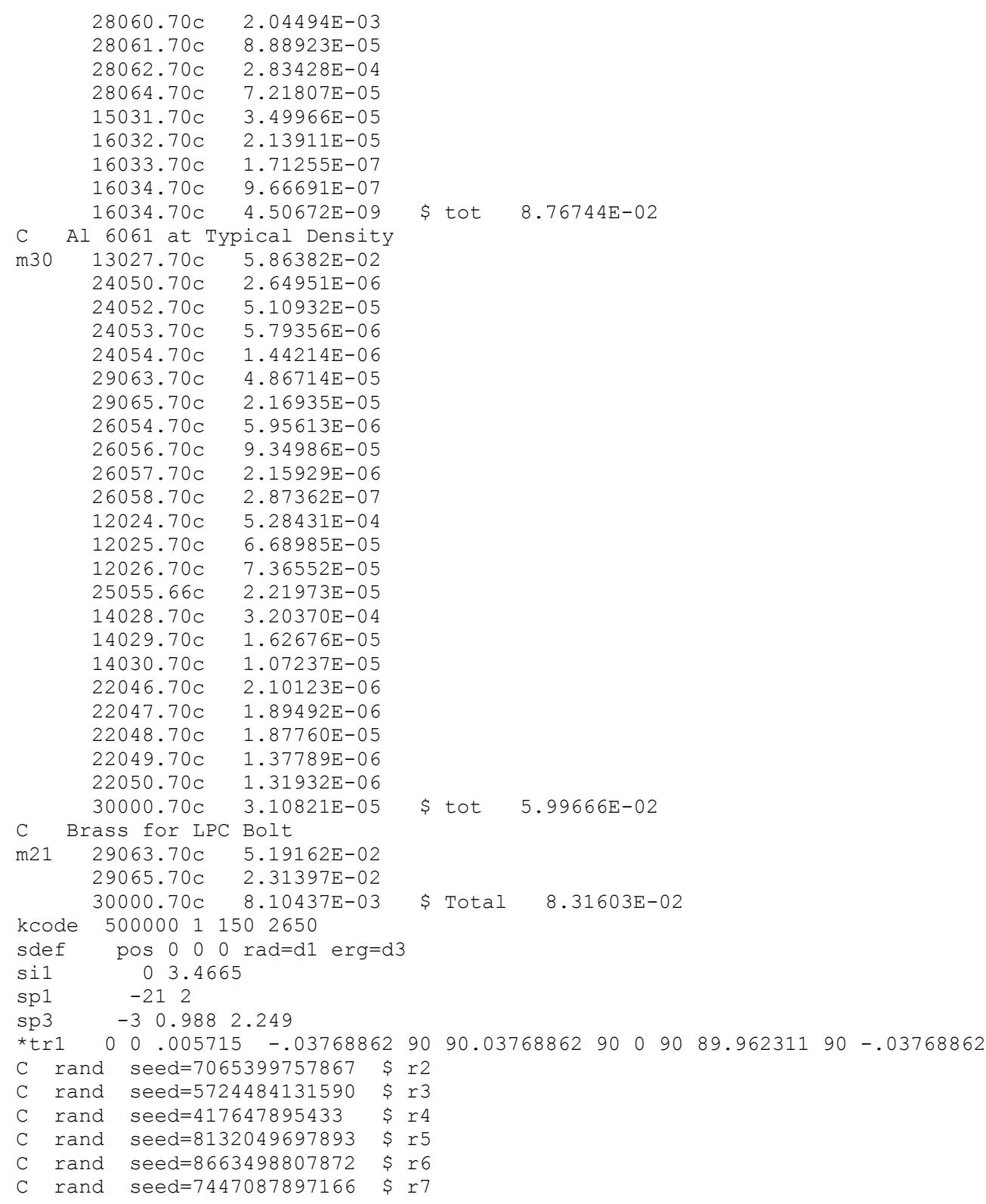

MCNP5 Input Deck for Diametral Filler Rod Worth Benchmark Models:

Reference Benchmark Model Diametral Filler Rod Worth

The reference benchmark model for the diametral filler rod worth was identical to the Case 2 detailed benchmark model of HEU-MET-FAST-100, given below. For the perturbed benchmark model the diametral filler rod was removed (cell 308).

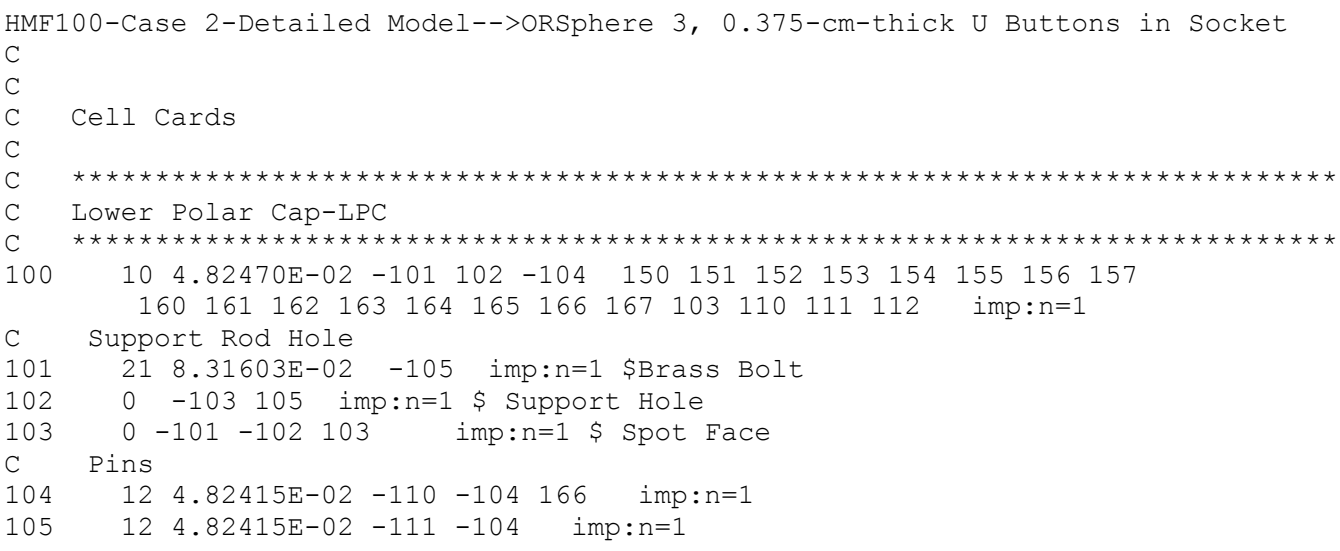

Revision: 1 
NEA/NSC/DOC(2006)1

Fundamental-FUND

ORSPHERE-FUND-EXP-001

CRIT-REAC-COEF-KIN-RRATE

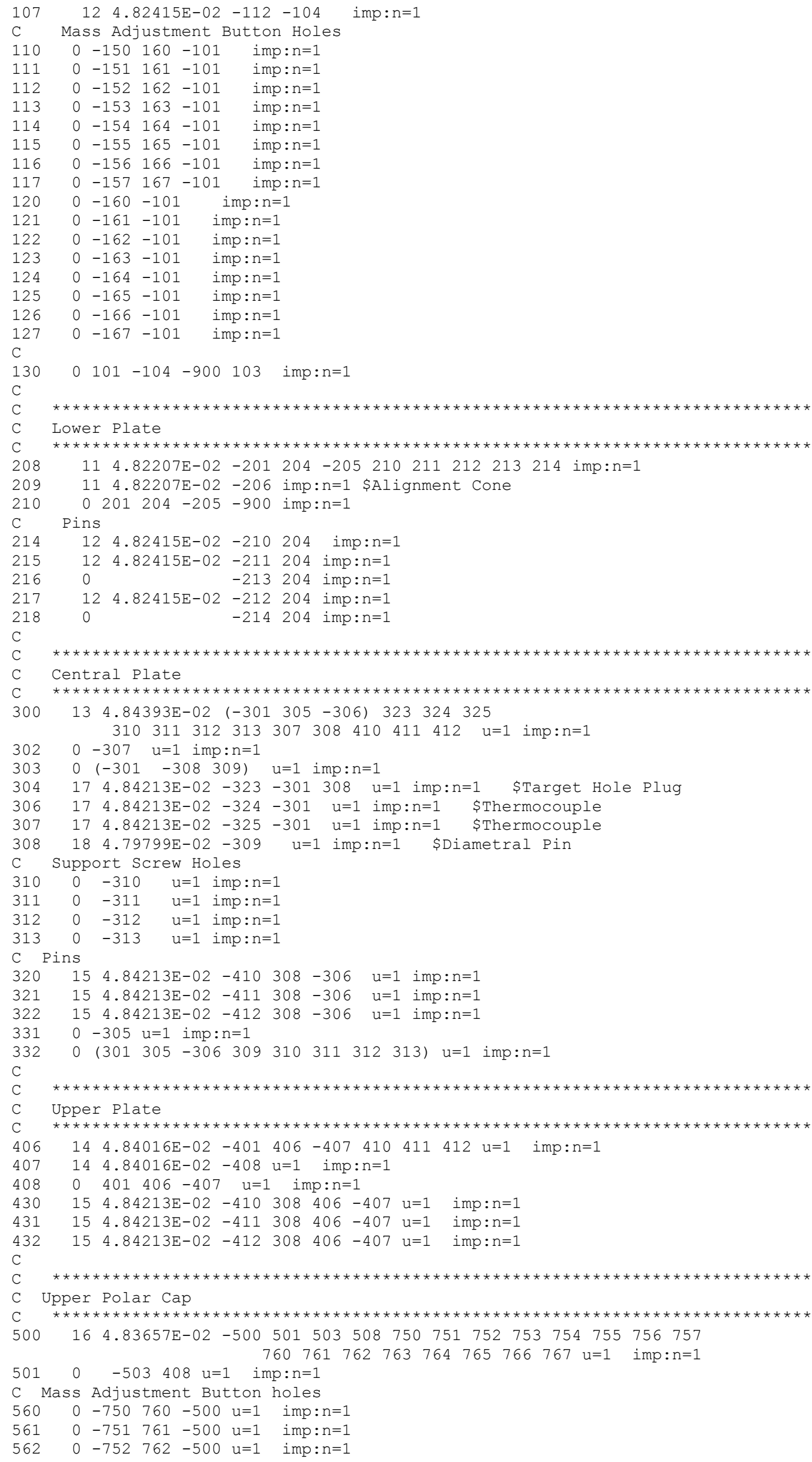

Revision: 1 
NEA/NSC/DOC(2006)1

Fundamental-FUND

ORSPHERE-FUND-EXP-001

CRIT-REAC-COEF-KIN-RRATE

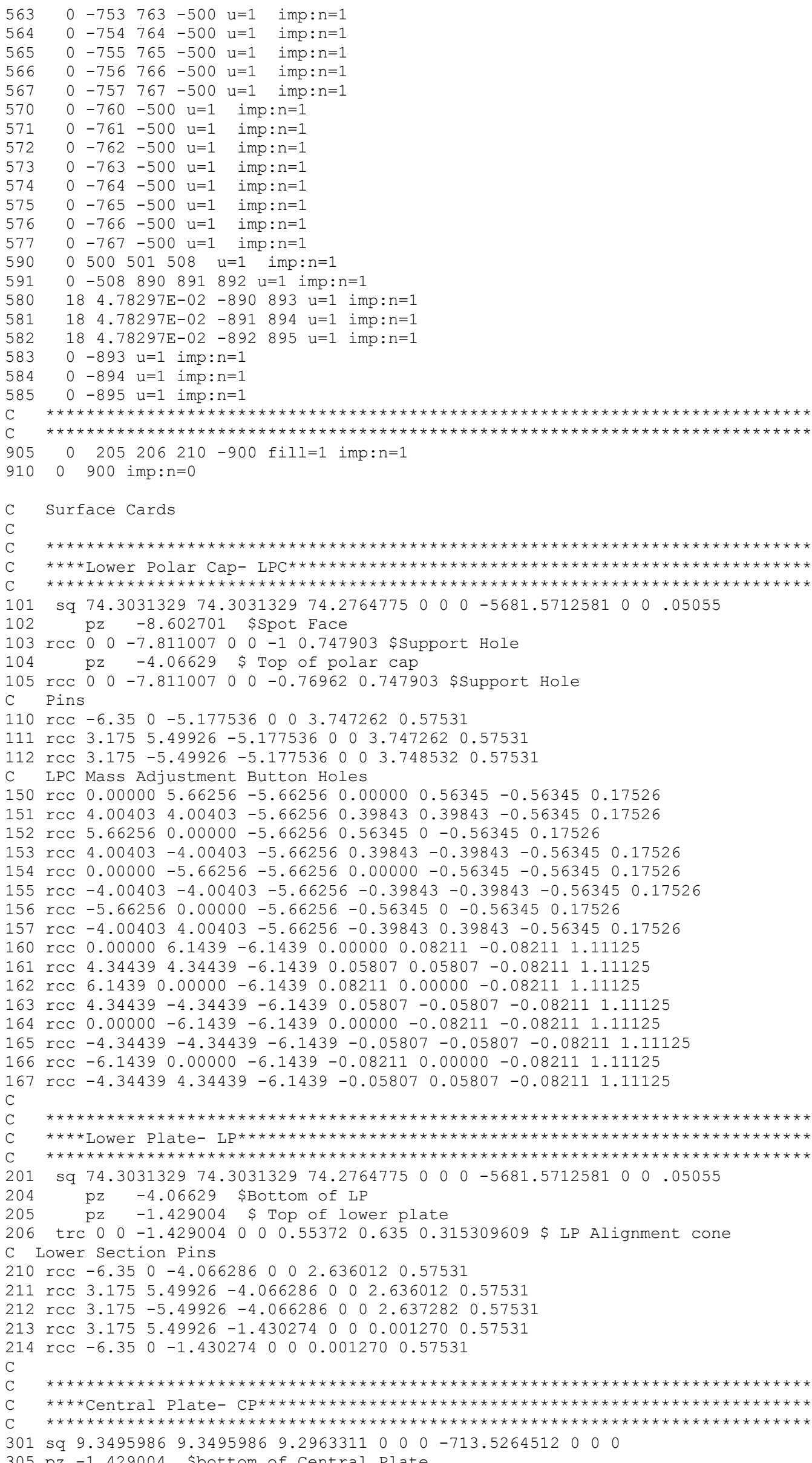

$305 \mathrm{pz}-1.429004$ \$bottom of Central Plate

Revision: 1 
NEA/NSC/DOC(2006)1

\section{Fundamental-FUND}

\section{ORSPHERE-FUND-EXP-001 \\ CRIT-REAC-COEF-KIN-RRATE}

$306 \mathrm{pz} 1.429004$ \$Top of Central Plate

307 trc $000-1.429004000 .57150 .63627 \quad 0.306314321$ \$ CP Alignment Hole

$308 \mathrm{cx} 0.17272$ \$Diametral Hole

309 rcc $-8.914765000 \quad 17.82953000 .164211$ \$ Diametral Pin

323 rcc 0.888238008 .80491001 .27 \$ Target Hole Plug

$324 \mathrm{rpp}-0.08890 .0889-0.9525 \quad 4.1275 \quad 1.281684 \quad 1.429004$ \$Thermocouple

$325 \mathrm{rpp}-0.08890 .08894 .1275 \quad 8.80491 \quad 1.1343641 .429004$ \$Thermocouple

C Support Rod Holes in CP

$\begin{array}{llllllllll}310 & \operatorname{rCC} & 5.74467 & 5.74467 & 0 & 0.43734 & 0.43734 & 0 & 0.351028\end{array}$

311 rec $5.74467-5.74467 \quad 0 \quad 0.43734 \quad-0.43734 \quad 0 \quad 0.351028$

312 rCC $-5.74467-5.74467 \quad 0 \quad-0.43734 \quad-0.43734 \quad 0 \quad 0.351028$

$\begin{array}{llllllllll}313 \operatorname{rCC} & -5.74467 & 5.74467 & 0 & -0.43734 & 0.43734 & 0 & 0.351028\end{array}$

C

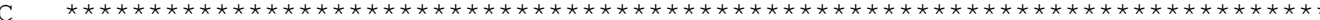

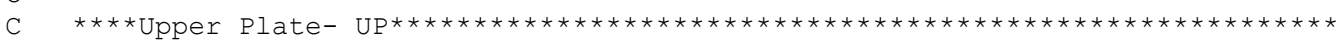

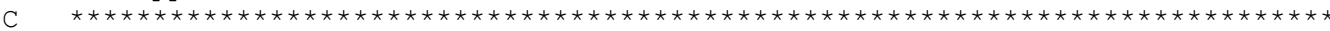

$401 \mathrm{sq} 9.3495986 \quad 9.3495986 \quad 9.296331100000-713.52645120000$

$406 \mathrm{pz} 1.429004$ \$Bottom of Upper Plate

407 pz 3.375152 \$Top of upper Plate

$408 \operatorname{trc} 0 \quad 0 \quad 3.375152000 .553720 .6350 .315309609$ \$ UP Alignment Cone

C Central Section Pins

410 rcc $-6.35-0.00063-1.42900400 \quad 0 \quad 4.804156 \quad 0.57531$

$411 \operatorname{rcc} 3.17445 \quad 5.49958-1.429004 \quad 0 \quad 0 \quad 4.804156 \quad 0.57531$

$412 \operatorname{rcc} 3.17555-5.49894-1.429004 \quad 0 \quad 0 \quad 4.804156 \quad 0.57531$

\section{$\mathrm{C}$}

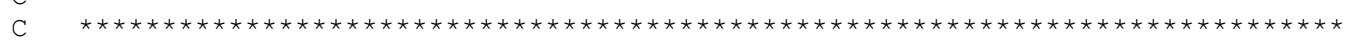

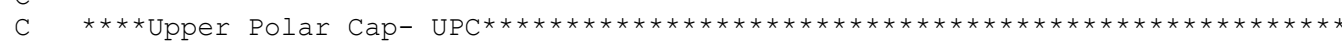

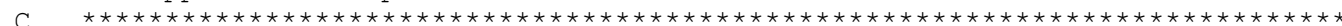

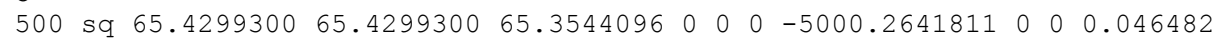

$501 \mathrm{pz} 3.375152$ \$Bottom of UPC

508 rCC 007.8061820001 .111251 .211072 \$top support hole

$503 \operatorname{trc} 0 \quad 0 \quad 3.375152 \quad 0 \quad 0 \quad 0.57150 .63627 \quad 0.306314321$ \$ UPC Alignment Hole

$504 \operatorname{trc} 0 \quad 0 \quad 3.375152000 .562610 .6356350 .310811965$ \$Cone for modeling

C UPC Mass Adjustment Button Holes

$750 \mathrm{rcc} 0.00000 \quad 5.66256 \quad 5.66256 \quad 0.00000 \quad 0.563450 .563450 .17526$

$\begin{array}{lllllllll}751 & \operatorname{rCC} & 4.00403 & 4.00403 & 5.66256 & 0.39843 & 0.39843 & 0.56345 & 0.17526\end{array}$

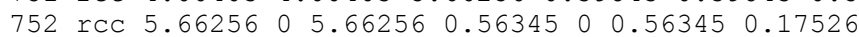

$753 \operatorname{rcc} 4.00403-4.00403 \quad 5.66256 \quad 0.39843-0.39843 \quad 0.563450 .17526$

$\begin{array}{lllllllll}754 & \text { rCC } & 0.00000 & -5.66256 & 5.66256 & 0.00000 & -0.56345 & 0.56345 & 0.17526\end{array}$

755 rCc $-4.00403-4.00403 \quad 5.66256-0.39843-0.39843 \quad 0.56345 \quad 0.17526$

$756 r C C-5.66256 \quad 0 \quad 5.66256-0.5634500 .563450 .17526$

757 rcc $-4.00403 \quad 4.00403 \quad 5.66256-0.39843 \quad 0.39843 \quad 0.563450 .17526$

$\begin{array}{lllllllllll}760 & \mathrm{rcc} & 0.00000 & 6.1439 & 6.1439 & 0.00000 & 0.08211 & 0.08211 & 1.11125\end{array}$

$\begin{array}{llllllllll}761 & \operatorname{rcc} & 4.34439 & 4.34439 & 6.1439 & 0.05807 & 0.05807 & 0.08211 & 1.11125\end{array}$

$\begin{array}{lllllllll}762 & \operatorname{rcc} & 6.14390 & 0 & 6.1439 & 0.08211 & 0 & 0.08211 & 1.11125\end{array}$

$\begin{array}{llllllllll}763 \operatorname{rcc} & 4.34439 & -4.34439 & 6.1439 & 0.05807 & -0.05807 & 0.08211 & 1.11125\end{array}$

$\begin{array}{llllllllll}764 & \text { rcc } & 0.00000 & -6.1439 & 6.1439 & 0.00000 & -0.08211 & 0.08211 & 1.11125\end{array}$

765 rcc $-4.34439-4.344396 .1439-0.05807-0.05807 \quad 0.082111 .11125$

$\begin{array}{llllllllll}766 & \mathrm{rCC} & -6.14390 & 0 & 6.1439 & -0.08211 & 0 & 0.08211 & 1.11125\end{array}$

$767 \operatorname{rcc}-4.344394 .344396 .1439-0.05807 \quad 0.05807 \quad 0.08211 \quad 1.11125$

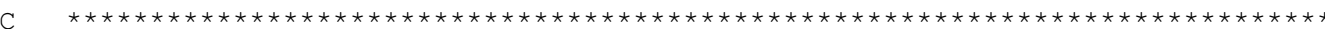

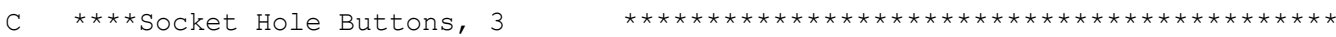

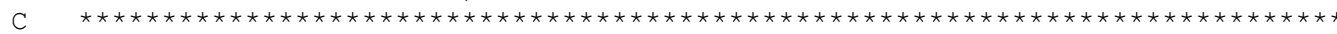

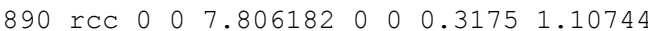

891 rcc $0000.123682 \quad 0 \quad 0 \quad 0.3175 \quad 1.10744$

892 rcc $000 \begin{array}{llllll}0 & 0.441182 & 0 & 0 & 0.3175 & 1.10744\end{array}$

$893 \operatorname{rcc} 0007.806182 \quad 0 \quad 0 \quad 0.3175 \quad 0.22479$

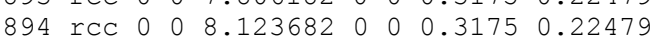

$895 \operatorname{rcc} 0 \quad 0 \quad 8.441182 \quad 0 \quad 0 \quad 0.3175 \quad 0.22479$

C

$900 \mathrm{rpp}-356.616713 .232-682.752 \quad 387.096-280.416629 .7168$ \$Inside Walls

C Data Cards

$\begin{array}{lll}\text { C } & \text { Lower Polar Cap } \\ \text { m10 } & 92234.70 \mathrm{C} & 4.74524 \mathrm{E}-04 \\ & 92235.70 \mathrm{C} & 4.47388 \mathrm{E}-02 \\ & 92236.70 \mathrm{C} & 1.71732 \mathrm{E}-05 \\ & 92238.70 \mathrm{C} & 2.74959 \mathrm{E}-03 \\ & 4009.70 \mathrm{C} & 6.26660 \mathrm{E}-09 \\ & 3006.70 \mathrm{C} & 1.23513 \mathrm{E}-08 \\ \text { 3007.70C } & 1.50380 \mathrm{E}-07 \\ 13027.70 \mathrm{C} & 2.09313 \mathrm{E}-06 \\ 14028.70 \mathrm{C} & 3.70921 \mathrm{E}-05 \\ 14029.70 \mathrm{C} & 1.88345 \mathrm{E}-06 \\ & 14030.70 \mathrm{C} & 1.24158 \mathrm{E}-06 \\ & 25055.70 \mathrm{C} & 5.08310 \mathrm{E}-06\end{array}$

Revision: 1 
NEA/NSC/DOC(2006)1

Fundamental-FUND

ORSPHERE-FUND-EXP-001

CRIT-REAC-COEF-KIN-RRATE

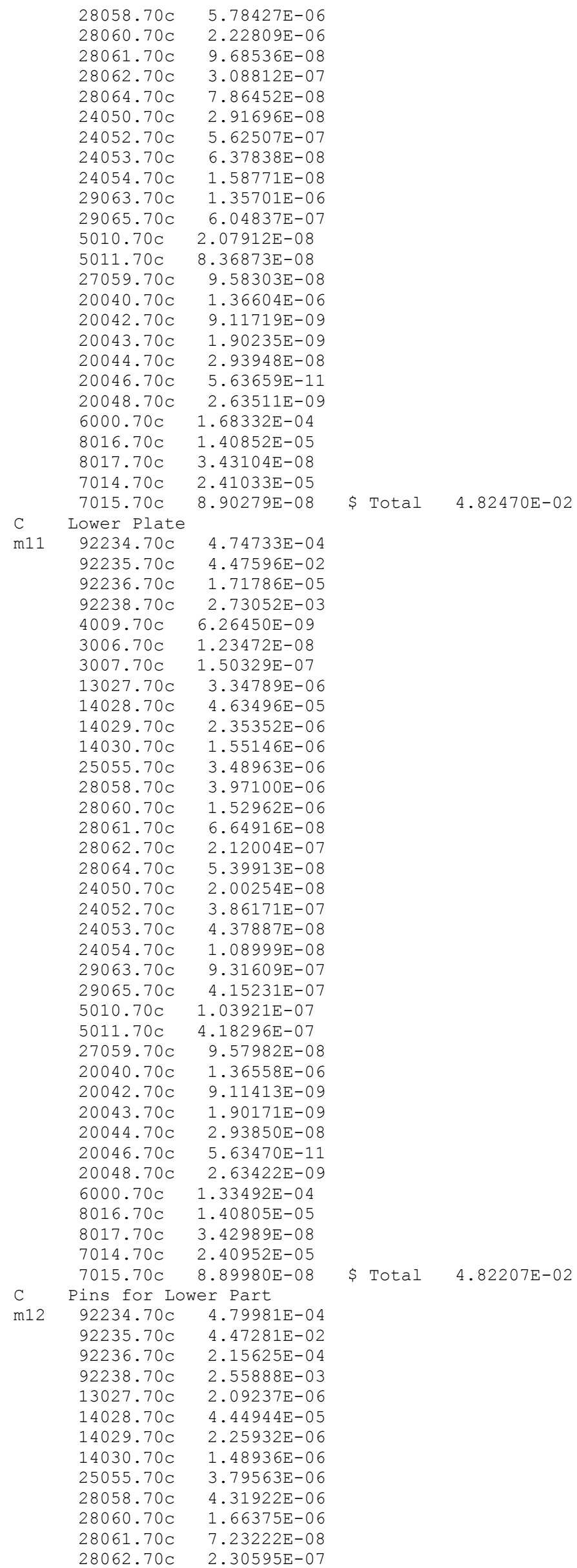

Revision: 1 
NEA/NSC/DOC(2006)1

Fundamental-FUND

ORSPHERE-FUND-EXP-001

CRIT-REAC-COEF-KIN-RRATE

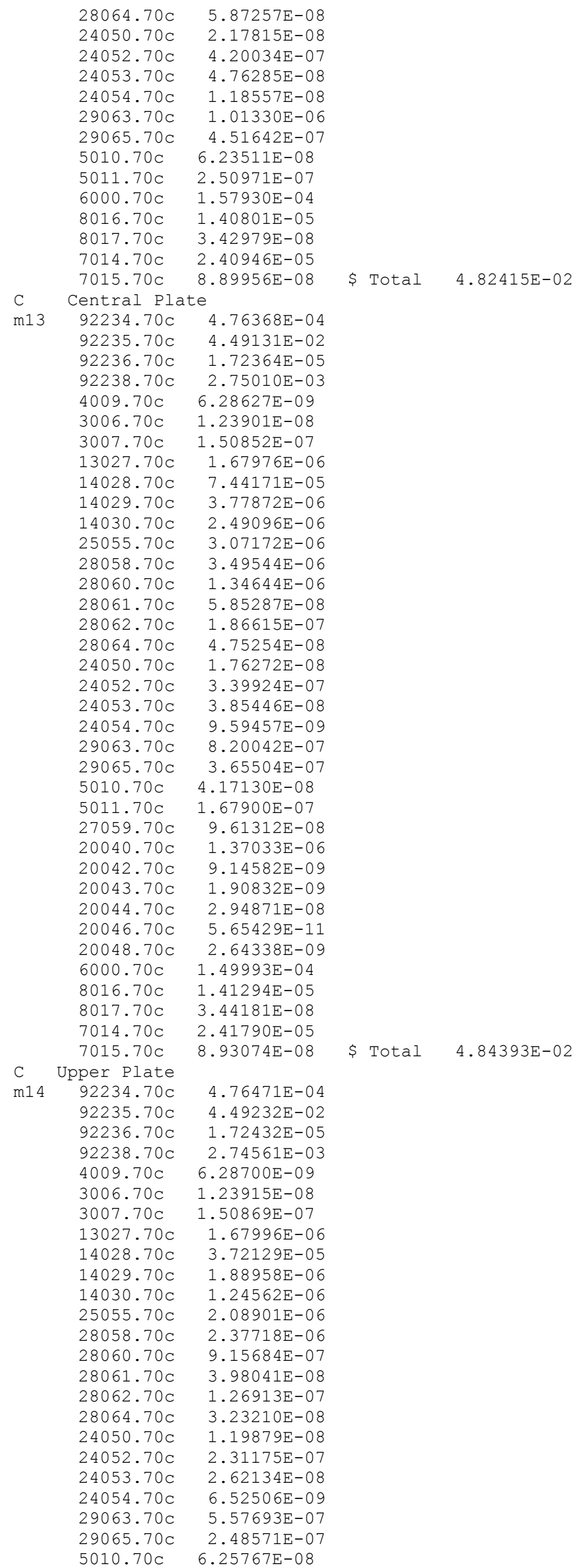

Revision: 1 
NEA/NSC/DOC(2006)1

Fundamental-FUND

ORSPHERE-FUND-EXP-001

CRIT-REAC-COEF-KIN-RRATE

$\begin{array}{lc}5011.70 \mathrm{C} & 2.51879 \mathrm{E}-07 \\ 27059.70 \mathrm{C} & 9.61423 \mathrm{E}-08 \\ 20040.70 \mathrm{C} & 1.37049 \mathrm{E}-06 \\ 20042.70 \mathrm{C} & 9.14688 \mathrm{E}-09 \\ 20043.70 \mathrm{C} & 1.90854 \mathrm{E}-09 \\ 20044.70 \mathrm{C} & 2.94905 \mathrm{E}-08 \\ 20046.70 \mathrm{C} & 5.65495 \mathrm{E}-11 \\ 20048.70 \mathrm{C} & 2.64369 \mathrm{E}-09 \\ 6000.70 \mathrm{C} & 1.50011 \mathrm{E}-04 \\ 8016.70 \mathrm{C} & 1.41310 \mathrm{E}-05 \\ 8017.70 \mathrm{C} & 3.44221 \mathrm{E}-08 \\ 7014.70 \mathrm{C} & 2.41818 \mathrm{E}-05 \\ 7015.70 \mathrm{C} & 8.93177 \mathrm{E}-08\end{array}$

$\begin{array}{ll}C & \text { Pins for Central Section } \\ \text { m15 } 92234.70 \mathrm{C} & 4.77221 \mathrm{E}-0\end{array}$

$92235.70 \mathrm{C} \quad 4.49020 \mathrm{E}-02$

$92236.70 \mathrm{C} \quad 2.03472 \mathrm{E}-04$

$92238.70 \mathrm{C} \quad 2.57860 \mathrm{E}-03$

$13027.70 \mathrm{C} \quad 2.10017 \mathrm{E}-06$

$14028.70 \mathrm{C} \quad 4.46602 \mathrm{E}-05$

$14029.70 \mathrm{C} \quad 2.26774 \mathrm{E}-06$

$14030.70 \mathrm{C} \quad 1.49491 \mathrm{E}-06$

$25055.70 \mathrm{C} \quad 3.80978 \mathrm{E}-06$

$28058.70 \mathrm{C} \quad 4.33532 \mathrm{E}-06$

$28060.70 \mathrm{C} \quad 1.66996 \mathrm{E}-06$

$28061.70 \mathrm{C} \quad 7.25918 \mathrm{E}-08$

$28062.70 \mathrm{C} \quad 2.31455 \mathrm{E}-07$

$28064.70 \mathrm{C} \quad 5.89446 \mathrm{E}-08$

$24050.70 \mathrm{C} \quad 2.18627 \mathrm{E}-08$

$24052.70 \mathrm{C} \quad 4.21600 \mathrm{E}-07$

$24053.70 \mathrm{C} \quad 4.78060 \mathrm{E}-08$

$24054.70 \mathrm{C} \quad 1.18999 \mathrm{E}-08$

$29063.70 \mathrm{C} \quad 1.01708 \mathrm{E}-06$

$29065.70 \mathrm{C} \quad 4.53326 \mathrm{E}-07$

$5010.70 \mathrm{C} \quad 6.25835 \mathrm{E}-08$

$5011.70 \mathrm{C} \quad 2.51906 \mathrm{E}-07$

$6000.70 \mathrm{C} \quad 1.58519 \mathrm{E}-04$

$8016.70 \mathrm{C} \quad 1.41326 \mathrm{E}-05$

$8017.70 \mathrm{C} \quad 3.44258 \mathrm{E}-08$

$7014.70 \mathrm{C} \quad 2.41844 \mathrm{E}-05$

$7015.70 \mathrm{C} \quad 8.93274 \mathrm{E}-08$

C Upper Polar $\mathrm{Cp}$

m16 $92234.70 \mathrm{c}$

$92235.70 \mathrm{C}$ p

$4.75689 \mathrm{E}-04$

4. $48495 \mathrm{E}-02$

1. $72149 \mathrm{E}-05$

$\begin{array}{ll}92238.70 \mathrm{C} & 2.74110 \mathrm{E}-03 \\ 4009.70 \mathrm{C} & 6.27700 \mathrm{E}-09\end{array}$

$3006.70 \mathrm{C} \quad 1.23718 \mathrm{E}-08$

$3007.70 \mathrm{C} \quad 1.50630 \mathrm{E}-07$

$13027.70 \mathrm{C} \quad 2.51593 \mathrm{E}-06$

$14028.70 \mathrm{C} \quad 2.97229 \mathrm{E}-05$

$14029.70 \mathrm{C} \quad 1.50926 \mathrm{E}-06$

$14030.70 \mathrm{C} \quad 9.94914 \mathrm{E}-07$

$25055.70 \mathrm{C} \quad 5.21422 \mathrm{E}-06$

$28058.70 \mathrm{C} \quad 5.93349 \mathrm{E}-06$

$28060.70 \mathrm{C} \quad 2.28557 \mathrm{E}-06$

$28061.70 \mathrm{C} \quad 9.93521 \mathrm{E}-08$

$28062.70 \mathrm{C} \quad 3.16778 \mathrm{E}-07$

$28064.70 \mathrm{C} \quad 8.06740 \mathrm{E}-08$

$24050.70 \mathrm{C} \quad 2.99221 \mathrm{E}-08$

$24052.70 \mathrm{C} \quad 5.77018 \mathrm{E}-07$

$24053.70 \mathrm{C} \quad 6.54292 \mathrm{E}-08$

$24054.70 \mathrm{C} \quad 1.62867 \mathrm{E}-08$

$29063.70 \mathrm{C} \quad 1.39201 \mathrm{E}-06$

$29065.70 \mathrm{C} \quad 6.20440 \mathrm{E}-07$

$5010.70 \mathrm{C} \quad 1.04129 \mathrm{E}-07$

$5011.70 \mathrm{C} \quad 4.19131 \mathrm{E}-07$

$27059.70 \mathrm{C} \quad 9.59894 \mathrm{E}-08$

$20040.70 \mathrm{C} \quad 1.36831 \mathrm{E}-06$

$20042.70 \mathrm{C} \quad 9.13233 \mathrm{E}-09$

$20043.70 \mathrm{C} \quad 1.90551 \mathrm{E}-09$

$20044.70 \mathrm{C} \quad 2.94436 \mathrm{E}-08$

$20046.70 \mathrm{C} \quad 5.64595 \mathrm{E}-11$

$20048.70 \mathrm{C} \quad 2.63948 \mathrm{E}-09$

$6000.70 \mathrm{C} \quad 1.90277 \mathrm{E}-04$

$8016.70 \mathrm{C} \quad 1.41086 \mathrm{E}-05$

$8017.70 \mathrm{C} \quad 3.43673 \mathrm{E}-08$

\$ Total 4.84016E-02

\$ Total 4.84213E-02

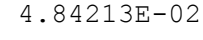

Revision: 1 
NEA/NSC/DOC(2006)1

Fundamental-FUND

ORSPHERE-FUND-EXP-001

CRIT-REAC-COEF-KIN-RRATE

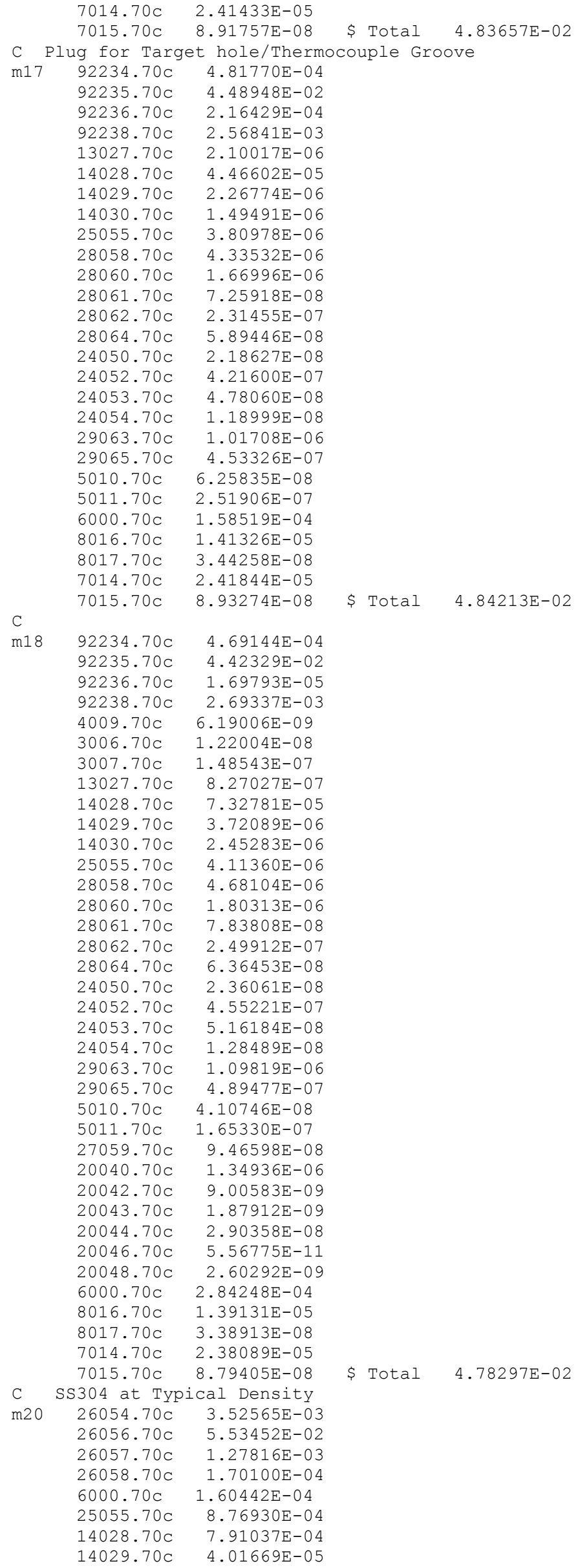

Revision: 1 
NEA/NSC/DOC(2006)1

Fundamental-FUND

ORSPHERE-FUND-EXP-001

CRIT-REAC-COEF-KIN-RRATE

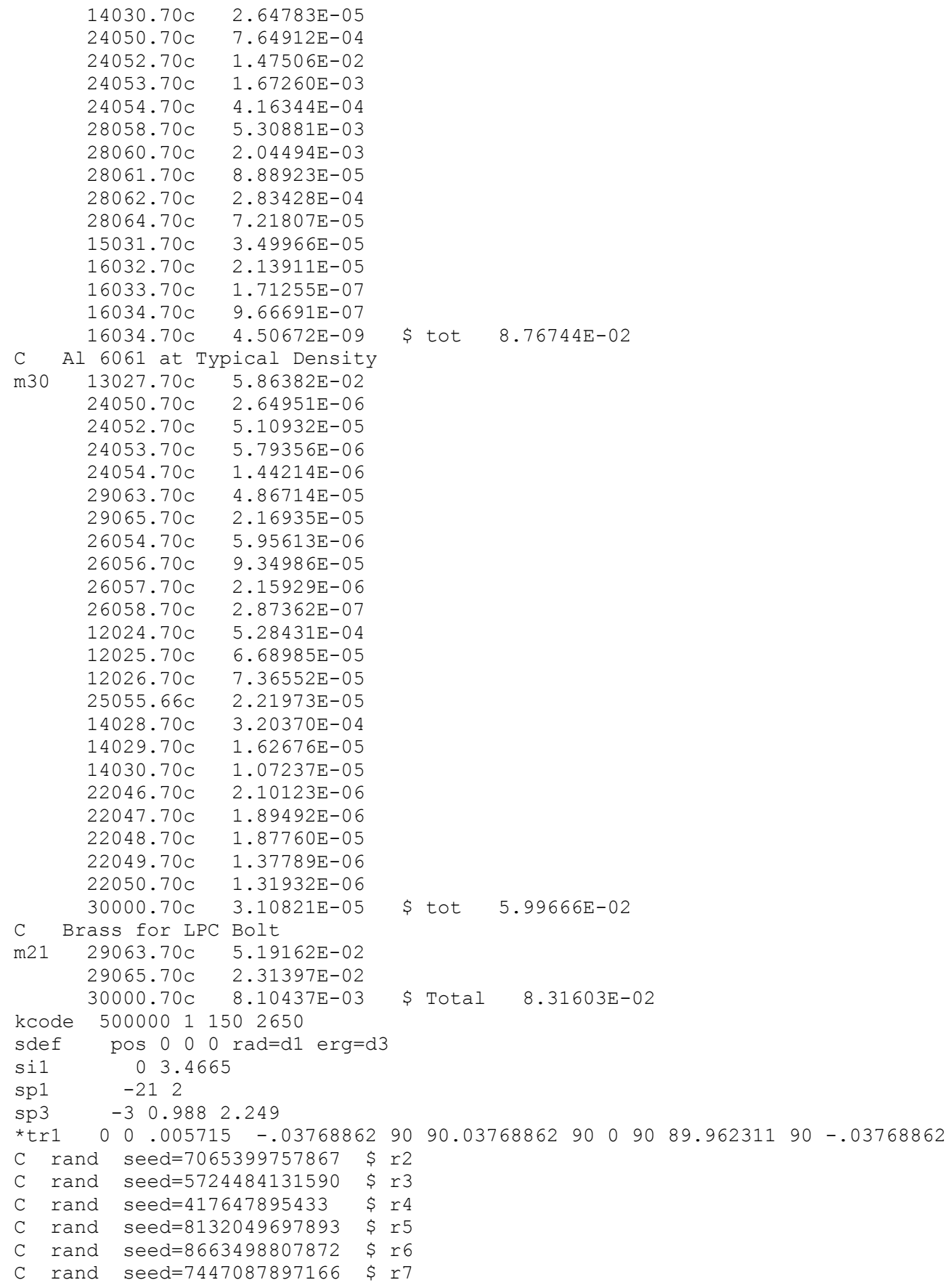




\section{NEA/NSC/DOC(2006)1 \\ Fundamental-FUND \\ ORSPHERE-FUND-EXP-001 \\ CRIT-REAC-COEF-KIN-RRATE}

\section{A.5 Reactivity Coefficient Configurations}

\section{A.5.1 Name(s) of Code System(s) Used}

1. Monte Carlo n-Particle, Version 5.1.60 (MCNP5).

\section{A.5.2 Bibliographic References for the Codes Used}

1. F. B. Brown, R. F. Barrett, T. E. Booth, J. S. Bull, L. J. Cox, R. A. Forster, T. J. Goorley, R. D. Mosteller, S. E. Post, R. E. Prael, E. C. Selcow, A. Sood, and J. Sweezy, "MCNP Version 5," LA-UR-02-3935, Los Alamos National Laboratory (2002).

\section{A.5.3 Origin of Cross-section Data}

The evaluated neutron data file library ENDF/B-VII.0 $0^{\text {a }}$ was utilized in the benchmark-model analysis.

\section{A.5.4 Spectral Calculations and Data Reduction Methods Used}

Not applicable.

\section{A.5.5 Number of Energy Groups or If Continuous-energy Cross Sections are Used in the Different Phases of Calculation}

1. Continuous-energy cross sections.

\section{A.5.6 Component Calculations}

Not applicable

\section{A.5.7 Other Assumptions and Characteristics}

Not applicable.

\section{A.5.8 Typical Input Listings for Each Code System Type}

The benchmark models for the worth per gram of uranium surface material are given below.

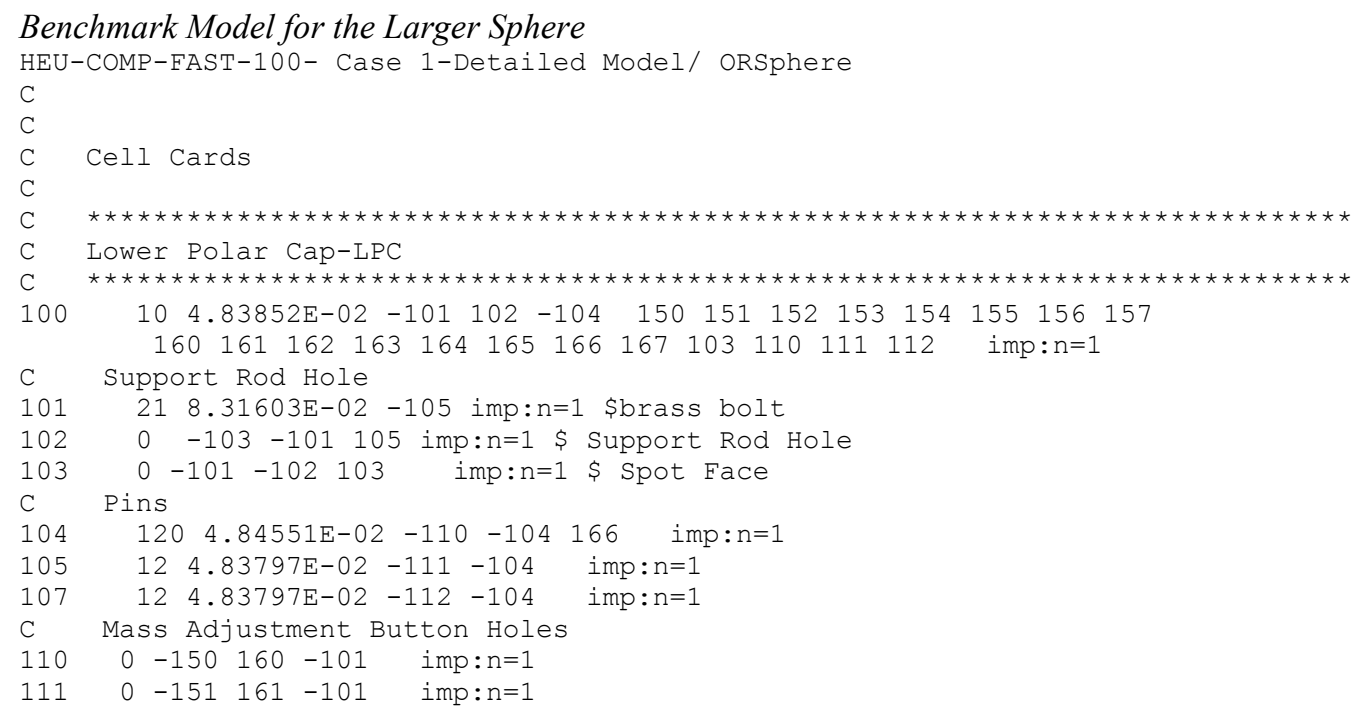

${ }^{\text {a }}$ M. B. Chadwick, et al., "ENDF/B-VII.0: Next Generation Evaluated Nuclear Data Library for Nuclear Science and Technology," Nucl. Data Sheets, 107: 2931-3060 (2006). 
NEA/NSC/DOC(2006)1

Fundamental-FUND

ORSPHERE-FUND-EXP-001

CRIT-REAC-COEF-KIN-RRATE

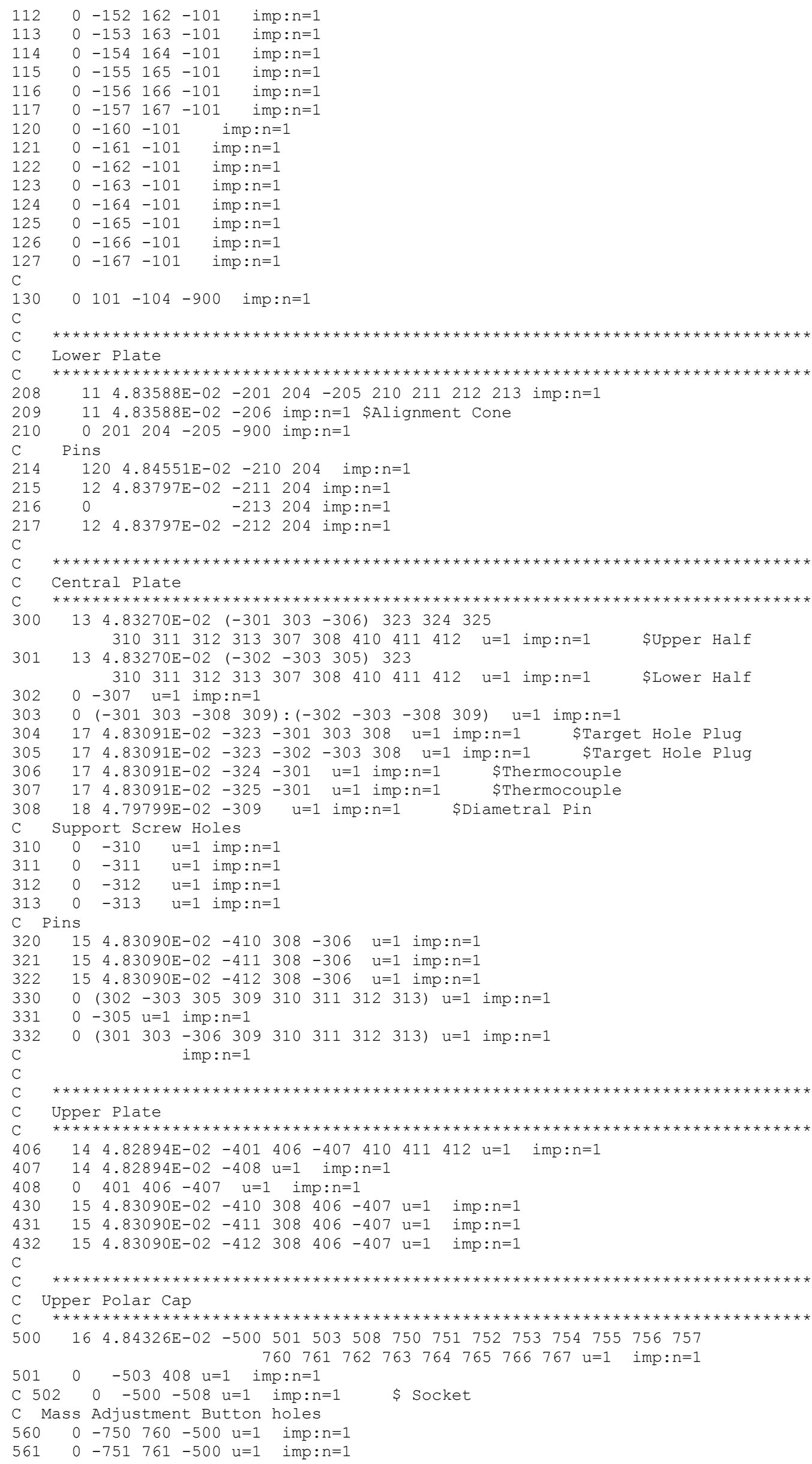

\section{Revision: 1}


NEA/NSC/DOC(2006)1

Fundamental-FUND

ORSPHERE-FUND-EXP-001

CRIT-REAC-COEF-KIN-RRATE

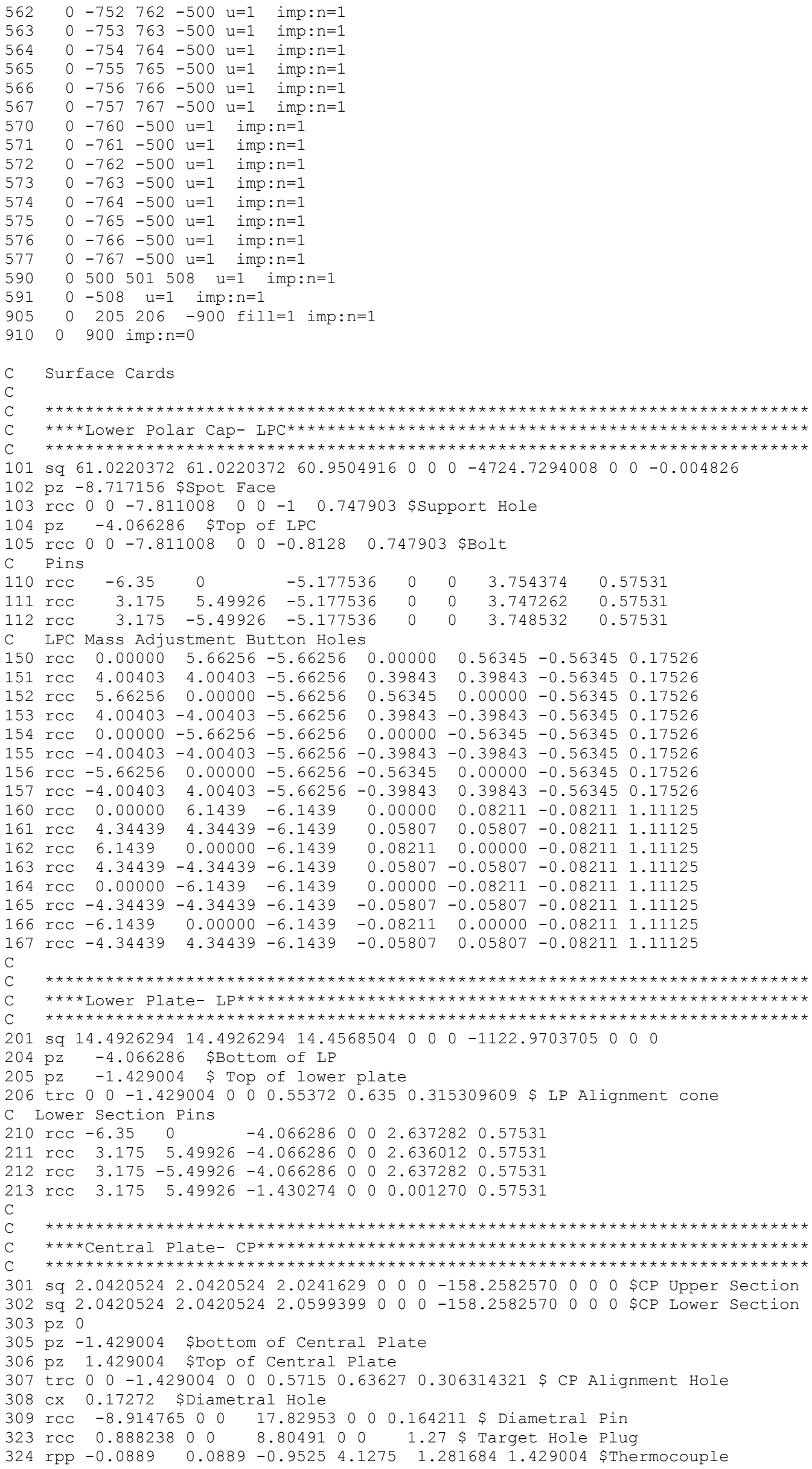

Revision: 1 
NEA/NSC/DOC(2006)1

Fundamental-FUND

\section{ORSPHERE-FUND-EXP-001 \\ CRIT-REAC-COEF-KIN-RRATE}

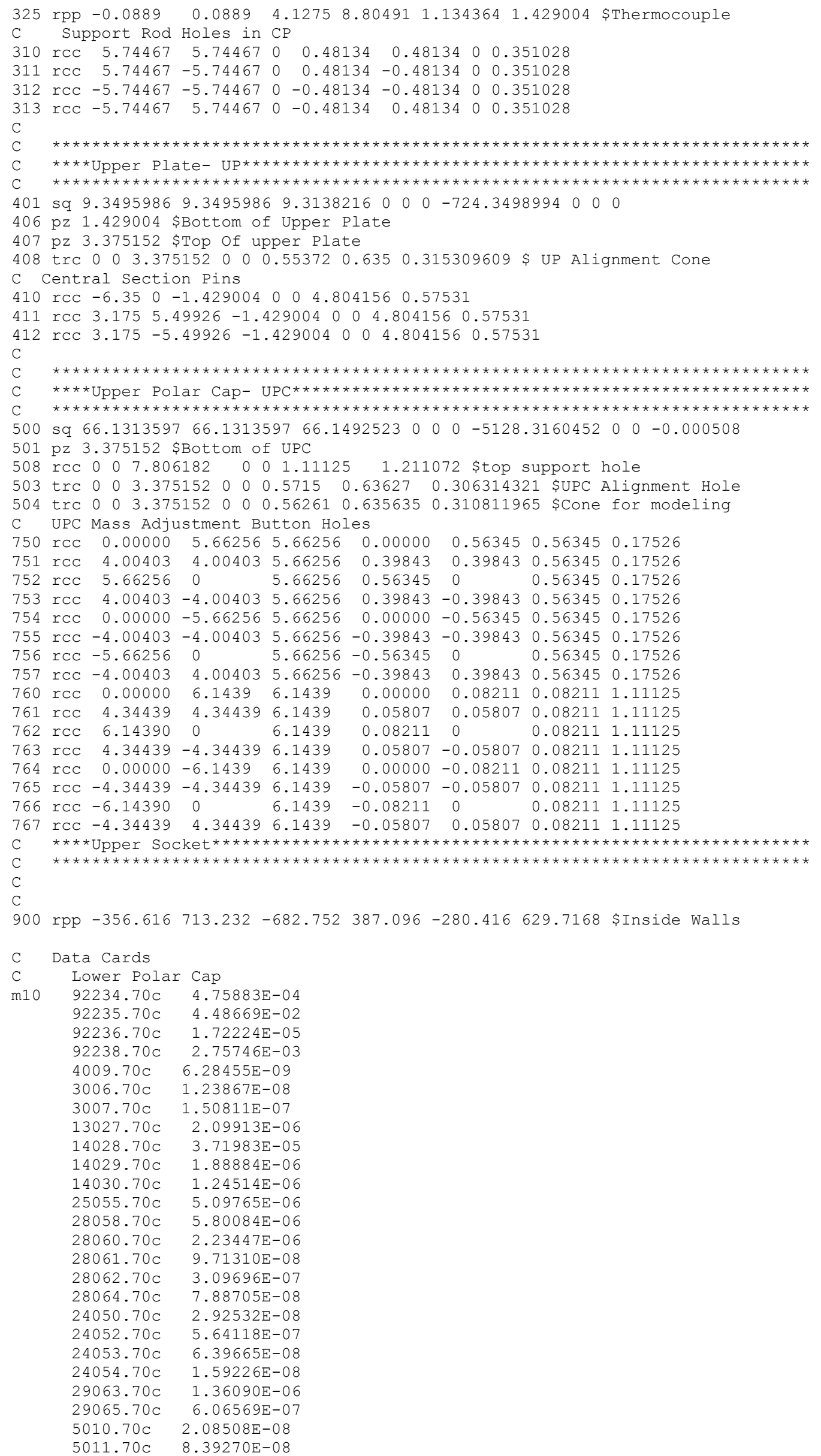

Revision: 1 
NEA/NSC/DOC(2006)1

Fundamental-FUND

ORSPHERE-FUND-EXP-001

CRIT-REAC-COEF-KIN-RRATE

\begin{tabular}{|c|c|c|}
\hline & $059.70 \mathrm{c}$ & $9.61048 \mathrm{E}-0$ \\
\hline & $20040.70 \mathrm{c}$ & 1. \\
\hline & $20042.70 c$ & $9.14330 \mathrm{E}-09$ \\
\hline & $20043.70 c$ & $1.90780 \mathrm{E}-09$ \\
\hline & $20044.70 c$ & $2.94790 \mathrm{E}-0$ \\
\hline & $20046.70 c$ & $5.65274 \mathrm{E}-1$ \\
\hline & $20048.70 c$ & $2.64265 \mathrm{E}-0$ \\
\hline & $6000.70 c$ & $1.68814 \mathrm{E}-04$ \\
\hline & $8016.70 \mathrm{c}$ & $1.41255 \mathrm{E}-05$ \\
\hline & $8017.70 \mathrm{c}$ & $3.44086 \mathrm{E}-08$ \\
\hline & $7014.70 \mathrm{c}$ & $2.41724 \mathrm{E}-05$ \\
\hline & $7015.70 \mathrm{c}$ & $8.92829 \mathrm{E}-08$ \\
\hline & Lower Plate & \\
\hline & $92234.70 \mathrm{c}$ & $4.76093 \mathrm{E}-0$ \\
\hline & $92235.70 \mathrm{c}$ & $4.48877 \mathrm{E}-0$ \\
\hline & $92236.70 \mathrm{c}$ & $1.72278 \mathrm{E}-0$ \\
\hline & $92238.70 \mathrm{c}$ & $2.73834 \mathrm{E}-0$ \\
\hline & $4009.70 \mathrm{c}$ & $6.28244 \mathrm{E}-09$ \\
\hline & $3006.70 \mathrm{c}$ & $1.23825 \mathrm{E}-08$ \\
\hline & $3007.70 c$ & $1.50760 \mathrm{E}-07$ \\
\hline & $13027.70 \mathrm{c}$ & $3.35748 \mathrm{E}-0$ \\
\hline & $14028.70 \mathrm{c}$ & $4.64823 \mathrm{E}-0$ \\
\hline & $14029.70 \mathrm{c}$ & $2.36026 \mathrm{E}-0$ \\
\hline & $14030.70 \mathrm{c}$ & $1.55590 \mathrm{E}-0$ \\
\hline & $25055.70 \mathrm{c}$ & $3.49962 \mathrm{E}-0$ \\
\hline & $28058.70 \mathrm{c}$ & $3.98237 \mathrm{E}-0$ \\
\hline & $28060.70 \mathrm{c}$ & $1.53400 \mathrm{E}-0$ \\
\hline & $28061.70 \mathrm{c}$ & $6.66820 \mathrm{E}-0$ \\
\hline & $28062.70 \mathrm{c}$ & $2.12612 \mathrm{E}-0$ \\
\hline & $28064.70 \mathrm{c}$ & $5.41459 \mathrm{E}-0$ \\
\hline & $24050.70 c$ & $2.00828 \mathrm{E}-0$ \\
\hline & $24052.70 c$ & $3.87277 \mathrm{E}-0$ \\
\hline & $24053.70 c$ & $4.39141 \mathrm{E}-0$ \\
\hline & $24054.70 c$ & $1.09311 \mathrm{E}-0$ \\
\hline & $29063.70 c$ & $9.34277 \mathrm{E}-0$ \\
\hline & $29065.70 \mathrm{c}$ & $4.16420 \mathrm{E}-0$ \\
\hline & $5010.70 \mathrm{c}$ & $1.04219 \mathrm{E}-07$ \\
\hline & $5011.70 \mathrm{c}$ & $4.19494 \mathrm{E}-07$ \\
\hline & $27059.70 \mathrm{c}$ & $9.60725 \mathrm{E}-0$ \\
\hline & $20040.70 c$ & $1.36950 \mathrm{E}-0$ \\
\hline & $20042.70 \mathrm{c}$ & $9.14024 \mathrm{E}-0$ \\
\hline & $20043.70 \mathrm{c}$ & $1.90716 \mathrm{E}-0$ \\
\hline & $20044.70 c$ & $2.94691 \mathrm{E}-0$ \\
\hline & $20046.70 \mathrm{c}$ & $5.65084 \mathrm{E}-1$ \\
\hline & $20048.70 \mathrm{c}$ & $2.64177 \mathrm{E}-0$ \\
\hline & $6000.70 \mathrm{c}$ & $1.33875 \mathrm{E}-04$ \\
\hline & $8016.70 \mathrm{c}$ & $1.41208 \mathrm{E}-05$ \\
\hline & $8017.70 \mathrm{C}$ & $3.43971 \mathrm{E}-08$ \\
\hline & $7014.70 \mathrm{c}$ & $2.41643 \mathrm{E}-05$ \\
\hline & $7015.70 \mathrm{C}$ & $8.92529 \mathrm{E}-08$ \\
\hline & Pins for Lo & ver Part \\
\hline & $92234.70 c$ & $4.81356 \mathrm{E}-0$ \\
\hline & $92235.70 \mathrm{c}$ & $4.48562 \mathrm{E}-0$ \\
\hline & $92236.70 \mathrm{c}$ & $2.16242 \mathrm{E}-0$ \\
\hline & $92238.70 \mathrm{c}$ & $2.56620 \mathrm{E}-0$ \\
\hline & $13027.70 \mathrm{c}$ & $2.09837 \mathrm{E}-0$ \\
\hline & $14028.70 \mathrm{c}$ & $4.46218 \mathrm{E}-0$ \\
\hline & $14029.70 \mathrm{c}$ & $2.26579 \mathrm{E}-0$ \\
\hline & $14030.70 \mathrm{c}$ & $1.49362 \mathrm{E}-0$ \\
\hline & $25055.70 \mathrm{c}$ & $3.80650 \mathrm{E}-0$ \\
\hline & $28058.70 \mathrm{c}$ & $4.33159 \mathrm{E}-0$ \\
\hline & $28060.70 \mathrm{c}$ & $1.66852 \mathrm{E}-0$ \\
\hline & $28061.70 \mathrm{c}$ & $7.25294 \mathrm{E}-0$ \\
\hline & $28062.70 \mathrm{c}$ & $2.31255 \mathrm{E}-0$ \\
\hline & $28064.70 c$ & $5.88939 \mathrm{E}-0$ \\
\hline & $24050.70 c$ & $2.18438 \mathrm{E}-0$ \\
\hline & $24052.70 \mathrm{c}$ & $4.21237 \mathrm{E}-0$ \\
\hline & $24053.70 c$ & $4.77649 \mathrm{E}-0$ \\
\hline & $24054.70 c$ & $1.18897 \mathrm{E}-0$ \\
\hline & $29063.70 \mathrm{c}$ & $1.01620 \mathrm{E}-0$ \\
\hline & $29065.70 \mathrm{c}$ & $4.52936 \mathrm{E}-0$ \\
\hline & $5010.70 \mathrm{c}$ & $6.25296 \mathrm{E}-08$ \\
\hline & $5011.70 \mathrm{c}$ & $2.51690 \mathrm{E}-07$ \\
\hline & $6000.70 \mathrm{C}$ & $1.58383 \mathrm{E}-04$ \\
\hline & $8016.70 c$ & $1.41204 \mathrm{E}-05$ \\
\hline & C & $3.43962 \mathrm{E}-08$ \\
\hline & 27170 & $2.41636 \mathrm{E}-0$ \\
\hline
\end{tabular}

Revision: 1 
NEA/NSC/DOC(2006)1

Fundamental-FUND

ORSPHERE-FUND-EXP-001

CRIT-REAC-COEF-KIN-RRATE

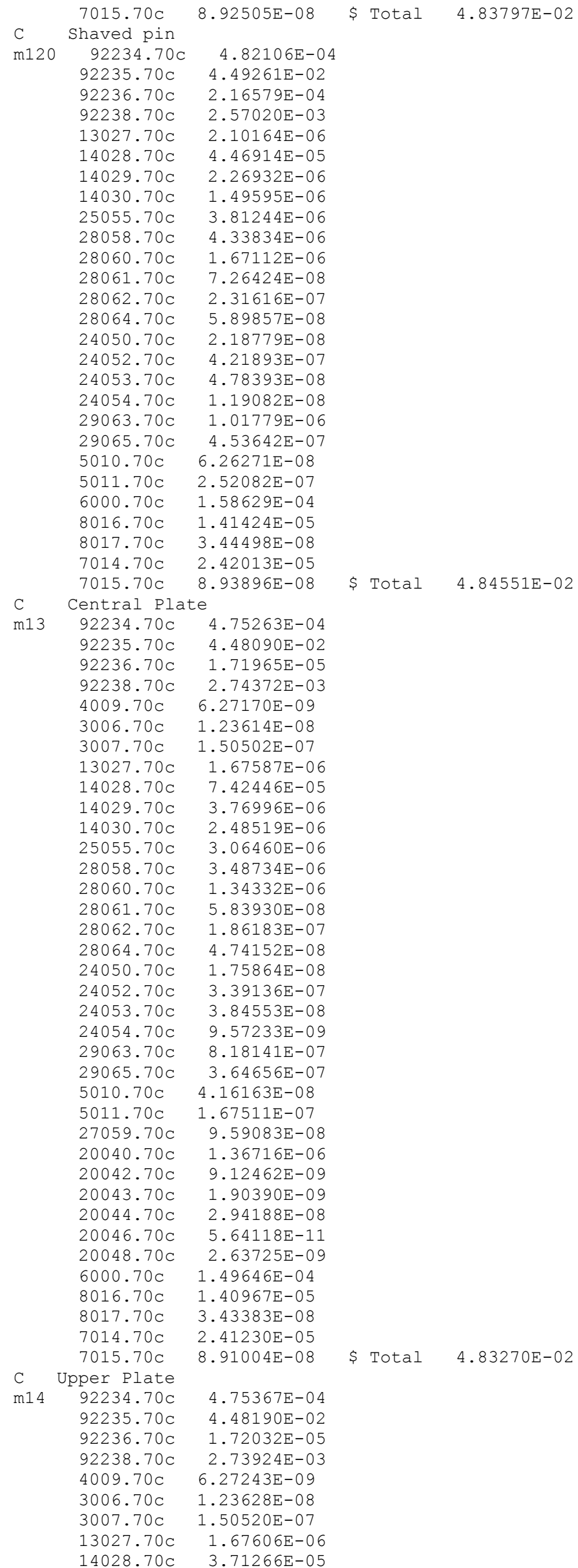

Revision: 1 
NEA/NSC/DOC(2006)1

Fundamental-FUND

ORSPHERE-FUND-EXP-001

CRIT-REAC-COEF-KIN-RRATE

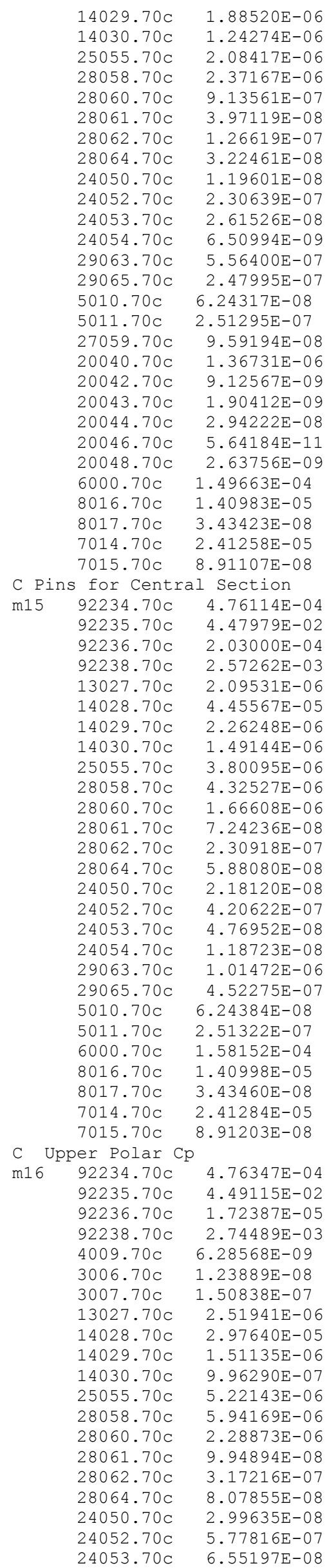

\$ Total 4.82894E-02

\$ Total 4.83090E-02 
NEA/NSC/DOC(2006)1

Fundamental-FUND

ORSPHERE-FUND-EXP-001

CRIT-REAC-COEF-KIN-RRATE

\begin{tabular}{|c|c|c|c|}
\hline $24054.70 \mathrm{C}$ & $1.63092 \mathrm{E}-08$ & & \\
\hline $29063.70 \mathrm{C}$ & $1.39394 \mathrm{E}-06$ & & \\
\hline $29065.70 \mathrm{C}$ & $6.21297 E-07$ & & \\
\hline $5010.70 \mathrm{C}$ & $1.04273 E-07$ & & \\
\hline $5011.70 \mathrm{C}$ & $4.19710 \mathrm{E}-07$ & & \\
\hline $27059.70 \mathrm{C}$ & $9.61221 \mathrm{E}-08$ & & \\
\hline $20040.70 \mathrm{C}$ & $1.37020 \mathrm{E}-06$ & & \\
\hline $20042.70 \mathrm{C}$ & $9.14495 E-09$ & & \\
\hline $20043.70 \mathrm{C}$ & $1.90814 \mathrm{E}-09$ & & \\
\hline $20044.70 \mathrm{C}$ & $2.94843 E-08$ & & \\
\hline $20046.70 \mathrm{C}$ & $5.65376 \mathrm{E}-11$ & & \\
\hline $20048.70 \mathrm{C}$ & $2.64313 E-09$ & & \\
\hline $6000.70 \mathrm{c}$ & $1.90540 \mathrm{E}-04$ & & \\
\hline $8016.70 \mathrm{c}$ & $1.41281 E-05$ & & \\
\hline $8017.70 \mathrm{C}$ & $3.44148 E-08$ & & \\
\hline $4.70 \mathrm{C}$ & $2.41767 \mathrm{E}-05$ & & \\
\hline $.70 \mathrm{c}$ & $8.92990 \mathrm{E}-08$ & $\$$ Total & $4.84326 E-02$ \\
\hline
\end{tabular}

C Plug for Target hole/Thermocouple Groove

m17 92234.70 C 4.80653E-04

$92235.70 \mathrm{C} \quad 4.47907 \mathrm{E}-02$

$92236.70 \mathrm{C} \quad 2.15927 \mathrm{E}-04$

$92238.70 \mathrm{C} \quad 2.56246 \mathrm{E}-03$

$13027.70 \mathrm{C} \quad 2.09531 \mathrm{E}-06$

$14028.70 \mathrm{C} \quad 4.45567 \mathrm{E}-05$

$14029.70 \mathrm{C} \quad 2.26248 \mathrm{E}-06$

$14030.70 \mathrm{C} \quad 1.49144 \mathrm{E}-06$

$25055.70 \mathrm{C} \quad 3.80095 \mathrm{E}-06$

$28058.70 \mathrm{C} \quad 4.32527 \mathrm{E}-06$

$28060.70 \mathrm{C} \quad 1.66608 \mathrm{E}-06$

$28061.70 \mathrm{C} \quad 7.24236 \mathrm{E}-08$

$28062.70 \mathrm{C} \quad 2.30918 \mathrm{E}-07$

$28064.70 \mathrm{C} \quad 5.88080 \mathrm{E}-08$

$24050.70 \mathrm{C} \quad 2.18120 \mathrm{E}-08$

$24052.70 \mathrm{C} \quad 4.20622 \mathrm{E}-07$

$24053.70 \mathrm{C} \quad 4.76952 \mathrm{E}-08$

$24054.70 \mathrm{C} \quad 1.18723 \mathrm{E}-08$

$29063.70 \mathrm{C} \quad 1.01472 \mathrm{E}-06$

$29065.70 \mathrm{C} \quad 4.52275 \mathrm{E}-07$

$5010.70 \mathrm{C} \quad 6.24384 \mathrm{E}-08$

$5011.70 \mathrm{C} \quad 2.51322 \mathrm{E}-07$

$6000.70 \mathrm{C} \quad 1.58152 \mathrm{E}-04$

$8016.70 \mathrm{C} \quad 1.40998 \mathrm{E}-05$

$8017.70 \mathrm{C} \quad 3.43460 \mathrm{E}-08$

$7014.70 \mathrm{C} \quad 2.41284 \mathrm{E}-05$

$7015.70 \mathrm{C} \quad 8.91203 \mathrm{E}-08$

C Diametral Pin, AVG Density

$92235.70 \mathrm{C} \quad 4.44855 \mathrm{E}-02$

$92236.70 \mathrm{C} \quad 2.14455 \mathrm{E}-04$

$92238.70 \mathrm{C} \quad 2.54500 \mathrm{E}-03$

$13027.70 \mathrm{C} \quad 2.08103 \mathrm{E}-06$

$14028.70 \mathrm{C} \quad 4.42531 \mathrm{E}-05$

$14029.70 \mathrm{C} \quad 2.24706 \mathrm{E}-06$

$14030.70 \mathrm{C} \quad 1.48128 \mathrm{E}-06$

$25055.70 \mathrm{C} \quad 3.77505 \mathrm{E}-06$

$28058.70 \mathrm{C} \quad 4.29579 \mathrm{E}-06$

$28060.70 \mathrm{C} \quad 1.65473 \mathrm{E}-06$

$28061.70 \mathrm{C} \quad 7.19300 \mathrm{E}-08$

$28062.70 \mathrm{C} \quad 2.29344 \mathrm{E}-07$

$28064.70 \mathrm{C} \quad 5.84073 \mathrm{E}-08$

$24050.70 \mathrm{C} \quad 2.16633 \mathrm{E}-08$

$24052.70 \mathrm{C} \quad 4.17756 \mathrm{E}-07$

$24053.70 \mathrm{C} \quad 4.73702 \mathrm{E}-08$

$24054.70 \mathrm{C} \quad 1.17914 \mathrm{E}-08$

$29063.70 \mathrm{C} \quad 1.00781 \mathrm{E}-06$

$29065.70 \mathrm{C} \quad 4.49193 \mathrm{E}-07$

$5010.70 \mathrm{c} \quad 6.20129 \mathrm{E}-08$

$5011.70 \mathrm{C} \quad 2.49610 \mathrm{E}-07$

$6000.70 \mathrm{C} \quad 1.57074 \mathrm{E}-04$

$8016.70 \mathrm{C} \quad 1.40037 \mathrm{E}-05$

$8017.70 \mathrm{C} \quad 3.41119 \mathrm{E}-08$

$7014.70 \mathrm{C} \quad 2.39639 \mathrm{E}-05$

$7015.70 \mathrm{C} \quad 8.85130 \mathrm{E}-08$

C SS304 at Typical Density

m20 26054.70c 3.49480E-03

$26056.70 \mathrm{C} \quad 5.48609 \mathrm{E}-02$

$26057.70 \mathrm{C} \quad 1.26698 \mathrm{E}-03$

Total 4.83091E-02

Revision: 1

Date: March 31, 2015 
NEA/NSC/DOC(2006)1

Fundamental-FUND

ORSPHERE-FUND-EXP-001

CRIT-REAC-COEF-KIN-RRATE

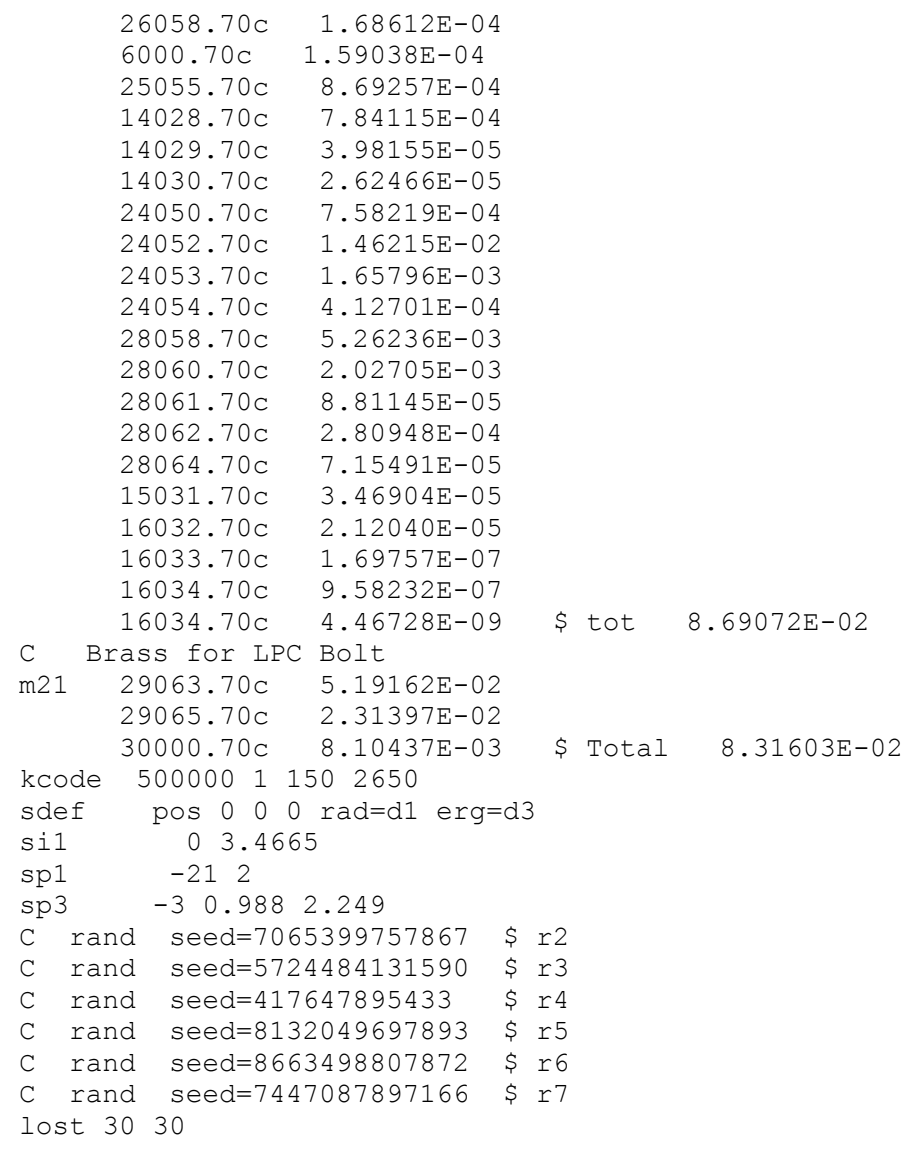

Benchmark Model for the Smaller Sphere

HEU-COMP-FAST-100-Case 2-Detailed Model/ ORSphere

$\mathrm{C}$

Cell Cards

Lower Polar Cap-LPC

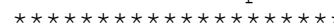

$100 \quad 10 \quad 4.82470 \mathrm{E}-02 \quad-101 \quad 102 \quad-104 \quad 150 \quad 151 \quad 152 \quad 153 \quad 154 \quad 155 \quad 156 \quad 157$

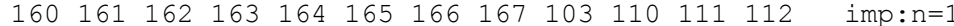

C Support Rod Hole

$101218.31603 \mathrm{E}-02$-105 imp:n=1 \$Brass Bolt

$102 \quad 0 \quad-103105$ imp:n=1 \$ Support Hole

$1030-101-102103$ imp:n=1 \$ Spot Face

C Pins

$104 \quad 12 \quad 4.82415 \mathrm{E}-02-110-104 \quad 166$ imp:n=1

$105 \quad 12 \quad 4.82415 \mathrm{E}-02-111-104$ imp: $\mathrm{n}=1$

$107 \quad 12 \quad 4.82415 \mathrm{E}-02-112-104$ imp: $\mathrm{n}=1$

C Mass Adjustment Button Holes

$110 \quad 0-150 \quad 160-101 \quad$ imp: $\mathrm{n}=1$

$111 \quad 0 \quad-151 \quad 161-101$ imp: $n=1$

$11200-152 \quad 162-101$ imp: $n=1$

imp $: n=1$

$11400-154 \quad 164-101 \quad$ imp: $n=1$

$1150 \begin{array}{lllll}155 & 165 & -101 & \text { imp: } \mathrm{n}=1\end{array}$

$116 \quad 0 \quad-156 \quad 166-101$ imp: $n=1$

$1170-157 \quad 167-101 \quad$ imp: $n=1$

$120 \quad 0-160-101$ imp: $n=1$

$121 \quad 0 \quad-161-101$ imp: $n=1$

$12200-162-101$ imp: $n=1$

$123-0-163-101$ imp: $n=1$

$124 \quad 0-164-101$ imp: $n=1$

$12500-165-101$ imp: $n=1$

imp: $n=1$

$1270-167-101$ imp: $n=1$

C

$1300101-104-900103$ imp:n=1

Revision: 1 
NEA/NSC/DOC(2006)1

Fundamental-FUND

ORSPHERE-FUND-EXP-001

CRIT-REAC-COEF-KIN-RRATE

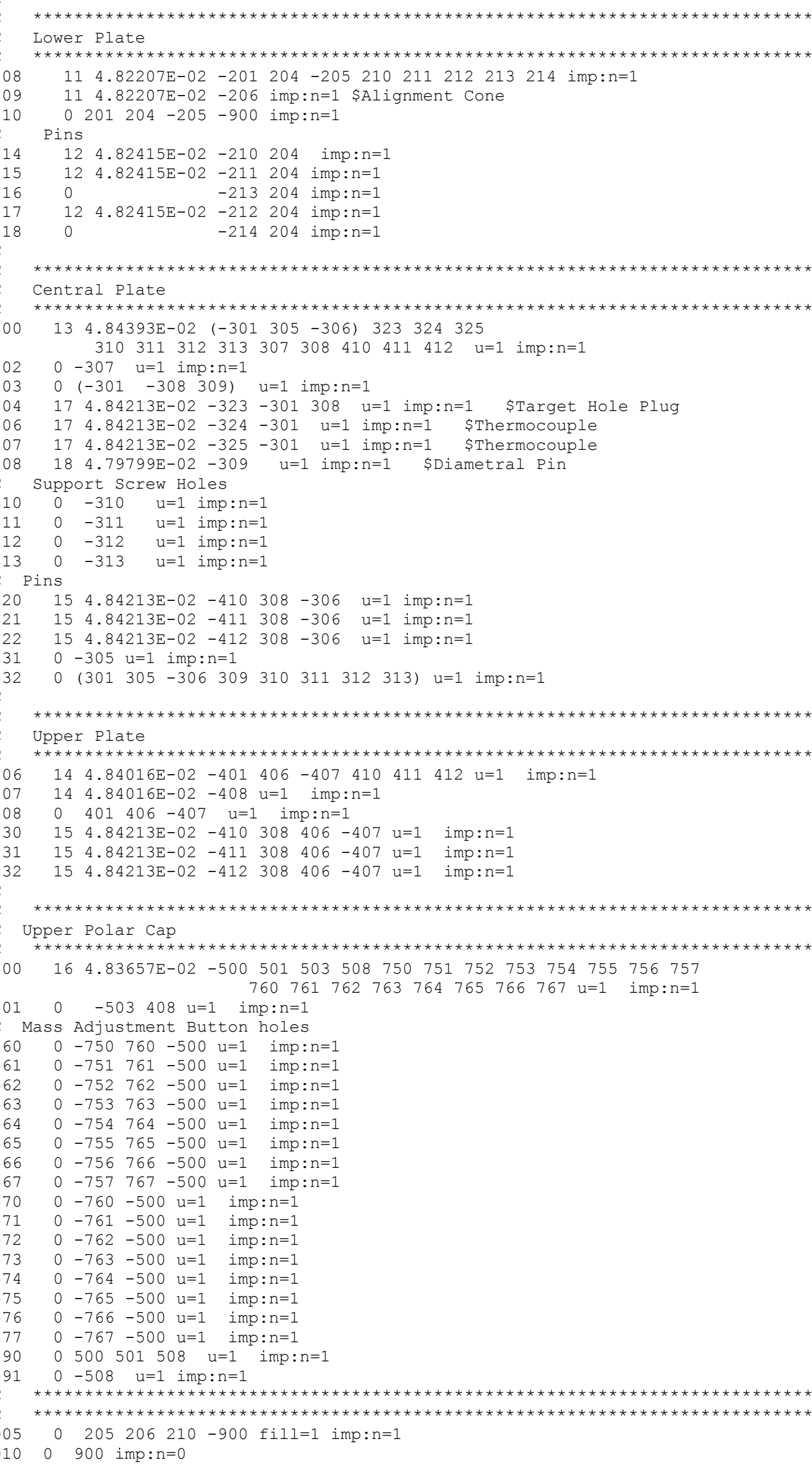


NEA/NSC/DOC(2006)1

Fundamental-FUND

ORSPHERE-FUND-EXP-001

CRIT-REAC-COEF-KIN-RRATE

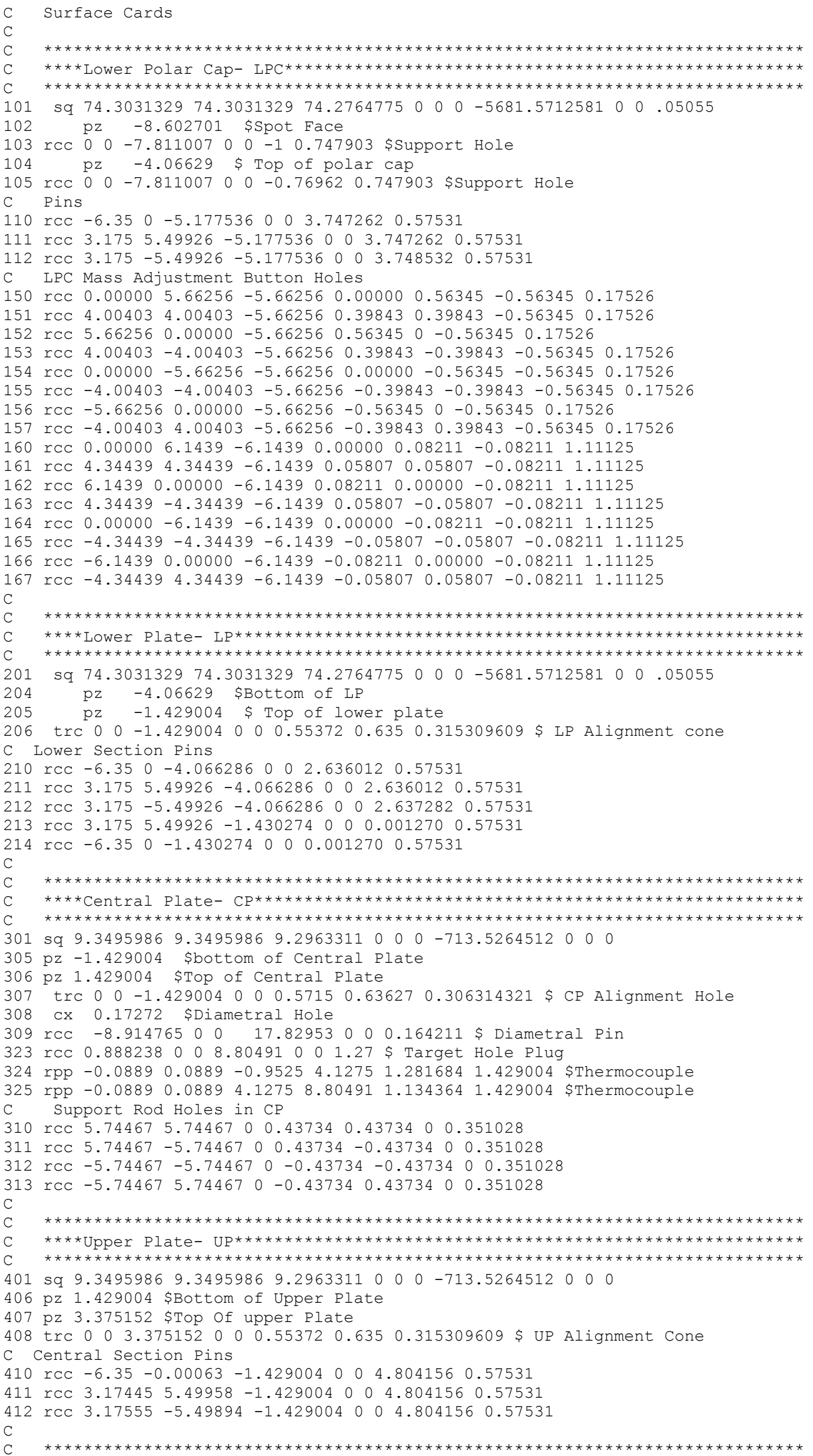


NEA/NSC/DOC(2006)1

Fundamental-FUND

ORSPHERE-FUND-EXP-001

CRIT-REAC-COEF-KIN-RRATE

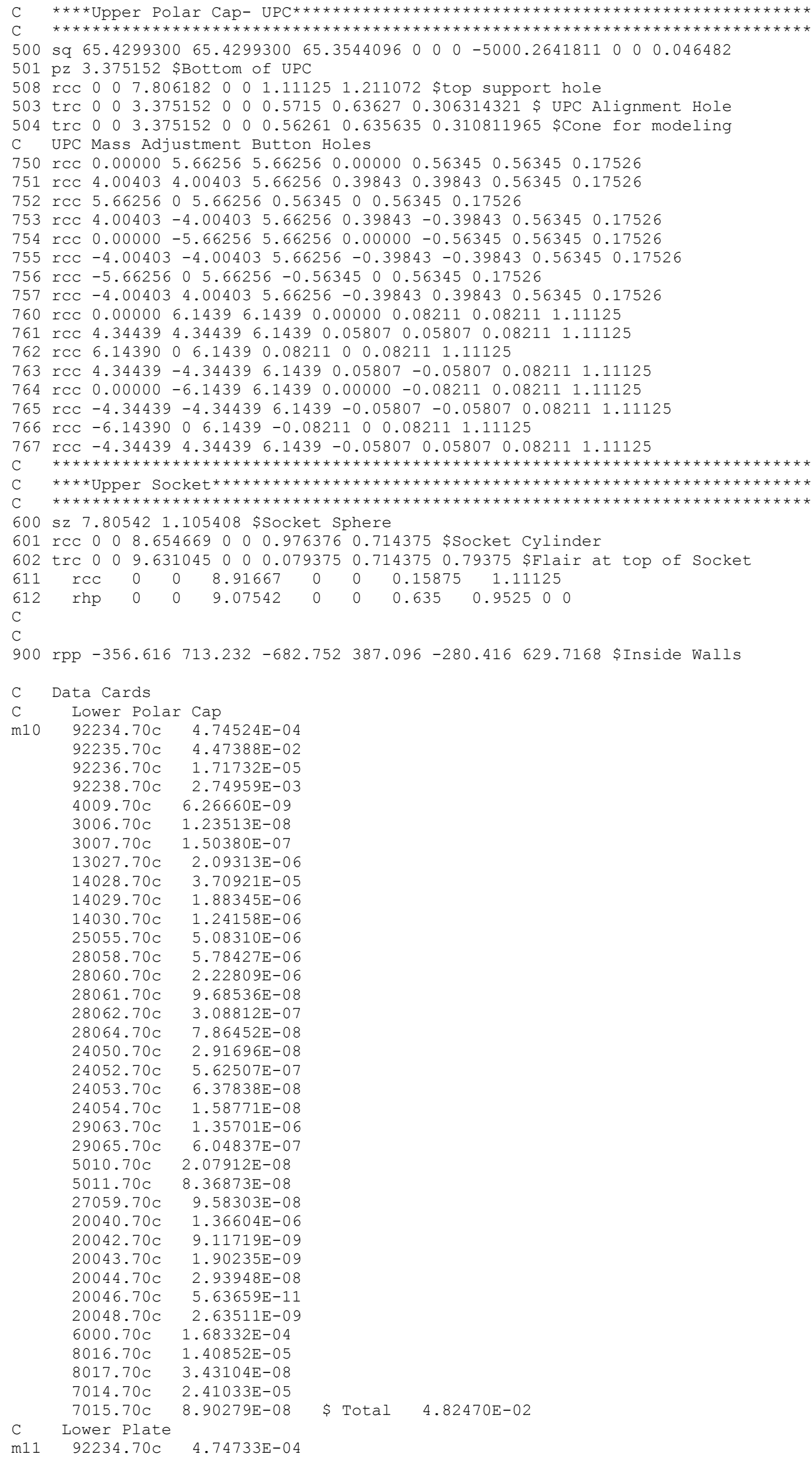

$4.74733 \mathrm{E}-04$

Revision: 1 
NEA/NSC/DOC(2006)1

Fundamental-FUND

ORSPHERE-FUND-EXP-001

CRIT-REAC-COEF-KIN-RRATE

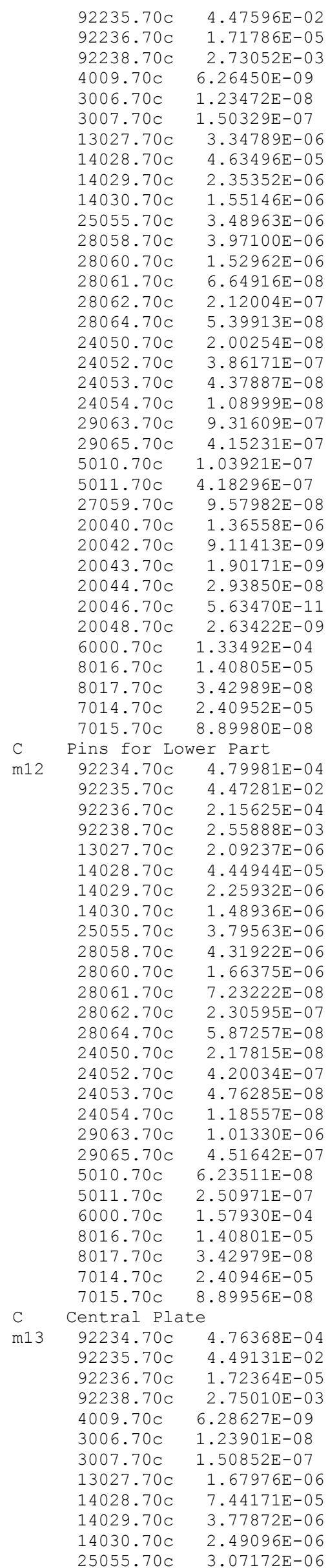

Revision: 1 
NEA/NSC/DOC(2006)1

Fundamental-FUND

ORSPHERE-FUND-EXP-001

CRIT-REAC-COEF-KIN-RRATE

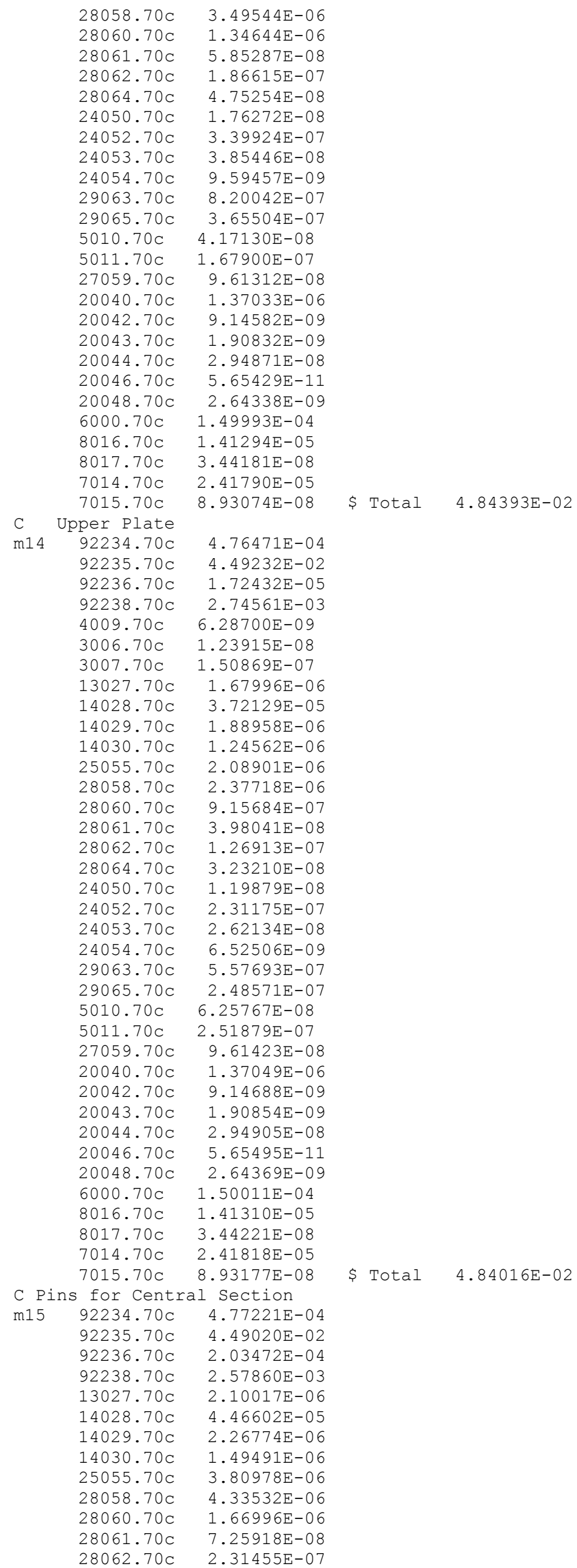

Revision: 1 
NEA/NSC/DOC(2006)1

Fundamental-FUND

ORSPHERE-FUND-EXP-001

CRIT-REAC-COEF-KIN-RRATE

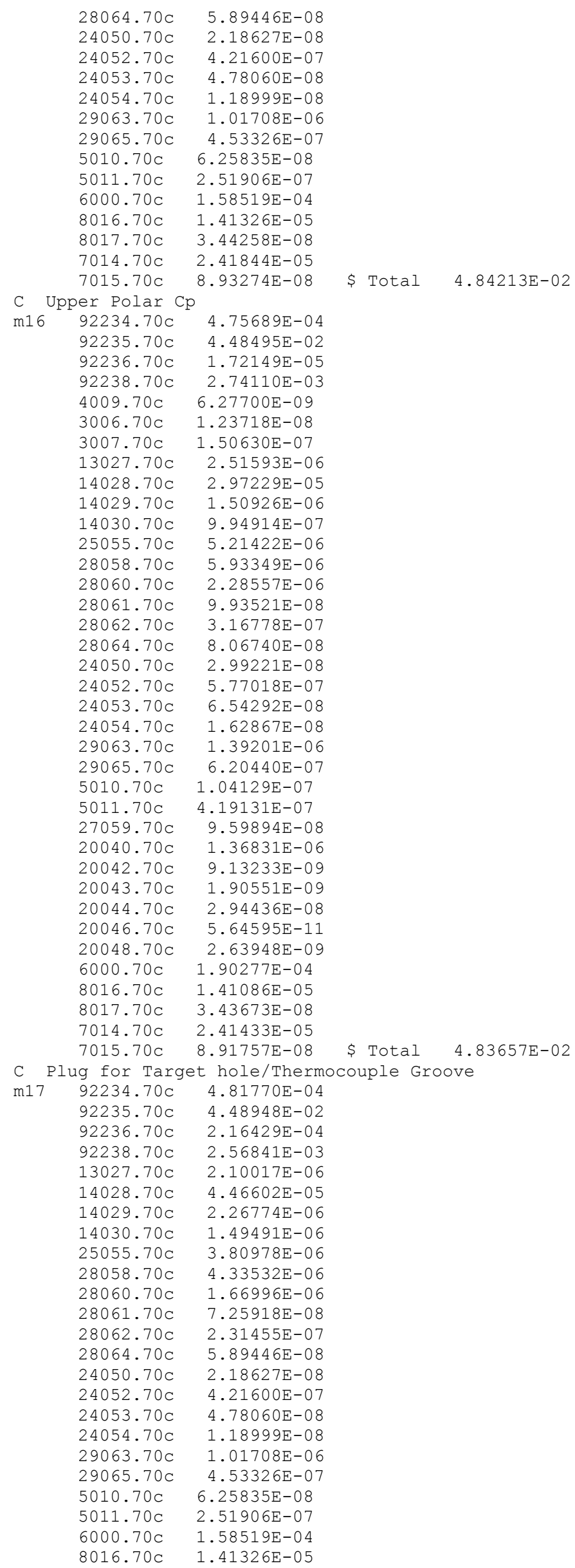

Revision: 1 
NEA/NSC/DOC(2006)1

Fundamental-FUND

ORSPHERE-FUND-EXP-001

CRIT-REAC-COEF-KIN-RRATE

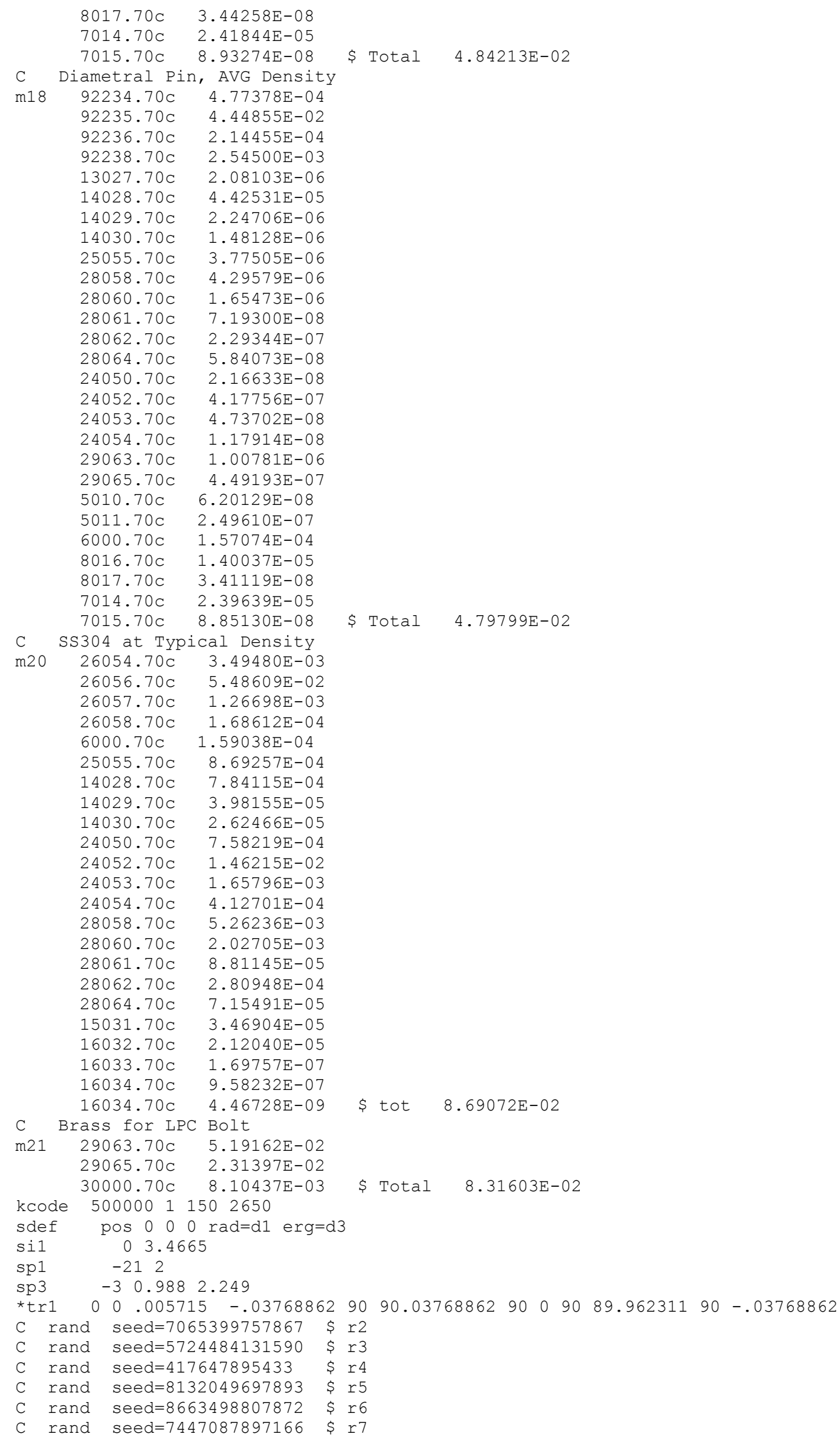

Revision: 1 
NEA/NSC/DOC(2006)1

Fundamental-FUND

ORSPHERE-FUND-EXP-001

CRIT-REAC-COEF-KIN-RRATE

\section{A.6 Kinetics Parameter Configurations}

\section{A.6.1 Name(s) of Code System(s) Used}

1. Monte Carlo n-Particle, Version 5.1.60 (MCNP5).

\section{A.6.2 Bibliographic References for the Codes Used}

1. F. B. Brown, R. F. Barrett, T. E. Booth, J. S. Bull, L. J. Cox, R. A. Forster, T. J. Goorley, R. D. Mosteller, S. E. Post, R. E. Prael, E. C. Selcow, A. Sood, and J. Sweezy, "MCNP Version 5," LA-UR-02-3935, Los Alamos National Laboratory (2002).

\section{A.6.3 Origin of Cross-section Data}

The evaluated neutron data file library ENDF/B-VII.0 $0^{\text {a }}$ was utilized in the benchmark-model analysis.

\section{A.6.4 Spectral Calculations and Data Reduction Methods Used}

Not applicable.

\section{A.6.5 Number of Energy Groups or If Continuous-energy Cross Sections are Used in the Different Phases of Calculation}

1. Continuous-energy cross sections.

\section{A.6.6 Component Calculations}

Not applicable

\section{A.6.7 Other Assumptions and Characteristics}

Not applicable.

\section{A.6.8 Typical Input Listings for Each Code System Type}

The benchmark model for the effective delayed neutron fraction, $\beta_{\text {eff }}$, was identical to the detailed Case 1 and Case 2 benchmark model in HEU-MET-FAST-100. To calculate the $\beta_{\text {eff }}$ the following data cards were added to the input decks given in HEU-MET-FAST-100.

$\frac{\text { Calculation using } k_{\text {prompt }}}{\text { totnu no }}$

Calculation using adjoint-weighted method

kopts blocksize=10 kinetics=yes precursor=yes

A sample input deck for the benchmark model for the prompt neutron decay constant and the mean neutron generation time is provided.

MCNP5 Input Deck for Prompt Neutron Decay Constant and Mean Neutron Generation Time Benchmark Models: HEU-COMP-FAST-100

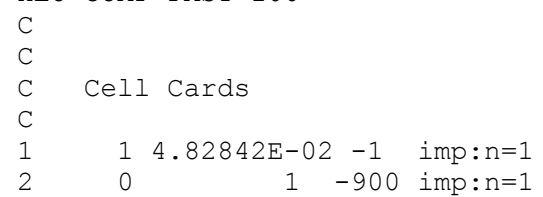

a M. B. Chadwick, et al., "ENDF/B-VII.0: Next Generation Evaluated Nuclear Data Library for Nuclear Science and Technology," Nucl. Data Sheets, 107: 2931-3060 (2006). 
NEA/NSC/DOC(2006)1

Fundamental-FUND

ORSPHERE-FUND-EXP-001

CRIT-REAC-COEF-KIN-RRATE

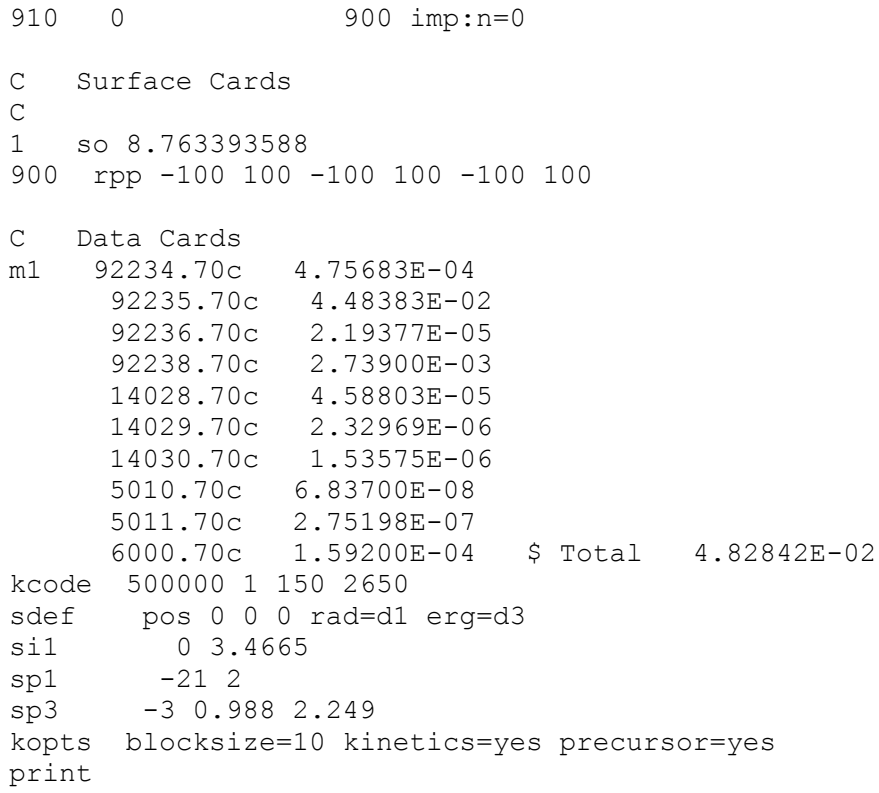

\section{A.7 Reaction-Rate Configurations}

\section{A.7.1 Name(s) of Code System(s) Used}

1. Monte Carlo n-Particle, Version 5.1.60 (MCNP5).

\section{A.7.2 Bibliographic References for the Codes Used}

1. F. B. Brown, R. F. Barrett, T. E. Booth, J. S. Bull, L. J. Cox, R. A. Forster, T. J. Goorley, R. D. Mosteller, S. E. Post, R. E. Prael, E. C. Selcow, A. Sood, and J. Sweezy, "MCNP Version 5," LA-UR-02-3935, Los Alamos National Laboratory (2002).

\section{A.7.3 Origin of Cross-section Data}

The evaluated neutron data file library ENDF/B-VII.0 $0^{\text {a }}$ was utilized in the benchmark-model analysis.

\section{A.7.4 Spectral Calculations and Data Reduction Methods Used}

Not applicable.

\section{A.7.5 Number of Energy Groups or If Continuous-energy Cross Sections are Used in the Different Phases of Calculation}

1. Continuous-energy cross sections.

\section{A.7.6 Component Calculations}

Not applicable

\section{A.7.7 Other Assumptions and Characteristics}

Not applicable.

\footnotetext{
${ }^{a}$ M. B. Chadwick, et al., "ENDF/B-VII.0: Next Generation Evaluated Nuclear Data Library for Nuclear Science and Technology," Nucl. Data Sheets, 107: 2931-3060 (2006). 
NEA/NSC/DOC(2006)1

Fundamental-FUND

ORSPHERE-FUND-EXP-001

CRIT-REAC-COEF-KIN-RRATE

\section{A.7.8 Typical Input Listings for Each Code System Type}

The simple benchmark models for the relative neutron importance for $\mathrm{BF}_{3}$ detector response and a $\mathrm{Cf}$ source sample calculation is given:

MCNP5 Input Deck for Relative Neutron Importance for BF3 Detector Response and a Cf Source Models: HEU-COMP-FAST-100-Case 2-Simple Model/ ORSphere

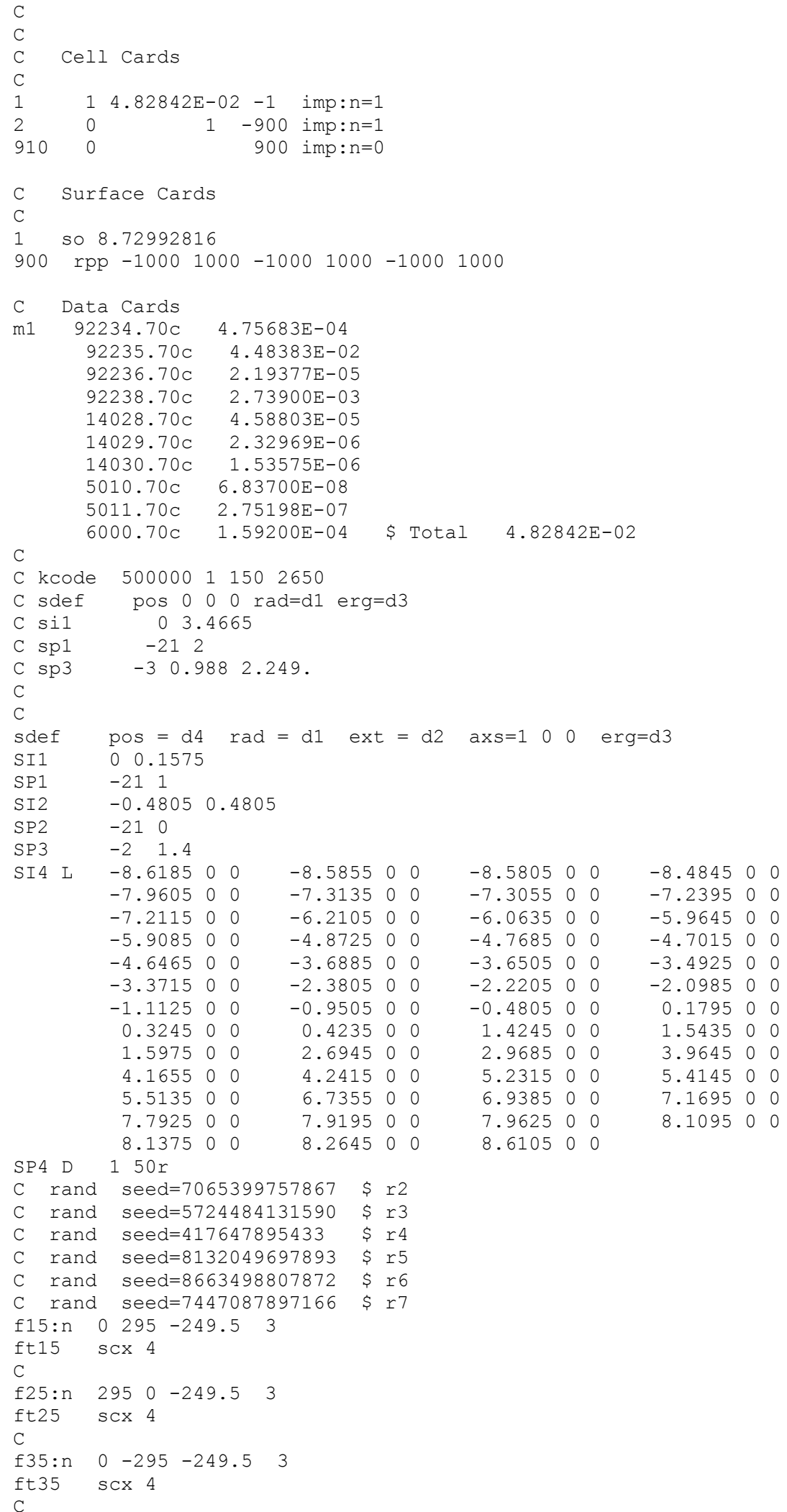

Revision: 1 


\section{NEA/NSC/DOC(2006)1 \\ Fundamental-FUND \\ ORSPHERE-FUND-EXP-001 \\ CRIT-REAC-COEF-KIN-RRATE}

A sample input deck for the relative fission density is provided.

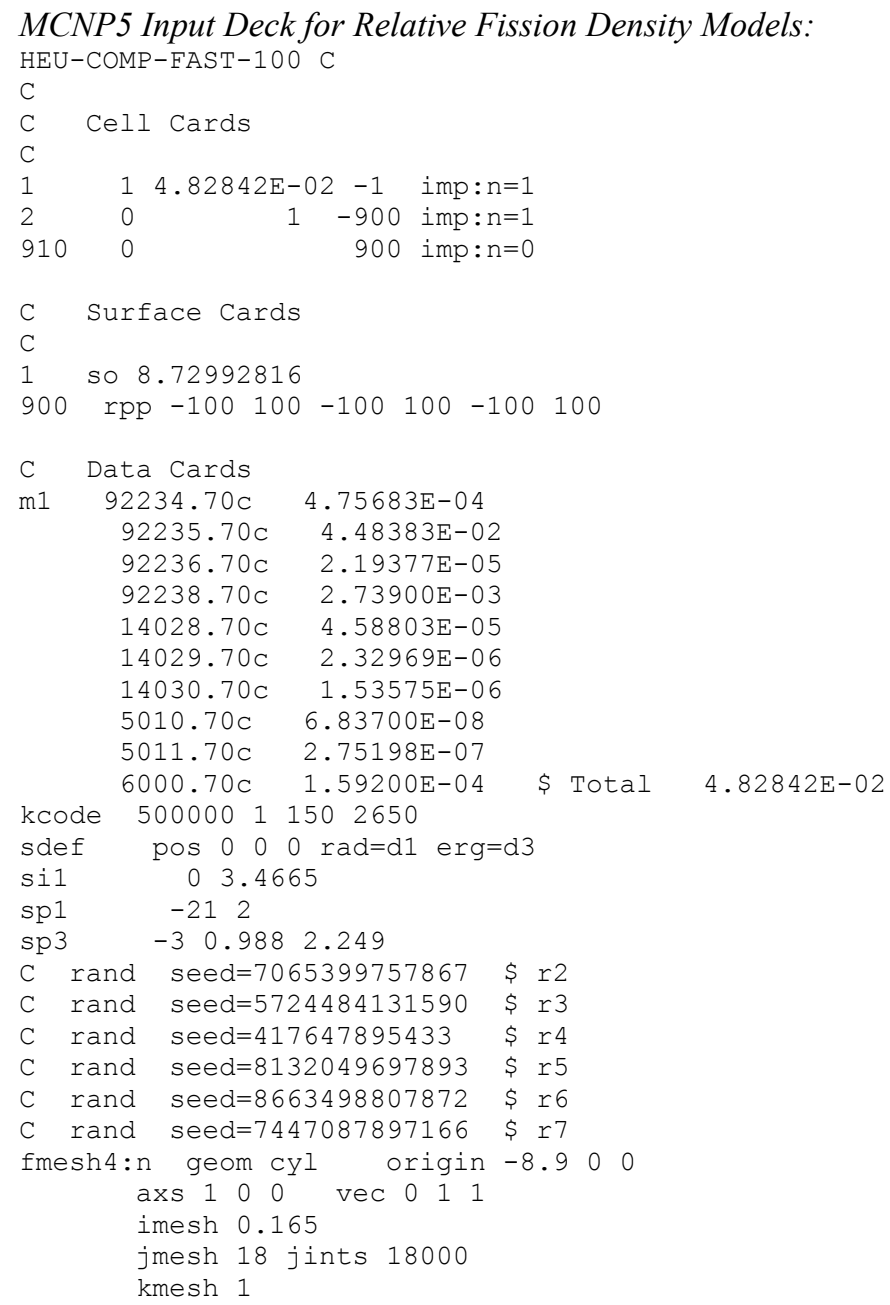

\section{A.8 Power Distribution Configurations}

Power distribution measurements were not performed.

\section{A.9 Isotopic Configurations}

Isotopic measurements were not performed.

\section{A.10 Configurations of Other Miscellaneous Types of Measurements}

Other miscellaneous types of measurements were not performed. 


\section{APPENDIX B: SAMPLE CALCULATION USING INHOUR EQUATION TO CONVERT STABLE REACTOR PERIOD TO REACTIVITY IN CENTS}

The stable reactor period was measured to determine system reactivity. The change in system reactivity corresponding to changes in the system yields the worth of those changes. To convert the stable reactor period to reactivity in dollars or cents the Inhour Equation is used, Equation B.1. It should be noted that this is the equation the experimenter refers to as "the Inhour Equation" and will be referred to as such in this evaluation. In "Nuclear Reactor Engineering" by Glasstone and Sesonske this equation is simply referred to as the relationship between stable reactor period and reactivity. The actual Inhour equation yields reactivity in units of Inhours but is not used in this evaluation because the desired reactivity is in units of dollars. ${ }^{\text {a }}$

Equation

B.1

Equation

B.2

$$
\begin{array}{r}
\rho^{k}=\frac{l}{T_{p}}+\sum_{i=1}^{6} \frac{\beta_{i}}{1+\lambda_{i} T_{p}} \\
I h=\frac{\frac{l}{T_{p}}+\sum_{i=1}^{6} \frac{\beta_{i}}{1+\lambda_{i} T_{p}}}{\frac{l}{3600}+\sum_{i=1}^{6} \frac{\beta_{i}}{1+3600 \lambda_{i}}}
\end{array}
$$

$\begin{array}{ll}\text { where: } & \rho^{k} \\ & I h \\ & T_{p} \\ & l \\ & \beta_{i} \\ & \lambda_{i}\end{array}$

System Reactivity, $\Delta \mathrm{k}_{\text {eff }}$

System Reactivity, Inhours

Stable Reactor Period, s

Prompt neutron lifetime, $\mathrm{s}$

Delayed neutron fraction of $i^{\text {th }}$ group

Decay constant for $i^{\text {th }}$ group

The first simplification to Equation B.1 employs the very small prompt neutron lifetime, $l \cong 6 \times 10^{-9} \mathrm{~s}$, for HEU systems, as measured with GODIVA. ${ }^{\mathrm{b}}$ When divided by the stable reactor period, which for the ORSphere measurements were typically on the order of 100-200 s, the first term in Equation B.1 become negligible. Next, the remaining two terms are divided by the delayed neutron fraction, $\beta$. For these calculations "it was assumed that the effectiveness of the delayed neutrons relative to prompt neutrons was the same for all six delayed neutron groups" (Reference 3 ). By this assumption $\beta_{\text {eff }}^{i} / \beta_{\text {eff }}$ equals $\beta^{i} / \beta$. With these two simplifications and (1) the fact that $\beta^{i} / \beta$ equals the relative yield, $\alpha_{i}$, and (2) the fact that the system reactivity in units of $\Delta \mathrm{k}_{\mathrm{eff}}$ over the effective delayed neutron fraction equals the system reactivity in units of dollars, $\rho^{\$}$, Equation B.1 becomes Equation B.3

Equation

B.3

$$
\rho^{\$}=\sum_{i=1}^{6} \frac{\alpha_{i}}{1+\lambda_{i} T_{p}}
$$

The six-group delayed neutron parameters and the measured stable reactor period are used in this equation. In order to combine the ${ }^{235} \mathrm{U}$ and ${ }^{238} \mathrm{U}$ groups the fission fractions are used. Since Keepin data for the delayed neutron parameters is only given for ${ }^{235} \mathrm{U}$ and ${ }^{238} \mathrm{U}, 50 \%$ of the ${ }^{234} \mathrm{U}$ fission fraction and $50 \%$ of the ${ }^{236} \mathrm{U}$ fission fraction were added to the ${ }^{235} \mathrm{U}$ and the other half to ${ }^{238} \mathrm{U}$ for the Inhour calculations. Equation B.4 shows the reactivity calculation using the fission fractions, $\mathrm{ff}^{k}$.

\footnotetext{
a S. Glassstone and A. Sesonske, "Nuclear Reactor Engineering," Van Nostrand Reinhold Company, New York, 1967. Equations 5.37 and 5.39.

${ }^{\mathrm{b}}$ Personal email communication with J.T. Mihalczo, July 17. 2013. 
Equation

B.4

$$
\rho^{\$}=f f^{235} \sum_{i=1}^{6} \frac{\alpha_{i}^{235}}{1+\lambda_{i}^{235} T_{p}}+f f^{238} \sum_{i=1}^{6} \frac{\alpha_{i}^{238}}{1+\lambda_{i}^{238} T_{p}}
$$

The delayed neutron parameters for uranium isotopes 235 and 238 and the fission fractions are given in Table 1.4-1. When the fission fractions from ${ }^{234} U$ and ${ }^{236} U$ are split $50 / 50$ between ${ }^{235} U$ and ${ }^{238} U$ the resulting fission fractions are $98.6104 \%$ and $1.3896 \%$ for ${ }^{235} \mathrm{U}$ and ${ }^{238} \mathrm{U}$, respectively. The following is a sample calculation for the stable reactor period $94.9 \mathrm{~s}$, measured for the central void reactivity (run 528A Ion Chamber A).

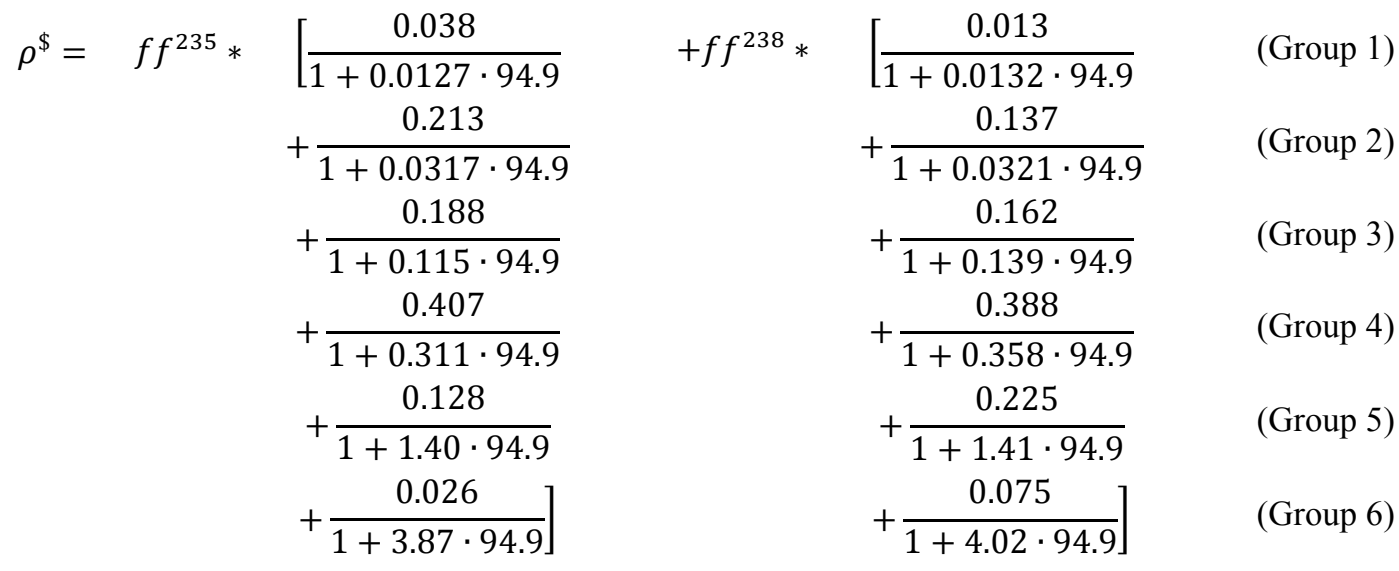

$$
\begin{aligned}
& \begin{aligned}
\rho^{\$}=\quad \begin{array}{r}
98.6104 \%[1.7232+5.3139+1.578+1.3338+.09562+.007060] \times 10^{-2} \\
+1.3896 \%[0.5771+3.3858+1.1416+1.1094+0.1669+0.0196079] \times 10^{-2}
\end{array}
\end{aligned}
\end{aligned}
$$

This calculation yields a system reactivity of $0.1000091 \$$ or $10.00091 \not$. This calculation can be repeated for stable reactor period for run 528B from the same ion chamber, $1750 \mathrm{~s}$.

$$
\begin{aligned}
& \rho^{\$}=f f^{235} *\left[\frac{0.038}{1+0.0127 \cdot 1750} \quad+f f^{238} *\left[\frac{0.013}{1+0.0132 \cdot 1750} \quad\right. \text { (Group 1) }\right. \\
& +\frac{0.213}{1+0.0317 \cdot 1750} \quad+\frac{0.137}{1+0.0321 \cdot 1750} \quad \text { (Group 2) } \\
& +\frac{0.188}{1+0.115 \cdot 1750} \quad+\frac{0.162}{1+0.139 \cdot 1750} \quad \text { (Group 3) } \\
& +\frac{0.407}{1+0.311 \cdot 1750} \quad+\frac{0.388}{1+0.358 \cdot 1750} \quad \text { (Group 4) } \\
& +\frac{0.128}{1+1.40 \cdot 1750} \quad+\frac{0.225}{1+1.41 \cdot 1750} \quad \text { (Group 5) } \\
& \left.\left.+\frac{0.026}{1+3.87 \cdot 1750}\right] \quad+\frac{0.075}{1+4.02 \cdot 1750}\right] \quad \text { (Group 6) } \\
& \begin{aligned}
\rho^{\$}=\quad \begin{array}{r}
98.6104 \%[0.1636+0.3772+0.093+0.0746+0.00522+0.0003838] \times 10^{-2} \\
+1.3896 \%[0.0539+0.2396+0.0663+0.0618+0.0091148+0.00106] \times 10^{-2}
\end{array}
\end{aligned}
\end{aligned}
$$

This calculation yields a system reactivity of $0.0071006 \$$ or $0.71006 \not$. 


\section{NEA/NSC/DOC(2006)1 \\ Fundamental-FUND \\ ORSPHERE-FUND-EXP-001 \\ CRIT-REAC-COEF-KIN-RRATE}

The resulting worth for the central void for run 528, measured with ion chamber A, is $9.29 \varnothing$

$(10.00091 \not-0.71006 \not)$. This agrees well with the worth given by the experimenter in Table 1.4-3

$(9.28 \not)$.

If the delayed neutron parameters are given with a consistent set of half-lives, rather than a half life for each group, this calculation must be modified slightly. To do this a yield for all isotopes for each group is found. This is done by multiplying the yield for each isotope by its respective fission fraction and then summing the four results together. This value is then used in Equation B.3. Since the values in Table 2.4-2 have eight groups rather than six, Equation B.5 is updated accordingly.

Equation

B.5

$$
\rho^{\$}=\sum_{i=1}^{8} \frac{\sum_{k=1}^{4} f f^{k} \cdot \alpha^{k}}{1+\lambda_{i} T_{p}}
$$

